\title{
Loss of muscle mass in hip fracture patients
}

Citation for published version (APA):

Kramer, I. F. (2019). Loss of muscle mass in hip fracture patients. [Doctoral Thesis, Maastricht University]. Gildeprint Drukkerijen. https://doi.org/10.26481/dis.20190509ik

Document status and date:

Published: 01/01/2019

DOI:

10.26481/dis.20190509ik

Document Version:

Publisher's PDF, also known as Version of record

\section{Please check the document version of this publication:}

- A submitted manuscript is the version of the article upon submission and before peer-review. There can be important differences between the submitted version and the official published version of record.

People interested in the research are advised to contact the author for the final version of the publication, or visit the DOI to the publisher's website.

- The final author version and the galley proof are versions of the publication after peer review.

- The final published version features the final layout of the paper including the volume, issue and page numbers.

Link to publication

\footnotetext{
General rights rights.

- You may freely distribute the URL identifying the publication in the public portal. please follow below link for the End User Agreement:

www.umlib.nl/taverne-license

Take down policy

If you believe that this document breaches copyright please contact us at:

repository@maastrichtuniversity.nl

providing details and we will investigate your claim.
}

Copyright and moral rights for the publications made accessible in the public portal are retained by the authors and/or other copyright owners and it is a condition of accessing publications that users recognise and abide by the legal requirements associated with these

- Users may download and print one copy of any publication from the public portal for the purpose of private study or research.

- You may not further distribute the material or use it for any profit-making activity or commercial gain

If the publication is distributed under the terms of Article $25 \mathrm{fa}$ of the Dutch Copyright Act, indicated by the "Taverne" license above, 


\section{LOSS OF MUSCLE MASS IN HIP FRACTURE PATIENTS}




\section{Ponsone RESEARCH

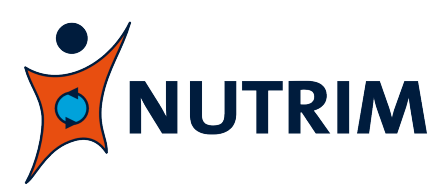

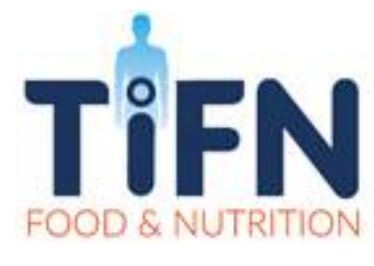

\section{saluda \\ medische keuringen}

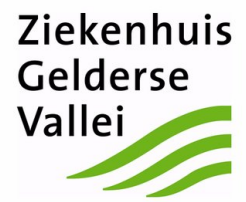

The work presented in this dissertation was performed within NUTRIM School of Nutrition and Translational Research in Metabolism, and within the framework of TI Food and Nutrition.

Printing of this dissertation was financially supported by Maastricht University, vakgroep chirurgie Ziekenhuis Gelderse Vallei, Saluda Medische Keuringen, Stichting Wetenschappelijk Onderzoek Assistenten Heelkundige Specialismen, and Danone Nutricia Research.

Cover design: Gildeprint

Printed by: Gildeprint

ISBN 978-94-6323-608-9

Copyright (C) 2019 Irene Fleur Kramer

All rights reserved. No part of this dissertation may be reproduced, distributed, or transmitted in any form or by any means, including photocopying, recording, or other electronic or mechanical methods, without the prior written permission of the author or publisher, except in the case of brief quotations embodied in critical reviews and certain other noncommercial uses permitted by copyright law. 


\title{
Loss of muscle mass in hip fracture patients
}

\author{
ACADEMISCH PROEFSCHRIFT
}

Ter verkrijging van de graad van doctor aan de Universiteit Maastricht, op gezag van de Rector Magnificus, Prof. dr. Rianne M. Letschert volgens het besluit van het College van Decanen, in het openbaar te verdedigen

op donderdag 9 mei 2019 om 16.00 uur

door

Irene Fleur Kramer 
Promotores

Prof. dr. L.J.C. van Loon

Prof. dr. M. Poeze

\section{Copromotor}

Dr. L.B. Verdijk

\section{Beoordelingscommissie}

Prof. dr. C.H.C. Dejong (voorzitter)

Prof. dr. M.J.R. Edwards (Radboud Universiteit)

Prof. dr. ir. C.P.G.M. de Groot (Wageningen University\&Research)

Prof. dr. S.W.M. Olde Damink

Prof. dr. J.M.G.A. Schols 
Begrijpen maakt de geest lui Mr Brundish, The Bookshop, Penelope Fitzgerald 



\section{Table of contents}

$\begin{array}{lll}\text { CHAPTER } 1 \quad \text { General introduction } & 9\end{array}$

CHAPTER 2 Outcomes in urgent and emergency surgery in orthopaedic patients: prospective observational data from the European Surgical Outcomes Study

CHAPTER 3 Extensive type II muscle fibre atrophy in elderly female hip fracture patients

CHAPTER 4 Skeletal muscle loss in elderly hip fracture patients during hospital admission

CHAPTER 5 Perioperative nutritional supplementation and skeletal muscle mass in elderly hip fracture patients

CHAPTER 6 Impact of the macronutrient composition of a nutritional supplement on muscle protein synthesis rates in elderly men: a randomised, double blind, controlled trial

CHAPTER 7 Both basal and post-prandial muscle protein synthesis rates, following the ingestion of a leucine-enriched whey protein supplement, are not impaired in sarcopenic elderly males

CHAPTER 8 General discussion

ADDENDUM Summary

Samenvatting

Dankwoord 



\section{CHAPTER 1}

General introduction 



\section{General introduction}

Muscle can be viewed as the engine of the human body. It is the dominant tissue in the heart that is of vital importance by propelling oxygen and nutrients to our cells, and it is found in the walls of our hollow organs, generating the driving force for propulsion of food and for the regulation of blood pressure. The mobility of the body as a whole reflects the activity of skeletal muscles. Because contracting muscles look like mice scurrying beneath the skin, they were dubbed muscles from the Latin word mus meaning 'mouse'. The four most important functions of skeletal muscle for the body are the production of movement, maintenance of posture, stabilisation of joints, and the production of heat. Skeletal muscle makes up nearly half of the body's mass in healthy adult humans.

The muscle is a highly adaptive tissue that responds rapidly to changing conditions. When the demand placed upon skeletal muscle is decreased, degeneration and loss of muscle mass ensues, with conditions of immobilisation or bed rest causing rapid muscle loss. With normal aging though, skeletal muscle mass also declines progressively, which may lead to frailty and an increased risk of morbidity and mortality. In situations such as injury or sickness, the loss of muscle function and mass may be exacerbated. In elderly, the condition of skeletal muscle mass is of vital importance for their daily functional performance and health. Understanding and combatting the deterioration of skeletal muscle mass and function in both healthy elderly and elderly patients is therefore necessary. In this thesis, different aspects of skeletal muscle are studied in hip fracture patients, and the effects of different nutritional intervention strategies are studied in healthy elderly and in elderly whom have already suffered from muscle loss or injury.

\section{Sarcopenia}

The ageing of the worldwide population is rapidly accelerating. In high-income countries such as the Netherlands, the continuing increase in life expectancy is mainly the result of a declining mortality among the oldest old ${ }^{1}$. If the lengthening of the life expectancy continues throughout the $21^{\text {st }}$ century, most babies born since 2000 in Western Europe will be able to celebrate their 100th birthdays. These demographic shifts have profound implications for healthcare systems and socialeconomic developments. One of the major challenges results from deteriorating health and functional performance of older people. At a biological level, molecular and cellular damage that accumulates over time leads to a general age-related decline of the individual health. However, the physiological changes that occur over 
time are only loosely associated with chronological age, and many other factors determine an individual's status at each phase throughout the lifespan.

One of the age-related changes that strongly impacts on health and function is a gradual, progressive loss of skeletal muscle mass. Adults lose an average of $25 \%$ of their muscle mass between the age of 40 and 70 years, with muscle loss accelerating after the age of 70 years ${ }^{2}$, although with individual variation. The co-occurrence of low muscle mass and decline in muscle function or strength has been termed sarcopenia, which is derived from the Greek words sarx and penia, meaning 'flesh' and 'poverty' or 'lack'. Although the term sarcopenia was firstly coined by Irwin Rosenberg in $1989^{3}$, it has been of some duration until an official (practical and clinical) definition was developed by the European Working Group on Sarcopenia in Older People (EWGSOP) ${ }^{4}$. In 2010, they described sarcopenia as "a syndrome characterised by progressive and generalised loss of skeletal muscle mass and strength increasing the risk of frailty and predicting physical disability, loss of independence, poor quality of life and death". Sarcopenia is, therefore, considered an undesirable consequence of ageing with both personal and societal impact, and the rapidly expanding aging population will only exacerbate its associated health problems. For these reasons it is of importance to understand the various factors underlying sarcopenia and develop interventional strategies to combat the loss of skeletal muscle mass in older individuals.

\section{Muscle mass maintenance}

Skeletal muscle mass is regulated by a constant state of muscle protein turnover, which refers to the continuous processes of muscle protein synthesis and muscle protein breakdown, and normally occurs at a rate of $1-2 \%$ per day ${ }^{5,6}$. Muscle protein turnover is essential for the maintenance of muscle protein quality and quantity ${ }^{7}$. The quantity of muscle mass remains constant when muscle protein synthesis and muscle protein breakdown are in balance. Loss of skeletal muscle mass is the result of a negative net muscle protein balance, due to a modulation of muscle protein synthesis, muscle protein breakdown, or a combination of both. A negative net muscle protein balance is the common ground for muscle loss whether it is due to ageing, disuse, hospitalisation, or morbidities.

\section{Muscle protein synthesis}

The net loss of muscle mass with ageing can be attributed to a structural imbalance between muscle protein synthesis and muscle protein breakdown rates. Muscle mass maintenance is influenced by basal muscle protein synthesis rate as well as by the 
muscle protein synthetic response to various stimuli, such as feeding. In an attempt to unravel the mechanisms leading to a change in muscle metabolism with aging, many research groups started by comparing basal muscle protein synthesis and breakdown rates in young and elderly subjects. From that work however, basal, i.e. fasted or post-absorptive, muscle protein synthesis rates did not seem to differ between young and older individuals ${ }^{8-10}$. Although even minor differences in basal muscle protein synthesis rates might be clinically relevant when their impact is calculated over multiple years, the most recent studies do not provide any indication of a relevant difference in these fasted muscle protein synthesis rates ${ }^{11}$. Therefore, many research groups have shifted their focus to the muscle protein synthetic response to anabolic stimuli as an important component in the regulation of muscle mass maintenance. The main anabolic stimuli for muscle protein synthesis are food intake and physical activity. Particularly the ingestion of protein is known to acutely stimulate muscle protein synthesis rates. Upon ingestion, dietary protein and amino acids are digested in the gut followed by absorption and appearance of amino acids in the blood stream ${ }^{12,13}$, although a portion of the amino acids is retained in the splanchnic area ${ }^{14}$. The perfusion of muscle tissue increases by the release of insulin as a response to food intake ${ }^{15}$, followed by uptake of the available amino acids into skeletal muscle tissue ${ }^{16}$. Both insulin and the appearance of (specific) amino acids in muscle tissue stimulate intramuscular anabolic signalling ${ }^{17}$, and finally induce an increase in muscle protein synthesis and an inhibition of muscle protein breakdown. Thus, one of the primary anabolic stimuli for muscle protein synthesis is a systemic hyperaminoacidemia, resulting from the ingestion of dietary protein or essential amino acids 6,18-21.

The postprandial rise in muscle protein synthesis rate has been shown to depend on the amount, type, and amino acid composition of the ingested protein ${ }^{21-}$ ${ }^{25}$. The rise in the plasma concentration of amino acids is dependent on the amount of ingested protein in a dose-dependent manner. It has been shown that a dose of approximately 20 grams of protein, which is comparable to a dose of 10 grams of essential amino acids, is sufficient to stimulate muscle protein synthesis rates in both young and older adults 17,19,26-28. A further increase of the ingested amount of protein may further increase the muscle protein synthetic response in older individuals ${ }^{29}$. Although all protein sources have the capacity to stimulate muscle protein synthesis rates, the effect can vary substantially following the ingestion of different protein sources. It has been suggested that the ingestion of more rapidly digested protein results in a greater stimulation of muscle protein synthesis when compared to slower digested proteins. This concept has been developed by investigating the digestion 
and absorption kinetics of whey protein compared to casein protein. It seems that ingestion of rapidly digestible proteins can increase protein synthesis rates to a greater extent than the ingestion of slowly digestible protein, although the latter may stimulate muscle protein synthesis for a longer time period ${ }^{30-33}$. However, in a study where casein was hydrolysed in order to make its digestion and absorption kinetics comparable to whey, the rise in muscle protein synthesis rate was still greater following whey compared with casein protein ingestion ${ }^{30}$. This can be explained by differences in amino acid composition between the various available protein sources. Indeed, the amino acid composition of a protein represents another key determinant in the muscle protein synthetic response to protein ingestion. Particularly leucine has been shown to be one of the more potent stimuli to induce muscle protein synthesis and decrease muscle protein breakdown. In agreement, it has been shown that addition of free leucine with protein can further increase the postprandial muscle protein synthetic response to the ingestion of a suboptimal dose or source of protein in the elderly $22,24,34$.

Apart from the effects of differences in digestibility and amino acid composition of different protein sources, regular meals generally provide all macronutrients, including both carbohydrate and fat. Co-ingestion of these macronutrients with protein may alter protein digestion and absorption kinetics as well as the endocrine response to feeding, thereby modulating the postprandial rise in muscle protein synthesis rate. Like amino acids, insulin is a very potent anabolic stimulus for muscle protein metabolism. The postprandial release of insulin with carbohydrate co-ingestion into the plasma is often suggested to have a positive effect on muscle protein synthesis by enlargement of the local availability of amino acids in muscle through stimulation of muscle perfusion, while simultaneously decreasing the rates of muscle protein breakdown ${ }^{15,35,36}$. However, the effect of insulin seems to be rather permissive, because even a modest rise in circulating insulin is sufficient to support the increase in muscle protein synthesis rates following protein ingestion $12,37,38$. In addition, when nutritional support is specifically required to prevent or treat the loss of muscle mass, it might be suitable to use tailored high protein clinical supplements aimed at stimulating muscle protein synthesis rates, without the need for a high energy content ${ }^{39-41}$. Yet, whether clinical nutritional supplements, either containing all macronutrients or tailored as high-protein supplements, are effective in the preservation of muscle mass at the long-term, remains to be elucidated.

The sensitivity of skeletal muscle tissue to anabolic stimuli seems to be blunted in the elderly population when compared to the young 11,42,43. The reduced capacity of muscle in the elderly to increase protein synthesis rates in response to 
feeding has been coined anabolic resistance or anabolic inflexibility ${ }^{44}$. This might provide a valid explanation for the loss of skeletal muscle mass observed with ageing. Several studies have shown that muscle protein synthesis rates are not increased to the same extent in older individuals compared to young individuals following intravenous or oral amino acid administration in euglycemic clamp conditions ${ }^{43,45,46}$. However, studies measuring the post-prandial muscle protein synthetic response to ingestion of meal-like amounts of protein or amino acids have been unable to confirm the presence of an impaired anabolic response to feeding in the elderly 9,19,20,47,48. A study combining data to build a more extensive data set, however, showed $16 \%$ lower post-prandial muscle protein synthesis rates in older subjects when compared with the young ${ }^{11}$. The previous studies may have failed to capture small but clinically relevant differences in the post-prandial muscle protein synthetic response due to a smaller number of included subjects.

Another key anabolic factor for the stimulation of muscle protein synthesis is physical activity. Anabolic resistance may be attributed to lower physical activity levels in the older population as opposed to the aging process per se ${ }^{44}$. Using bed rest studies in healthy young individuals, a substantial decrease in basal muscle protein synthesis rates has been reported multiple times ${ }^{49,50}$. Likewise, a pronounced reduction in basal muscle protein synthesis rates was observed in older adults after bed rest ${ }^{51}$. Furthermore, recent studies have shown an impaired skeletal muscle protein synthetic response to the ingestion of protein as a result of physical inactivity or disuse ${ }^{52-54}$. Bed rest and immobilisation in elderly could therefore lead to a substantial reduction in the post-prandial muscle protein synthetic response. Concluding, anabolic resistance likely plays a key role in the loss of skeletal muscle mass with ageing, and may be partly attributed to a decline in physical activity. Importantly, hospitalisation in the elderly is often accompanied by bed rest and associated physical inactivity. Given the negative consequences of this 'muscle disuse', it is of particular interest to study skeletal muscle mass, function, and metabolism in older, more clinically comprised, elderly such as those entering the hospital.

\section{Hip fractures}

The clinical relevance of the concept of muscle loss and sarcopenia is emphasised in trauma surgery, because a decline in skeletal muscle mass and function predisposes to falls ${ }^{55}$. The ability of skeletal muscle to generate an adequate amount of force is fundamental for balance and reflexive recovery of posture to prevent falling. Elderly suffering from sarcopenia are, therefore, over three times more likely to fall, 
regardless of age, gender, or comorbidities, with an increased risk of injury ${ }^{56}$. Overall, significant injuries ranging from lacerations to fractures occur in 20 to $60 \%$ of the falls in elderly ${ }^{57}$. Hip fractures are a particularly devastating type of geriatric fractures, because it coincides with high morbidity and mortality rates in the elderly 58. Hip (proximal femur) fractures constitute a significant global public health problem, with a current incidence rate of 100 per 100.000 citisens in the Netherlands 59. As a consequence of demographic changes, it is predicted that the total number of hip fracture patients will continue to grow in the next decades ${ }^{60,61}$. In general, hip fracture patients have an increased all-cause mortality risk which is 5- to 8-fold increased during the first months post-fracture, but which seems to persist even several years post-fracture ${ }^{62,63}$. Furthermore, more than half of the patients do not regain their pre-fracture mobility in the first year ${ }^{64}$, and individuals affected by a hip fracture are at risk for the loss of independence and, consequently, the need for institutionalisation ${ }^{65}$. It is, therefore, not surprising that hip fracture patients report lower post-fracture health-related quality of life than age-matched controls ${ }^{66,67}$. Sarcopenia has been recognised as a predictor for adverse outcomes in hospitalised patients, such as longer hospitalisation, physical frailty, disability, and demand for long-term care or institutionalisation ${ }^{68-70}$. Therefore, sarcopenia is not only associated with hip fractures from an aetiological perspective, but it could also represent an important factor during the recovery and rehabilitation phase. Maintaining or increasing muscle mass and strength is of importance for the general older population, but could be an even more crucial factor in the prevention and recovery of hip fractures.

\section{Models of muscle loss}

Sarcopenia is a multifactorial process and the extent to which different factors contribute to its development likely varies between individuals. Some of the main contributers to age-related loss of muscle mass are inadequate (protein) nutrition, sedentary lifestyle, chronic diseases, and hormonal factors ${ }^{71}$. The loss of muscle mass with ageing generally progresses in a gradual manner, but it can also be acutely accelerated, such as during short periods of disuse due to bed rest or limb immobilisation. Successive episodes of exacerbated muscle loss are assembled in the concept of the catabolic crisis model ${ }^{72}$, which is depicted in figure 1. In comparison to the traditional model of gradual, almost linear muscle loss with ageing, this model proposes that successive periods of short term accelerated muscle loss in combination with an inability to fully regain the muscle mass culminate in substantial muscle loss over a more prolonged period of time. 


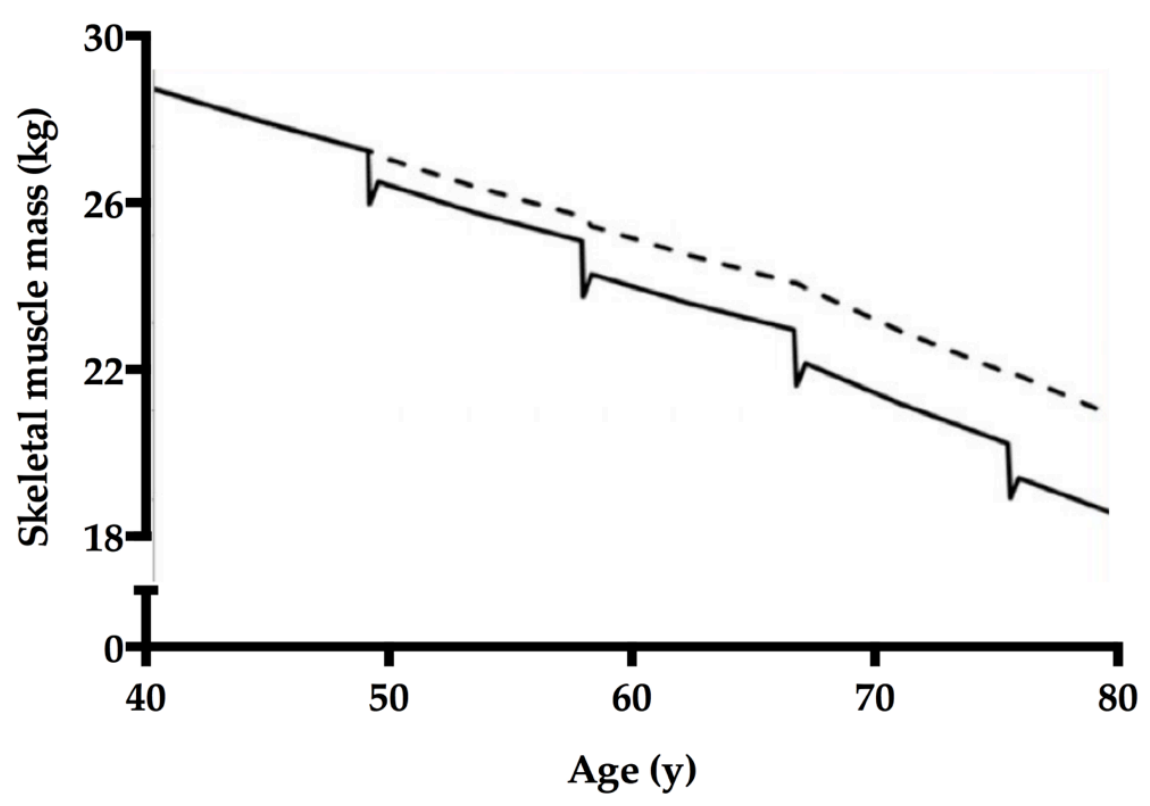

Proposed model of age-related muscle loss characterised by a progressive decline in muscle mass due to short successive episodes of muscle disuse. Dashed line represents the traditional sarcopenia model; solid line represents the catabolic crisis model. Adapted from English et al., $2010{ }^{72}$.

In the elderly hip fracture patient, both immobilisation and stress-inducing events are applicable. The injury-related trauma and subsequent surgery in hip fracture patients are associated with a major elevation of inflammatory markers and cytokines such as TNF- $\alpha$, IL-1 $\beta$ and IL- $6{ }^{73}$, which sustain a prolonged catabolic state characterised by the loss of nitrogen and the development of insulin resistance ${ }^{74}$. It activates the molecular pathways involved in skeletal muscle wasting, leading to a decrease of muscle protein synthesis rates and and increase in muscle protein breakdown ${ }^{75-79}$. Furthermore, long periods of preoperative fasting will also induce a state of insulin resistance and catabolism thereby aggravating the fracture-induced catabolism ${ }^{80}$. A period of illness or injury can also reduce appetite such that individuals consume an insufficient amount of calories and protein to maintain energy and protein balance, respectively ${ }^{81,82}$. Last but not least; during perioperative immobilisation and hospitalisation, a period of severe physical inactivity is induced, consequently initiating muscle disuse atrophy.

Overall, these findings suggest that the combination of bed rest and stressinducing events entailed in hip fracture patients will result in substantial loss of muscle mass and function in the absence of a robust countermeasure to preserve muscle mass. Research is needed to determine the extent of this loss of skeletal muscle mass and strength in hip fracture patients. It is furthermore of importance to 
determine which nutritional interventions are effective to adequately stimulate muscle protein synthesis rates in sarcopenic elderly in order to design more appropriate interventional strategies to combat muscle loss. However, whether active nutritional treatment is able to improve clinical outcomes in older hip fracture patients remains an unresolved question up to date. 


\section{Dissertation outline}

In this dissertation we present a collection of studies related to sarcopenia and muscle loss in older hip fracture patients. We examine skeletal muscle characteristics and clinical outcome in orthopaedic patients and evaluate the efficacy of nutritional interventions to stimulate muscle anabolism in healthy and sarcopenic elderly.

Hip fracture patients are part of a diverse population of orthopaedic or trauma patients, who all have an urgency for surgery in common. In chapter 2 we evaluate the in-hospital outcomes of surgical patients in an international setting, comparing elective with non-elective surgery in orthopaedic patients and assessing the effect of co-morbidity and age on outcomes. In chapter 3 we further focus on hip fracture patients and compare skeletal muscle fibre characteristics in female hip fracture patients with age-matched healthy elderly and with young healthy controls to assess which of these characteristics may predispose to falls and fractures in the older population. Due to immobilisation and stress-inducing events such as the operative treatment, elderly hip fracture patients are prone to (further) muscle loss during hospitalisation. In chapter 4 we, therefore, assess muscle mass and fibre type characteristics during hospitalisation in elderly hip fracture patients, and show that even during short-term hospital stay following a hip fracture, further muscle atrophy is induced.

In the second part of this thesis, we focus on nutritional factors in relation to muscle mass. Since a close relation between protein intake and muscle loss has been demonstrated, (protein) malnutrition could negatively impact clinical outcomes in hip fracture patients. In chapter 5, we evaluate the existing literature on nutritional status of hip fracture patients and the possible role for nutritional interventions on in-hospital as well as long-term outcomes. Subsequently, we present the effects of a nutritional intervention on muscle protein synthesis rates in the elderly. Since protein is generally consumed as part of a meal with the other macronutrients (carbohydrate and fat) included, we assessed the effects of the macronutrient composition of an oral nutritional supplement on the muscle protein synthetic response in healthy elderly in chapter $\mathbf{6}$. The nutritional supplement that was able to effectively increase postprandial muscle protein synthesis rates in healthy elderly, was further investigated in chapter 7, in which we compared muscle protein synthesis rates between healthy and sarcopenic elderly after ingestion of a nutritional supplement. In chapter 8, we finally discuss the implications of the findings presented in this thesis and address key areas for future research. 


\section{References}

1. Christensen K, Doblhammer G, Rau R, Vaupel JW. Ageing populations: the challenges ahead. The Lancet. 2009;374(9696):1196-1208.

2. Grimby G, Saltin B. The ageing muscle. Clinical Physiology. 1983;3(3):209-218.

3. Rosenberg IH. Sarcopenia: origins and clinical relevance. The Journal of nutrition. May 1997;127(5 Suppl):990S991S.

4. Crus-Jentoft AJ, Baeyens JP, Bauer JM, et al. Sarcopenia: European consensus on definition and diagnosis: Report of the European Working Group on Sarcopenia in Older People. Age and ageing. Jul 2010;39(4):412-423.

5. Koopman R, van Loon LJ. Aging, exercise, and muscle protein metabolism. Journal of applied physiology (Bethesda, Md. : 1985). 2009;106(6):2040-2048.

6. Rennie MJ, Edwards RH, Halliday D, Matthews DE, Wolman SL, Millward DJ. Muscle protein synthesis measured by stable isotope techniques in man: the effects of feeding and fasting. Clinical science. Dec 1982;63(6):519-523.

7. Dorrens J, Rennie MJ. Effects of ageing and human whole body and muscle protein turnover. Scandinavian journal of medicine $\mathcal{E}$ science in sports. 2003;13(1):26-33.

8. Volpi E, Sheffield-Moore M, Rasmussen BB, Wolfe RR. Basal muscle amino acid kinetics and protein synthesis in healthy young and older men. JAMA : the journal of the American Medical Association. Sep 12 2001;286(10):1206-1212.

9. Paddon-Jones D, Sheffield-Moore M, Zhang XJ, et al. Amino acid ingestion improves muscle protein synthesis in the young and elderly. American journal of physiology. Endocrinology and metabolism. Mar 2004;286(3):E321-328.

10. Kumar V, Selby A, Rankin D, et al. Age-related differences in the dose- response relationship of muscle protein synthesis to resistance exercise in young and old men. The Journal of physiology. 2009;587(Pt 1):211-217.

11. Wall BT, Gorissen SH, Pennings B, et al. Aging Is Accompanied by a Blunted Muscle Protein Synthetic Response to Protein Ingestion. PloS one. 2015;10(11).

12. Gorissen SH, Burd NA, Hamer HM, Gijsen AP, Groen BB, van Loon LJ. Carbohydrate coingestion delays dietary protein digestion and absorption but does not modulate postprandial muscle protein accretion. The Journal of clinical endocrinology and metabolism. Jun 2014;99(6):2250-2258.

13. Dangin M, Boirie $Y$, Garcia-Rodenas $C$, et al. The digestion rate of protein is an independent regulating factor of postprandial protein retention. American journal of physiology. Endocrinology and metabolism. 2001;280(2):8.

14. Boirie Y, Gachon P, Beaufrere B. Splanchnic and whole-body leucine kinetics in young and elderly men. The American journal of clinical nutrition. Feb 1997;65(2):489-495.

15. Timmerman KL, Lee JL, Dreyer HC, et al. Insulin stimulates human skeletal muscle protein synthesis via an indirect mechanism involving endothelial-dependent vasodilation and mammalian target of rapamycin complex 1 signaling. The Journal of clinical endocrinology and metabolism. Aug 2010;95(8):3848-3857.

16. Drummond MJ, Glynn EL, Fry CS, Timmerman KL, Volpi E, Rasmussen BB. An increase in essential amino acid availability upregulates amino acid transporter expression in human skeletal muscle. American journal of physiology. Endocrinology and metabolism. 2010;298(5):8.

17. Cuthbertson D, Smith K, Babraj J, et al. Anabolic signaling deficits underlie amino acid resistance of wasting, 
aging muscle. FASEB journal : official publication of the Federation of American Societies for Experimental Biology. Mar 2005;19(3):422-424.

18. Volpi E, Kobayashi H, SheffieldMoore M, Mittendorfer B, Wolfe RR. Essential amino acids are primarily responsible for the amino acid stimulation of muscle protein anabolism in healthy elderly adults. Am J Clin Nutr. Aug 2003;78(2):250258.

19. Volpi E, Ferrando AA, Yeckel CW, Tipton KD, Wolfe RR. Exogenous amino acids stimulate net muscle protein synthesis in the elderly. The Journal of clinical investigation. May 1 1998;101(9):2000-2007.

20. Volpi E, Mittendorfer B, Wolf SE, Wolfe RR. Oral amino acids stimulate muscle protein anabolism in the elderly despite higher first-pass splanchnic extraction. The American journal of physiology. Sep 1999;277(3 Pt 1):E513-520.

21. Paddon-Jones D, Sheffield-Moore $M$, Katsanos CS, Zhang XJ, Wolfe RR. Differential stimulation of muscle protein synthesis in elderly humans following isocaloric ingestion of amino acids or whey protein. Experimental gerontology. Feb 2006;41(2):215-219.

22. Rieu I, Balage $M$, Sornet $C$, et al. Leucine supplementation improves muscle protein synthesis in elderly men independently of hyperaminoacidaemia. The Journal of physiology. Aug 15 2006;575(Pt 1):305315.

23. Timmerman KL, Dhanani S, Glynn EL, et al. A moderate acute increase in physical activity enhances nutritive flow and the muscle protein anabolic response to mixed nutrient intake in older adults. The American journal of clinical nutrition. Jun 2012;95(6):14031412.

24. Wall BT, Hamer HM, de Lange A, et al. Leucine co-ingestion improves post-prandial muscle protein accretion in elderly men. Clinical nutrition. Jun 2013;32(3):412-419.

25. Volpi E, Kobayashi H, SheffieldMoore M, Mittendorfer B, Wolfe RR. Essential amino acids are primarily responsible for the amino acid stimulation of muscle protein anabolism in healthy elderly adults. The American journal of clinical nutrition. Aug 2003;78(2):250-258.

26. Bohé J, Low A, Wolfe RR, Rennie MJ. Human Muscle Protein Synthesis is Modulated by Extracellular, Not Intramuscular Amino Acid Availability: A Dose-Response Study. The Journal of Physiology. 2003;552(1):315-324.

27. Witard OC, Jackman SR, Breen L, Smith K, Selby A, Tipton KD. Myofibrillar muscle protein synthesis rates subsequent to a meal in response to increasing doses of whey protein at rest and after resistance exercise. The American journal of clinical nutrition. 2014;99(1):86-95.

28. Pennings B, Groen B, de Lange A, et al. Amino acid absorption and subsequent muscle protein accretion following graded intakes of whey protein in elderly men. American journal of physiology. Endocrinology and metabolism. Apr 2012;302(8):E992-999.

29. Yang Y, Breen L, Burd NA, et al. Resistance exercise enhances myofibrillar protein synthesis with graded intakes of whey protein in older men. The British journal of nutrition. Nov 28 2012;108(10):17801788.

30. Pennings B, Boirie $\mathrm{Y}$, Senden JM, Gijsen AP, Kuipers H, van Loon LJ. Whey protein stimulates postprandial muscle protein accretion more effectively than do casein and casein hydrolysate in older men. The American journal of clinical nutrition. May 2011;93(5):997-1005.

31. Tang JE, Moore DR, Kujbida GW, Tarnopolsky MA, Phillips SM. Ingestion of whey hydrolysate, casein, or soy protein isolate: effects on mixed 
muscle protein synthesis at rest and following resistance exercise in young men. Journal of applied physiology. Sep 2009;107(3):987-992.

32. Burd NA, Yang Y, Moore DR, Tang JE, Tarnopolsky MA, Phillips SM. Greater stimulation of myofibrillar protein synthesis with ingestion of whey protein isolate $\mathrm{v}$. micellar casein at rest and after resistance exercise in elderly men. The British journal of nutrition. Sep 28 2012;108(6):958-962.

33. Boirie $\mathrm{Y}$, Dangin $\mathrm{M}$, Gachon $\mathrm{P}$, Vasson MP, Maubois JL, Beaufrere B. Slow and fast dietary proteins differently modulate postprandial protein accretion. Proceedings of the National Academy of Sciences of the United States of America. Dec 23 1997;94(26):1493014935.

34. Katsanos CS, Kobayashi H, SheffieldMoore M, Aarsland A, Wolfe RR. A high proportion of leucine is required for optimal stimulation of the rate of muscle protein synthesis by essential amino acids in the elderly. American journal of physiology. Endocrinology and metabolism. Aug 2006;291(2):E381-387.

35. Gelfand RA, Barrett EJ. Effect of physiologic hyperinsulinemia on skeletal muscle protein synthesis and breakdown in man. J Clin Invest. Jul 1987;80(1):1-6.

36. Denne SC, Liechty EA, Liu YM, Brechtel G, Baron AD. Proteolysis in skeletal muscle and whole body in response to euglycemic hyperinsulinemia in normal adults. The American journal of physiology. Dec 1991;261(6 Pt 1):E809-814.

37. Hamer HM, Wall BT, Kiskini A, et al. Carbohydrate co-ingestion with protein does not further augment post-prandial muscle protein accretion in older men. Nutrition \& metabolism. 2013;10(1):15.

38. Greenhaff PL, Karagounis LG, Peirce $\mathrm{N}$, et al. Disassociation between the effects of amino acids and insulin on signaling, ubiquitin ligases, and protein turnover in human muscle.
American journal of physiology. Endocrinology and metabolism. Sep 2008;295(3):E595-604.

39. Ferrando AA, Paddon-Jones D, Hays $\mathrm{NP}$, et al. EAA supplementation to increase nitrogen intake improves muscle function during bed rest in the elderly. Clinical nutrition. Feb 2010;29(1):18-23.

40. Paddon-Jones D, Sheffield-Moore M, Urban RJ, et al. Essential amino acid and carbohydrate supplementation ameliorates muscle protein loss in humans during 28 days bedrest. The Journal of clinical endocrinology and metabolism. Sep 2004;89(9):4351-4358.

41. Stuart CA, Shangraw RE, Peters EJ, Wolfe RR. Effect of dietary protein on bed-rest-related changes in wholebody-protein synthesis. The American journal of clinical nutrition. Sep 1990;52(3):509-514.

42. Volpi E, Mittendorfer B, Rasmussen $\mathrm{BB}$, Wolfe RR. The response of muscle protein anabolism to combined hyperaminoacidemia and glucoseinduced hyperinsulinemia is impaired in the elderly. The Journal of clinical endocrinology and metabolism. Dec 2000;85(12):4481-4490.

43. Katsanos CS, Kobayashi H, SheffieldMoore M, Aarsland A, Wolfe RR. Aging is associated with diminished accretion of muscle proteins after the ingestion of a small bolus of essential amino acids. The American journal of clinical nutrition. Nov 2005;82(5):10651073.

44. Burd NA, Gorissen SH, van Loon LJ. Anabolic resistance of muscle protein synthesis with aging. Exerc Sport Sci Rev. Jul 2013;41(3):169-173.

45. Volpi E, Mittendorfer B, Rasmussen $\mathrm{BB}$, Wolfe RR. The response of muscle protein anabolism to combined hyperaminoacidemia and glucoseinduced hyperinsulinemia is impaired in the elderly. The Journal of clinical endocrinology and metabolism. Dec 2000;85(12):4481-4490. 
46. Guillet C, Prod'homme M, Balage M, Faseb ... G-P. Impaired anabolic response of muscle protein synthesis is associated with S6K1 dysregulation in elderly humans. The FASEB .... 2004.

47. Koopman R, Walrand S, Beelen M, et al. Dietary protein digestion and absorption rates and the subsequent postprandial muscle protein synthetic response do not differ between young and elderly men. The Journal of nutrition. 2009;139(9):1707-1713.

48. Symons TB, Schutzler SE, journal of ... C-TL. Aging does not impair the anabolic response to a protein-rich meal-.... American journal of .... 2007.

49. Ferrando AA, Lane HW, Stuart CA, Davis-Street J, Wolfe RR. Prolonged bed rest decreases skeletal muscle and whole body protein synthesis. The American journal of physiology. 1996;270(4 Pt 1):33.

50. Ferrando AA, Tipton KD, Bamman MM, Wolfe RR. Resistance exercise maintains skeletal muscle protein synthesis during bed rest. Journal of applied physiology (Bethesda, Md. : 1985). 1997:807-810.

51. Kortebein P, Ferrando A, Lombeida J, Wolfe R, Evans WJ. Effect of 10 days of bed rest on skeletal muscle in healthy older adults. JAMA : the journal of the American Medical Association. Apr 25 2007;297(16):17721774.

52. Breen L, Phillips SM. Skeletal muscle protein metabolism in the elderly: Interventions to counteract the 'anabolic resistance' of ageing. Nutrition E metabolism. 2011;8:68.

53. Drummond MJ, Dickinson JM, of ... FCS. Bed rest impairs skeletal muscle amino acid transporter expression, mTORC1 signaling, and protein synthesis in response to essential amino acids in older adults. American Journal of .... 2012.

54. Wall BT, Snijders T, Senden JM, et al. Disuse impairs the muscle protein synthetic response to protein ingestion in healthy men. The Journal of clinical endocrinology and metabolism. 2013;98(12):4872-4881.

55. Moreland JD, Richardson JA, Goldsmith $\mathrm{CH}$, Clase CM. Muscle weakness and falls in older adults: a systematic review and meta-analysis. Journal of the American Geriatrics Society. 2004;52(7):1121-1129.

56. Landi F, Liperoti R, Russo A, et al. Sarcopenia as a risk factor for falls in elderly individuals: results from the ilSIRENTE study. Clinical nutrition. Oct 2012;31(5):652-658.

57. Hartholt KA, Stevens JA, Polinder S, van der Cammen TJ, Patka P. Increase in fall-related hospitalizations in the United States, 2001-2008. The Journal of trauma. Jul 2011;71(1):255-258.

58. Hartholt KA, van Beeck EF, Polinder $\mathrm{S}$, et al. Societal consequences of falls in the older population: injuries, healthcare costs, and long-term reduced quality of life. The Journal of trauma. Sep 2011;71(3):748-753.

59. Zorg LNAZLNA. Landelijke Traumaregistratie 2011-2015. 2016.

60. Holt G, Smith R, Duncan K, Hutchison JD, Reid D. Changes in population demographics and the future incidence of hip fracture. Injury. 2009;40(7):722-726.

61. Icks A, Arend W, Becker C, Rapp K, Jungbluth $\mathrm{P}$, Haastert B. Incidence of hip fractures in Germany, 1995-2010. Archives of osteoporosis. 2013;8:140.

62. Farahmand BY, Michaëlsson K, Ahlbom A, Ljunghall S, Baron JA, Group S. Survival after hip fracture. Osteoporosis International. 2005;16(12):1583-1590.

63. Haentjens P, Magaziner J, ColónEmeric CS, et al. Meta-analysis: excess mortality after hip fracture among older women and men. Annals of internal medicine. 2010;152(6):380-390.

64. Vochteloo AJ, Moerman S, Tuinebreijer WE, et al. More than half of hip fracture patients do not regain mobility in the first postoperative 
year. Geriatrics $\mathcal{E}$ gerontology international. 2013;13(2):334-341.

65. Bentler SE, Liu L, Obrizan M, et al. The aftermath of hip fracture: discharge placement, functional status change, and mortality. American journal of epidemiology. 2009;170(10):1290-1299.

66. Cranney AB, Coyle D, Hopman WM, Hum V, Power B, Tugwell PS. Prospective evaluation of preferences and quality of life in women with hip fractures. The Journal of rheumatology. Dec 2005;32(12):2393-2399.

67. Peeters CMM, Visser E, Van de Ree CL, Gosens T, Den Oudsten BL, De Vries J. Quality of life after hip fracture in the elderly: A systematic literature review. Injury. 2016;47(7):1369-1382.

68. Landi F, Calvani R, Ortolani E, et al. The association between sarcopenia and functional outcomes among older patients with hip fracture undergoing in-hospital rehabilitation. Osteoporosis international : a journal established as result of cooperation between the European Foundation for Osteoporosis and the National Osteoporosis Foundation of the USA. 2017.

69. Cruz-Jentoft AJ, Landi F, Schneider SMM, et al. Prevalence of and interventions for sarcopenia in ageing adults: a systematic review. Report of the International Sarcopenia Initiative (EWGSOP and IWGS). Age and ageing. 2014;43(6):748-759.

70. Gariballa S, Alessa A. Sarcopenia: prevalence and prognostic significance in hospitalized patients. Clinical nutrition (Edinburgh, Scotland). 2013;32(5):772-776.

71. Marzetti E, Calvani R, Tosato M, et al. Sarcopenia: an overview. Aging clinical and experimental research. 2017;29(1):1117.

72. English KL, Paddon-Jones D. Protecting muscle mass and function in older adults during bed rest. Current opinion in clinical nutrition and metabolic care. 2010;13(1):34-39.
73. Sun T, Wang X, Liu Z, Chen X, Zhang J. Plasma concentrations of pro- and anti-inflammatory cytokines and outcome prediction in elderly hip fracture patients. Injury. 2011;42(7):707-713.

74. Weissman C. The metabolic response to stress: an overview and update. Anesthesiology. 1990;73(2):308-327.

75. Schaap LA, Pluijm SM, Deeg DJ, Visser M. Inflammatory markers and loss of muscle mass (sarcopenia) and strength. The American journal of medicine. 2006;119(6):20139898882013989817.

76. Lang $\mathrm{CH}$, Frost RA, Vary TC. Regulation of muscle protein synthesis during sepsis and inflammation. American journal of physiology. Endocrinology and metabolism. 2007;293(2):9.

77. Budui SL, Rossi AP, and Metabolism Z-M. The pathogenetic bases of sarcopenia. ... in Mineral and Bone Metabolism. 2015.

78. Frost RA, Lang CH. Protein kinase B/Akt: a nexus of growth factor and cytokine signaling in determining muscle mass. Journal of applied physiology (Bethesda, Md. : 1985). 2007;103(1):378-387.

79. Puthucheary ZA, Rawal J, McPhail M, et al. Acute skeletal muscle wasting in critical illness. JAMA : the journal of the American Medical Association. 2013;310(15):1591-1600.

80. Ljungqvist $\mathrm{O}$, Scott $\mathrm{M}$, Fearon KC. Enhanced Recovery After Surgery: A Review. JAMA surgery. 2017;152(3):292-298.

81. Carlsson P, Tidermark J, Ponzer S, Söderqvist A, Cederholm T. Food habits and appetite of elderly women at the time of a femoral neck fracture and after nutritional and anabolic support. Journal of human nutrition and dietetics : the official journal of the British Dietetic Association. 2005;18(2):117-120.

82. Stratton RJ, Green CJ, Elia M. Diseaserelated malnutrition: an evidence-based approach to treatment. Cabi; 2003. 




\section{CHAPTER 2}

Outcomes in urgent and emergency surgery in orthopaedic patients: prospective observational data from the European Surgical Outcomes Study 


\section{Abstract}

\section{Background}

The factors that are considered to have a potential impact on patient survival are complex and are multifactorial. It has been suggested that age, comorbidities, and urgency of surgery affect outcomes. We hypothesised that non-elective surgery (urgency and emergency) and a higher age in orthopaedic patients would be associated with higher in-hospital mortality in this specific group of patients.

\section{Methods}

Secondary analyses of the EuSOS data set were performed, of which the objective was to describe mortality rates and patterns of intensive care resource use for patients undergoing non-cardiac and non-neurological surgery across 28 European nations. Data were collected for in-hospital mortality, duration of hospital stay, admission to intensive care, and intensive care resource use. Multivariable logistic regression analysis was performed to understand the effects of urgency of surgery, age, and comorbidities on in-hospital mortality in the total orthopaedic patient cohort.

\section{Results}

We included 11873 patients in this study. Higher urgency of surgery, age, higher ASA scores and the presence of co-morbid diseases were associated with in-hospital mortality. The adjusted odds of death in a patient having urgent orthopaedic surgery was 1.64 times higher than patients having elective orthopaedic surgery, and 2.13 times higher in emergency orthopaedic surgery (both $\mathrm{p}<0.001$ ). There was no significant difference in mortality between urgent and emergency surgery $(p=0.22)$. Orthopaedic patients that died during hospital admission were significantly older than patients that survived $(\mathrm{p}<0.0001)$. We observed significantly higher crude mortality odds ratios in the octogenarian and nonagenarian orthopaedic patients than in the young age group.

\section{Conclusions}

Non-elective surgery and a higher age are associated with worse in-hospital outcomes in the orthopaedic patient cohort in this study. 


\section{Introduction}

An estimated 234 million surgical procedures are performed worldwide each year ${ }^{1}$, of which $25 \%$ involving operations on the musculoskeletal system ${ }^{2}$. Although surgery is used to treat a diverse range of conditions and can even prevent the loss of life, it also is associated with a considerable risk of complications and death. The mortality rates between countries and surgical specialities greatly varies and is overall estimated between 0.1 and $4 \%{ }^{3}$. The factors that are considered to have a potential impact on patient survival are complex and are multifactorial. Of these, comorbidity is one of the most intensively studied predictors for perioperative mortality ${ }^{4-6}$. Previous studies showed that acute mortality is mainly related to patient characteristics, instead of hospital characteristics ${ }^{7}$. Comorbidities are therefore routinely used in risk prediction models in the surgical population, such as the Elixhauer and the Charlson measures ${ }^{5,8,9}$. Urgency of surgery may be another contributing factor in perioperative mortality ${ }^{10}$. Patients in the overall patient population in need of urgent or emergency surgery are considered to have an increased mortality risk. Mortality in the group of general surgical patients undergoing an emergency procedure seems to be even eight times higher when compared to elective surgery ${ }^{11}$. This may be due to time of the day at which the procedure is performed, the availability of the most skilled physician, or it can be that these patients are just more severely ill than those admitted electively ${ }^{12-14}$. Age of the patient is considered to be another major risk factor for perioperative inhospital mortality. However, the impact of advanced age on the mortality risk has not been fully understood, despite the rapid increase of surgical treatment in elderly patients.

Surgical outcome studies have been widely performed for the general surgical population often based on national databases ${ }^{15,16}$. However, data on international outcomes are rare, and are even absent when specifically the orthopaedic patient cohort is considered. The orthopaedic surgical population consists of a diverse group of patients whom may differ from the general surgical population. Postoperative mortality after orthopaedic surgery has often been evaluated in relation to joint replacement and hip fracture surgery. However, inpatient mortality may strongly vary among the different orthopaedic subspecialties ${ }^{6}$, and might be related to the urgency of the operation. As previously stated, patient factors such as age and comorbidities may furthermore influence the outcomes of orthopaedic patients. We were specifically interested in outcomes of patients receiving urgent or emergency 
orthopaedic care and wanted to identify the high-risk patients among this orthopaedic group.

In this study, we assessed in-hospital outcomes of orthopaedic patients in hospitals in an international setting undergoing urgent of emergency operations. We performed a secondary analysis on data of the European Surgical Outcomes Study (EuSOS), of which the objective was to describe mortality rates and patterns of intensive care resource use for patients undergoing non-cardiac and nonneurological surgery across several European nations. We furthermore studied length of hospital stay and admission to critical care. Finally, the effect of age within the urgent and emergency orthopaedic cohort was assessed.

\section{Materials and methods}

\section{Patients}

We performed a secondary analysis of the European Surgical Outcomes Study (EuSOS) data set ${ }^{3}$. This is an observational cohort study performed between 09:00 $\mathrm{h}$ (local time) on 4 April 2011, and 08:59 h on 11 April 2011 in 498 hospitals across 28 European countries. All patients older than 16 years admitted to participating centres for elective or non-elective inpatient surgery commencing during the 7-day cohort period were eligible for inclusion. Patients undergoing planned day-case surgery, cardiac surgery, neurosurgery, radiological and obstetrical procedures were excluded. Participating hospitals were a voluntary convenience sample, identified through membership of the European Society of Intensive Care Medicine and the European Society of Anaesthesiology and by direct approach from national study coordinators. Study design and procedures have been described previously ${ }^{3}$ and can be accessed via eusos.esicm.org. An operating theatre paper case record form was completed for consecutive patients including patient's characteristics and comorbidities. Patients were followed up until hospital discharge or death for a maximum of 60 days after surgery. Data describing hospital stay, admission to critical care, and in-hospital mortality were collected. These were anonymised before entry onto electronic case record forms, assessed for completeness and checked for plausibility. To improve data quality, a data set that excludes sites with $\leq 10$ patients and sites above 95th centile for mortality was used for analyses.

\section{Ethics}

All 498 participating centres applied for and obtained local ethical approval, except for Denmark because the study was deemed to be a clinical audit. Primary ethical 
approval for this study (Ethical Committee Number 10/H0605/72) was provided by the ethical committee of South Hampton, United Kingdom on the 15 November 2010. The study is registered with ClinicalTrials.gov, number NCT01203605.

\section{Cohort description}

For this secondary analysis, all patients within the EuSOS database who had orthopaedic surgery were included. Exclusion criteria were any patient with missing data for in-hospital mortality, and any patient with missing data for the urgency of surgery. The definition of emergency surgery was immediately, without delay, ideally within 24 hours. The definition of urgent surgery was planned surgery within hours or days of the decision to operate. The definition of elective surgery was planned surgery without a time limit.

\section{Outcomes}

The primary endpoint was in-hospital mortality; the secondary outcome measures were length of hospital stay and admission to critical care.

\section{Statistical analysis}

Sample size calculation was performed for the primary European Surgical Outcome Study, we did not perform a new formal sample size calculation for this secondary analysis. Statistical analysis was performed using SPSS (version 23). Categorical variables are presented as number $(\%)$ and continuous variables as means $\pm S D$ when normally distributed of median (interquartile range, IQR) when not. Fisher's exact tests and $\chi^{2}$ tests were used to compare categorical variables and the t-test or the Mann-Whitney $U$ test to compare continuous variables between groups. Significance was set at a $P$ value less than 0.05 .

We conducted univariate binary analysis in the total orthopaedic patient cohort to identify factors that were independently related to in-hospital mortality. Factors with a significant relation to outcome in the univariate analysis were entered as co-variables into a multivariable logistic regression model. The results of the model are reported as adjusted odds ratios (OR) with 95\% CI. Univariate binary analysis was furthermore conducted in the non-elective (urgent and emergency) cohort of orthopaedic patients to identify factors that were associated with mortality in this specific population. Primary and secondary outcomes were compared between the elective and non-elective orthopaedic patient groups using $\chi^{2}$ and Mann-Whitney $U$ tests for categorical and continuous variables, respectively. 


\section{Results}

Of the 45591 patients from 426 sites included in primary analysis, 11873 patients fulfilled the cohort criteria and were included in this study. Characteristics of the orthopaedic patient cohort are presented in table 1. Unadjusted 30-day in-hospital mortality for patients who underwent orthopaedic surgery was $2.3 \%$. In comparison, the overall in-hospital mortality in the total EuSOS cohort was 3.0\%. Higher urgency of surgery was associated with significantly higher mortality rates with an unadjusted OR of 2.11 (95\% CI 1.63-2.72, p<0.01) for urgent surgery, and an unadjusted OR of 2.78 (95\% CI 1.83-4.21, p<0.01) for emergency surgery. Other associations with in-hospital mortality included age, higher American Society of Anaesthesiologists (ASA) scores, and the presence of co-morbid diseases.

Table 1 | Descriptives of the orthopaedic cohort including univariable logistic regression

\begin{tabular}{|c|c|c|c|c|c|}
\hline & $\begin{array}{l}\text { All orthopaedic } \\
\text { patients } \\
n=11875\end{array}$ & $\begin{array}{c}\text { Died in } \\
\text { hospital } \\
n=273\end{array}$ & $\begin{array}{l}\text { Survived to } \\
\text { hospital } \\
\text { discharge } \\
n=11602\end{array}$ & $\begin{array}{c}\text { Unadjusted } \\
\text { odds ratio }(95 \% \\
\text { CI) }\end{array}$ & $p$ value \\
\hline Age (y) & $59.0 \pm 19.4$ & $67 \pm 21$ & $59 \pm 19$ & $0.98(0.97-0.98)$ & $<0.0001$ \\
\hline \multicolumn{6}{|l|}{ Sex } \\
\hline Male & 5508 & $124(45.4)$ & $5348(46.4)$ & Reference & - \\
\hline Female & 6367 & 149 (54.6) & $6218(53.6)$ & $1.04(0.82-1.32)$ & 0.75 \\
\hline Present smoker & 2311 & $41(15.1)$ & $2270(19.7)$ & $0.73(0.52-1.02)$ & 0.06 \\
\hline \multicolumn{6}{|l|}{ ASA score } \\
\hline 1 & 2984 & $58(21.3)$ & $2927(25.3)$ & Reference & - \\
\hline 2 & 5642 & $80(29.4)$ & $5562(48.0)$ & $0.73(0.52-1.02)$ & 0.07 \\
\hline 3 & 2924 & $91(33.5)$ & $2834(24.5)$ & $1.62(1.16-2.26)$ & $<0.01$ \\
\hline 4 & 292 & $42(15.4)$ & $250(2.2)$ & 8.48 (5.58-12.87) & $<0.0001$ \\
\hline 5 & 6 & $1(0.4)$ & $5(0)$ & 10.09 (1.16-87.76) & 0.036 \\
\hline \multicolumn{6}{|l|}{ Grade of surgery } \\
\hline Minor & 2438 & 54 (19.9) & $2384(20.6)$ & Reference & - \\
\hline Intermediate & 5585 & $113(41.5)$ & $5472(47.2)$ & $0.91(0.66-1.27)$ & 0.58 \\
\hline Major & 3832 & 105 (38.6) & 3727 (32.3) & $1.24(0.89-1.73)$ & 0.20 \\
\hline \multicolumn{6}{|l|}{ Urgency of surgery } \\
\hline Elective & 7956 & $132(1.7)$ & & Reference & - \\
\hline Urgent & 3292 & $113(3.4)$ & & $2.11(1.63-2.72)$ & $<0.01$ \\
\hline Emergency & 625 & $28(4.5)$ & & $2.78(1.83-4.21)$ & $<0.01$ \\
\hline \multicolumn{6}{|l|}{ Anaesthetic technique } \\
\hline $\begin{array}{l}\text { General } \\
\text { anaesthesia }\end{array}$ & 7252 & $164(60.1)$ & 7089 (61.1) & $0.96(0.75-1.22)$ & 0.73 \\
\hline Spinal anaesthesia & 4023 & $97(35.5)$ & $3926(33.8)$ & $1.08(0.84-1.39)$ & 0.56 \\
\hline $\begin{array}{l}\text { Epidural } \\
\text { anaesthesia }\end{array}$ & 336 & $4(1.5)$ & $332(2.9)$ & $0.51(0.19-1.36)$ & 0.18 \\
\hline Sedation & 1289 & $27(9.9)$ & $1262(10.9)$ & $0.9(0.6-1.33)$ & 0.6 \\
\hline
\end{tabular}


Local anaesthetic

Grade of anaesthetist

Attending

Middle grade

Junior

Grade of surgeon

Attending

Middle grade

Junior

Comorbid disorder

Cirrhosis

Congestive heart

failure

Chronic

obstructive

pulmonary

disease

Coronary heart

disease

Diabetes Mellitus

(insulin

dependent)

Diabetes Mellitus

(non-insulin

dependent)

Metastatic cancer

Stroke
349

$6(2.2)$

$0.74(0.33-1.67)$

0.46

8007

2548

1229

198 (72.5)

45 (16.5)

$30(11)$

9357

2260

244

200 (73.5)

$63(23.2)$

9 (3.3)

87

580

5 (1.8)

37 (13.6)

1286

48 (17.6)

1542

480

876

247

525

7811 (67.8)

2503 (21.7)

1199 (10.4)

Reference

$0.71(0.51-0.98)$

$0.99(0.67-1.46)$

0.039

0.95

9158 (79.0)

2198 (19.0)

Reference

$235(2.0)$

1.31 (0.99-1.75)

0.06

1.75 (0.89-3.46)

0.11

$82(0.7)$

$2.62(1.05-6.52)$

0.04

$3.2(2.24-4.57)$

$<0.0001$

1238 (10.7)

$1.79(1.3-2.46) \quad<0.0001$

$55(20.2)$

1487 (12.9)

$1.72(1.27-2.32)$

$<0.000$

$20(7.4)$

$460(4.0)$

$1.92(1.2-3.05)$

$<0.01$

$21(7.7)$

855 (7.4)

$1.05(0.67-1.65)$

0.84

9 (3.3)

238 (2.1)

$1.63(0.83-3.2)$

0.16

26 (9.6)

499 (4.3)

$2.35(1.55-3.55)$

$<0.0001$

Abbreviations: ASA= American Society of Anaesthesiologists. Data are means \pm SD, n (\%), or odds ratios (95\% $\mathrm{CI})$, unless otherwise specified. Unadjusted odds ratios were constructed for in-hospital mortality with univariate binary logistic regression analysis.

Primary and secondary outcomes after elective $(n=7956)$, urgent $(n=3293)$, and emergency orthopaedic surgery $(n=625)$ were compared, as shown in table 2 . Inhospital mortality was $1.7 \%$ after elective surgery, $3.4 \%$ after urgent surgery, and $4.5 \%$ in emergency surgery $(p<0.0001)$. Length of stay in hospital significantly increased with higher urgency of surgery. Patients in the elective group stayed on average $6 \pm 7$ days in hospital, whereas the duration of hospital stay for patients in the non-elective groups was significantly longer $(8 \pm 10$ and $10 \pm 12$ days in the urgent and emergency group, respectively; $\mathrm{p}<0.0001)$. The highest numbers of admission to critical care were found after emergency surgery, with a percentage of $7.4 \%$ $(\mathrm{p}<0.0001)$. 
Table 2 | Outcomes in the orthopaedic patient cohort

$\begin{array}{cccc}\begin{array}{c}\text { Elective } \\ n=7956\end{array} & \begin{array}{c}\text { Urgent } \\ n=3292\end{array} & \begin{array}{c}\text { Emergency } \\ n=625\end{array} & p \text { value } \\ & & & \\ 40(0.5) & 21(0.6) & 3(0.5) & 0.56 \\ 39(0.5) & 46(1.4) & 33(5.3) & <0.0001 \\ & & & \\ 62(0.8) & 40(1.2) & 27(4.3) & <0.0001 \\ & & & \\ 241(3.0) & 127(3.9) & 46(7.4) & <0.0001 \\ 119 \pm 68 & 108 \pm 65 & 118 \pm 86 & <0.0001 \\ & & & \\ 134 \pm 86 & 113 \pm 149 & 131 \pm 197 & <0.0001 \\ 6 \pm 7 & 8 \pm 10 & 10 \pm 12 & <0.0001 \\ 132(1.7) & 113(3.4) & 28(4.5) & <0.0001\end{array}$

Data are means \pm SD or $\mathrm{n}(\%)$ unless otherwise specified. Differences between groups were tested with $\chi^{2}$ test to compare categorical variables and Mann-Whitney $U$ test to compare continuous variables.

Characteristics of the non-elective cohort of orthopaedic patients are presented in table 3. Unadjusted OR for in-hospital mortality for patients after urgent and emergency surgery are shown. The same factors were associated with inhospital mortality for this specific group when compared with the total orthopaedic patient cohort (table 1 vs table 3), namely age, ASA classification, and the presence of co-morbid diseases. For the non-elective cohort only, major grade of surgery was also associated with in-hospital mortality.

Table 3 | Univariable logistic regression in the urgent and emergency cohort of the orthopaedic patients

$\begin{array}{ccc}\begin{array}{c}\text { Urgent and Emergency } \\ \text { patients } \\ n=3917\end{array} & \begin{array}{c}\text { Odds ratio (95\% } \\ \text { CI) }\end{array} & p \text { value } \\ 61.1 \pm 22.2 & 1.04(1.03-1.05) & <0.01 \\ & \text { Reference } & - \\ 1882(48.0) & 1.12(0.8-1.57) & 0.52 \\ 2035(52.0) & 0.68(0.42-1.08) & 0.10 \\ 790(2.4) & & \\ & \text { Reference } & - \\ 1018(26.0) & 1.07(0.57-2.02) & 0.83 \\ 1484(38.0) & 3.58(2.06-6.22) & <0.01 \\ 1203(30.8) & \end{array}$


4

5

Grade of surgery

Minor

Intermediate

Major

Anaesthetic technique

General anaesthesia

Spinal anaesthesia

Epidural anaesthesia

Sedation

Local anaesthetic

Other regional

Cardiac output monitoring

Doppler ultrasound

Pulmonary artery catheter

Arterial wave form

Other monitoring

No monitoring

Central venous catheter

Grade of anaesthetist

Attending

Middle grade

Junior

Grade of surgeon

Attending

Middle grade

Junior

\section{Comorbid disorder}

Cirrhosis

Congestive heart failure

Chronic obstructive

pulmonary disease

Coronary heart disease

Diabetes Mellitus (insulin

dependent)

Diabetes Mellitus (non-

insulin dependent)

Metastatic cancer

Stroke
199 (5.1)

$5(0.1)$

763 (19.5)

$2102(53.7)$

1047 (26.8)

2483 (63.4)

$1215(31.0)$

$51(1.3)$

$366(9.3)$

124 (3.2)

$552(14.1)$

$12(0.3)$

$2(0.1)$

$80(2.0)$

45 (1.1)

3787 (96.7)

$109(2.8)$

2497 (64.2)

977 (25.1)

418 (10.7)

2694 (68.9)

1084 (27.7)

$132(3.4)$

49 (1.3)

$271(6.9)$

472 (12.1)

611 (15.7)

$194(5.0)$

287 (7.4)

112 (2.9)

$244(6.3)$
$12.91(6.97-23.91)$

15.66 (1.66-147.99)

$<0.01$

0.02

Reference

0.99 (0.60-1.62)

0.97

$2.01(1.22-3.31)$

$<0.01$

$0.82(0.58-1.16)$

0.26

$1.23(0.87-1.75)$

0.25

0.53 (0.07-3.88)

0.53

1.25 (0.74-2.13)

0.41

0.66 (0.21-2.09)

0.48

1.69 (1.11-2.55)

0.01

9.10 (2.22-33.98)

$<0.01$

Not enough cases

1.81 (0.72-4.56)

0.21

$1.93(0.59-6.31)$

0.28

$0.43(0.22-0.84)$

0.01

4.26 (2.37-7.67)

$<0.01$

Reference

0.59 (0.38-0.93)

0.02

0.87 (0.50-1.52)

0.63

Reference

1.22 (0.85-1.77)

$1.62(0.74-3.57)$

0.23

$3.12(1.21-7.95) \quad 0.02$

$3.94(2.58-6.03)$

$<0.01$

$2.61(1.77-3.86)$

$<0.01$

$2.13(1.46-3.11)$

$<0.01$

$1.65(0.88-3.11)$

0.12

$1.41(0.80-.248)$

$1.82(0.83-3.98)$

0.14

$3.30(2.08-5.22)$

$<0.01$

Abbreviations: ASA= American Society of Anaesthesiologists. Data are means \pm SD or $n(\%)$ unless otherwise specified. Unadjusted odds ratios were constructed for in-hospital mortality with univariate binary logistic regression analysis.

The effect of urgency of surgery on in-hospital mortality was further tested in a multivariate regression model (table 4). Factors that were independently associated with mortality were used to adjust univariable estimates of mortality. 
These were entered into a two-level binary logistic regression model with patient as factor at the first level and hospital as a random factor at the second level. The adjusted odds of death in a patient having urgent orthopaedic surgery was 1.64 times higher than patients having elective orthopaedic surgery (95\% CI 1.25-2.15, $\mathrm{p}<0.01)$. Emergency orthopaedic surgery was also significantly associated with inhospital mortality in comparison with elective orthopaedic surgery, showing an adjusted odds ratio of 2.13 (95\% CI 1.38-3.29, p<0.01). There was no significant difference in mortality between urgent and emergency surgery $(p=0.22)$ (data not shown).

Table 4 | Multivariable logistic regression in the orthopaedic cohort

\section{Adjusted odds ratio (95\% CI)}

$p$ value

Age (y)

$1.02(1.01-1.03)$

$<0.0001$

Sex

$$
\begin{aligned}
& \text { Male } \\
& \text { Female }
\end{aligned}
$$

Reference

Present smoker

0.86 (0.66-1.12)

0.93 (0.64-1.33)

0.26

ASA score

1

Reference

0.68

\section{2}

$0.50(0.34-0.75)$

$<0.0001$

$0.82(0.52-1.30)$

$<0.0001$

$3.21(1.80-5.74)$

0.40

4

$6.30(0.64-61.86)$

$<0.0001$

Grade of surgery

Minor

Reference

0.12

Intermediate

0.74 (0.53-1.04)

0.08

Major

$0.93(0.65-1.33)$

0.70

Urgency of surgery

Elective

Reference

Urgent

1.64 (1.25-2.15)

$<0.01$

Emergency

$2.13(1.38-3.29)$

$<0.01$

Comorbid disorder

Cirrhosis

$1.46(0.55-3.87)$

0.44

Congestive heart failure

$1.37(0.91-2.06)$

0.14

Chronic obstructive pulmonary

$1.37(0.97-1.93)$

0.08

disease

Coronary heart disease

$0.81(0.57-1.15)$

0.25

Diabetes Mellitus (insulin

$1.12(0.67-1.85)$

0.67

dependent)

Diabetes Mellitus (non-insulin

$0.82(0.51-1.31)$

0.41

Adjusted odds ratios for in-hospital mortality for the total orthopaedic cohort. Odds ratios were adjusted for baseline risk factors of age, ethnicity, sex, smoking status, ASA class, urgency of surgery, grade of surgery, and comorbid disorders. 
The odds ratios for in-hospital mortality by age group are depicted in table 5 . Orthopaedic patients that died during hospital admission were significantly older than patients that survived $(p<0.0001)$. Univariate analyses of the in-hospital morality in age groups per 10 years of age in the total orthopaedic patient cohort revealed significantly higher odds for death in the 80-90 years old and the 90+ years old groups $(\mathrm{p}<0.001)$. The group of 70-80 years old was showing a trend with odds of in-hospital death being 1.6 times higher than the 20-30 years old $(p=0.08)$.

Table 5 I Mortality per age-group in the total orthopaedic cohort

\begin{tabular}{lcccc}
\hline \hline Age (y) & $\begin{array}{c}\text { Number of patients } \\
\text { (n) }\end{array}$ & $\begin{array}{c}\text { Mortality } \\
(\mathbf{\%})\end{array}$ & Odds ratio & $p$ value \\
\hline & & & & N/A \\
$\mathbf{0 - 1 0}$ & 0 & N/A & 1.235 & 0.629 \\
$\mathbf{1 0 - 2 0}$ & 376 & 2.1 & Reference & Reference \\
$\mathbf{2 0 - 3 0}$ & 925 & 1.7 & 0.77 & 0.478 \\
$\mathbf{3 0 - 4 0}$ & 1047 & 1.3 & 0.797 & 0.478 \\
$\mathbf{4 0 - 5 0}$ & 1445 & 1.4 & 1.013 & 0.967 \\
$\mathbf{5 0 - 6 0}$ & 1884 & 1.8 & 0.731 & 0.318 \\
$\mathbf{6 0 - 7 0}$ & 2283 & 1.3 & 1.633 & 0.082 \\
$\mathbf{7 0 - 8 0}$ & 2326 & 2.8 & 3.114 & $<0.001$ \\
$\mathbf{8 0 - 9 0}$ & 1347 & 5.2 & 4.627 & $<0.001$ \\
$\mathbf{9 0}$ and above & 239 & 7.5 & &
\end{tabular}

Abbreviations: N/A = not applicable. Unadjusted odds ratios for in-hospital mortality per age group in the total orthopaedic cohort.

\section{Discussion}

In this prospective European study, in-hospital outcomes of 11873 patients undergoing orthopaedic surgery were assessed. This database provided us the information to determine 30-day in-hospital mortality for orthopaedic operations and to identify potential risk factors for death and adverse outcome.

$2.3 \%$ of the orthopaedic patients in our study died before hospital discharge. We identified significant differences in crude and risk adjusted mortality rates, ICU admission rates, and length of stay between patient subgroups. Patients undergoing non-elective surgery had a significantly higher odds ratio of in-hospital mortality. Furthermore, factors associated with worse outcomes in urgent and emergency surgery were age, ASA classification, and co-morbid diseases.

This secondary analysis of the EuSOS dataset is, as far as we know, the first large international investigation of in-hospital outcomes of orthopaedic patients, which is one of the major strengths of the study. We show a relatively low 30-day in- 
hospital baseline mortality rate of $2.3 \%$, which seems to be lower than the mortality rate found in the original EuSOS study, where it was 3.0\%. Inpatient mortality varied among the different urgencies of surgery. The lowest mortality rate was following elective orthopaedic surgery $(1.7 \%)$. This is in line with the low 30-day inhospital mortality rate of $1.0 \%$ after \pm 12000 elective hip replacement surgeries in a study of Khuri et al ${ }^{16}$, and of $0.5 \%$ after non-hip-fracture surgery in a large national study of Bhattacharyya et al ${ }^{6}$. However, both studies were conducted in the United States of America and only a selection of elective orthopaedic procedures were included in these studies. In-hospital mortality rates in these studies might therefor be slightly higher than the in-hospital mortality rates in our study.

Non-elective surgery was significantly associated with postoperative death in our orthopaedic patient cohort. Crude mortality odds ratios increased from elective to urgent surgery, to emergency surgery. When adjusted for confounding factors, the odds of dying after urgent or emergency orthopaedic surgery were 1.64 till 2.13 times increased compared to patients undergoing elective orthopaedic surgery $(\mathrm{p}<0.01$ and $\mathrm{p}<0.01)$. Comparing the data of our non-elective orthopaedic group to existing literature is a challenge. The non-elective orthopaedic patient cohort exists of a wide range of patients and morbidities: from young patients after high-energy trauma to elderly patients after low-energy trauma, and procedures for infections to oncological procedures. Mortality after polytrauma has been studied extensively 17,18, but there are few selective studies on orthopaedic trauma. Most orthopaedic studies are conducted on specified patient groups or exemplified by a common operation such as a hip fracture. We focussed on investigating outcomes in a large group of unselected patients undergoing non-elective orthopaedic surgery. We showed a significantly higher proportion of deaths in the urgent and emergency patients (3.4 and $4.5 \%$ respectively, versus $1.7 \%$ in the elective group). Surgical urgency is identified as a contributing factor for perioperative mortality and has been used in diverse risk stratification models ${ }^{11,19,20}$. Our study shows that this also accounts for the orthopaedic population. Urgent and emergency procedures are commonly performed after normal office hours, and consequently circumstances may be less ideal. A higher mortality rate for patients who underwent surgery at night was found in a study of van Zaane ${ }^{14}$, and this finding was accounted to the difference in surgical urgency of the procedures. Emergency procedures in specifically orthopaedic patients were also related to adverse outcomes in a study of Ricci et al ${ }^{21}$. Patients requiring urgent or emergency surgery are possibly sicker or more severely injured, which is the reason why there is no time for careful preoperative planning and preparation. This is reflected in the numbers of critical care admission, need of 
mechanical ventilation and need of vasopression in the first 24 hours post-surgery (table 1).

The presence of substantial co-morbidities and a high ASA classification were significantly associated with greater risk of in-hospital death. In the full orthopaedic cohort, crude mortality odds ratios increased sequentially from ASA 1 to ASA 5 (OR 10.09). Following adjustment for confounding factors, only ASA 4 was significantly associated with an increased risk of postoperative death (table 4). In the urgent and emergency cohort, a higher ASA number also resulted in sequentially increasing crude mortality odds ratios, from ASA 1 to ASA 3 (OR 3.58), to ASA 4 (OR 12.91), to ASA 5 (OR 15.66) (table 3). Various comorbidities were significantly associated with increased risk of postoperative death (coronary artery disease, COPD, congestive heart failure, insulin-dependent Diabetes Mellitus, stroke, and cirrhosis). After adjustment for confounding factors however, none of these was associated with higher risk of postoperative death. Diverse risk stratification models have been developed over time, in which comorbidities or ASA score take a prominent position. Our study shows that the ASA score is a contributing factor for postoperative outcome in unselected orthopaedic patients too.

As the changing global demography results in an older population worldwide, the incidence of orthopaedic procedures in the elderly is expected to further rise in the upcoming decades ${ }^{22,23}$. Elderly orthopaedic patients can be more vulnerable due to interplay of multiple comorbidities, reduced cardiovascular fitness, and functional decline. Frailty in elderly orthopaedic patients contributes to a higher risk of adverse outcomes and consequently requires customised care. In our study, crude mortality odds ratios were significantly higher in the octogenarian and nonagenarian orthopaedic patients than the age group between 20 and 30 years. This is in line with other literature, showing higher mortality rates among the oldest patients ${ }^{6}$. Age distribution of both elective and urgent orthopaedic admissions together showed a peak age of 79 years in this study, but mortality showed a significant rise after 80 years of age. Hip fracture patients accounted for about $50 \%$ of all orthopaedic postoperative deaths in the cited study, which confirms the vulnerability of the elderly non-elective orthopaedic patient. A retrospective study of Tornetta ${ }^{24}$ reported a mortality rate of $9 \%$ after orthopaedic operations for traumatic injury in elderly patients above 60 years of age. However, advanced chronological age does not seem to be the sole determinant of surgical risk, because biological age and underlying health status seems to be a more important determinant. This is also reflected in the results of our study, in which ASA score is one of the contributing factors in both the total orthopaedic cohort as well as in the non-elective cohort, and 
is associated with mortality after adjustment for confounding factors (table $\mathbf{1}$ and $\mathbf{4}$ ). According to literature, increased comorbidity burden has a greater impact on postoperative mortality and major complications than age alone in elderly adults undergoing (orthopaedic) surgery ${ }^{25}$. Again, chronological age is not a complete reflection of one's medical condition.

With this study, a unique insight is gained into outcomes of the orthopaedic patient population. This secondary analysis of the EuSOS dataset provided us the opportunity to analyse a large number of unselected orthopaedic patients enrolled in a multicentre and multinational study. Studies on risk stratification in surgical patients are often based on large administrative databases, which have recognised limitations. Data is extracted from form codes, which may not fully capture the patient population of interest, has the possibility of errors in coding, and are often based on a certain limited topographical area ${ }^{25,26}$, such as the USA. By employing a large international database, biases inherent in studies on patients from one country, one institution, and one orthopaedic subspecialty were minimised.

\section{Conclusions}

An episode of surgical care is defined by a continuum of pre-, peri-, and postoperative factors and events, all having potential impact on patient survival. The aim of our research was to study if the elderly orthopaedic patient whom is undergoing urgent or emergency surgery is more prone to in-hospital mortality than other orthopaedic patient groups. In summary, we showed a relationship between the urgency of surgery in the orthopaedic patients groups and in-hospital mortality. Non-elective surgery in the orthopaedic patient cohort was furthermore associated with higher admission rates to critical care and longer hospital stay. An age of over 80 years and a higher ASA classification were identified as significant contributing factors to postoperative mortality. 


\section{References}

1. Weiser TG, Regenbogen SE, Thompson KD, et al. An estimation of the global volume of surgery: a modelling strategy based on available data. Lancet (London, England). 2008;372(9633):139-144.

2. Weiss AJ, Elixhauser A. Trends in Operating Room Procedures in U.S. Hospitals, 2001-2011: Statistical Brief \#171. Healthcare Cost and Utilization Project (HCUP) Statistical Briefs. Rockville (MD)2006.

3. Pearse RM, Moreno RP, Bauer P, et al. Mortality after surgery in Europe: a 7 day cohort study. Lancet (London, England). 2012;380(9847):1059-1065.

4. Menendez ME, Neuhaus V, Ring D. Inpatient mortality after orthopaedic surgery. International orthopaedics. 2015;39(7):1307-1314.

5. Austin SR, Wong Y-N, Uzzo RG, Beck RJ, Egleston BL. Why Summary Comorbidity Measures Such As the Charlson Comorbidity Index and Elixhauser Score Work. Medical Care. 2015;53(9).

6. Bhattacharyya $T$, Iorio R, Healy WL. Rate of and risk factors for acute inpatient mortality after orthopaedic surgery. The Journal of bone and joint surgery. American volume. 2002;84A(4):562-572.

7. Silber JH, Williams SV, Krakauer H, Schwartz JS. Hospital and patient characteristics associated with death after surgery. A study of adverse occurrence and failure to rescue. Medical care. 1992;30(7):615-629.

8. Elixhauser A, Steiner C, Harris DR, Coffey RM. Comorbidity measures for use with administrative data. Medical care. 1998;36(1):8-27.

9. Charlson ME, Pompei P, Ales KL, MacKenzie CR. A new method of classifying prognostic comorbidity in longitudinal studies: development and validation. Journal of chronic diseases. 1987;40(5):373-383.
10. Pearse RM, Harrison DA, James P, et al. Identification and characterisation of the high-risk surgical population in the United Kingdom. Critical care (London, England). 2006;10(3).

11. Thompson AM, Stonebridge PA. Building a framework for trust: critical event analysis of deaths in surgical care. BMJ (Clinical research ed.). 2005;330(7500):1139-1142.

12. Guevara OA, Rubio-Romero JA, RuizParra AI. Unplanned reoperations: is emergency surgery a risk factor? A cohort study. The Journal of surgical research. 2013;182(1):11-16.

13. Peets A, Ayas NT. Restricting resident work hours: the good, the bad, and the ugly. Critical care medicine. 2012;40(3):960-966.

14. van Zaane B, van Klei WA, Buhre WF, et al. Nonelective surgery at night and in-hospital mortality: Prospective observational data from the European Surgical Outcomes Study. European journal of anaesthesiology. 2015.

15. Keene GS, Parker MJ, Pryor GA. Mortality and morbidity after hip fractures. BMJ (Clinical research ed.). 1993;307(6914):1248-1250.

16. Khuri SF, Henderson WG, DePalma RG, Mosca C, Healey NA, Kumbhani DJ. Determinants of long-term survival after major surgery and the adverse effect of postoperative complications. Annals of surgery. 2005;242(3):326-343.

17. Pfeifer R, Tarkin IS, Rocos B, Pape HCC. Patterns of mortality and causes of death in polytrauma patients--has anything changed? Injury. 2009;40(9):907-911.

18. Woodford M. Scoring systems for trauma. BMJ (Clinical research ed.). 2014;348.

19. Watters DA, Hollands MJ, Gruen RL, et al. Perioperative mortality rate (POMR): a global indicator of access to safe surgery and anaesthesia. World journal of surgery. 2015;39(4):856-864. 
20. Glance LG, Lustik SJ, Hannan EL, et al. The Surgical Mortality Probability Model: derivation and validation of a simple risk prediction rule for noncardiac surgery. Annals of surgery. 2012;255(4):696-702.

21. Ricci WM, Gallagher B, Brandt A, Schwappach J, Tucker M, Leighton R. Is after-hours orthopaedic surgery associated with adverse outcomes? A prospective comparative study. The Journal of bone and joint surgery. American volume. 2009;91(9):2067-2072.

22. Kannus P, Parkkari J, Sievanen H, Heinonen A, Vuori I, Jarvinen M. Epidemiology of hip fractures. Bone. Jan 1996;18(1 Suppl):57S-63S.

23. Spijker J, MacInnes J. Population ageing: the timebomb that isn't? BMJ (Clinical research ed.). 2013;347.
24. Tornetta P, Mostafavi H, Riina J, et al. Morbidity and mortality in elderly trauma patients. The Journal of trauma. 1999;46(4):702-706.

25. Chikuda $\mathrm{H}$, Yasunaga $\mathrm{H}$, Horiguchi $\mathrm{H}$, et al. Impact of age and comorbidity burden on mortality and major complications in older adults undergoing orthopaedic surgery: an analysis using the Japanese diagnosis procedure combination database. BMC musculoskeletal disorders. 2013;14:173.

26. Menendez ME, Neuhaus V, van Dijk $\mathrm{CN}$, Ring D. The Elixhauser comorbidity method outperforms the Charlson index in predicting inpatient death after orthopaedic surgery. Clinical orthopaedics and related research. 2014;472(9):2878-2886. 




\section{CHAPTER 3}

\section{Extensive type II muscle fibre atrophy in elderly female hip fracture patients}

I.F. Kramer, T. Snijders, J.S.J. Smeets, M. Leenders, J. van Kranenburg, M. den Hoed, L.B. Verdijk, M. Poeze, L.J.C. van Loon 


\section{Abstract}

\section{Background}

Sarcopenia, or the loss of muscle mass and strength, is known to increase the risk for falls and (hip) fractures in elderly people. The objective of this study was to assess the skeletal muscle fibre characteristics in elderly female hip fracture patients.

\section{Methods}

Percutaneous needle biopsies were collected from the vastus lateralis muscle in 15 healthy young women ( $20 \pm 0.4$ year), 15 healthy elderly women ( $79 \pm 1.7$ year) and 15 elderly women with a fall-related hip fracture $(82 \pm 1.5$ year). Immunohistochemical analyses were performed to assess type I and type II muscle fibre size, and myonuclear and satellite cell content.

\section{Results}

Type II muscle fibre size was significantly different between all groups $(\mathrm{p}<0.05)$, with smaller type II muscle fibres in the hip fracture patients $\left(2609 \pm 185 \mu \mathrm{m}^{2}\right)$ compared with healthy elderly $\left(3723 \pm 322 \mu \mathrm{m}^{2}\right)$ and the largest type II muscle fibres in the healthy young $\left(4755 \pm 335 \mu \mathrm{m}^{2}\right)$. Furthermore, type I muscle fibre size was significantly lower in the hip fracture patients $\left(4684 \pm 211 \mu \mathrm{m}^{2}\right)$ compared with the healthy elderly $\left(5842 \pm 316 \mu \mathrm{m}^{2}, \mathrm{p}=0.02\right)$. The number of myonuclei per type II muscle fibre was significantly lower in the healthy elderly and hip fracture group compared with the healthy young ( $\mathrm{p}=0.011$ and $\mathrm{p}=0.002$, respectively). Muscle fibre satellite cell content did not differ between groups.

\section{Conclusions}

Elderly female hip fracture patients show extensive type II muscle fibre atrophy when compared with healthy young or age-matched healthy elderly controls. Type II muscle fibre atrophy is an important hallmark of sarcopenia and may predispose to falls and (hip) fractures in the elderly population. 


\section{Introduction}

Aging is accompanied by a progressive decline in skeletal muscle mass and strength, also known as sarcopenia. The loss of muscle mass and strength puts elderly persons at a high risk for falls and fractures ${ }^{1}$. It has been estimated that approximately $30 \%$ of community-dwelling elderly aged 65 and over falls at least once a year, and half of them falls recurrently ${ }^{2,3}$. The rate of falls increases to over $40 \%$ in people 80 years and older ${ }^{4-6}$. Furthermore, the risk of falling is generally higher for elderly who have experienced an injurious fall or recurrent falls ${ }^{4,7}$. Fall-related hospital admissions in elderly patients are generally due to hip (28\%), wrist $(20 \%)$, or upper arm $(7 \%)$ fractures ${ }^{8}$. Falls and fall-related injuries can lead to the loss of independence ${ }^{8-11}$, and increase the risk of morbidity ${ }^{12}$ and mortality ${ }^{11,13,14}$. Due to their high frequency and the large impact on health and functional status, the annual estimated worldwide cost of hip fractures was US $\$ 34.8$ billion in 1990, and is expected to rise to US \$131 billion by $2050^{15}$.

The ability of skeletal muscle to generate an adequate amount of force is fundamental during normal daily activities such as climbing stairs, rising from a chair or recovering posture to prevent a fall. Hence, skeletal muscle weakness in the lower extremities has been shown to be an independent risk factor for falls and fallrelated injuries in the elderly ${ }^{16}$. The loss of skeletal muscle mass with aging can mainly be attributed to a reduced muscle fibre number and size ${ }^{17}$ with specific type II muscle fibre atrophy accounting for the majority of muscle loss ${ }^{18}$. Type II muscle fibres are essential for rapid muscle force production during muscle contraction, thus essential in regaining posture to prevent a fall. In accordance, quadriceps muscle strength correlates positively with type II muscle fibre size ${ }^{19}$. As such, type II muscle fibre atrophy represents an important contributing factor in the development of muscle weakness during aging. Therefore, we hypothesize that elderly that are predisposed to falls and fractures suffer from extensive type II muscle fibre atrophy.

Skeletal muscle fibres contain hundreds of myonuclei and it is generally believed that each myonucleus controls the gene expression over a certain amount of cytoplasm. A close association has been observed between the number of myonuclei and muscle fibre size ${ }^{19,20}$. It is generally acknowledged that the addition of new myonuclei to existing muscle fibres represents an essential step in the maintenance and repair processes of skeletal muscle tissue. Skeletal muscle stem cells, also known as satellite cells, are the sole source in the formation of new myonuclei. As such, satellite cells are required to provide the additional myonuclei to maintain skeletal muscle fibre size. In accordance, type II muscle fibre atrophy with aging is associated 
with a substantial reduction in the number of satellite cells in the type II muscle fibres ${ }^{21,22}$. Therefore, we also assessed whether severe type II muscle fibre atrophy is associated with a lower myonuclear and/or satellite cell content.

In the present study, we obtained muscle biopsies from elderly women (65 year and older) admitted to the hospital with a hip fracture due to a fall and compared skeletal muscle fibre characteristics with muscle biopsy samples obtained from healthy young (18-25 year) and age-matched healthy elderly (65 year and older) controls. This is the first study to show that skeletal muscle tissue of elderly female hip fracture patients is characterised by extensive type II muscle fibre atrophy.

\section{Methods}

\section{Participants}

In this cross-sectional, observational study we recruited one group of healthy young women (18-25 year), one group of healthy elderly women ( $\geq 65$ year), and one group of hospitalised elderly women ( $\geq 65$ year) with a fractured neck of the femur or intertrochanteric fracture of the femur (together defined as hip fractures). Only female patients were selected since this is the main risk population for suffering hip fractures. All subjects were Caucasian. Exclusion criteria included all co-morbidities and use of medication interacting with muscle metabolism and mobility of the limbs, such as COPD, peripheral arterial disease, neurological disorders, Diabetes Mellitus and metastatic disease. For the hip fracture group specifically, patients with a time to surgery of $>48 \mathrm{~h}$ after hospital admission and patients with a hip fracture due to a high-energy trauma or a pathological fracture were excluded. The study was conducted at the Maastricht University Medical Centre+, Maastricht, the Netherlands. Hip fracture patients were recruited at the emergency department or general ward of the Surgery department, and all healthy female volunteers (young and elderly) were recruited through local advertisements. Subjects were informed on the nature and possible risks of the experimental procedures before providing their written informed consent. All procedures were performed in compliance with the Declaration of Helsinki and the study was approved by the Medical Ethics Committee of the Maastricht University Medical Centre+.

\section{Muscle biopsies}

We obtained one muscle biopsy sample from the vastus lateralis muscle from each participant to compare muscle fibre size as primary outcome measure and myonuclear and satellite cell content as secondary outcome measures between study 
groups. Participants in the two healthy groups (young and old) arrived at the laboratory by car or public transport following an overnight fast. After local anaesthesia, a percutaneous needle biopsy (50-100 $\mathrm{mg}$ ) was taken from the vastus lateralis muscle $\sim 15 \mathrm{~cm}$ above the patella ${ }^{23}$. In the elderly females suffering from a hip fracture, the muscle biopsy was obtained from the vastus lateralis muscle in the operating room (OR) prior to the surgical procedure (either hemiarthroplasty or intramedullary nail stabilisation) and after induction of anaesthesia. The mean time between hospital admission and the biopsy procedure at the OR was $29 \pm 2$ hours in this group. Any visible non-muscle tissue was removed from the muscle biopsy needle, after which muscle samples were embedded in tissue-tek, frozen in liquid nitrogen cooled isopentane, (Sakura Finetek Europe BV, The Netherlands) and stored at $-80^{\circ} \mathrm{C}$ until further analyses.

\section{Immunohistochemistry}

From all muscle biopsy samples, $5 \mu \mathrm{M}$ thick cross-sections were cut at $-20{ }^{\circ} \mathrm{C}$ using a cryostat. Muscle cross-sections were stained to determine muscle fibre type distribution, i.e. type I and type II muscle fibres, myonuclear and satellite cell content. Muscle samples collected from one participant of each group were mounted together on uncoated glass slides, and air-dried for $3 \mathrm{~h}$ at room temperature before being stored at $-20{ }^{\circ} \mathrm{C}$ for subsequent analyses. First antibodies used were directed against MHC-I (A4.951, Developmental Studies Hybridoma Bank [DSHB], Iowa City, IA; dilution 1:20), laminin (polyclonal rabbit anti-laminin; Sigma, Zwijndrecht, The Netherlands; dilution 1:50), and CD56 (BD biosciences, San Jose, CA; dilution 1:40). CD56 has been extensively used to identify satellite cells ${ }^{17,19,24,25}$. Appropriate secondary antibodies were applied: goat anti-rabbit IgG AlexaFluor555 (Molecular Probes: dilution 1:50), goat anti-mouse IgG1 Alexa488, Goat anti-mouse biotine (Vector Lab: dilution: 1:133), and streptavidine Alexa 488 (Molecular Probes: dilution 1:200). Nuclei were stained with 4-,6-diamidino-2-phenylindole (DAPI; Molecular Probes; $0.238 \mu \mathrm{M})$. The immunohistochemical staining procedures for satellite cell content were adapted from previously published methods ${ }^{17,24,26}$. Fibre type staining resulted in laminin stained in red, nuclei in blue and MHC-I green. In addition, satellite cell staining resulted in laminin stained in red, nuclei in blue, and CD56 in green (figure 1).

From the biopsy slides, all images were captured using a Nikon E800 fluorescence microscope (Nikon Instruments Europe, Badhoevedorp, the Netherlands) outfitted with a Basler A113 C progressive scan colour CCD camera 

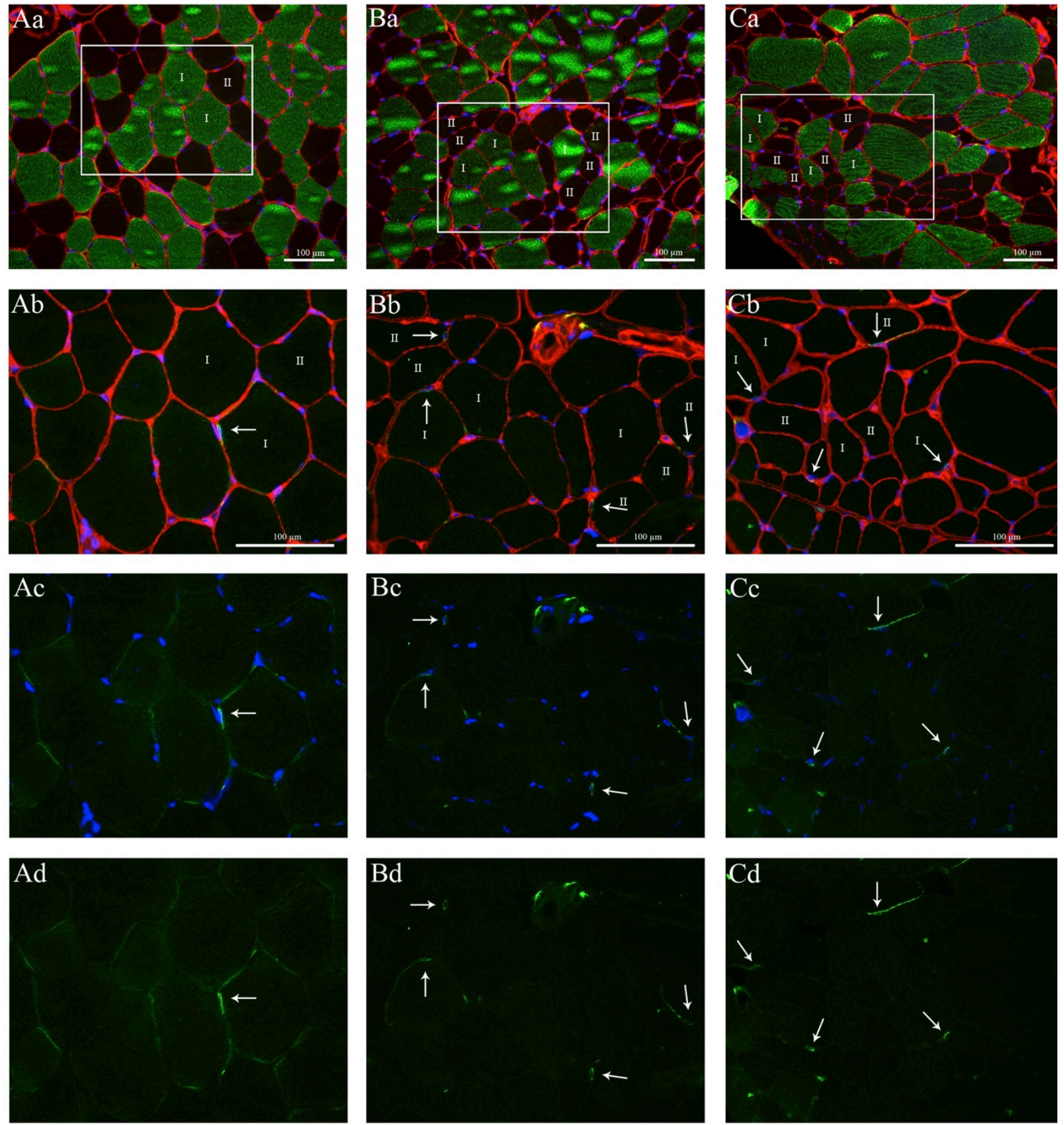

Fibre type-specific analyses of skeletal muscle satellite cell content in the young (A), elderly (B), and hip fracture group (C). (Aa-Ba-Ca) MHC-1 (green) +laminin (red) +dapi staining (blue); the marked area represents the same area as presented in frames Ab-Cd. (Ab-Bb-Cb) CD56 (green) +dapi (blue) +laminin (red). (Ac-Bc-Cc) CD56+dapi staining. (Ad-Bd-Cd) CD56 staining. Numbers indicate type I and type II muscle fibres. Arrows point at the satellite cells. 
with a Bayer colour filter. Image processing and quantitative analyses were done using the Lucia 4.81 software package, as described previously ${ }^{24-26}$. Images were captured at 120x magnification. Laminin was used to determine cell borders, and for all muscle fibres within each image, type I (green), and type II (black) fibres were identified. Within each image the number of muscle fibres and the mean fibre crosssectional area (CSA) were measured. Fibre circularity was calculated as $(4 \pi \cdot \mathrm{CSA}) /(\text { perimeter })^{2}$ to confirm fibre cross-sectional orientation. No differences were observed in fibre circularity between groups or fibre types. For muscle fibre size a mean total of $425 \pm 48$ (mean $\pm \mathrm{SE}$ ) muscle fibres were analysed for each muscle biopsy sample collected from healthy young, healthy elderly and hip fracture patients. The frequency distribution was calculated to acquire further insight into the distribution and variability of muscle fibre size. Intervals of $1000 \mu \mathrm{m}^{2}$ were defined and the percentage of muscle fibres in each interval was determined for the type I and type II muscle fibres separately.

Images were captured at a 240x magnification to allow clear satellite cell localisation from the satellite cell stained muscle cross-sections. Laminin was used to visualise cell borders. Satellite cells were determined at the periphery of each fibre and stained positive for both DNA (DAPI) and CD56.

Fibre typing was determined by matching type I and type II muscle fibres in the serial muscle fibre type slides (figure 1). The number of satellite cells per muscle fibre was calculated for type I and type II muscle fibres separately. Moreover, the number of myonuclei and central myonuclei per muscle fibre, as well as the mean myonuclear domain (i.e. fibre CSA/\#myonuclei per fibre) were assessed for the type I and type II muscle fibres within each image. According to Mackey et al. ${ }^{27}$, at least 150 fibres are needed to accurately assess muscle fibre satellite cell content. In this study, we evaluated a mean total of $397 \pm 28$ muscle fibres for muscle fibre typespecific analyses of satellite cell content per muscle sample.

\section{Statistics}

All values are expressed as means \pm standard error (SEM). Power calculation was based on a difference in type II muscle fibre size between healthy elderly adults and hip fracture patients. Relevant differences in type II muscle fibre size were estimated using data from previous studies ${ }^{17,28}$. The sample size was calculated with a power of $80 \%$ and a significance level of 0.017 (taking post-hoc Bonferroni correction in to account), yielding a minimum of 13 subjects for each group. For comparisons of descriptive outcome measures and fibre type-specific outcomes measures (i.e. fibre size, myonuclear content, and satellite cell content) between groups, a one-way 
ANOVA was performed with Bonferroni post-hoc tests to locate group differences. In addition, differences between type I and type II muscle fibre type-specific variables within groups were analysed by paired samples t-tests in the healthy young control, healthy elderly, and hip fracture patient groups separately. Pearson correlation coefficients $(r)$ were calculated between muscle fibre size and myonuclear content in both type I and type II muscle fibres separately. An alpha-level of 0.05 was used to determine statistical significance. All analyses were performed using SPSS version 21 (Chicago, IL).

\section{Results}

\section{Subjects' characteristics}

Fifteen healthy young women (age: $20.3 \pm 0.4$ year), 15 healthy elderly women (age: $78.8 \pm 1.7$ year) and 15 elderly women with a hip fracture (age: $82.3 \pm 1.5$ year) were included in the study between January 2010 and July 2014. Subjects' characteristics are displayed in table $\mathbf{1}$. No significant differences were observed in body weight and BMI between healthy young women, healthy elderly women and elderly women suffering from a hip fracture, respectively. Both elderly groups had a significantly higher age than the healthy young women $(\mathrm{p}<0.001)$, with no difference between the healthy and hip fractured elderly women $(p=0.2)$. Previous fall-related fractures were reported in 7 of the 15 hip fracture patients. In contrast, among the healthy elderly only 2 subjects and none of the healthy young had ever suffered from a fracture as the result of low-energy fall.

Table 1 | Subjects' characteristics

\begin{tabular}{lccc}
\hline \hline & $\begin{array}{c}\text { Healthy young } \\
\boldsymbol{n}=\mathbf{1 5}\end{array}$ & $\begin{array}{c}\text { Healthy elderly } \\
\boldsymbol{n}=\mathbf{1 5}\end{array}$ & $\begin{array}{c}\text { Hip fracture patients } \\
\boldsymbol{n}=\mathbf{1 5}\end{array}$ \\
\hline Age $(\mathbf{y})$ & & & $82.3 \pm 1.5^{*}$ \\
Height (m) & $20.3 \pm 0.4$ & $78.8 \pm 1.7^{*}$ & $1.60 \pm 0.02$ \\
Weight $(\mathbf{k g})$ & $1.68 \pm 0.01$ & $1.61 \pm 0.02$ & $59.9 \pm 2.6$ \\
BMI (kg/m) & $64.3 \pm 2.0$ & $63.9 \pm 2.3$ & $23.2 \pm 0.7$ \\
& $22.7 \pm 0.53$ & $24.6 \pm 0.8$ & \\
\hline \hline
\end{tabular}

Data represent means \pm SEM. BMI, body mass index. Age of the healthy elderly and hip fracture patients was comparable. * Age was significantly different compared with healthy young subjects $(\mathrm{p}<0.05)$. No other differences were observed between groups. 


\section{Muscle fibre type composition, size and frequency distribution}

No significant differences were observed in muscle fibre type composition between the healthy young ( $61 \pm 12 \%$ type I fibres), healthy elderly (62 $\pm 14 \%$ type I fibres), and hip fracture patients (66 $\pm 12 \%$ type I fibres). Type II muscle fibres were significantly smaller when compared with type I muscle fibres in all three groups $(\mathrm{p}<0.01)$ (figure 2). Type I muscle fibre size was not different between the young and healthy elderly women, but was significantly smaller in the hip fracture group compared with the healthy elderly $\left(4684 \pm 211\right.$ vs $5842 \pm 316 \mu \mathrm{m}^{2}$, respectively; $\left.\mathrm{p}=0.02\right)$. Type II muscle fibre size was significantly different between all groups (healthy young vs healthy elderly $p=0.04$; healthy young vs hip fracture patients $p<0.001$; healthy elderly vs hip fracture patients $p=0.03$ ), with the smallest type II muscle fibres observed in the hip fracture group $\left(2609 \pm 185 \mu \mathrm{m}^{2}\right)$ (figure 2).

Figure 2 | Muscle fibre size (in $\mu^{2}$ ) for both type I and type II muscle fibres in all groups.

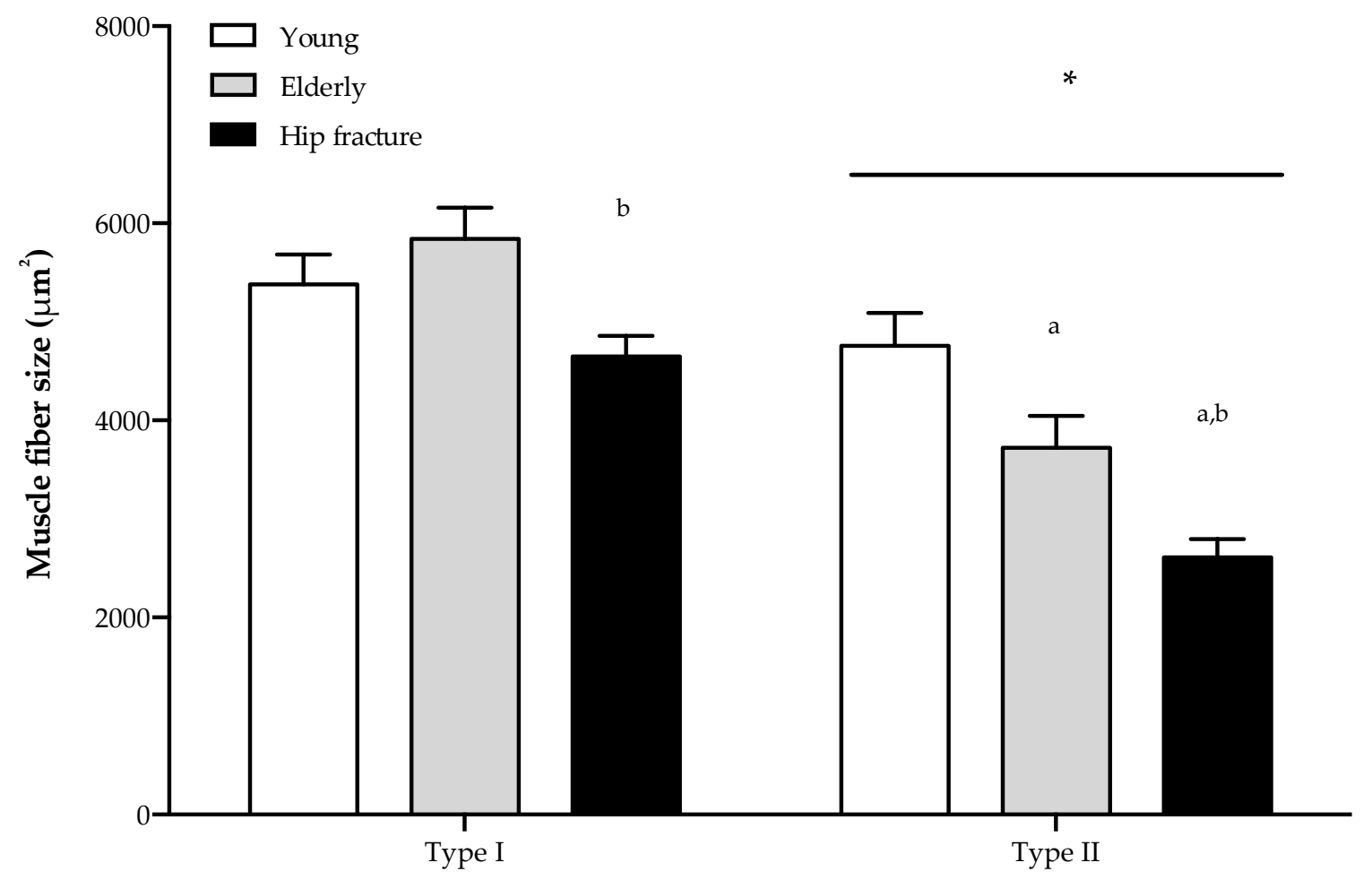

Data represent means \pm SEM. * significantly different compared with type I muscle fibre size $(P<0.05)$;

${ }^{a}$ significantly different compared with healthy young $(P<0.05) ;{ }^{b}$ significantly different compared with healthy elderly $(P<0.05)$. Bar indicates that the effect is present in all groups.

In line with the differences in muscle fibre size, substantial differences were observed in the frequency distribution of muscle fibres (figure 3). The smallest type I 
muscle fibres of $<1000 \mu \mathrm{m}^{2}$ and from $1000-2000 \mu \mathrm{m}^{2}$ were more prevalent in the hip fracture patients than in the healthy elderly and healthy young groups $(p=0.002$ and $p=0.006$, respectively; figure 3a). A particular shift in muscle fibre size distribution was observed for the type II muscle fibres, with a higher percentage of small fibres in both elderly groups compared to the young women. In the healthy young subjects, less than $5 \%$ of the muscle fibres were smaller than $2000 \mu^{2}$, compared with $\sim 25 \%$ in the healthy elderly and $>45 \%$ in hip fracture patients (figure $3 \mathbf{b}$ ).
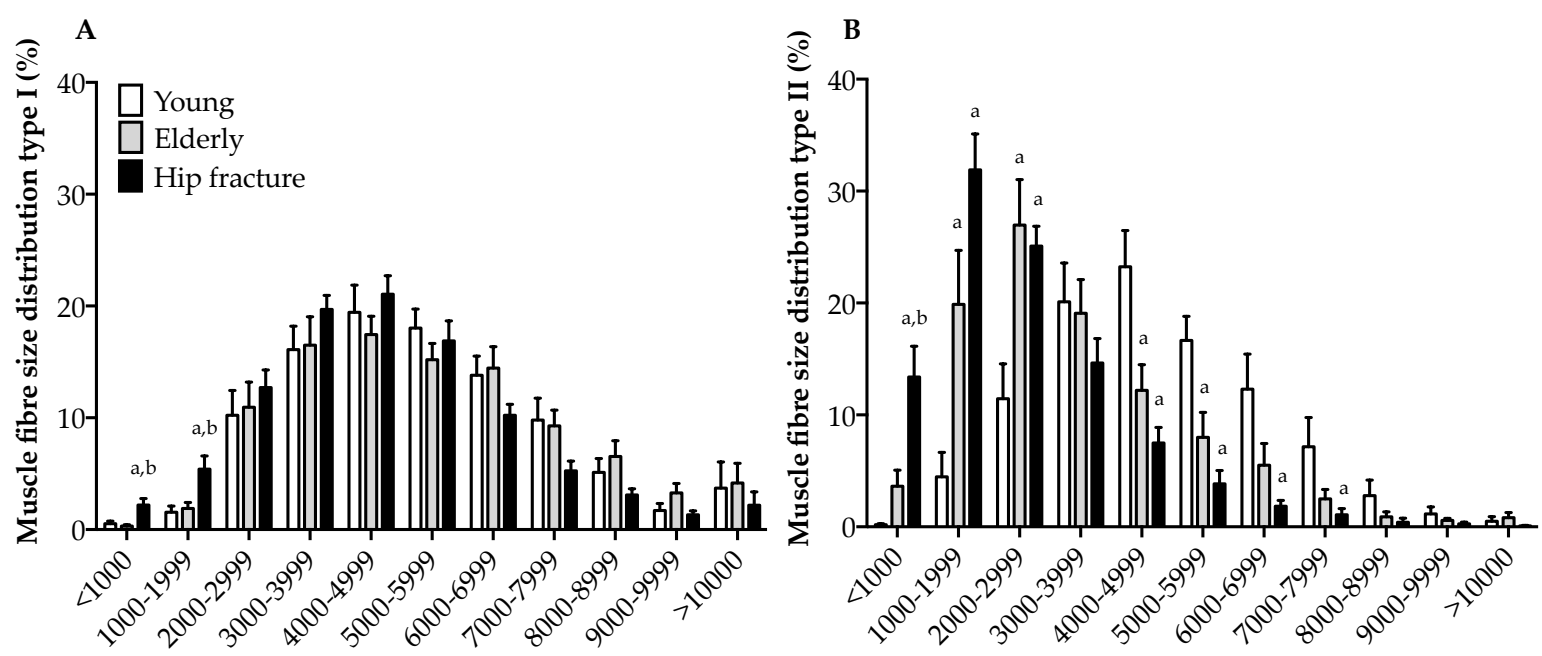

Muscle fibre size distribution (in percentage) for both type I (A) and type II (B) muscle fibres in all groups. Data represent means \pm SEM. ${ }^{a}$ significantly different compared with healthy young subjects $(\mathrm{p}<0.05) ;{ }^{\mathrm{b}}$ significantly different compared with healthy elderly subjects $(\mathrm{p}<0.05)$.

\section{Myonuclear and satellite cell content}

The number of myonuclei per muscle fibre was significantly lower in type II compared with type I muscle fibres in all groups $(\mathrm{p}<0.01$; table 2$)$. No differences were observed in type I muscle fibre myonuclear content between groups. In contrast, type II muscle fibre myonuclear content was significantly lower in both the hip fracture patients and the healthy elderly compared with healthy young controls $(2.2 \pm 0.1$ and $2.3 \pm 0.2$ vs $3.0 \pm 0.2$ myonuclei per type II muscle fibre, $p=0.002$ and $\mathrm{p}=0.01$, respectively; table 2 ). No significant difference in type II muscle fibre myonuclear content was observed between the hip fracture patients and healthy elderly. A significant correlation was observed between myonuclear content and muscle fibre size for both type I and II muscle fibres in the healthy young $(r=0.65$ and $r=0.67$, respectively; $\mathrm{p}<0.05)$ and healthy elderly subjects $(r=0.58$ and $r=0.71$, respectively; $\mathrm{p}<0.05$ ) (figure 4). In contrast, for the hip fracture patients no significant 
Table 2 | Myonuclear and satellite cell content

\begin{tabular}{lcccc}
\hline \hline & $\begin{array}{c}\text { Fibre } \\
\text { type }\end{array}$ & Healthy young & Healthy elderly & $\begin{array}{c}\text { Hip fracture } \\
\text { patients } \\
n=15\end{array}$ \\
\hline & & $n=15$ & $n=15$ & $3.2 \pm 0.2$ \\
Number of nuclei per fibre & I & $3.5 \pm 0.2$ & $3.0 \pm 0.2$ & $2.2 \pm 0.1^{* a}$ \\
Fibre area per nucleus $\left(\boldsymbol{\mu m}^{2}\right)$ & II & $3.0 \pm 0.2^{*}$ & $2.3 \pm 0.2^{* a}$ & $1581 \pm 116^{\mathrm{b}}$ \\
& I & $1562 \pm 74$ & $2051 \pm 104^{\text {a }}$ & $1261 \pm 130^{* b}$ \\
Number of central nuclei per fibre & II & $1575 \pm 88$ & $1679 \pm 94^{*}$ & $0.044 \pm 0.014^{\text {a }}$ \\
& I & $0.010 \pm 0.003$ & $0.022 \pm 0.004$ & $0.038 \pm 0.009$ \\
Central myonuclei \% & II & $0.027 \pm 0.004^{*}$ & $0.020 \pm 0.003$ & $1.2 \pm 0.3$ a \\
Number of satellite cells per fibre & I & $0.3 \pm 0.1$ & $0.8 \pm 0.1$ & $1.8 \pm 0.4$ \\
Number of satellite cells per mm $^{2}$ & II & $0.9 \pm 0.1^{*}$ & $0.9 \pm 0.2$ & $0.066 \pm 0.009$ \\
& I & $0.062 \pm 0.006$ & $0.078 \pm 0.005$ & $0.030 \pm 0.004^{*}$ \\
& II & $0.039 \pm 0.006^{*}$ & $0.044 \pm 0.006^{*}$ & $14.2 \pm 1.8$ \\
& I & $11.8 \pm 1.1$ & $14.1 \pm 1.3$ & $11.1 \pm 1.3$
\end{tabular}

Data represent means \pm SEM. I, type I muscle fibres; II, type II muscle fibres; Fibre area per nucleus, myonuclear domain size in square millimetre; Central myonuclei \%, number of myonuclei as a percentage of the total number of myonuclei (i.e., number of myonuclei + number of central myonuclei). ${ }^{*}$ Significantly different compared with type I muscle fibres $(\mathrm{p}<0.05)$. a significantly different compared with healthy young subjects $(p<0.05) .{ }^{b}$ significantly different compared with healthy elderly subjects $(p<0.05)$

correlation was observed between the number of myonuclei and muscle fibre size ( $r=0.37 ; \mathrm{p}=0.18$ and $r=0.08 ; \mathrm{p}=0.79$, respectively) (figure 4).

A smaller type I muscle fibre area per nucleus was observed in the healthy young and the hip fracture patients compared with the healthy elderly group ( $p=0.003$ and $p=0.005$, respectively; table 2 ). In the type II muscle fibres, the myonuclear domain was significantly different between the hip fracture patients and the healthy elderly $(p=0.02)$. In addition, type I myonuclear domain size was significantly smaller than type II myonuclear domain size in the healthy elderly and hip fracture group (table 2). The percentage of central myonuclei per myonuclei was significantly greater in the hip fracture group compared to the healthy young controls in the type I muscle fibres ( $p=0.01$; table 2 ). In the type II muscle fibres, the percentage of central myonuclei of the hip fracture patients tended to be greater compared to healthy elderly and healthy young ( $\mathrm{p}=0.076$ and $\mathrm{p}=0.076$, respectively). In all groups, the number of satellite cells per muscle fibre was significantly lower in type II compared to type I muscle fibres $(p<0.05$; table 2$)$. No differences in the number of satellite cells per muscle fibre were observed between the groups for both the type I and type II muscle fibres. Furthermore, the number of SCs per squared millimetre of muscle fibre was not different between groups for both the type I and type II fibres (table 2). 

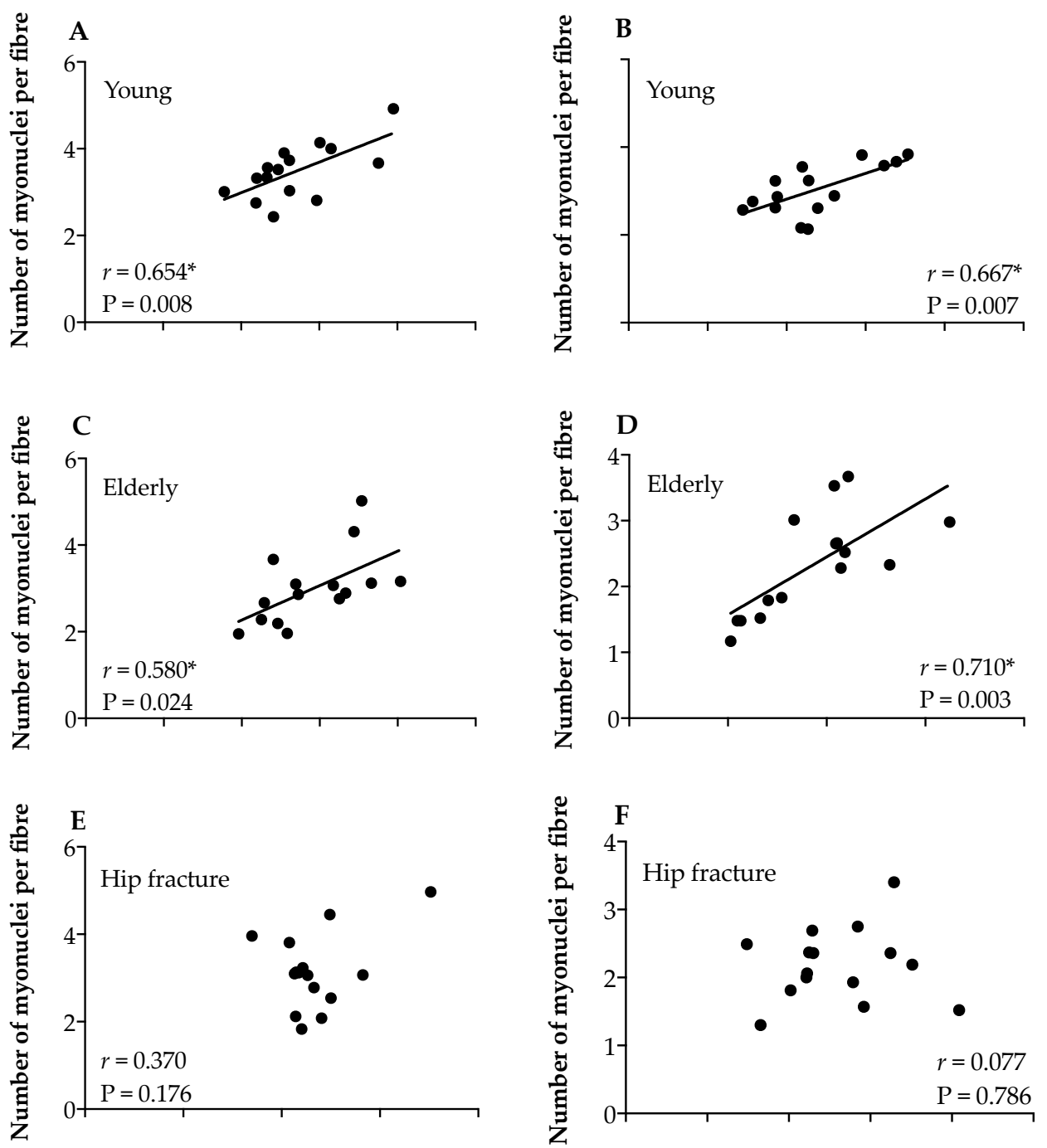

Scatter plot for the relation between the number of myonuclei per muscle fibre and muscle fibre size for the healthy young $(\mathbf{A}+\mathbf{B})$, healthy elderly $(\mathbf{C}+\mathbf{D})$, and hip fracture group $(\mathbf{E}+\mathbf{F})$ for both type I and type II muscle fibres separately. $r$ : Pearson correlation coefficient. * Significant correlation $(\mathrm{p}<0.05)$. 


\section{Discussion}

The present study shows that elderly women who experience a low energy fall resulting in a hip fracture suffer from type I and type II muscle fibre atrophy, with an extensive decline in type II muscle fibre size. Type II muscle fibre atrophy in these patients is accompanied by a reduction in type II muscle fibre myonuclear content.

With global aging, falls and fall-related injuries among the elderly have become a major public health burden ${ }^{29,30}$. Falls are the leading cause of injuries in elderly adults and affect functional capacity, habitual physical activity, and cognition, eventually resulting in reduced quality of life and even death ${ }^{8,31,32}$. Falls in later life can be attributed to a range of factors, including general health status, medication use, and environmental factors 2,3,31,33. However, the most important risk factor for falls in elderly individuals is low muscle strength, particularly of the lower extremities ${ }^{1}$. A decline in muscle strength and physical performance impairs postural reflexes and increases the risk of falls and the likelihood of fractures. Since low skeletal muscle strength is generally associated with the loss of type II muscle fibre size ${ }^{19}$, we hypothesised that elderly women that are hospitalised for hip surgery following a fall suffer from extensive type II muscle fibre atrophy. Indeed, we report that type II muscle fibres were $\sim 30 \%$ smaller in the women with a hip fracture when compared with healthy age-matched controls (figure 2), and observed a substantial shift in the frequency distribution of especially type II muscle fibres with aging, with the highest percentage of very small type II muscle fibres in the female hip fracture group (figure $3 \mathbf{b}$ ). Furthermore, we observed that the hip fracture patients even show the first signs of type I muscle fibre atrophy (figure 3a). We have previously shown that in a healthy elderly population, the age-related reduction in muscle mass is mainly attributed to specific atrophy of the type II muscle fibres ${ }^{18}$. Based on the current findings, we speculate that in addition to the extensive type II muscle fibre atrophy, a reduction in type I muscle fibre size further attributes to the accelerated muscle loss as observed in clinically compromised and/or frail elderly individuals such as those suffering from a hip fracture. It remains to be determined which factors (such as disuse, sedentary lifestyle, and malnutrition ${ }^{34}$ ) may play a primary role in the extensive atrophy as observed in the hip fracture patients. Importantly though, the observed smaller type I and type II muscle fibre size and greater percentage of (very) small fibres in muscle samples from the hip fracture patients could be associated with the reduced ability of these women to generate the force required to counteract unexpected perturbations in postural balance, explaining falls and hip fractures. 
It has been suggested that changes in skeletal muscle fibre size are achieved by the regulation of three important factors: 1) the number of nuclei in a single muscle fibre; 2) the rate of muscle protein synthesis per myonucleus; and 3) the rate of muscle protein breakdown ${ }^{35}$. In line with this, the myonuclear domain theory suggests that every myonucleus determines transcriptional processes in a certain amount of cytoplasm ${ }^{36}$. Accordingly, changes in muscle fibre size (e.g. hypertrophy or atrophy) are accompanied by changes in myonuclear content, myonuclear domain size or both. However, a discrepancy exists in the reported changes in myonuclear content and/or domain size during aging in humans. Whereas some studies report that the age-related muscle fibre atrophy is accompanied by an increase in myonuclear content in human skeletal muscle ${ }^{37}$, other human studies report no change ${ }^{38,39}$. We recently reported that part of this discrepancy may be caused by the different age cohorts included in these studies, as a smaller myonuclear content was only observed in very old subjects (70-86 y) when compared with old (50-69 y) and young (18-49 y) subjects ${ }^{28}$. Furthermore, a recent study from Karlsen et al. suggests that part of this discrepancy might also be due to determining a mean myonuclear content and domain size for each biopsy sample ${ }^{40}$. By using a fibre-size dependent cluster analysis, they showed that smaller fibres have less myonuclei and a smaller myonuclear domain size, independent of the age of the subjects ${ }^{40}$. In the present study, we report a significantly lower number of myonuclei in the type II muscle fibres in healthy elderly women and hip fracture patients compared with healthy young controls. In addition, the healthy young and elderly women show a significant correlation between myonuclear content and muscle fibre size in the type I and type II muscle fibres (figure 4), in agreement with the recent suggestions of Karlsen et al ${ }^{40}$. These observations suggest that during healthy aging the loss of myonuclear content is proportional to the age-related decline in muscle fibre size. In contrast to the healthy young and healthy elderly women, no significant correlations were observed between type I and type II muscle fibre myonuclear content and muscle fibre size in the hip fracture patients (figure 4). The absence of any relation between myonuclear content and muscle fibre size in these patients might indicate that either the loss in myonuclear content or muscle fibre size is occurring at an accelerated pace when compared with healthy controls. In accordance with the latter suggestion, myonuclear domain size was lowest in the type II muscle fibres in the hip fracture patients, implying a disproportionate decline in fibre size versus myonuclear content (table 2). It remains to be determined whether there is a causal relationship between fibre atrophy and the reduction in myonuclear content. Alternatively, there may be a preferential loss of large type II muscle fibres, 
explaining the greater percentage of small muscle fibres in the elderly groups, resulting in both smaller muscle fibre size and lower myonuclear content.

In line with previous observations ${ }^{41}$, we also observed a number of myonuclei located in a central position of the muscle fibre. The presence of central myonuclei may be indicative of repetitive muscle fibre damage and subsequent repair over an extensive period of time ${ }^{42}$. Interestingly, in the hip fracture patients the percentage of centrally located myonuclei was significantly higher in type I muscle fibres and tended to be higher in type II muscle fibres when compared with the healthy young controls.

During the last decade, the role of skeletal muscle satellite cells in muscle fibre maintenance has gained much interest. Satellite cells are the sole source for providing new myonuclei to human skeletal muscle ${ }^{43}$. These stem cells play an important role in muscle growth, repair and regeneration, and, as such, have been implicated as a key regulator of muscle mass maintenance ${ }^{19,44}$. It has been previously shown that type II muscle fibre atrophy in healthy elderly men is associated with a lower number of type II muscle fibre satellite cells ${ }^{21,22}$. In contrast to this and to our hypothesis however, the present study shows that type II muscle fibre satellite cell content is not reduced in healthy elderly women and elderly hip fracture patients when compared with the young controls (table 2), despite a substantially smaller type II muscle fibre size in both elderly groups. Previous reports on mixed muscle fibre satellite cell content in healthy young women show mixed results. Whereas Kadi et al. ${ }^{37}$ reported an average of 0.17 satellite cells per muscle fibre, a more recent study found approximately 0.07 satellite cells per muscle fibre in healthy young women ${ }^{45}$. When expressed the same way (i.e. mixed muscle fibre satellite cell content), we observed $0.053 \pm 0.005$ satellite cells per muscle fibre in the young females. As such, satellite cell content in our group of healthy young women appears to be particularly low. The fact that the decline in muscle fibre size was not accompanied by a reduction in satellite cell content appears to be (at least partly) explained by the low number of satellite cells as observed in the young women in the present study.

In this study, we have focused on differences in type I and type II skeletal muscle fibre characteristics of female hip fracture patients and healthy young and agematched controls, since the majority of hip fracture patients is known to be female ${ }^{46}$. Though our findings provide a relevant first insight in differences of muscle quality at the muscle fibre level between females that suffer from a hip fracture and healthy females that do not, future work should establish whether similar differences are evident for males. Furthermore, apart from skeletal muscle fibre atrophy, sarcopenia 
is also defined by a loss in muscle mass and/or function. Unfortunately, we were not able to assess any measures of muscle mass and/or strength in our hip fracture patients. We have previously shown that smaller muscle fibre size is associated with smaller quadriceps muscle mass and strength ${ }^{18}$. Nevertheless, whether muscle fibre atrophy in elderly hip fracture patients leads to reduced physical function, thereby increasing the risk of falls and fractures in these elderly, still remains to be elucidated. Furthermore, it would be interesting to examine whether the extent of muscle atrophy, both on the muscle fibre and the whole-muscle level, could be predictive for post-surgery recovery in these hip fracture patients. Such information could prove relevant to better target intervention strategies aimed at preventing fallrelated hip fractures, as well as speeding up recovery in case a hip fracture has taken place, thereby reducing the burden of illness resulting from hip fractures 9,11 .

\section{Conclusions}

In conclusion, frail elderly at risk for a fall-related hip fracture show type I muscle fibre atrophy and extensive type II muscle fibre atrophy and a decline in myonuclear content. The present findings indicate that extensive type II muscle fibre atrophy may predispose to reduced muscle strength and functional capacity and to an increased risk of falls and fractures. 


\section{References}

1. Landi F, Liperoti R, Russo A, et al. Sarcopenia as a risk factor for falls in elderly individuals: results from the ilSIRENTE study. Clinical nutrition. Oct 2012;31(5):652-658.

2. Graafmans WC, Ooms ME, Hofstee HM, Bezemer PD, Bouter LM, Lips P. Falls in the elderly: a prospective study of risk factors and risk profiles. American journal of epidemiology. Jun 1 1996;143(11):1129-1136.

3. Tinetti ME, Speechley M, Ginter SF. Risk factors for falls among elderly persons living in the community. $N$ Engl J Med. Dec 29 1988;319(26):17011707.

4. Pohl P, Nordin E, Lundquist A, Bergström U, Lundin-Olsson L. Community-dwelling older people with an injurious fall are likely to sustain new injurious falls within 5 years--a prospective long-term followup study. BMC geriatrics. 2014;14:120.

5. Ambrose AF, Paul G, Hausdorff JM. Risk factors for falls among older adults: a review of the literature. Maturitas. 2013;75(1):51-61.

6. Stalenhoef PA, Crebolder HFJM, Knottnerus JA, Horst FGEMVD. Incidence, risk factors and consequences of falls among elderly subjects living in the community A criteria-based analysis. The European Journal of Public Health. 1997.

7. Deandrea S, Lucenteforte E, Bravi F, Foschi R, La Vecchia C, Negri E. Risk factors for falls in communitydwelling older people: a systematic review and meta-analysis. Epidemiology (Cambridge, Mass.). 2010;21(5):658-668.

8. Hartholt KA, van Beeck EF, Polinder $S$, et al. Societal consequences of falls in the older population: injuries, healthcare costs, and long-term reduced quality of life. I Trauma. Sep;71(3):748-753.
9. Boonen S, Singer AJ. Osteoporosis management: impact of fracture type on cost and quality of life in patients at risk for fracture I. Curr Med Res Opin. Jun 2008;24(6):1781-1788.

10. Tinetti ME, Williams CS. Falls, injuries due to falls, and the risk of admission to a nursing home. The New England journal of medicine. 1997;337(18):12791284.

11. Tajeu GS, Delzell E, Smith W, et al. Death, debility, and destitution following hip fracture. The journals of gerontology. Series A, Biological sciences and medical sciences. 2014;69(3):346-353.

12. Farahmand BY, Michaelsson $\mathrm{K}$, Ahlbom A, Ljunghall S, Baron JA. Survival after hip fracture. Osteoporos Int. Dec 2005;16(12):1583-1590.

13. van Staa TP, Dennison EM, Leufkens HG, Cooper C. Epidemiology of fractures in England and Wales. Bone. Dec 2001;29(6):517-522.

14. Smeets SJ, Poeze M, Verbruggen JP. Preoperative cardiac evaluation of geriatric patients with hip fracture. Injury. Dec 2012;43(12):2146-2151.

15. Johnell O. The socioeconomic burden of fractures: today and in the 21st century. Am J Med. Aug 18 1997;103(2A):20S-25S; discussion 25S$26 \mathrm{~S}$.

16. Moreland JD, Richardson JA, Goldsmith $\mathrm{CH}$, Clase CM. Muscle weakness and falls in older adults: a systematic review and meta-analysis. $J$ Am Geriatr Soc. Jul 2004;52(7):11211129.

17. Verdijk LB, Koopman R, Schaart G, Meijer K, Savelberg HH, van Loon LJ. Satellite cell content is specifically reduced in type II skeletal muscle fibers in the elderly. American journal of physiology. Endocrinology and metabolism. Jan 2007;292(1):E151-157.

18. Nilwik R, Snijders T, Leenders $M$, et al. The decline in skeletal muscle mass with aging is mainly attributed to a 
reduction in type II muscle fiber size. Experimental gerontology. 2013;48(5):492-498.

19. Verdijk LB, Snijders T, Beelen M, et al. Characteristics of muscle fiber type are predictive of skeletal muscle mass and strength in elderly men. Journal of the American Geriatrics Society. Nov 2010;58(11):2069-2075.

20. Kadi F, Eriksson A, Holmner S, ButlerBrowne GS, Thornell LE. Cellular adaptation of the trapezius muscle in strength-trained athletes. Histochemistry and cell biology. 1999;111(3):189-195.

21. Verney J, Kadi F, Charifi N, et al. Effects of combined lower body endurance and upper body resistance training on the satellite cell pool in elderly subjects. Muscle Nerve. Sep 2008;38(3):1147-1154.

22. McKay BR, Ogborn DI, Bellamy LM, Tarnopolsky MA, Parise G. Myostatin is associated with age-related human muscle stem cell dysfunction. FASEB J. Jun 2012;26(6):2509-2521.

23. Bergstrom J. Percutaneous needle biopsy of skeletal muscle in physiological and clinical research. Scand J Clin Lab Invest. Nov 1975;35(7):609-616.

24. Snijders T, Verdijk LB, Beelen M, et al. A single bout of exercise activates skeletal muscle satellite cells during subsequent overnight recovery. Exp Physiol. Feb 10 2012;97(6):762-773.

25. Snijders T, Verdijk LB, Hansen D, Dendale P, van Loon LJ. Continuous endurance-type exercise training does not modulate satellite cell content in obese type 2 diabetes patients. Muscle Nerve. Mar 2011;43(3):393-401.

26. Verdijk LB, Gleeson BG, Jonkers RA, et al. Skeletal muscle hypertrophy following resistance training is accompanied by a fiber type-specific increase in satellite cell content in elderly men. J Gerontol A Biol Sci Med Sci. Mar 2009;64(3):332-339.

27. Mackey AL, Kjaer M, Charifi N, et al. Assessment of satellite cell number and activity status in human skeletal muscle biopsies. Muscle Nerve. Sep 2009;40(3):455-465.

28. Verdijk LB, Snijders $T$, Drost $M$, Delhaas T, Kadi F, van Loon LJ. Satellite cells in human skeletal muscle; from birth to old age. Age (Dordrecht, Netherlands). 2014;36(2):545-547.

29. Hartholt KA, Stevens JA, Polinder S, van der Cammen TJ, Patka P. Increase in fall-related hospitalizations in the United States, 2001-2008. J Trauma. Jul;71(1):255-258.

30. Hartholt KA, van der Velde $N$, Looman CW, et al. Trends in fallrelated hospital admissions in older persons in the Netherlands. Arch Intern Med. May 24 2010;170(10):905911.

31. Hartholt KA, Polinder S, van Beeck $\mathrm{EF}$, et al. End of the spectacular decrease in fall-related mortality rate: men are catching up. Am J Public Health. May;102 Suppl 2:S207-211.

32. Nachreiner NM, Findorff MJ, Wyman JF, McCarthy TC. Circumstances and consequences of falls in communitydwelling older women. J Womens Health (Larchmt). Dec 2007;16(10):14371446.

33. Prudham D, Evans JG. Factors associated with falls in the elderly: a community study. Age Ageing. Aug 1981;10(3):141-146.

34. Cruz-Jentoft AJ, Baeyens JP, Bauer JM, et al. Sarcopenia: European consensus on definition and diagnosis: Report of the European Working Group on Sarcopenia in Older People. Age and ageing. Jul 2010;39(4):412-423.

35. Gundersen K. Excitation-transcription coupling in skeletal muscle: the molecular pathways of exercise. Biol Rev Camb Philos Soc. Aug 2011;86(3):564-600.

36. Cheek DB. The control of cell mass and replication. The DNA unit--a personal 20-year study. Early human development. Dec 1985;12(3):211-239. 
37. Kadi F, Charifi N, Denis C, Lexell J. Satellite cells and myonuclei in young and elderly women and men. Muscle Nerve. Jan 2004;29(1):120-127.

38. Manta P, Vassilopoulos D, Spengos M. Nucleo-cytoplasmic ratio in ageing skeletal muscle. Eur Arch Psychiatry Neurol Sci. 1987;236(4):235-236.

39. Renault V, Thornell LE, Eriksson PO, Butler-Browne G, Mouly V. Regenerative potential of human skeletal muscle during aging. Aging Cell. Dec 2002;1(2):132-139.

40. Karlsen A, Couppé C, Andersen JL, et al. Matters of fiber size and myonuclear domain; does size matter more than age? Muscle E nerve. 2015.

41. Kadi F, Thornell LE. Concomitant increases in myonuclear and satellite cell content in female trapezius muscle following strength training. Histochem Cell Biol. Feb 2000;113(2):99-103.

42. Mackey AL, Andersen LL, Frandsen U, Suetta C, Sjogaard G. Distribution of myogenic progenitor cells and myonuclei is altered in women with vs. those without chronically painful trapezius muscle. J Appl Physiol. Dec 2010;109(6):1920-1929.

43. Moss FP, Leblond CP. Satellite cells as the source of nuclei in muscles of growing rats. Anat Rec. Aug 1971;170(4):421-435.

44. Snijders T, Verdijk LB, van Loon LJ. The impact of sarcopenia and exercise training on skeletal muscle satellite cells. Ageing research reviews. Oct 2009;8(4):328-338.

45. Walker DK, Fry CS, Drummond MJ, et al. PAX7+ satellite cells in young and older adults following resistance exercise. Muscle $\mathcal{E}$ nerve. Jul 2012;46(1):51-59.

46. Klop C, Welsing PM, Leufkens HG, et al. The Epidemiology of Hip and Major Osteoporotic Fractures in a Dutch Population of CommunityDwelling Elderly: Implications for the Dutch FRAX(R) Algorithm. PloS one. 2015;10(12):e0143800. 



\section{CHAPTER 4}

\section{Skeletal muscle loss in elderly hip fracture patients during hospital admission}

I.F. Kramer, S. Broen, R. Nilwik, J. van Kranenburg, M. Hadfoune, A.A. van Bijnen, S.J.R. Meex, B.B. Groen, I.W.K. Kouw, B. Winkens, L.B. Verdijk, L.J.C. van Loon, M. Poeze. 


\section{Abstract}

\section{Background}

Loss of skeletal muscle mass and strength puts elderly at risk for fall-related hip fractures. Periods of physical inactivity and stress-inducing events can exacerbate the muscle loss. We hypothesised that a hip fracture is accompanied by a substantial loss of leg muscle mass in elderly hospitalised patients.

\section{Methods}

Sixteen elderly patients (age $82.1 \pm 1.8$ year) suffering from a fall-related hip fracture participated in this observational study. Computed tomographic (CT) scans were obtained perioperatively and on the day of hospital discharge to assess muscle crosssectional area (CSA) of both legs. Skeletal muscle biopsies were taken prior to surgery and on the day of discharge to assess muscle fibre CSA.

\section{Results}

After a mean hospital stay $( \pm$ SEM) of $7.0 \pm 0.4$ days, a significant decline in whole thigh $(-5.4 \%)$ and quadriceps muscle CSA $(-4.5 \%)$ was observed in the non-fractured leg $(p<0.01)$. No significant changes were seen in the fractured leg. During hospitalisation, muscle fibre CSA in the fractured leg did not significantly change over time in both type I and type II muscle fibres ( $\mathrm{p}=0.70$ and $\mathrm{p}=0.48$, respectively). However, our hip fracture patients showed significant type II muscle fibre atrophy compared to type I fibres at both time points ( $\mathrm{p}<0.001$ and $\mathrm{p}=0.010$, respectively). A significant increase in plasma IL-6 and serum CRP was seen after surgery.

\section{Conclusions}

Elderly patients recovering from (surgery after) a hip fracture lose a substantial amount of skeletal muscle mass during hospital admission. The development of effective interventional strategies to combat the loss of skeletal muscle mass in elderly hip fracture patients is warranted. 


\section{Introduction}

As a consequence of worldwide demographic changes, the total number of hip fracture patients is expected only to rise in the upcoming decades ${ }^{1}$. The occurrence of a hip fracture places a significant burden on the individuals' health but also substantially on healthcare systems and expenses ${ }^{2}$. The cost of care for hip fracture patients are about three times greater than age and residency-matched controls without a fracture, but might be reduced by improving functional outcomes, shortening of hospital length-of-stay, and accelerating rehabilitation ${ }^{2}$. Although current levels of care have significantly improved since the introduction of the early recovery after surgery guidelines and multidisciplinary involvement, outcomes in this patient group are still devastating. Hip fracture patients have an increased risk of dying, which persists for several years post-fracture ${ }^{3,4}$. Up to $30 \%$ of the hip fracture patients does not survive the first year following the injury ${ }^{5-8}$. Importantly, more than half of the patients does not regain their pre-fracture mobility in the first year ${ }^{9}$, due to a decline in mobility and functional status $2,6,10$, and become unable of living independently.

Hip fractures in the elderly are mainly the consequence of a simple fall ${ }^{11}$. The incidence of falling rises with increasing age, and falls lead to hospital admission in approximately one third of the cases ${ }^{12-14}$. Skeletal muscle weakness and an impaired response to postural imbalance are independent risk factors for falls and fall-related injuries in the elderly ${ }^{15}$. The loss of skeletal muscle mass and strength with ageing has been termed sarcopenia ${ }^{16}$. On a cellular level, sarcopenia is characterised by a reduction in skeletal muscle fibre number and size, with specific type II muscle fibre atrophy and a reduction in skeletal muscle stem cells ${ }^{17}$. Loss of skeletal muscle mass and strength puts elderly at risk for fall-related injury, but also seems to be an independent predictor for worse outcomes following a hip fracture. It is associated with longer length of hospital stay in elderly ${ }^{18}$, and multiplies in-hospital mortality rates of hospitalised elderly even after adjustment for comorbidities ${ }^{19}$. Although sarcopenia is often depicted as a gradual loss of skeletal muscle mass and strength with ageing, periods of physical inactivity and stress-inducing events can exacerbate the muscle loss ${ }^{20}$. Bed rest induces the loss of substantial amounts of muscle tissue in the absence of a robust countermeasure ${ }^{21}$. In addition, the inflammatory response to the injury and operative treatment ${ }^{22}$ can further augment muscle mass and function loss in elderly hip fracture patients. However, the extent of muscle loss in hip fracture patients during hospitalisation has never been studied before. 
In the present study, we assessed the course of skeletal muscle atrophy in hospitalised elderly hip fracture patients. We quantified muscle mass at the time of surgery and at hospital discharge using CT-scans and evaluated muscle fibre atrophy by applying histology on repeated muscle biopsies obtained. This is the first study to evaluate the degree of muscle loss and muscle fibre atrophy in elderly hip fracture patients during hospital admission.

\section{Methods}

\section{Subjects}

A total of 16 patients were recruited in this prospective observational study. Four male and 12 female patients of 65 years of age or older with a low-energy fall-related hip fracture (neck of femur or pertrochanteric fracture) participated. Exclusion criteria included co-morbidities and pre-existing neuromuscular disorders of the lower limbs severely interacting with mobility. Patients with a time to surgery of more than 48 hours after hospital admission, and hip fractures due to a high-energy trauma or a pathological hip fracture were excluded. Subjects were informed about the nature and risks of the experimental procedures before obtaining their written consent.

\section{Study protocol}

The study was approved by the Medical Ethical Committee of the Maastricht University Medical Centre, The Netherlands, and complied with the guidelines set out in the sixth Declaration of Helsinki. This study was conducted at the Maastricht University Medical Centre+, Maastricht, The Netherlands.

Hip fracture patients were recruited at the emergency department or general ward prior to surgery. After inclusion, baseline demographic details were registered. Body composition was assessed using dual-energy X-ray absorptiometry (DEXA, Discovery A; Hologic, Bedford, USA). Whole-body and regional lean mass, fat mass, and bone mineral content were determined. A baseline blood sample was drawn before the operation was commenced. During the surgical intervention (either hemiarthroplasty or intramedullary nail stabilisation), directly after induction of anaesthesia the first percutaneous needle muscle biopsy was obtained from the $m$. vastus lateralis of the fractured leg $\sim 15 \mathrm{~cm}$ above the patella ${ }^{23}$. Within 12 hours after surgery, a baseline CT-scan of both legs was made in order to assess anatomic crosssectional area of the whole thigh muscle and quadriceps muscle (Brilliance 64, Philips Medical Systems, Best, the Netherlands). The scanning characteristics were as 
follows: $120 \mathrm{kV}, 300 \mathrm{~mA}$, rotation time of $0.75 \mathrm{~s}$, and a field of view of $500 \mathrm{~mm}$. While the subjects were supine with their legs extended and their feet secured, a 3-mm thick axial image was taken $15 \mathrm{~cm}$ proximal to the base of the patella. The exact scanning position was measured and marked to ensure the right position for the subsequent CT-scan. Repeated blood samples were drawn at day 1, 3, and 5 postoperatively (POD1, POD3, POD5). At discharge or at maximum day 10 after surgery, the second muscle biopsy of the fractured leg was collected under local anaesthesia was obtained and a second CT-scan was performed.

\section{CT scans}

The obtained pre- and postoperative CT scans were analysed and compared using ImageJ software (version 1.46d, National Institute of Health, Maryland, USA). Muscle tissue was defined by threshold values of -29 to +150 Hounsfield Units (HU) 24. Whole thigh and quadriceps muscle, and femoral bone were manually selected and the software provided the cross sectional areas and grey scale measures. Two investigators performed the analyses and outcomes were mediated. In case of large variation, a third investigator was available for an additional analysis. Furthermore, the cross-sectional area of the femoral bone was used as a comparison to verify the position of the pre and post CT-scans.

\section{Muscle biopsies}

We obtained a pre- and postoperative percutaneous needle muscle biopsy (50 - 100 $\mathrm{mg}$ ) from the vastus lateralis muscle of the fractured leg from each patient to compare muscle fibre size, myonuclear and satellite cell content as secondary outcome measures over time. Any visible non-muscle tissue was removed from the muscle biopsy needle, after which muscle samples were embedded in tissue-tek, frozen in liquid nitrogen cooled isopentane, (Sakura Finetek Europe BV, The Netherlands) and stored at $-80^{\circ} \mathrm{C}$ until further analyses.

\section{Immunohistochemistry}

From all muscle biopsy samples, $5 \mu \mathrm{m}$ thick cross-sections were cut using a cryostat and mounted on uncoated pre-cleaned glass slides. Samples from pre- and postsurgery were mounted together on the same glass slide. Care was taken to properly align the samples for cross-sectional fibre analyses. Muscle cross-sections were stained to determine muscle fibre type distribution, i.e. type I and type II muscle fibres, myonuclear and satellite cell content. The analytical procedure has been described in detail previously ${ }^{25}$. 
First antibodies used were directed against MHC-I, laminin, and CD56. CD56 has been extensively used to identify satellite cells ${ }^{17,26}$. Appropriate secondary antibodies were applied: goat anti-rabbit IgG AlexaFluor647, goat anti-mouse IgM AlexaFluor555, and Streptavidin Alexa 488 (dilution 1:400, 1:500, and 1:200, respectively; Molecular Probes, Invitrogen, Breda, the Netherlands). Nuclei were stained with 4,6-diamidino-2-phenylindole (DAPI, $0.238 \mu \mathrm{M}$; Molecular Probes). Images were visualised and automatically captured at $10 \mathrm{x}$ magnification with a fluorescent microscope equipped with an automatic stage (IX81 motorised inverted microscope, Olympus, Hamburg, Germany). Quantitative analyses were done using Image J software package (version 1.46d, National Institute of Health, MD). An investigator blinded to subject coding performed all image recordings and analyses. For muscle fibre size a mean $( \pm$ SEM) total of $425 \pm 54$ muscle fibres were analysed for each muscle biopsy sample. The frequency distribution was calculated to acquire further insight into the distribution and variability of muscle fibre size. Intervals of $1000 \mu \mathrm{m}^{2}$ were defined and the percentage of muscle fibres in each interval was determined for the type I and type II muscle fibres separately. The number of satellite cells per muscle fibre was calculated for type I and type II muscle fibres separately. Moreover, the number of myonuclei and central myonuclei per muscle fibre, as well as the mean myonuclear domain (i.e. fibre CSA/\#myonuclei per fibre) were assessed for the type I and type II muscle fibres within each image.

\section{Blood sampling}

Venous blood samples were drawn at baseline, day 1, day 3, and day 5 postoperatively. Blood samples were cooled and centrifuged at 3,500 rotations per minute for 15 minutes and plasma and serum samples were stored at $-80^{\circ} \mathrm{C}$ until batch analyses.

\section{Plasma analyses}

The plasma levels of Interleukin-1beta (IL-1 $\beta$ ) and Interleukin-6 (IL-6), and the serum levels of C-reactive protein (CRP) were assayed as markers of the systemic inflammatory response to trauma and surgery. CRP levels were determined by immunoturbidimetric assays on a Cobas 8000 analyser (lower detection limit 2.9nmol/L, CRPL3, Roche, Ref: 0004956842190c501). IL-1 $\beta$ levels were measured using commercially available ELISA kits (lower detection limit 0.1pg/mL, HSLB00C, R\&D systems). IL-6 levels were measured by ELISA as described previously (lower detection limit $10 \mathrm{pg} / \mathrm{mL})^{27}$. 


\section{Statistics}

Data from numerical and categorical variables are summarised using means \pm standard error (SEM) and number of patients (\%), respectively. For comparisons of CT outcome measures and fibre type-specific outcome measures (i.e. fibre size, myonuclear content, and satellite cell content) over time, a linear mixed model analysis with time as fixed factor and an unstructured covariance structure for the two repeated measures was used to be able to include subjects with non-complete outcome data. Outcomes are reported as observed and estimated means with corresponding 95\% confidence intervals (95\% CI). Differences in CT outcome measures between the non-fractured and fractured leg were assessed using pairedsamples t-tests. In addition, differences in the frequency distribution of fibre size in type I and type II muscle fibres were assessed using paired-samples t-tests. Blood outcome measures over time were also analysed using a linear mixed model analysis with time as fixed factor and a compound symmetry covariance structure for the four repeated measures, and reported as stated above. Two-sided p-values $\leq 0.05$ were considered to indicate statistical significance. False discovery rate correction was applied to all P-values. All analyses were performed using IBM SPSS Statistics for Windows (version 24. Armonk, NY: IBM Corp.) and GraphPad Prism software version 6 (San Diego, CA).

\section{Results}

Table 1 | Patients' characteristics

\begin{tabular}{lc}
\hline \hline & Patients \\
& $n=\mathbf{1 6}$ \\
Female (n (\%) & $12(75 \%)$ \\
Age (y) & $82.1 \pm 1.8$ \\
Time to surgery (h) & $21.25 \pm 2.03$ \\
Time between CTs (d) & $7.0 \pm 0.4$ \\
Time between biopsies (d) & $7.6 \pm 1.4$ \\
BMI (kg/m $\left.{ }^{2}\right)$ & $22.9 \pm 0.6$ \\
Lean body mass (kg) & $44.4 \pm 2.1$ \\
SMMI (kg/m $\left.{ }^{2}\right)$ & $7.0 \pm 0.3$ \\
Body fat (\%) & $26.7 \pm 2.2$ \\
& \\
\hline \hline Abbreviations: CT = Computed tomography scans. BMI = Body mass index. SMMI $=$ Skeletal Muscle Mass Index. \\
Values are expressed as observed means \pm SEM.
\end{tabular}

Values are expressed as observed means \pm SEM. 


\section{Patients' characteristics}

Sixteen hip fracture patients (age: $82.1 \pm 1.8$ year) were included in the study between September 2013 and September 2015. Patients' characteristics are presented in Table 1. The mean time between hospital admission and surgery was $21 \mathrm{~h} 15 \mathrm{~min} \pm 2 \mathrm{~h} 2 \mathrm{~min}$, and all patients were operated within 36 hours. Total lean body mass averaged $44.4 \pm 2.1 \mathrm{~kg}(68.3 \pm 1.1 \%)$, appendicular lean mass $18.8 \pm 1.0 \mathrm{~kg}(28.8 \pm 0.7 \%)$, and fat mass $17.8 \pm 2.0 \mathrm{~kg}(26.7 \pm 2.2 \%)$. Skeletal muscle mass index (SMMI) was calculated for women $(n=12)$ and men $(n=4)$ separately and averaged $6.6 \pm 0.4 \mathrm{~kg} / \mathrm{m}^{2}$ in women and $7.9 \pm 0.2 \mathrm{~kg} / \mathrm{m}^{2}$ in men.

\section{CT scans}

The observed and estimated cross-sectional areas of the whole thigh and quadriceps muscle of the non-fractured leg over time, which are our primary outcome measures, are presented in table 2 and in figure 1. The mean time between the baseline and postoperative CT-scan was 7.0 \pm 0.4 days. In this period, whole thigh muscle CSA of the non-fractured leg significantly declined by $5.4 \%$ (7963 vs $7536 \mathrm{~mm}^{2}$, time effect $427.2,95 \% \mathrm{CI}(-685,-169), \mathrm{p}=0.005)$. In agreement, quadriceps muscle CSA of the nonfractured leg significantly declined over time by $4.5 \%$ (3877 vs $3701 \mathrm{~mm}^{2}$, time effect $-176.4,95 \%$ CI $(-300,-53), p=0.01)$. In contrast, for both whole thigh muscle CSA in the fractured leg (8529 vs $8587 \mathrm{~mm}^{2}$, time effect $\left.-58.6,95 \% \mathrm{CI}(-449,566), \mathrm{p}=0.80\right)$ and quadriceps muscle CSA in the fractured leg (4390 vs $4299 \mathrm{~mm}^{2}$, time effect -90.7, $95 \%$ CI $(-436,255), p=0.57)$, no significant changes were observed over time. Additionally, the cross-sectional areas of the whole thigh and quadriceps muscle were compared between the non-fractured and fractured leg at both hospital admission and discharge. A significant difference was observed in both the observed

Figure 1 | CT-scan muscle cross-sectional area
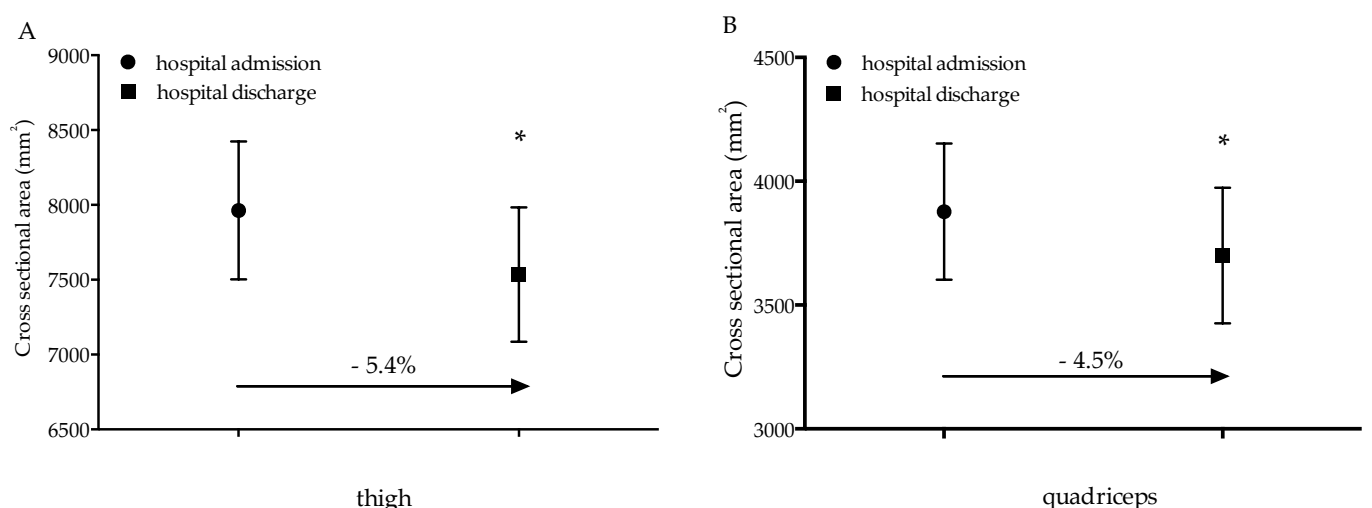

thigh

quadriceps

Muscle cross-sectional area of the whole thigh muscles and quadriceps muscle of the non-fractured leg in elderly hip fracture patients at hospital admission and hospital discharge. A: Estimated means $\left(\mathrm{mm}^{2}\right)$ whole thigh muscle. B: Estimated means $\left(\mathrm{mm}^{2}\right)$ quadriceps muscle. ${ }^{*}$ Significantly different from hospital admission. 
whole thigh muscle CSA and the observed quadriceps muscle CSA at hospital discharge $\left(7293 \pm 428\right.$ vs $8243 \pm 465 \mathrm{~mm}^{2}, \mathrm{p}=0.02$, and $3559 \pm 250$ vs $4152 \pm 290 \mathrm{~mm}^{2}$, $\mathrm{p}=0.01$, respectively). At hospital admission, no significant difference was seen in whole thigh muscle CSA between the non-fractured and fractured leg $(p=0.14)$.

Table 2 | CT-scan characteristics observed and estimated means

\begin{tabular}{|c|c|c|c|c|c|c|c|}
\hline & \multicolumn{2}{|c|}{ Observed means ( \pm SEM) } & \multicolumn{2}{|c|}{ Estimated means } & \multirow{2}{*}{$\begin{array}{l}\text { Time } \\
\text { effect }\end{array}$} & \multirow[t]{2}{*}{$p$ value } & \multirow[t]{2}{*}{$95 \%$ CI } \\
\hline & Admission & Discharge & Admission & Discharge & & & \\
\hline $\begin{array}{l}\text { Non-fractured leg } \\
\text { Whole thigh muscle, } \\
\text { CSA }\left(\mathrm{mm}^{2}\right)\end{array}$ & $7953 \pm 564$ & $7293 \pm 428$ & $7963 \pm 461$ & $7535 \pm 449$ & -427.2 & 0.005 & $-685,-169$ \\
\hline $\begin{array}{l}\text { Non-fractured leg } \\
\text { Quadriceps muscle, } \\
\text { CSA }\left(\mathrm{mm}^{2}\right)\end{array}$ & $3729 \pm 308$ & $3558 \pm 249$ & $3877 \pm 275$ & $3700 \pm 274$ & -176.4 & 0.01 & $-300,-53$ \\
\hline $\begin{array}{l}\text { Fractured leg } \\
\text { Whole thigh muscle, } \\
\text { CSA }\left(\mathrm{mm}^{2}\right)\end{array}$ & $8480 \pm 694$ & $8243 \pm 464$ & $8529 \pm 565$ & $8587 \pm 511$ & -58.6 & 0.80 & $-449,566$ \\
\hline $\begin{array}{l}\text { Fractured leg } \\
\text { Quadriceps muscle, } \\
\text { CSA }\left(\mathrm{mm}^{2}\right)\end{array}$ & $4293 \pm 485.4$ & $4152 \pm 289$ & $4390 \pm 402$ & $4299 \pm 317$ & -90.7 & 0.57 & $-436,255$ \\
\hline $\begin{array}{l}\text { Non-fractured leg } \\
\text { Whole thigh muscle, } \\
\text { HU }\end{array}$ & $31.3 \pm 2.6$ & $32.2 \pm 2.9$ & $31.8 \pm 2.7$ & $31.3 \pm 2.5$ & -0.43 & 0.58 & $-2.1,1.3$ \\
\hline $\begin{array}{l}\text { Non-fractured leg } \\
\text { Quadriceps muscle, } \\
\text { HU }\end{array}$ & $35.7 \pm 2.9$ & $37.5 \pm 3.1$ & $37.0 \pm 2.5$ & $36.1 \pm 2.7$ & -0.94 & 0.32 & $-2.9,1.1$ \\
\hline $\begin{array}{l}\text { Fractured leg } \\
\text { Whole thigh muscle, } \\
\text { HU }\end{array}$ & $34.3 \pm 2.5$ & $30.4 \pm 2.7$ & $34.3 \pm 2.6$ & $29.6 \pm 2.3$ & -4.7 & 0.004 & $-7.5,-1.8$ \\
\hline $\begin{array}{l}\text { Fractured leg } \\
\text { Quadriceps muscle, } \\
\text { HU }\end{array}$ & $39.2 \pm 2.6$ & $35.6 \pm 2.6$ & $39.2 \pm 2.7$ & $34.7 \pm 2.3$ & -4.5 & 0.02 & $-8.4,-0.7$ \\
\hline
\end{tabular}

Abbreviations: $\mathrm{CSA}=$ cross-sectional area $\left(\mathrm{mm}^{2}\right)$. HU = Hounsfield units. $\mathrm{CI}=$ Confidence Interval. Muscle crosssectional area and muscle attenuation index of the whole thigh and quadriceps muscle in the non-fractured and fractured leg assessed by single slice CT scans taken at hospital admission and hospital discharge. Observed means are expressed as means \pm SEM, estimated means are expressed as means, time effect, and confidence intervals.

In addition, mean grey scale of the muscle, also known as the muscle radiation attenuation value expressed as Hounsfield Units (HU), was tested for changes over time (table 2). The average grey scale of both the whole thigh muscle and the quadriceps muscle in the non-fractured leg did not significantly differ over time (31.8 vs $31.3 \mathrm{HU}, \mathrm{p}=0.58$, and 37 vs $36.1 \mathrm{HU}, \mathrm{p}=0.32$, respectively). However, in the fractured leg, a significant decline in average grey scale was seen over time in both the whole thigh muscle as well as the quadriceps muscle (34.3 vs $29.6 \mathrm{HU}$, 
$\mathrm{p}<0.01$, and 39.2 vs $34.7 \mathrm{HU}, \mathrm{p}=0.02$, respectively). Observed mean grey scale was significantly lower in the whole thigh of the fractured leg compared to the nonfractured leg at hospital discharge $(\mathrm{p}=0.03)$. To test for correct positioning of the CTscans, the CSA of the femoral bone was compared between time points. No significant differences were seen between time points $(\mathrm{p}=0.12)$.

\section{Muscle fibre type composition, size, and frequency distribution}

The mean time between the pre and post muscle biopsy was $7.6 \pm 1.4$ days. No significant differences were observed in muscle fibre type composition between beginning and end of hospital admission (66.9 vs 64.8\% type I fibres, time effect -2.1 , $95 \%$ CI $(-11.9,7.7), p=0.65)$. Both type I and type II muscle fibre size did not significantly change over time (type I: 4232 vs $4412 \mu \mathrm{m}^{2}$, time effect 180.2, 95\%CI ($822,1182), \mathrm{p}=0.70$, and type II: 2391 vs $2657 \mu \mathrm{m}^{2}$, time effect $266.1,95 \% \mathrm{CI}(-545,1078)$, $\mathrm{p}=0.48$; figure 2 ). At both time points, the type II muscle fibres were significantly smaller than type I fibres $(p<0.001$ and $p=0.010)$.

Figure 2 | Muscle fibre characteristics

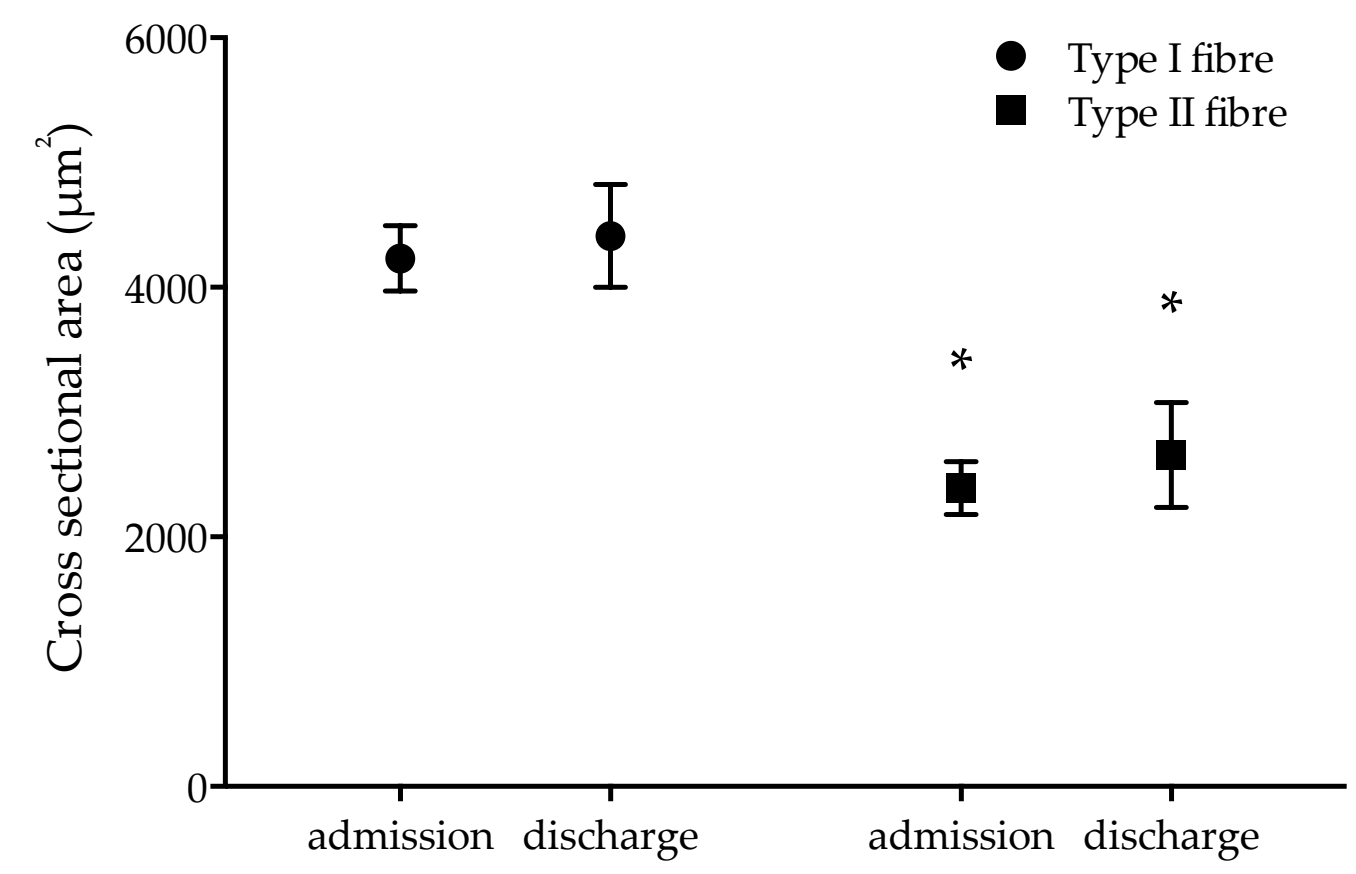

Muscle fibre size (in $\mu \mathrm{m}^{2}$ ) for both type I and type II fibres at hospital admission and hospital discharge in the fractured leg. Data represent estimated means. No significant differences were observed over time. * Significantly different compared to type I muscle fibre size.

The muscle fibre frequency distribution is depicted in figure 3 . The proportion of 'smaller' muscle fibres (i.e., with a muscle fibre CSA up to $3000 \mu^{2}$ ) was larger for the type II vs type I muscle fibres both at the beginning and at the end 
of hospital admission. No significant differences were seen in the frequency distribution between the time points for both the type I and the type II muscle fibres, except for two frequency categories in type II fibres.

Figure 3 | Muscle fibre size distribution

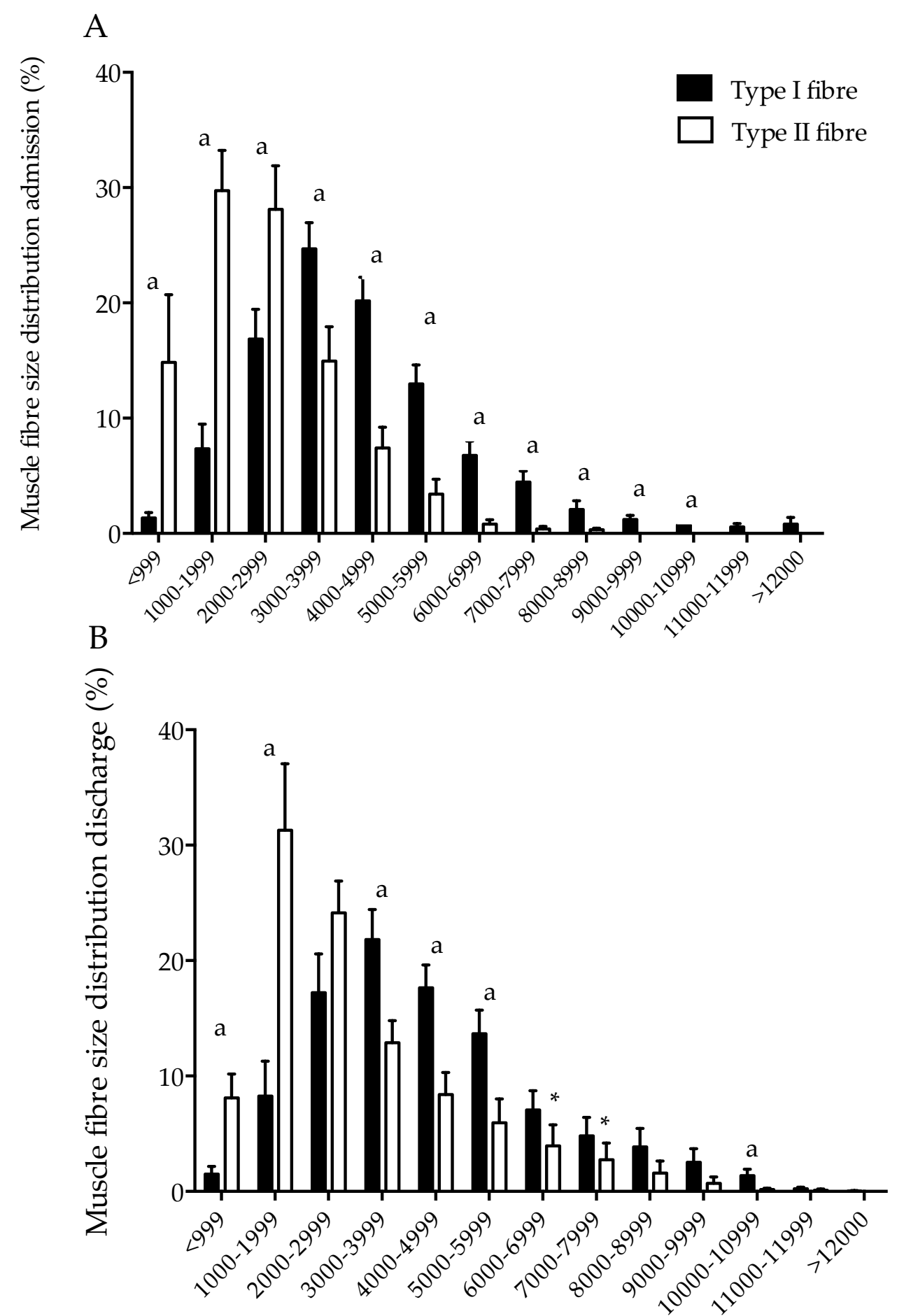

Muscle fibre size distribution (in percentage) at admission (A) and discharge (B). Data represents observed means \pm SEM. a Significant difference between \% of type I and type II fibres. ${ }^{*}$ Significant difference between time points. 
The number of myonuclei per fibre was significantly lower in the type II muscle fibres compared to the type I muscle fibres at hospital admission but not at hospital discharge ( $\mathrm{p}=0.004$ and $\mathrm{p}=0.09$, respectively). However, myonuclear content did not change significantly over time for both fibre types (type I: 2.42 vs 2.69 , time effect $0.27,95 \% \mathrm{CI}(-0.27,0.77), \mathrm{p}=0.25$, and type II: 1.85 vs 1.90 , time effect 0.05 , $95 \%$ CI $(-0.49,0.59) \mathrm{p}=0.84)$. Furthermore, the satellite cell content did not significantly change over time in both type I and type II muscle fibres (type I: 0.054 vs 0.044 , time effect $-0.01,95 \% \mathrm{CI}(-0.037,0.018), \mathrm{p}=0.47$, type II: 0.032 vs 0.025 , time effect $-0.007,95 \% \mathrm{CI}(-0.022,0.009), \mathrm{p}=0.34)$.

\section{Plasma and serum inflammatory markers}

Inflammatory measures CRP, IL-1 $\beta$ and IL- 6 were measured over time, i.e. at baseline (day of operation), postoperative day 1,3 , and 5 (figure 4). CRP peaked at postoperative day 3 and CRP was significantly higher at all postoperative time points compared to baseline. Moreover, IL-6 peaked at postoperative day 1 and the concentration at postoperative day 1 was significantly higher compared to all other time points. By contrast, IL-1 $\beta$ did not change significantly over time.

Figure 4 | Inflammatory markers

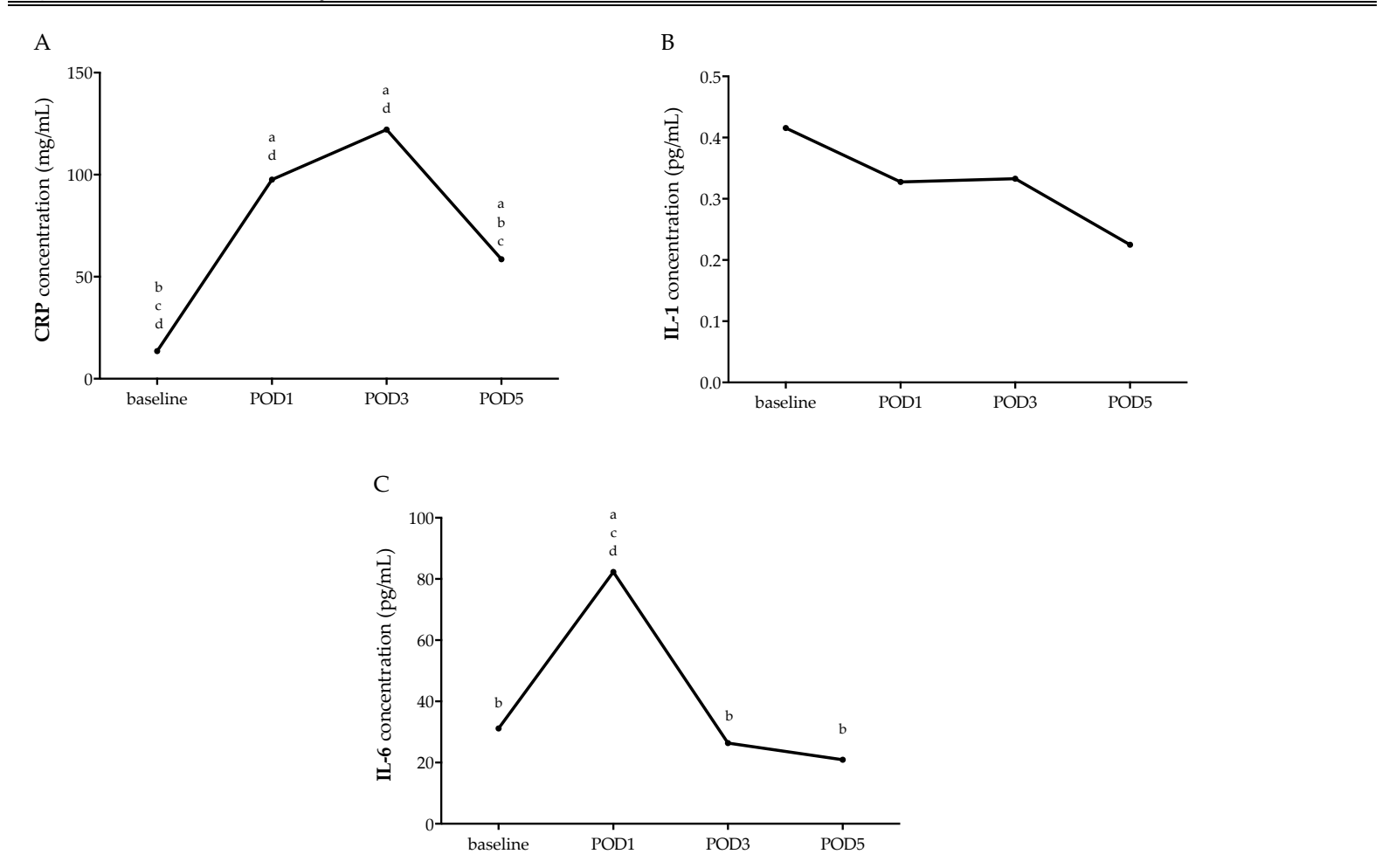

$\overline{\text { Inflammatory markers CRP (A), IL-1 } \beta \text { (B) and IL-6 (C). Data represent estimated means. }{ }^{\text {a }} \text { significantly different }}$ from baseline, ${ }^{b}$ significantly different from POD1, ${ }^{c}$ significantly different from POD3, ${ }^{d}$ significantly different from POD5. 


\section{Discussion}

The present study showed that during hospitalisation a substantial loss of whole thigh (estimated decrease of 5.4\%) and quadriceps muscle cross-sectional area (estimated decrease of $4.5 \%$ ) occurred in elderly hip fracture patients recovering from surgical intervention. Subjects suffered from pre-existing type II muscle fibre atrophy, however, no significant differences were observed in muscle fibre type composition or size between beginning and end of hospital admission in the fractured leg.

Loss of skeletal muscle mass represents a major health threat in the elderly population, because of the ensuing loss of skeletal muscle strength and function ${ }^{28,29}$. It has been hypothesised that the loss of muscle mass with ageing is not predominantly characterised by a progressive decline, but by short periods of exacerbated muscle loss that accumulate throughout the lifespan ${ }^{20}$. Bed rest or immobilisation facilitates inactivity-induced muscle loss. Previous work on muscle disuse indicates that even a short period of 5 days of immobilisation can lead to substantial loss of muscle mass and strength ${ }^{30}$. Studies in elderly subjects and studies comparing young and old have shown a greater loss of muscle mass due to immobilisation in the young, but an equivalent or even greater negative effect on muscle strength in the old ${ }^{21,31-33}$. Furthermore, it seems that elderly individuals have more difficulty regaining the amount of muscle lost when compared to the young ${ }^{34}$. A short period of hospitalisation may therefore already induce a substantial decline in skeletal muscle mass and function in elderly patients. We hypothesised that elderly hip fracture patients would lose a substantial amount of skeletal muscle mass during hospital stay.

Since the introduction of fast-track surgical treatment programs in the 1990s, treatment of hip fractures has rapidly evolved to the current levels of care combining a multidisciplinary approach with elements of the Early Recovery After Surgery principles. An example of a multidisciplinary integrated care pathway involves; 1) a fast track admission from the emergency department to the surgical ward within one hour; 2) involvement of a geriatrician with special attention to risk of delirium and comorbidities, 3) sufficient pain relief by the anaesthetist, 4) early and standardised intensive mobilisation programme by a physiotherapist, and 5) involvement of a dietician ${ }^{35}$. In the present study, we assessed the impact of a hip fracture, the operative treatment and its subsequent hospitalisation on skeletal muscle mass in elderly patients whom are standardly treated by such a hip fracture protocol. We performed single-slice CT scans of the upper legs within 24 hours after surgery in 
hip fracture patients and on the day of discharge or day 10 of hospital stay at the latest. We clearly show a substantial $~ 5 \%$ decline in whole thigh and quadriceps muscle cross-sectional area of the non-fractured leg over an average of 7 days following operative treatment in elderly hip fracture patients.

In contrast to the non-fractured leg, no changes were observed in muscle cross-sectional area of the fractured leg. The difference in change over time between the fractured and non-fractured leg are likely explained by the effect of swelling due to haematoma and oedema. Muscle radiation attenuation values reflect fat and water deposition in tissue visualised with CT scanning. Pre-defined radiation attenuation ranges are used to demarcate muscle tissue within the range of -29 to +150 Hounsfield Units. A physiological variation of the muscle radiation attenuation or mean grey scale of muscle tissue can be induced by the process of aging or training over time ${ }^{24}$. Intra- and extracellular oedema due to local or systemic inflammatory response after trauma and surgery, haematoma, and/or change in fat deposition after injury can influence the muscle radiation attenuation over a shorter period of time. Mean grey scales of the tissue of interest on a CT-scan can provide information on pathological changes ${ }^{36}$. In this study, a pronounced decrease in grey scale was observed in the fractured leg over time, but not in the non-fractured leg, indicating a change in soft tissue composition mainly in the fractured leg. In support, a substantially lower grey scale was seen in the fractured compared with the nonfractured leg at hospital discharge. Performing CT-scans in the fractured leg can therefore be considered an unreliable technique to observe changes in muscle mass over time shortly after the trauma and operative treatment. Alternatively, assessment of muscle tissue changes could be performed in the contralateral nonfractured control leg. Indeed, the changes in muscle mass as observed in the nonfractured leg in the present study clearly show the impact of a hip fracture, the subsequent treatment and hospitalisation in elderly patients.

Skeletal muscle biopsies of the vastus lateralis muscle of the fractured leg were obtained in addition to the single-slice CT-scans. Muscle biopsies were collected during the operation and on the day of discharge or maximum at postoperative day 10 . The type II muscle fibres were significantly smaller than type I fibres in this group of hip fracture patients. The smallest muscle fibres were more frequently present among the type II muscle fibres at both time points. Sarcopenia or the decline of skeletal muscle mass with aging is mainly characterised by type II muscle fibre atrophy and a reduction in type II fibre number 17,37,38. The finding of more smaller type II muscle fibres is in line with previous work on skeletal muscle fibre atrophy in hip fracture patients ${ }^{39}$. We hypothesised that a decline in skeletal 
muscle mass during hospitalisation would be accompanied by a reduction in type II muscle fibre size on a histological level. However, both type I and type II muscle fibre size did not significantly change over time. In this study, skeletal muscle loss was observed on CT-scans of the non-fractured leg, but not in the fractured leg, likely because of the swelling and haematoma. Muscle biopsies were taken from the fractured leg. The observed post-traumatic and postoperative changes on a wholeleg level likely also caused intra-cellular oedema on a histological level, thereby increasing muscle fibre CSA. We therefore propose that the observed fibre CSA in the fractured leg is not representative for the actual fibre size changes over time accompanying the change in muscle CSA as seen on CT-scan in the control leg. Our hypothesis was however, that following a hip fracture the observed muscle atrophy would be accompanied by a decline in muscle fibre size. Other studies investigating the effect of bed rest on muscle fibre size did manage to observe substantial decreases in muscle fibre size ${ }^{40}$, a characteristic that was not reliably assessed in our studies due to oedema. We therefore propose to assess short term changes in muscle fibre size in hip fracture patients in the non-operated leg, as was done with the assessment of changes in muscle CSA with CT scan in the present study.

Skeletal muscle mass is maintained by a constant state of muscle protein turnover, and remains constant when muscle protein synthesis and muscle protein breakdown rates are equal over time ${ }^{41}$. Since muscle contraction is one of the main stimuli for muscle protein synthesis, a reduction in physical activity during disuse situations such as hospitalisation can lead to loss of skeletal muscle ${ }^{42}$. The muscle loss as induced by immobilisation can be worsened by a concomitant effect of an increased stress response in the event of trauma, surgery, or disease ${ }^{43}$. Previous studies showed that inflammatory cytokines activate the molecular pathways involved in skeletal muscle wasting, leading to a decrease of protein synthesis rates and increase in muscle protein breakdown rates ${ }^{44-48}$. Consequently, elderly hip fracture patients have a high risk of exacerbated muscle loss due to the combination of bed rest and stress-inducing events in the absence of a robust countermeasure. Although regeneration of (damaged) muscle involves acute inflammation, hyperinflammation is a well-known inhibitor of muscle regeneration. Hip fracture patients seem to have substantial hyper-inflammation post-surgery when compared to elderly operated for elective hip replacement, although the surgical insult is comparable ${ }^{49}$. In the current study, serum and plasma inflammatory parameters (CRP, IL-1 $\beta$ and IL-6) were measured over time. A significant increase in serum/plasma concentrations was observed for CRP and IL-6, at postoperative day 3 and postoperative day 1 , respectively. We aimed to assess the association between 
the observed inflammatory changes and skeletal muscle loss during hospitalisation. However, due to small study population and missing blood draws, associations could not be reliably assessed. The suggestion that inflammation is one of the determinants of the loss of skeletal muscle mass after a hip fracture remains to be established, but previous studies showing a markedly depressed rate of muscle protein synthesis in hip fracture patients with high inflammatory markers point in this direction ${ }^{49}$.

A recently published study ${ }^{50}$ assessed the amount of skeletal muscle loss during hospitalisation in elderly patients following elective hip replacement surgery. In this study, a $4.2 \%$ and $3.4 \%$ decrease was seen of the cross-sectional area of the whole thigh and quadriceps muscle during hospitalisation. In our study, the amount of muscle loss even exceeds these percentages. Although the operative technique is comparable between the mentioned study and the present study, the total burden is higher in the hip fracture patients due to the trauma and the inflammatory reaction. Furthermore, elderly hip fracture patients seem to already have lower lean body mass and a lower skeletal muscle mass index preoperatively. Prevention of the loss of muscle loss postoperatively may therefore be of even greater consent in hip fracture patients.

The loss of skeletal muscle strength and functional performance are more relevant than changes in skeletal muscle mass alone ${ }^{51}$. Previous research indicates that loss of skeletal muscle in elderly concomitantly has great impact on muscle strength and function. Elderly suffering from sarcopenia are over three times more likely to fall, regardless of age, gender, or comorbidities, and the risk of sequential falls and fractures will only rise when muscle loss during hospitalisation is not combatted ${ }^{52}$. It has been shown that hospitalised elderly spend the majority of the day in bed during their admission despite mobilisation programs ${ }^{53,54}$. Physical activity is one of the most effective interventions to increase muscle mass or attenuate the loss of muscle mass ${ }^{55}$. In addition, exercise increases the anabolic response to protein or food intake ${ }^{56,57}$. Ingestion of protein or amino acids is the other main anabolic stimulus for skeletal muscle tissue ${ }^{58}$. Protein and caloric malnutrition in elderly aggravates muscle loss during a period of bed rest or immobilisation ${ }^{20}$. A combination of optimal dietary intake and physical activity should be implemented in clinical hip fracture treatment to target the loss of muscle mass, strength, and function during hospitalisation for elderly patients recovering from surgery after a hip fracture. 


\section{Conclusions}

In conclusion, elderly patients recovering from an operatively treated hip fracture lose a substantial amount of skeletal muscle mass during hospital admission. Since muscle loss has negative effects on functional performance and outcomes, it is of importance to develop interventional strategies to prevent or attenuate the loss of skeletal muscle mass during hospitalisation in elderly hip fracture patients. 


\section{References}

1. Holt G, Smith R, Duncan K, Hutchison JD, Reid D. Changes in population demographics and the future incidence of hip fracture. Injury. 2009;40(7):722-726.

2. Hartholt KA, van Beeck EF, Polinder $\mathrm{S}$, et al. Societal consequences of falls in the elderly population: injuries, healthcare costs, and long-term reduced quality of life. The Journal of trauma. Sep 2011;71(3):748-753.

3. Farahmand BY, Michaëlsson K, Ahlbom A, Ljunghall S, Baron JA, Group S. Survival after hip fracture. Osteoporosis International. 2005;16(12):1583-1590.

4. Haentjens P, Magaziner J, ColónEmeric CS, et al. Meta-analysis: excess mortality after hip fracture among older women and men. Annals of internal medicine. 2010;152(6):380-390.

5. Mariconda M, Costa GG, Cerbasi S, et al. The determinants of mortality and morbidity during the year following fracture of the hip: a prospective study. The bone $\mathcal{E}$ joint journal. 2015;97B(3):383-390.

6. Bentler SE, Liu L, Obrizan M, et al. The aftermath of hip fracture: discharge placement, functional status change, and mortality. American journal of epidemiology. 2009;170(10):1290-1299.

7. Panula J, Pihlajamäki H, Mattila VM, et al. Mortality and cause of death in hip fracture patients aged 65 or older: a population-based study. BMC musculoskeletal disorders. 2011;12:105.

8. Abrahamsen B, van Staa T, Ariely R, Olson M, Cooper C. Excess mortality following hip fracture: a systematic epidemiological review. Osteoporosis international : a journal established as result of cooperation between the European Foundation for Osteoporosis and the National Osteoporosis Foundation of the USA. 2009;20(10):1633-1650.

9. Vochteloo AJ, Moerman S, Tuinebreijer WE, et al. More than half of hip fracture patients do not regain mobility in the first postoperative year. Geriatrics \& gerontology international. 2013;13(2):334-341.

10. Holt $G$, Smith R, Duncan K, Hutchison JD, Gregori A, Reid D. Outcome after sequential hip fracture in the elderly. The Journal of bone and joint surgery. American volume. Oct 3 2012;94(19):1801-1808.

11. Parkkari J, Kannus P, Palvanen M, et al. Majority of hip fractures occur as a result of a fall and impact on the greater trochanter of the femur: a prospective controlled hip fracture study with 206 consecutive patients. Calcified tissue international. 1999;65(3):183-187.

12. Blake AJ, Morgan K, Bendall MJ, et al. Falls by elderly people at home: prevalence and associated factors. Age and ageing. 1988;17(6):365-372.

13. Pohl $\mathrm{P}$, Nordin E, Lundquist A, Bergström U, Lundin-Olsson L. Community-dwelling older people with an injurious fall are likely to sustain new injurious falls within 5 years--a prospective long-term followup study. BMC geriatrics. 2014;14:120.

14. Hartholt KA, Stevens JA, Polinder S, van der Cammen TJ, Patka P. Increase in fall-related hospitalizations in the United States, 2001-2008. The Journal of trauma. Jul 2011;71(1):255-258.

15. Moreland JD, Richardson JA, Goldsmith $\mathrm{CH}$, Clase CM. Muscle weakness and falls in older adults: a systematic review and meta-analysis. Journal of the American Geriatrics Society. 2004;52(7):1121-1129.

16. Cruz-Jentoft AJ, Baeyens JP, Bauer JM, et al. Sarcopenia: European consensus on definition and diagnosis: Report of the European Working Group on Sarcopenia in Older People. Age and ageing. Jul 2010;39(4):412-423.

17. Verdijk LB, Snijders T, Beelen M, et al. Characteristics of muscle fiber type are predictive of skeletal muscle mass and 
strength in elderly men. Journal of the American Geriatrics Society. Nov 2010;58(11):2069-2075.

18. Sousa AS, Guerra RS, Fonseca I, Pichel F, Amaral TF. Sarcopenia and length of hospital stay. European journal of clinical nutrition. 2015.

19. Vetrano DL, Landi F, Volpato S, et al. Association of sarcopenia with shortand long-term mortality in older adults admitted to acute care wards: results from the CRIME study. The journals of gerontology. Series A, Biological sciences and medical sciences. 2014;69(9):1154-1161.

20. English KL, Paddon-Jones D. Protecting muscle mass and function in older adults during bed rest. Current opinion in clinical nutrition and metabolic care. 2010;13(1):34-39.

21. Kortebein P, Ferrando A, Lombeida J, Wolfe R, Evans WJ. Effect of 10 days of bed rest on skeletal muscle in healthy older adults. JAMA : the journal of the American Medical Association. Apr 25 2007;297(16):17721774.

22. Sun T, Wang X, Liu Z, Chen X, Zhang J. Plasma concentrations of pro- and anti-inflammatory cytokines and outcome prediction in elderly hip fracture patients. Injury. 2011;42(7):707-713.

23. Bergstrom J. Percutaneous needle biopsy of skeletal muscle in physiological and clinical research. Scandinavian journal of clinical and laboratory investigation. Nov 1975;35(7):609-616.

24. Aubrey J, Esfandiari N, Baracos VE, et al. Measurement of skeletal muscle radiation attenuation and basis of its biological variation. Acta physiologica (Oxford, England). 2014;210(3):489-497.

25. Verdijk LB, Gleeson BG, Jonkers RA, et al. Skeletal muscle hypertrophy following resistance training is accompanied by a fiber type-specific increase in satellite cell content in elderly men. The journals of gerontology.
Series A, Biological sciences and medical sciences. 2009;64(3):332-339.

26. Snijders T, Verdijk LB, Beelen M, et al. A single bout of exercise activates skeletal muscle satellite cells during subsequent overnight recovery. Exp Physiol. Feb 10 2012;97(6):762-773.

27. Hanssen SJ, Derikx JP, Vermeulen Windsant IC, et al. Visceral injury and systemic inflammation in patients undergoing extracorporeal circulation during aortic surgery. Annals of surgery. 2008;248(1):117-125.

28. Covinsky KE, Palmer RM, Fortinsky $\mathrm{RH}$, et al. Loss of independence in activities of daily living in older adults hospitalized with medical illnesses: increased vulnerability with age. Journal of the American Geriatrics Society. 2003;51(4):451-458.

29. Mitchell WK, Williams J, Atherton P, Larvin $M$, Lund J, Narici $M$. Sarcopenia, dynapenia, and the impact of advancing age on human skeletal muscle size and strength; a quantitative review. Frontiers in physiology. 2012;3:260.

30. Wall BT, Dirks ML, Snijders T, Senden JM, Dolmans J, van Loon LJ. Substantial skeletal muscle loss occurs during only 5 days of disuse. Acta physiologica (Oxford, England). 2014;210(3):600-611.

31. Dirks ML, Wall BT, Nilwik R, Weerts $\mathrm{DHH}$, Verdijk LB, van Loon LJ. Skeletal muscle disuse atrophy is not attenuated by dietary protein supplementation in healthy older men. The Journal of nutrition. 2014;144(8):1196-1203.

32. Suetta C, Frandsen U, Jensen L, et al. Aging affects the transcriptional regulation of human skeletal muscle disuse atrophy. PloS one. 2012;7(12).

33. Suetta C. Plasticity and function of human skeletal muscle in relation to disuse and rehabilitation: Influence of ageing and surgery. Danish medical journal. 2017;64(8).

34. Hvid L, Aagaard P, Justesen L, et al. Effects of aging on muscle mechanical 
function and muscle fiber morphology during short-term immobilization and subsequent retraining. Journal of applied physiology. Dec 2010;109(6):1628-1634.

35. Folbert E, Smit R, van der Velde D, Regtuijt M, Klaren H, Hegeman JHH. [Multidisciplinary integrated care pathway for elderly patients with hip fractures: implementation results from Centre for Geriatric Traumatology, Almelo, The Netherlands]. Nederlands tijdschrift voor geneeskunde. 2011;155(26).

36. Goodpaster BH, Kelley DE, Thaete FL, He J, Ross R. Skeletal muscle attenuation determined by computed tomography is associated with skeletal muscle lipid content. Journal of applied physiology (Bethesda, Md. : 1985). 2000;89(1):104-110.

37. Verdijk LB, Koopman R, Schaart G, Meijer K, Savelberg HH, van Loon LJ. Satellite cell content is specifically reduced in type II skeletal muscle fibers in the elderly. American journal of physiology. Endocrinology and metabolism. Jan 2007;292(1):E151-157.

38. Nilwik R, Snijders T, Leenders $M$, et al. The decline in skeletal muscle mass with aging is mainly attributed to a reduction in type II muscle fiber size. Experimental 2013;48(5):492-498.

39. Kramer IF, Snijders T, Smeets JS, et al. Extensive Type II Muscle Fiber Atrophy in Elderly Female Hip Fracture Patients. The journals of gerontology. Series A, Biological sciences and medical sciences. 2017.

40. Dirks ML, Wall BT, van de Valk B, et al. One Week of Bed Rest Leads to Substantial Muscle Atrophy and Induces Whole-Body Insulin Resistance in the Absence of Skeletal Muscle Lipid Accumulation. Diabetes. 2016;65(10):2862-2875.

41. Rennie MJ, Edwards RH, Halliday D, Matthews DE, Wolman SL, Millward DJ. Muscle protein synthesis measured by stable isotope techniques in man: the effects of feeding and fasting. Clinical science. Dec 1982;63(6):519-523.

42. Baumgartner RN, Waters DL, Gallagher D, Morley JE, Garry PJ. Predictors of skeletal muscle mass in elderly men and women. Mechanisms of ageing and development. 1999;107(2):123-136.

43. Paddon-Jones D, Sheffield-Moore $M$, Cree MG, et al. Atrophy and impaired muscle protein synthesis during prolonged inactivity and stress. The Journal of clinical endocrinology and metabolism. 2006;91(12):4836-4841.

44. Schaap LA, Pluijm SM, Deeg DJ, Visser M. Inflammatory markers and loss of muscle mass (sarcopenia) and strength. The American journal of medicine. 2006;119(6):20139898882013989817.

45. Lang $\mathrm{CH}$, Frost RA, Vary TC. Regulation of muscle protein synthesis during sepsis and inflammation. American journal of physiology. Endocrinology and metabolism. 2007;293(2):9.

46. Budui SL, Rossi AP, and Metabolism Z-M. The pathogenetic bases of sarcopenia. ... in Mineral and Bone Metabolism. 2015.

47. Frost RA, Lang $\mathrm{CH}$. Protein kinase B/Akt: a nexus of growth factor and cytokine signaling in determining muscle mass. Journal of applied physiology (Bethesda, Md. : 1985). 2007;103(1):378-387.

48. Puthucheary ZA, Rawal J, McPhail M, et al. Acute skeletal muscle wasting in critical illness. JAMA : the journal of the American Medical Association. 2013;310(15):1591-1600.

49. Bamman MM, Ferrando AA, Evans $\mathrm{RP}$, et al. Muscle inflammation susceptibility: a prognostic index of recovery potential after hip arthroplasty? American journal of physiology. Endocrinology and metabolism. 2015;308(8):9.

50. Kouw IWKWK, Groen BBLBL, Smeets JSJSJ, et al. One Week of 
Hospitalization Following Elective Hip Surgery Induces Substantial Muscle Atrophy in Older Patients. Journal of the American Medical Directors Association. 2018.

51. Visser M, Harris TB, Fox KM, et al. Change in muscle mass and muscle strength after a hip fracture: relationship to mobility recovery. The journals of gerontology. Series $A$, Biological sciences and medical sciences. 2000;55(8):40.

52. Kim SM, Moon YW, Lim SJ, et al. Prediction of survival, second fracture, and functional recovery following the first hip fracture surgery in elderly patients. Bone. Jun 2012;50(6):13431350.

53. Brown CJ, Redden DT, Flood KL, Allman RM. The underrecognized epidemic of low mobility during hospitalization of older adults. Journal of the American Geriatrics Society. 2009;57(9):1660-1665.

54. Pedersen MM, Bodilsen AC, Petersen $\mathrm{J}$, et al. Twenty-four-hour mobility during acute hospitalization in older medical patients. The journals of gerontology. Series A, Biological sciences and medical sciences. 2013;68(3):331-337.
55. Phillips SM, Tipton KD, Aarsland A, Wolf SE, Wolfe RR. Mixed muscle protein synthesis and breakdown after resistance exercise in humans. The American journal of physiology. 1997;273(1 Pt 1):107.

56. Holwerda AM, Kouw IW, Trommelen $\mathrm{J}$, et al. Physical Activity Performed in the Evening Increases the Overnight Muscle Protein Synthetic Response to Presleep Protein Ingestion in Older Men. The Journal of nutrition. 2016;146(7):1307-1314.

57. Pennings B, Koopman R, Beelen M, Senden JM, Saris WH, van Loon LJ. Exercising before protein intake allows for greater use of dietary protein-derived amino acids for de novo muscle protein synthesis in both young and elderly men. The American journal of clinical nutrition. 2011;93(2):322-331.

58. Paddon-Jones D, Sheffield-Moore M, Zhang XJ, et al. Amino acid ingestion improves muscle protein synthesis in the young and elderly. American journal of physiology. Endocrinology and metabolism. Mar 2004;286(3):E321-328. 



\section{CHAPTER 5}

\section{Perioperative nutritional supplementation and skeletal muscle mass in elderly hip fracture patients}

I.F. Kramer, T.J. Blokhuis, L.B. Verdijk, L.J.C. van Loon, M. Poeze. 


\section{Abstract}

Elderly people with hip fractures are often malnourished at the time of fracture, which can have substantial influence on mortality and clinical outcomes, but also functional outcome and quality of life. A close relationship between protein intake and muscle maintenance has been demonstrated. Skeletal muscle weakness is an independent risk factor for falls and fall-related injuries in the elderly, and is an independent marker of prognosis. However, the effect of perioperative nutritional interventions on outcomes in elderly hip fracture patients remains controversial. In this narrative review, an overview is presented of the existing literature on nutritional status and sarcopenia in elderly hip fracture patients, clinical outcomes, and the effects of nutritional intervention on outcome and rehabilitation in this patient group. 


\section{Introduction}

Hip fractures, or proximal femur fractures, are a growing concern in modern society because of the substantial morbidity and mortality in the elderly patients affected ${ }^{1}$. A hip fracture and the subsequent surgery represent severe stresses for elderly, sometimes medically compromised, patients. Quality of life often decreases after a hip fracture and remains poorer in a substantial group of patients, even after months of recovery ${ }^{2}$. Many patients are not able to return to their pre-fracture residential environment and level of mobility ${ }^{3}$.

One of the problems is that people with a hip fracture are frequently malnourished or at risk of malnourishment at the time of the fracture ${ }^{4}$, with various factors contributing to poor or inadequate food intake in these people such as an increased energy expenditure combined with low dietary intake due to lack of appetite, nausea and psychological factors. Poor nutritional status is associated with worse outcomes, and may challenge rehabilitation through its effect on skeletal muscle status and mobility. Perioperative nutritional strategies may therefore improve muscle mass and functional recovery, and reduce morbidity and mortality in this vulnerable patient group.

This literary review aims to summarise and extract data from the existing scientific literature on malnutrition and body composition of elderly hip fracture patients, as well as on ways to modify these by nutritional interventions, and on results regarding in-hospital outcomes and post-hospital functional recovery and mortality.

\section{Epidemiology of hip fractures}

Hip (i.e. proximal femur) fractures constitute a significant global public health problem. The highest incidence rates are seen in Northern Europe (574 per 100,000 citizens in Norway, Sweden and Austria) and the United States, the lowest incidence rates in Africa (2 per 100,000 citizens in Nigeria), and intermediate incidence rates in Asian countries (110 per 100,000 citizens in Hong Kong) ${ }^{5,6}$. Although the age-specific incidence of hip fractures may be decreasing in some Western countries ${ }^{7}$, it is predicted that the total number of patients worldwide will continue to grow in the next decades as a consequence of demographic changes, including increasing life expectancy ${ }^{8,9}$.

The care of hip fracture patients requires input from multiple healthcare organizations, placing a significant burden on society's healthcare resources, so the 
increasing number of hip fractures will lead to expanding health care expenditures 10-12. The costs of care for hip fracture patients are highest in the first three months after injury, and are about three times higher than those for age- and residencymatched controls without a fracture ${ }^{13}$. The main determinants of high costs of care in hip fracture patients are their age at the time of the injury and institutionalised living prior to the fracture ${ }^{13}$. Improving functional outcomes, reducing hospital length-of-stay, and accelerating rehabilitation might reduce healthcare costs for hip fracture patients ${ }^{10}$.

Hip fractures primarily represent a burden on patients individually. Hip fracture patients have a substantially elevated risk of all-cause death, the risk being increased 5- to 8-fold during the first months after the fracture ${ }^{14}$. Compared to patients undergoing an elective total hip replacement (THR) operation, hip fracture patients have a higher risk of mortality and major complications, even though the surgical insult is comparable, especially in patients undergoing hemiarthroplasty as a hip fracture repair ${ }^{15}$. This increased all-cause mortality seems to persist for several years after the fracture. ${ }^{1}$ Three months after a hip fracture, reported mortality rates average around $10 \% 3,16,17$,but they rise to up to $30 \%$ one year after the fracture $3,17-21$. Studies have reported a higher relative mortality hazard following a hip fracture for men (7.95 [95\% CI 6.13 to 10.30]) than for women (5.75 [95\% CI 4.94 to 6.67]) ${ }^{14}$.

Post-fracture mortality rates seem to be at least partly age-dependent ${ }^{21,22}$, as pre-fracture health status may act as a confounding variable, although this is not unambiguously shown by research findings. On the one hand, studies among hip fracture patients without comorbidity have found both normal and increased mortality rates ${ }^{23,24}$, while other studies have shown comparable mortality rates between hip fracture patients with and without comorbidities. On the other hand, all hip fracture patients have increased mortality rates compared to the general population ${ }^{1}$, and patients with higher ASA (American Society of Anaesthesiologists) scores have higher reported postoperative mortality rates after hip fracture surgery 20,21,25,26. Survival rates are lowest in hip fracture patients who sustain a second fracture in the first year after their hip fracture ${ }^{27}$. Factors contributing to the high mortality rates in hip fracture patients need to be identified to understand and potentially prevent post-fracture deaths.

\section{(Functional) outcomes in hip fracture patients}

Since the introduction of fast-track surgical treatment programs in the 1990s ${ }^{28-30}$, treatment of hip fractures has rapidly evolved to the current levels of care. The 
multidisciplinary approach includes preoperative optimisation of cardiac function, electrolyte disturbances, and respiratory function, early surgery and early mobilisation, adequate multimodal analgesia, and thromboprofylaxis. This approach has decreased length of hospital admission over time ${ }^{31}$. Although these are important issues, other postoperative results, such as functional outcomes, in terms of independent living and mobility and quality of life are essential to monitor. Poor functional status at hospital discharge is an important predictor for poor functional status one year after a hip fracture ${ }^{32}$, and is worse in individuals who sustain a subsequent fracture ${ }^{27}$. In general, hip fracture patients report lower post-fracture health-related quality of life than age-matched controls ${ }^{2,33}$. Patients experience a decline in mobility and functional status ${ }^{3,10}$, and are less likely to be independently walking following the fracture ${ }^{27}$. More than half of the patients do not regain their pre-fracture mobility in the first year ${ }^{34}$, sometimes as a result of a developed fear of falling ${ }^{35}$. Furthermore, a limited pre-fracture mobility is associated with worse mobility outcomes ${ }^{34}$.

Hip fracture patients are often restricted in their activities of daily living as a result of the loss of mobility, leading to loss of independence. More than half of the hip fracture patients are admitted to a rehabilitation of nursing home facility after discharge ${ }^{3}$. Falls are therefore a strong predictor of loss of independence in elderly ${ }^{36}$. Risk factors for a definite failure to return to the pre-fracture place of residence are a low pre-fracture level of activities of daily living, age, and cognitive status ${ }^{34,37}$. However, in all age groups, not even half of the patients eventually return to their own home.

\section{Sarcopenia in hip fracture patients}

Hip fractures in the elderly are the result of a simple fall in over $90 \%$ of the cases ${ }^{38}$. Of people aged 75 years and older, $35 \%$ fall at least once a year, with $16 \%$ suffering from recurrent falls ${ }^{39-41}$, and fall incidence increases to 50 percent by the age of 80 years ${ }^{10,42}$. Medical treatment is required in 20 to $60 \%$ of the falls, leading to hospital admissions in more than $30 \%$ of the cases annually ${ }^{43}$. The ability of skeletal muscle to generate an adequate amount of force is fundamental during normal daily activities such as climbing stairs, rising from a chair, or recovering posture to prevent a fall. Impairment of balance, leg-extension strength and gait is strongly associated with falls (OR 2.6) and recurrent falls (OR 5.0) in a study of Graafmans ${ }^{40}$. Nursing home residents with a history of falls have less than half of the knee and ankle strength of non-falling residents. These subjects furthermore have an impaired 
response to postural perturbations ${ }^{44}$. Thus, skeletal muscle weakness and declined balance performance are independent risk factors for falls and fall-related injuries in the elderly ${ }^{45}$.

The decline in skeletal muscle mass, strength, and/or functional performance with advancing age is termed sarcopenia. Although there is no universal definition, several working groups have published definitions that differ mainly in the cut-offs points for skeletal muscle strength or mass ${ }^{46-48}$. Sarcopenia is accelerated by poor nutrition and physical inactivity, but other factors contributing to sarcopenia are genetics, hormones, neuromuscular dysfunction, and trauma ${ }^{49}$. The loss of skeletal muscle mass and strength can be exacerbated during periods of bed rest or following injury and/or surgery ${ }^{50}$. However, the process of muscle wasting is complex and influenced by various internal and external factors. Insufficient energy and especially protein intake is the most important external factor contributing to skeletal muscle wasting. Protein and essential amino acids are essential for the maintenance of skeletal muscle. Nutritional deficits and malnutrition therefore aggravate loss of skeletal muscle ${ }^{51,52}$. Malnourishment is indeed associated with the presence of sarcopenia among hospitalised patients $53247,48,54,55$.

Data on the prevalence of sarcopenia in the population are widely available, and the standardisation of the definition by consensus criteria ${ }^{46}$ made it possible to compare the prevalence in different populations of elderly. The European Working Group on Sarcopenia in Older People (EWGSOP) recommends using the presence of both low muscle mass and low muscle function (strength or performance) for the diagnosis of sarcopenia, since muscle strength does not depend solely on muscle mass. The EWGSOP has defined cut-off thresholds for skeletal muscle mass indexes as $9.2 \mathrm{~kg} / \mathrm{m}^{2}$ and $7.4 \mathrm{~kg} / \mathrm{m}^{2}$ in males and females respectively, in combination with cutoff thresholds for low physical performance based on the Short Physical Performance Battery. ${ }^{46}$ Among hospitalised patients in general, reported prevalence rates of sarcopenia vary between 10 to $25 \%$ among all patients aged 18 years and older ${ }^{55-57}$. Sarcopenia seems to have the greatest prevalence at the orthopaedic trauma wards among all surgical wards ${ }^{56,58}$. Reported numbers on prevalence of sarcopenia in elderly hip fracture patients differ greatly, from $17 \%$ in a study from Otero et al ${ }^{59}$, a rate of $17 \%$ hip fracture patients staged pre-sarcopenic and $58 \%$ staged as sarcopenic in a study of di Monaco et al. ${ }^{60}$, a prevalence of $47 \%$ among Japanese hip fracture patients in a study of Hida et al ${ }^{58}$, to a very high prevalence of $71 \%$ in a study from Singh et al ${ }^{61}$. Postoperatively, lean body mass has been shown to significantly decrease further in the first 2 months after admission ${ }^{62}$. Evaluation of sarcopenia in hip fracture patients is difficult due to mobility problems and pain, 
both for the measurement of muscle function and for measurement of muscle mass. The gold standard for estimating muscle mass is considered to be computed tomography or magnetic resonance imaging, although dual energy X-ray absorptiometry (DEXA) and bioelectrical impedance analysis (BIA) are acceptable alternatives. Different methods used can result in different outcomes, especially when only few patients are included in the study ${ }^{58}$. Furthermore, not the same EWGSOP (European Working Group on Sarcopenia in Older People) criteria are met in all studies, with different skeletal muscle mass index cut-offs used, or only muscle mass measurement applied but muscle function not being evaluated.

The composition of the skeletal muscle in elderly hip fracture patients can give essential information on muscle loss. Extensive (type II) muscle fibre atrophy was seen in elderly female patients with a hip fracture when compared with agematched controls and young controls (figure 1) ${ }^{63}$. Type II muscle fibre atrophy is an important hallmark for sarcopenia, and muscle fibre atrophy may predispose to falls and (hip) fractures in the elderly population, since it is essential for rapid muscle force production during muscle contraction, thus in regaining posture to prevent a fall.

$\underline{\text { Figure } 1 \text { | Muscle fibre size }}$

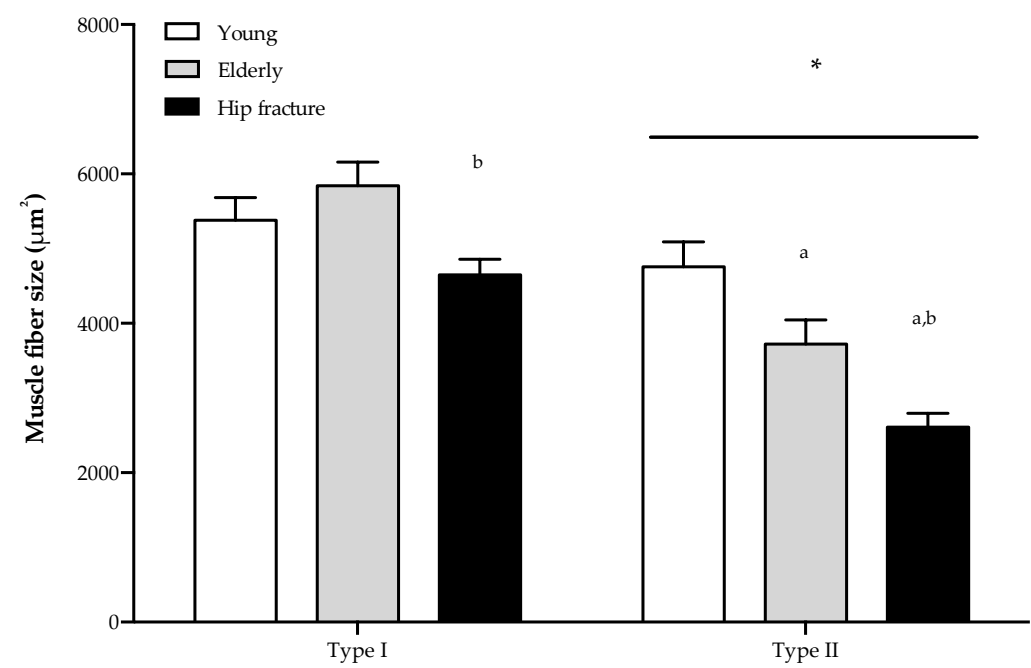

Type II muscle fibre size in elderly female hip fracture patients ( $\mathrm{n}=15)$, age-matched elderly controls ( $\mathrm{n}=15)$, and healthy young controls $(\mathrm{n}=15)$. ${ }^{*}$ Significant difference between all groups. Data adapted from Kramer et al ${ }^{63}$.

When the decline of muscle mass and function following a hip fracture is not regained during the recovery, risk for recurrence of fall-related fractured will only rise. The risk of a sequential fracture after a hip fracture is highest in the first year, varying from 3 to $10 \%$ among studies ${ }^{21,27}$. Elderly suffering from sarcopenia are over three times more likely to fall, regardless of age, gender, or comorbidities ${ }^{64}$. 
Measurement of muscle mass can be done with several imaging techniques, such as CT scans or DXA scans. Recent studies have shown an increased risk of a hip fracture of $40 \%$ to $60 \%$ when a decrease in either muscle mass quantity (muscle cross-sectional area) or muscle quality (X-ray attenuation) is seen ${ }^{65-67}$.

Sarcopenia is of importance for hip fracture patients, because it puts them at risk for (recurrent) falls and fractures, but also has effect on outcomes. Sarcopenia is well known to be an independent marker of poor prognosis among older individuals in general. For example, data show that institutionalised elderly suffering form sarcopenia have higher one-year mortality rates compared to elderly habitants with normal skeletal muscle mass ${ }^{54}$. Of patients admitted to acute care units in the CRIME study, those with sarcopenia had threefold higher in-hospital mortality as compared with non-sarcopenic patients ${ }^{68}$. This association remained significant after adjustment for a number of potential confounders, including the presence of cancer, cardiovascular disease, chronic obstructive pulmonary disease, dementia, chronic kidney disease, and pre-hospital disability.

Besides this, sarcopenia has been found to influence hospital length of stay. In a study from Sousa et al., sarcopenia was independently associated with longer hospital admission, and this association was strongest for patients aged 65 years or older ${ }^{53}$. A Scottish study found significantly longer hospital stays with a mean difference of 4 days in sarcopenic patients compared to non-sarcopenic patients ${ }^{55}$. Subsequently, skeletal muscle function is closely related to rehabilitation and regaining pre-fracture quality of life after hip fracture. When compared to nonsarcopenic hip fracture patients, sarcopenic hip fracture patients have a significant risk of incomplete functional recovery. Sarcopenic hip fracture patients display lower Barthell scores at discharge, but also during the first months of follow up ${ }^{69}$. The prevalence of sarcopenia among hip fracture patients is consequently of importance because of its prognostic significance.

Sarcopenia thus has significant clinical implications for the elderly, in particular for hip fracture patients. Nutrition plays a major role in its genesis. Prevention of the loss of skeletal muscle mass and conquering malnutrition are consequently two of the factors that should be assessed and treated in elderly hip fracture patients.

\section{Malnutrition in hip fracture patients}

According to the ESPEN guidelines, malnutrition or undernutrition can be defined as "a state resulting from lack of intake or uptake of nutrition that leads to altered body 
composition and body cell mass leading to diminished physical and mental function and impaired clinical outcome from disease" ${ }^{70}$. One of the subtypes of malnutrition is protein malnutrition. The recommended amount of protein in healthy adults is $0.8 \mathrm{~g} / \mathrm{kg} / \mathrm{day}$. Several working groups ${ }^{71,72}$ recommend a greater amount of protein per day for healthy elderly people (>65 year) of at least 1.0 to $1.2 \mathrm{~g} / \mathrm{kg} /$ day to maintain lean body mass and function. A higher $(>1.2 \mathrm{~g} / \mathrm{kg} /$ day) amount of protein is advised for elderly exercising of being otherwise active. Older adults with acute or chronic morbidities need even more dietary protein per day $(1.5 \mathrm{~g} / \mathrm{kg} / \mathrm{day}$. This is supported by both the American Society for Nutrition and the European Society for Clinical Nutrition and Metabolism ${ }^{73,74}$. An overview is presented in table $\mathbf{1}$.

Table 1 | Nutritional recommendations in RDA

\begin{tabular}{lc}
\hline \hline Group & Protein RDA \\
\hline & \\
Adults & $0.8 \mathrm{~g} / \mathrm{kg}$ body weight/day \\
Older adults ( $>65$ year) & $1.0-1.2 \mathrm{~g} / \mathrm{kg}$ body weight/day \\
Active older adults ( $>65$ year) & $1.2-1.5 \mathrm{~g} / \mathrm{kg}$ body weight/day \\
Older adults ( $>65$ year) with morbidities & $>1.5 \mathrm{~g} / \mathrm{kg}$ body weight/ day
\end{tabular}

Abbreviations: RDA = Recommended dietary allowances

Deteriorated nutritional status in elderly hospitalised patients at both general and surgical wards is a well-known problem. Low nutrient intake seems to be present among all hospital wards and disease types ${ }^{75}$. Protein-energy malnutrition is present in up to $60 \%$ of the patients at time of admission or nutritional deficiencies develop during hospital stay ${ }^{75,76}$. The influence of malnutrition on postoperative mortality and morbidity has been the topic of a considerable number of retrospective and prospective studies. Malnutrition leads to impaired mobility due to muscle wasting and reduced muscle function, thereby hindering and prolonging recovery, even after uncomplicated surgery ${ }^{77}$. In combination with an impairment of the immune response due to malnutrition, it increases the inclination to develop medical complications such as infections (pneumonia, urinary tract infection), and pressure sores ${ }^{75,78,79}$. Malnutrition is independently associated with longer length of hospital stay in hip fracture patients ${ }^{80-84}$, and re-admissions are higher ${ }^{84}$. Furthermore, mortality rates are higher in malnourished hip fracture patients and it is a predictor for 12-month mortality, independent of age or associated disease ${ }^{16,85-87}$. Nutritional status in hip fracture patients can be assessed by anthropometric measurements such as body weight or BMI, triceps skin fold thickness, upper arm circumference, or measurement of body composition. Also biochemical markers can be used for 
assessment of nutritional status, such as albumin, transferrin, and IGF-1 88,89. Essential signs of undernutrition in the elderly are a BMI $<18.5 \mathrm{~kg} / \mathrm{m}^{2}$, or unintentional weight loss of $>5 \%$ in three months, or $>10 \%$ in 6 months as well as a BMI below 20 90,91.

As may be expected, undernutrition is highly present in elderly admitted to the hospital suffering from a hip fracture. As protein intake of less than $15 \%$ of daily energy intake is associated with an increased risk of osteoporotic fractures in elderly individuals ${ }^{92}$, most of the hip fracture patients have nutritional deficiencies at admission 93,94, including protein-energy malnutrition $16,83,95$. Compared to agematched independently living elderly, hip fracture patients have lower body weight or BMI, mid upper arm circumference, and triceps skin fold thickness ${ }^{4,96}$. Studies on malnourishment in hip fracture patients report rates of 28 to $60 \%$ of the hip fracture patients at time of admission ${ }^{83,87,97}$. Malnutrition is frequently present even in a selection of previously healthy patients with hip fractures ${ }^{98}$. Undernutrition may be the result of reduced appetite before the fracture, which is not seldom reported by patients admitted after hip fracture ${ }^{99}$. This can also undermine the ability to combat the malnutrition during the postoperative recovery phase. Inadequate intake during hospital stay has been shown to be a problem. It has been reported that the nutritional status of hip fracture patients further deteriorates during admission $4,100,101$. Variety in taste and encouragement by caretakers are important to achieve desired energy and nutrient intake. The presence of cognitive impairment in patients with hip fractures may further impair the actual dietary energy and protein intake. In a study of Miller et al. cognitively impaired patients consumed $48 \%$ of their estimated total energy expenditure, against $78 \%$ in non-cognitively impaired patients ${ }^{102}$. Nutritional requirements of elderly patients are not well defined. Daily energy needs can be measured in a research setting by calculating resting energy expenditure, and can consequently be compared with intake. Spontaneous energy and protein intake in elderly with hip fractures seems to be significantly lower than the resting energy expenditure in these patients. This results in a net negative energy balance of $200-780 \mathrm{kcal}$ per day observed in studies ${ }^{98,103}$. Not only daily energy intake, but also protein intake of hip fracture patients may be lower than recommended (table 1). A study of Hessov et al. found lower protein intake of patients admitted to an acute orthopaedic surgical ward than the recommended amount in the majority of the patients, but more concerning is that more than half of these patients did not even reach the recommended amount for healthy adults ${ }^{104}$.

In conclusion, people with hip fractures are often malnourished or at risk of malnourishment at the time of the fracture, and the dietary intake of patients 
recovering form a hip fracture during hospital admission is frequently suboptimal. Through its association with unfavourable outcomes, modification of nutritional status may be beneficial in reducing functional decline, mortality, and complications.

\section{Nutritional intervention after hip fracture}

Modification of nutritional status by using nutritional interventions, during hospital admission and afterwards during the rehabilitation phase, could be beneficial in terms of improving outcomes. However, the effectiveness of oral nutritional supplementation in elderly hip fracture patients remains controversial and is the subject of on-going debate. There is a need to evaluate the use of nutritional interventions in this group by examining relevant published research. An overview of the included and discussed articles in this literary review can be found in table 2 $93,105-118$.

\section{Nutritional support}

The measurement of daily intake during nutritional support is a key issue in the design of nutritional intervention trials. This is, however, not always monitored. Any nutritional supplement may have impact on the usual food intake and intake of other macronutrients. If daily intake is not measured, it is impossible to assess what factor has produced the positive effect or no effect. Hip fracture patients often have a reduced appetite both prior to their fracture and during hospitalisation. However, a further negative effect on appetite due to nutritional supplementation was not seen in a study of Carlsson et al., but appetite was already impaired at baseline ${ }^{99}$. Also Bastow et al. ${ }^{105}$ did not observe a decline in voluntary food intake with nutritional supplementation, despite patients receiving an extra $1000 \mathrm{kcal}$ during the night.

Goal of nutritional supplementation may be treatment or prevention of undernutrition during admission. Dieticians can help in encouraging and assisting to enable patients to eat properly. Feeding support may be especially helpful in patients with cognitive impairments ${ }^{102}$, making up about $40 \%$ of the hip fracture population. The clinical impact of dietetic assistants has been investigated in some studies, of which one randomised controlled trial. In this British trial, patients supported by dietetic assistants had significantly higher mean caloric intake than 
Table 2 | Summery of included studies

\begin{tabular}{|c|c|c|c|c|c|}
\hline Reference & $\begin{array}{l}\text { Setting, study } \\
\text { participants, mean } \\
\text { age } \pm S D\end{array}$ & Study design & $\begin{array}{l}\text { Nutritional } \\
\text { supplement }\end{array}$ & $\begin{array}{l}\text { Outcome } \\
\text { measures }\end{array}$ & Results \\
\hline $\begin{array}{l}\text { Bastow et } \\
\text { al. } 1983105 \\
\text { RCT }\end{array}$ & $\begin{array}{l}744 \text { female hip } \\
\text { fracture patients } \\
\text { - well nourished, } \\
79 y(59-93) \\
\text { - thin, 83y (65-102) } \\
\text { - very thin, 81y } \\
(68-96)\end{array}$ & $\begin{array}{l}\text { Until discharge, } \\
\text { Overnight tube } \\
\text { feeding in group } 2 \\
\text { and 3, group } 1 \text { as } \\
\text { control }\end{array}$ & $\begin{array}{l}\text { Multi-nutrient, } \\
1000 \text { kcal incl. } \\
28 \text { g protein }\end{array}$ & 1. Mortality & $\begin{array}{l}\text { 1. no } \\
\text { difference }\end{array}$ \\
\hline $\begin{array}{l}\text { Hartgrink } \\
\text { et al. } 1998 \\
106 \\
\text { RCT }\end{array}$ & $\begin{array}{l}140 \text { hip fracture } \\
\text { patients } \\
\text { - control } 83.3 \pm 8.1 \mathrm{y} \\
\text { - intervention } \\
84.0 \pm 7.1 \mathrm{y}\end{array}$ & $\begin{array}{l}\text { 2-week overnight } \\
\text { tube feeding }\end{array}$ & $\begin{array}{l}\text { Multi-nutrient, } \\
1500 \mathrm{kcal} \text { incl } \\
60 \mathrm{~g} \text { protein/day }\end{array}$ & $\begin{array}{l}\text { 1. Pressure } \\
\text { sores } \\
\text { 2. Energy and } \\
\text { protein intake }\end{array}$ & $\begin{array}{l}\text { 1. no } \\
\text { difference } \\
\text { 2. higher }\end{array}$ \\
\hline $\begin{array}{l}\text { Sullivan et } \\
\text { al. } 2004{ }^{107} \\
\text { RCT }\end{array}$ & $\begin{array}{l}75 \text { hip fracture } \\
\text { patients }>64 y \\
\text { - control } 81.7 \pm 7.7 y \\
\text { - intervention } \\
75.9 \pm 7.4 y\end{array}$ & $\begin{array}{l}\text { 2-week overnight } \\
\text { tube feeding or oral } \\
\text { supplement in case } \\
\text { of intolerance }\end{array}$ & $\begin{array}{l}\text { Multi-nutrient, } \\
1375 \mathrm{kcal} / \text { day }\end{array}$ & $\begin{array}{l}1.6 \text { month } \\
\text { mortality } \\
\text { 2. energy } \\
\text { intake }\end{array}$ & $\begin{array}{l}\text { 1. no } \\
\text { difference } \\
\text { 2. higher }\end{array}$ \\
\hline $\begin{array}{l}\text { Sullivan et } \\
\text { al. } 1998^{108} \\
\text { RCT }\end{array}$ & $\begin{array}{l}18 \text { hip fracture } \\
\text { patients } \\
\text { - control } 76.5 \pm 6.1 y \\
\text { intervention } \\
74.5 \pm 2.1 y\end{array}$ & $\begin{array}{l}\text { Until discharge, } \\
\text { Overnight tube } \\
\text { feeding }\end{array}$ & $\begin{array}{l}\text { Multi-nutrient, } \\
125 \mathrm{cc} / \text { h over } 11 \\
\text { hours/day }\end{array}$ & $\begin{array}{l}\text { 1. } 6 \text { month } \\
\text { mortality } \\
\text { 2. energy } \\
\text { intake } \\
\text { 3. life } \\
\text { threatening } \\
\text { complications } \\
\text { 4. in-hospital } \\
\text { mortality }\end{array}$ & $\begin{array}{l}\text { 1. lower } \\
\text { 2. higher } \\
\text { 3. no } \\
\text { difference } \\
\text { 4. no } \\
\text { difference }\end{array}$ \\
\hline $\begin{array}{l}\text { Anbar et al. } \\
2014{ }^{109} \\
\text { RCT }\end{array}$ & $\begin{array}{l}50 \text { hip fracture } \\
\text { patients }>65 y \\
\text { - control } 83.7 \pm 6.4 y \\
\text { - intervention } \\
82.3 \pm 6.1 y\end{array}$ & $\begin{array}{l}\text { Until discharge, } \\
\text { Supplementation } \\
\text { based on energy } \\
\text { expenditure in } \\
\text { intervention group }\end{array}$ & $\begin{array}{l}\text { Multi-nutrient } \\
\text { ONS, } 355 \mathrm{kcal} \\
\text { and } 13.5 \mathrm{~g} \\
\text { protein /unit }\end{array}$ & $\begin{array}{l}\text { 1. } \\
\text { complications } \\
\text { 2. length of } \\
\text { stay } \\
\text { 3. energy } \\
\text { intake }\end{array}$ & $\begin{array}{l}\text { 1. sign } \\
\text { negative } \\
\text { correlation } \\
\text { 2. sign } \\
\text { negative } \\
\text { correlation } \\
\text { 3. higher } \\
\end{array}$ \\
\hline $\begin{array}{l}\text { Eneroth et } \\
\text { al. } 2006^{82} \\
\text { RCT }\end{array}$ & $\begin{array}{l}80 \text { healthy hip } \\
\text { fracture patients } \\
>60 \mathrm{y} \\
\text { - control } 78 \pm 8 \mathrm{y} \\
\text { - intervention } \\
84 \pm 7 \mathrm{y}\end{array}$ & $\begin{array}{l}\text { 10-days: 3-day } \\
\text { intravenous } \\
\text { supplement, } 7 \text {-day } \\
\text { oral supplement }\end{array}$ & $\begin{array}{l}\text { Multi-nutrient } \\
\text { iv } 1000 \mathrm{kcl} / \text { day, } \\
\text { multi-nutrient } \\
\text { ONS } \\
400 \mathrm{kcal} / \text { day }\end{array}$ & $\begin{array}{l}\text { 1. energy } \\
\text { intake } \\
2 . \\
\text { complications } \\
\text { 3. } 4 \text { month } \\
\text { mortality }\end{array}$ & $\begin{array}{l}\text { 1. higher } \\
\text { 2. lower } \\
\text { 3. no } \\
\text { difference }\end{array}$ \\
\hline $\begin{array}{l}\text { Botella- } \\
\text { Carretero et } \\
\text { al. } 2010^{110} \\
\text { RCT }\end{array}$ & $\begin{array}{l}60 \text { elderly hip } \\
\text { fracture patients } \\
>65 y \\
\text { - control } \\
\text { - intervention } \\
\end{array}$ & $\begin{array}{l}\text { Until discharge, oral } \\
\text { supplementation }\end{array}$ & $\begin{array}{l}\text { Multi-nutrient } \\
\text { ONS, } 400 \mathrm{kcl} \text { and } \\
40 \mathrm{~g} \text { protein/day }\end{array}$ & $\begin{array}{l}\text { 1. serum } \\
\text { albumin } \\
2 . \\
\text { complications }\end{array}$ & $\begin{array}{l}\text { 1. higher } \\
\text { 2. lower }\end{array}$ \\
\hline $\begin{array}{l}\text { Botella- } \\
\text { Carretero et } \\
\text { al. } 20088^{111} \\
\text { RCT }\end{array}$ & $\begin{array}{l}90 \text { normally- } \\
\text { mildly } \\
\text { undernourished } \\
\text { hip fracture } \\
\text { patients }>65 y \\
\text { - control } 83.7 \pm 7.9 y \\
\text { - protein } \\
\text { intervention } \\
83.1 \pm 6.3 y \\
\text { - energy } \\
\text { intervention } \\
84.6 \pm 5.7 y\end{array}$ & $\begin{array}{l}\text { Until discharge, oral } \\
\text { supplementation }\end{array}$ & $\begin{array}{l}\text { - Protein ONS } \\
36 \mathrm{~g} \text { protein/day, } \\
\text { - Multi-nutrient } \\
\text { ONS 500kcal an } \\
37.6 \mathrm{~g} \\
\text { protein/day }\end{array}$ & $\begin{array}{l}\text { 1. nutritional } \\
\text { status } \\
\text { 2. BMI } \\
\text { 3. length of } \\
\text { stay } \\
4 . \\
\text { complications }\end{array}$ & $\begin{array}{l}\text { 1. no } \\
\text { difference } \\
\text { 2. no } \\
\text { difference } \\
\text { 3. no } \\
\text { difference } \\
\text { 4. no } \\
\text { difference }\end{array}$ \\
\hline
\end{tabular}




\begin{tabular}{|c|c|c|c|c|c|}
\hline $\begin{array}{l}\text { Bruce et al. } \\
2003112 \\
\text { RCT }\end{array}$ & $\begin{array}{l}109 \text { non- } \\
\text { malnourished } \\
\text { female hip fracture } \\
\text { patients } \\
\text { - control } 83.3 \pm 8.0 y \\
\text { - intervention } \\
84.7 \pm 7.3 y\end{array}$ & $\begin{array}{l}28 \text {-day oral } \\
\text { supplementation }\end{array}$ & $\begin{array}{l}\text { Multi-nutrient } \\
\text { ONS, } 352 \mathrm{kcal} \\
\text { and } 37.6 \mathrm{~g} \\
\text { protein/day }\end{array}$ & $\begin{array}{l}\text { 1. weight loss } \\
\text { 2. length of } \\
\text { stay } \\
\text { 3. place of } \\
\text { discharge } \\
4.6 \text { month } \\
\text { mortality }\end{array}$ & $\begin{array}{l}\text { 1. no } \\
\text { difference } \\
\text { 2. no } \\
\text { difference } \\
\text { 3. no } \\
\text { difference } \\
\text { 4. no } \\
\text { difference }\end{array}$ \\
\hline $\begin{array}{l}\text { Delmi et al. } \\
1990^{93} \\
\text { RCT }\end{array}$ & $\begin{array}{l}59 \text { hip fracture } \\
\text { patients }>60 y \\
\text { - control } 82.9 \pm 7.9 y \\
\text { - intervention } \\
80.4 \pm 8.5 y\end{array}$ & $\begin{array}{l}\text { Until rehabilitation } \\
\text { discharge, oral } \\
\text { supplementation }\end{array}$ & $\begin{array}{l}\text { Multi-nutrient } \\
\text { ONS, } 254 \mathrm{kcal} \\
\text { and } 20.4 \mathrm{~g} \\
\text { protein/day }\end{array}$ & $\begin{array}{l}\text { 1. energy } \\
\text { intake } \\
2 . \text { serum } \\
\text { albumin } \\
\text { 3. length of } \\
\text { stay } \\
4 . \\
\text { unfavourable } \\
\text { outcomes }\end{array}$ & $\begin{array}{l}\text { 1. higher } \\
\text { 2. higher } \\
\text { 3. lower } \\
\text { 4. lower }\end{array}$ \\
\hline $\begin{array}{l}\text { Tidermark } \\
\text { et al. } 2004 \\
114 \\
\text { RCT }\end{array}$ & $\begin{array}{l}60 \text { female hip } \\
\text { fracture patients } \\
>70 \mathrm{y} \\
\text { - control } 84.1 \pm 4.3 \mathrm{y} \\
\text {-intervention PR } \\
83.5 \pm 6.1 \mathrm{y} \\
\text { - intervention with } \\
\text { nandrolone PR/N } \\
81.1 \pm 5.5 \mathrm{y}\end{array}$ & $\begin{array}{l}6 \text { months, oral } \\
\text { supplementation }\end{array}$ & $\begin{array}{l}\text { - Protein ONS } \\
\text { 20g/day } \\
\text { - Protein ONS } \\
\text { 20g/day with } \\
\text { nandrolone } \\
25 \mathrm{mg} / 3 \text { weeks }\end{array}$ & $\begin{array}{l}\text { 1. lean body } \\
\text { mass } \\
\text { 2. functional } \\
\text { performance } \\
\text { 3. health- } \\
\text { related quality } \\
\text { of life }\end{array}$ & $\begin{array}{l}\text { 1. decrease } \\
\text { in C en PR } \\
\text { 2. higher in } \\
\mathrm{PR} \text { and } \\
\mathrm{PR} / \mathrm{N} \\
\text { 3. higher in } \\
\mathrm{PR} \text { and } \\
\mathrm{PR} / \mathrm{N}\end{array}$ \\
\hline $\begin{array}{l}\text { Tkatch et } \\
\text { al. } 1992115 \\
\text { RCT }\end{array}$ & $\begin{array}{l}62 \text { hip fracture } \\
\text { patients } 82 y \\
\text { - isocaloric control } \\
\text { - protein } \\
\text { intervention PR }\end{array}$ & $\begin{array}{l}\text { Until rehabilitation } \\
\text { discharge, oral } \\
\text { supplementation }\end{array}$ & $\begin{array}{l}\text { - Protein ONS, } \\
20.4 \mathrm{~g} / \text { day } \\
\text { - Isocaloric ONS } \\
\text { without protein } \\
\text { 250kcal/day }\end{array}$ & $\begin{array}{l}\text { 1. length of } \\
\text { stay } \\
2 . \\
\text { complications } \\
\text { 3. mortality } \\
\text { during } \\
\text { rehabilitation } \\
4.7 \text { month } \\
\text { mortality }\end{array}$ & $\begin{array}{l}\text { 1. shorter } \\
\text { 2. lower } \\
\text { 3. lower } \\
\text { 4. lower }\end{array}$ \\
\hline $\begin{array}{l}\text { Schürch et } \\
\text { al. } 1998116 \\
\text { RCT }\end{array}$ & $\begin{array}{l}82 \text { hip fracture } \\
\text { patients } 80.7 \pm 2.4 y \\
\text { - isocaloric control } \\
\text { - protein } \\
\text { intervention }\end{array}$ & $\begin{array}{l}6 \text { months, oral } \\
\text { supplementation }\end{array}$ & $\begin{array}{l}\text { - Protein ONS } \\
\text { 20g/day } \\
\text { - Isocaloric ONS }\end{array}$ & $\begin{array}{l}\text { 1. muscle } \\
\text { strength } \\
2 . \text { bone } \\
\text { mineral } \\
\text { density } \\
\text { 3. length of } \\
\text { stay }\end{array}$ & $\begin{array}{l}\text { 1. no } \\
\text { difference } \\
\text { 2. less } \\
\text { decrease } \\
\text { 3. shorter }\end{array}$ \\
\hline $\begin{array}{l}\text { Espaulella } \\
\text { et al. } 2000 \\
117 \\
\text { RCT }\end{array}$ & $\begin{array}{l}171 \text { hip fracture } \\
\text { patients }>70 y \\
\text { - control } 82.7 \pm 6.6 y \\
\text { - protein } \\
\text { intervention } \\
82.4 \pm 6.6 y\end{array}$ & $\begin{array}{l}60 \text { days, oral } \\
\text { supplementation }\end{array}$ & $\begin{array}{l}\text { Protein ONS } \\
20 \mathrm{~g} / \text { day }\end{array}$ & $\begin{array}{l}\text { 1. Barthell } \\
\text { index } \\
\text { 2. mobility } \\
\text { index } \\
3.2 \text { month } \\
\text { mortality }\end{array}$ & $\begin{array}{l}\text { 1. no } \\
\text { difference } \\
\text { 2. no } \\
\text { difference } \\
\text { 3. lower }\end{array}$ \\
\hline $\begin{array}{l}\text { Neumann } \\
\text { et al. } 2004 \\
118 \\
\text { RCT }\end{array}$ & $\begin{array}{l}46 \text { hip fracture } \\
\text { patients }>60 y \\
\text { - low protein } \\
83.7 \pm 1.5 y \\
\text { - high protein } \\
82.7 \pm 1.6 y\end{array}$ & $\begin{array}{l}28 \text { days, oral } \\
\text { supplementation }\end{array}$ & $\begin{array}{l}\text { - Protein ONS } \\
17.8 \mathrm{~g} / \text { day } \\
\text { - Protein ONS } \\
30 \mathrm{~g} / \text { day }\end{array}$ & $\begin{array}{l}\text { 1. functional } \\
\text { dependence } \\
\text { measure } \\
\text { 2. serum } \\
\text { albumin } \\
\text { 3. length of } \\
\text { stay }\end{array}$ & $\begin{array}{l}\text { 1. no } \\
\text { difference } \\
\text { 2. higher } \\
\text { 3. no } \\
\text { difference }\end{array}$ \\
\hline
\end{tabular}


non-supported patients ${ }^{119}$. The dietetic assistants supported patients for a mean of 16 days. In this particular study, it resulted in significantly lower mortality rates up to 4 months postoperatively. However, no favourable results were seen on length of stay, although the trial was sufficiently powered with a high number of patients participating, and randomisation was done adequately ${ }^{82}$.

A Dutch prospective cohort study ${ }^{120}$ investigated a multidisciplinary approach on nutritional care, using a combination of dedicated nurses, doctors, and dieticians. This was associated with increased energy and protein intake in the first 7 days postoperatively during hospitalisation. After three months, significantly fewer patients in the intervention group were malnourished, and a significantly lower decline in quality of life was found in the intervention group. Multidisciplinary nutritional care, in a study of Bell et al. reduced intake barriers, and increased total $24 \mathrm{~h}$ energy and protein intakes ${ }^{121}$. Nutritional counselling can be extended after discharge of the hospital. This has been found to be feasible in a Dutch process evaluation study ${ }^{122}$. Costs of nutritional intervention are relatively low when compared with medical costs. The additional costs for nutritional intervention are as low as $3 \%$ of the total costs for hip fracture care ${ }^{123}$. Based on the available evidence, the use of dietetic assistants may be useful in increasing food and supplement intake, which can result in reduced mortality rates, but the results need to be validated in further randomised controlled trials.

\section{Nutritional interventions during hospitalisation}

Nutritional intervention during hospitalisation can be applied in several ways, such as multinutrient supplements, protein supplements, nasogastric tube feeding, or intravenous administration of supplementation.

Nutritional support via a nasogastric tube is one of the most invasive ways of administering supplementary calories or protein in patients. It can be applied in an overnight feed or in a continuous manner over 24 hours. Up until now, nutritional support via NGT does not show promising results on outcomes in hip fracture patients. The first study investigating multinutrient supplementation via nasogastric route in hip fracture patients was Bastow in $1983{ }^{105}$. Patients were given overnight nasogastric tube feeding of $1000 \mathrm{kcal}$ including $28 \mathrm{~g}$ of protein, in addition to their normal ward diet. No difference was seen in mortality between the study group and the controls. Another study tested the effect of nightly tube energy and protein supplementation, but investigated the effect on the incidence, progression, and severity of pressure sores ${ }^{106}$. Although the intervention resulted in a significantly higher protein intake, no effect was seen on the pressure sore development or 
severity of the pressure ulcers. Toleration of the tube catheter and thereby early withdrawal from the intervention might be an explanation, since a significant number (37 out of 65) of the tube-fed patients dropped out of intervention before end of the trial ${ }^{106}$. A study from Sullivan on nightly tube feeding experienced similar problems ${ }^{107}$. Supplementation of $1375 \mathrm{kcal}$ per night versus standard care was investigated. During the first week, no difference in the amount of voluntary nutrient intake was seen between groups, but intake decreased in the intervention group in the second week. Intolerance to the tube feedings developed commonly. In the end, there was no difference in mortality or complication rate 6 months after surgery between the groups. In a subsequent study of Sullivan et al. ${ }^{108}$, nightly tube feeding (125mL/h for 11 hours) was actually well tolerated, with an average of 15 days postoperatively. Both the treatment and the control group had reduced voluntary nutrient intake in the first week postoperatively, but the treatment subjects had a greater total nutrient intake. This resulted in reduced mortality numbers in the intervention group within the first 6 months. However, there was no difference between groups in the rate of postoperative life-threatening complications (25 vs 30\%) or in-hospital mortality (0 vs 30\%), which can be explained by the small number of patients included in this study ( 9 patients per group). Summarising, because of high numbers of intolerance to the nasogastric tube resulting in high numbers of dropouts, evidence on the effect of multi-nutrient supplementation via tube feeding on outcomes such as complications or mortality is low. However, when tube feeding is actually tolerated by patients, it can result in a promising improvement in nutritional intake.

The effectiveness of nutritional interventions may be dependent on individual needs. Nutritional support can therefore be guided by energy expenditure levels to estimate requirements, but this might not be suitable in all clinical settings. In this way, patients do not receive a standard nutritional supplementation regimen, but receive calories and protein for their individual energy goal. The daily energy and protein delivered with this method was significantly higher than in the control group receiving standard nutritional care in a study by Anbar et al ${ }^{109}$. This was related to a significantly lower incidence of complications in the hip fracture patients, mainly due to a reduction in infectious complications. However, only a select group of hip fracture patients were eligible for inclusion, since a wide range of exclusion criteria was applied. The trial was stopped early due to poor recruitment, probably biasing results. A trial of Eneroth et al. ${ }^{82}$ also investigated the effects of nutritional supplementation in relation to calculated optimal energy intake in hip fracture patients. Supplementation was administered combining enteral and 
parenteral feeding. Intravenous supplementation of $1000 \mathrm{kcal} /$ day was given for 3 consecutive days, followed by oral supplementation of $400 \mathrm{kcal}$ including $40 \mathrm{~g}$ of protein for 4 days. Hip fracture patients were compared with a control group receiving ordinary hospital food. The average daily energy intake during the first 3 days was $665 \mathrm{kcal}$ in the control group and $1468 \mathrm{kcal}$ in the treatment group. This difference was still significant when compared for the total intervention period of 10 days between groups ( $916 \mathrm{kcal} /$ day vs $1296 \mathrm{kcal} /$ day). For the intervention group it means that they received $85 \%$ of the calculated daily optimal energy intake, but the control group reached only $54 \%$. Complication rate (urinary tract infection, wound infection, pneumonia) was significantly lower in the intervention group, with $15 \%$ having at least one complication vs $70 \%$ of the patients in the control group. No difference in mortality rate was seen between groups. However, major limitations apply to this study. Patients with previous functional impairments other than the hip facture were excluded from the study. Furthermore, this intervention is usually reserved for people with non-functioning gastro-intestinal tracts. It involves risks of adverse events and limits mobilisation of patients. Consequently, it is not desired to make this intervention widely available for elderly hip fracture patients. However, the message that can be drawn from these studies is that increasing energy intake to almost optimal levels in elderly hip fracture patients may actually affect outcomes in a positive way.

Nutritional status can be reflected by serum albumin status in patients. In a randomised trial by Botella-Carretero et al., a significant change in serum albumin at follow-up was seen in hip fracture patients receiving a nutritional intervention, and a significant difference compared with controls. In this study, supplementation of $400 \mathrm{kcal}$ including $40 \mathrm{~g}$ of protein started already prior to surgery in normally nourished or mildly undernourished hip fracture patients ${ }^{110}$. Higher daily protein intake was associated with less postoperative complications. Thus, perioperative supplementation of a protein rich nutritional supplement may result in improved nutritional status and less complications in undernourished hip fracture patients. On the other hand, use of supplementation might not be beneficial in hip fracture patients without malnutrition. Supplementation of $500 \mathrm{kcal}$ including or without $37.6 \mathrm{~g}$ of protein per day in normally nourished hip fracture patients both had no effect on nutritional status during in-hospital follow-up, as assessed by albumin and BMI ${ }^{111}$. Hospital length of stay was also not different between the groups in this study.

Following from the above, poor compliance with the nutritional supplement can result in considerable variation between subjects, as was also seen in a study by 
Bruce et al ${ }^{112}$. Intervention group patients were allocated to supplementation of 352 kcal per day. However, no significant difference in weight changes or clinical outcomes (length of hospital stay, place of discharge, mortality) were seen between the intervention and control group. With a variation of 0 to 28 cans of ingested supplement, low study compliance may explain the lack of clinical improvements. However, more compliant patients had significantly less loss of weight than noncompliant patients.

In conclusion, studies on nutritional supplementation in hip fracture patients during hospital admission vary widely in terms of intervention, exclusion criteria, numbers of included patients, and outcomes. Supplementation during hospitalisation may result in improvement of nutritional status, especially when paying attention to individual needs. This can results in a lower complication rate after hip fracture, but none of the cited studies show an effect on mortality. Adequately sized studies, using high quality designs are required to draw more robust conclusions in the future.

\section{Nutritional supplementation during rehabilitation}

Nutritional supplementation may not only be effective during hospitalization, since recovery after a hip fracture also includes an intensive rehabilitation period. The first randomised controlled trial investigating the effect of protein-rich nutritional supplementation during both acute hospital and rehabilitation stay on outcomes in elderly hip fracture patients was from Delmi et al. and published in the Lancet ${ }^{93}$. Patients received an oral nutritional supplement containing $20 \mathrm{~g}$ of protein and 254 kcal once daily for a mean of 32 days. During hospitalisation, despite offering supplementation, nutritional requirements were not met in both the supplemented and non-supplemented groups. Unfavourable outcome was the primary outcome, and was defined as the number of participants who died plus the number of survivors with one major complication or two minor complications. Clinical unfavourable outcomes were lower in the supplemented group, with significantly lower combined rates of complications and death (44 vs $87 \%$ ) during hospital stay, and even 6 months after the fracture (40 vs 74\%). The median duration of acute and rehabilitation hospital stay taken together was significantly shorter in the supplemented group (24 vs 40 days). However, many comorbidities were excluded in this study, such as dementia, renal, hepatic, or endocrine disease, as well as patients using steroids or calcitonin. Only 59 patients were included in the trial. This limits the external validity of this study. 
Other studies started the nutritional supplementation not postoperatively, but at the beginning of the rehabilitation period. An example of this is a randomised controlled trial of Myint et al. ${ }^{113}$, in which supplementation of 18-24 g protein in a $500 \mathrm{kcal}$ containing nutritional supplement was given during admission for a maximum of 4 weeks to a rehabilitation ward and compared with the normal rehabilitation-centre diet. Four types of nutritional supplements were offered, according to patients' preferences. The investigators reported a significant shorter length of stay at the rehabilitation ward by 3.8 days (26.2 days versus 29.9 days) for the group receiving nutritional supplementation. There was no effect in mortality rates 6 months post-discharge. No real rehabilitation benefits were seen, since there was no difference in functional independence or mobility between the groups, and even a higher proportion of patients in the intervention group were discharged to nursing homes (19/61 versus 15/60). The study excluded patients having a BMI >25 $\mathrm{kg} / \mathrm{m}^{2}$, thereby targeting on a selected group of hip fracture patients, namely patients who were malnourished. Outcome data were incomplete, due to compliance to the supplementation of $78 \%$.

In a study of Tidermark et al., supplementation of an oral protein-only nutritional supplement $(20 \mathrm{~g})$, compared with controls receiving no intervention, was given for 6 months ${ }^{114}$. Lean body mass decreased in both the control group and the protein-supplemented group. Activities of daily living remained at high level in the intervention group, but declined significantly in the control group. The decline in health-related quality of life was least pronounced in the intervention group at 6 months. Important differences were however seen in baseline characteristics between the groups concerning the type of fracture. In the control group, a higher proportion of patients experienced fracture-related complications than patients in the intervention group (7/17 versus 4/18), indicating a need for re-operation or problems during rehabilitation. The contribution of the nutritional intervention is probably overestimated, because outcome results (activities of daily living en healthrelated quality of life) are influenced by the fracture-related complications in the control group.

Four randomised controlled trials investigated outcomes in hip fracture patients whom ingested a protein-energy supplement versus an isocaloric control product or placebo, to study the beneficial effect of protein specifically. The first, a trial of Tkatch et al. ${ }^{115}$, offered nutritional supplementation for a mean of 38 days during rehabilitation. One product contained $250 \mathrm{kcal}$ with $20.4 \mathrm{~g}$ of protein, and the other product contained $250 \mathrm{kcal}$ without protein. The group receiving the proteinrich nutritional supplement had a significantly lower rate of complications and death 
(52 vs $80 \%$ ) up to 7 months post-fracture. Furthermore, the median hospital stay was significantly lower in the protein-supplemented group (acute 23.5 vs 24.7 days, rehabilitation 78.6 vs 91.8 days). However, although the number of complications was reported, the numbers of participants with complications were not, thereby potentially overestimating the lower complication rate in the supplemented group. Patients with a wide range of medical comorbidities were excluded in this trial. Patients in the intervention group with poor compliance were excluded for the data analysis. The second trial comparing a protein-rich supplement with an isocaloric control was of Schürch et al ${ }^{116}$. Hip fracture patients ingested $20 \mathrm{~g}$ of protein supplementation per day versus an isocaloric placebo, and were followed-up after 6 months. The median rehabilitation stay was significantly shorter for patients who received protein supplements than for control, reporting a difference of 21 days (33 vs 54 days). However, no difference in muscle strength was reported in this trial, which could have been an explanation for the difference in rehabilitation length of stay. The third study is a Spanish study comparing protein supplementation versus a placebo ${ }^{117}$. Hip fracture patients received a supplement containing $20 \mathrm{~g}$ of protein for 60 days. No differences in return to functional status 6 months post-fracture, measured by the Barthell index, mobility index, and the use of walking aids, were seen between groups. No difference in fracture-related mortality was seen (13 vs $10 \%$ ), but unfavourable outcomes (death or complications by the end of the study) were significantly reduced by protein supplementation at the end of the study. In the fourth study of Neumann ${ }^{118}$, supplementation of $+/-18 \mathrm{~g}$ and $30 \mathrm{~g}$ of liquid protein supplement was compared in hip fracture patients during stay in a rehabilitation clinic for 28 days. The group ingesting the higher amounts of protein showed significantly greater improvement of serum albumin over the 28-day period. However, no outcomes differences regarding complications or rehabilitation length of stay were observed.

To summarise the findings of the above studies, offering multinutrient or protein-rich supplementation during the rehabilitation period resulted in shorter length of rehabilitation stay in four studies and lower rates of unfavourable outcomes in three studies, but a convincing effect on mobility, independence, muscle strength or muscle function was not observed. Because of the differences between studies and several shortcomings on all studies, no robust conclusions can be drawn. However, nutritional interventions may have an overall positive effect during rehabilitation in hip fracture patients. 


\section{Conclusions}

Nutritional studies are challenging because of the complexity of modulating the total daily energy and/or protein intake. It is a challenge to change or add one nutrient without influencing the others in order to get a clear view of its effect. The currently available literature is insufficient to draw robust conclusions, but studies seem to have a tendency towards a positive effect. While appetite is often impaired in hip fracture patients, a further decline in voluntary food intake is not seen in nutritional intervention studies. In selected patients, for example experiencing cognitive impairments, feeding support by dietetic assistants or nurses can encourage an appropriate intake. Reaching the individual optimal energy intake may be key in the efficacy of nutritional interventions in both the clinical setting and in studies. Trials where energy and protein requirements were individualised, and nutritional supplementation was optimised for the individual patient, more often showed positive effects of the intervention. Adequate nutritional supplementation may be useful in decreasing complications and shortening length of stay both in hospital and during rehabilitation. Furthermore, there is low-quality evidence that mortality rates can be reduced, although results between studies are conflicting. Malnutrition leads to muscle wasting and reduced muscle function, which both are highly important during recovery after hip fracture. Up until now however, trials investigating nutritional interventions in hip fracture patients do not show persuasive evidence for improvement of functional recovery or discharge destination from hospital. The effect of nutritional supplementation may be limited by poor compliance. Strategies need to be implemented to ensure adequate intake meeting energy and/or protein requirements in the individual patient. In addition, adequately designed and executed clinical trials are required to give us robust conclusions about the effectiveness of nutritional support in elderly hip fracture patients. 


\section{References}

1. Farahmand BY, Michaëlsson $\mathrm{K}$, Ahlbom A, Ljunghall S, Baron JA, Group S. Survival after hip fracture. Osteoporosis International. 2005;16(12):1583-1590.

2. Peeters CMM, Visser E, Van de Ree CL, Gosens T, Den Oudsten BL, De Vries J. Quality of life after hip fracture in the elderly: A systematic literature review. Injury. 2016;47(7):1369-1382.

3. Bentler SE, Liu L, Obrizan M, et al. The aftermath of hip fracture: discharge placement, functional status change, and mortality. American journal of epidemiology. 2009;170(10):1290-1299.

4. Bachrach-Lindström $\mathrm{M}$, Unosson $\mathrm{M}$, Ek AC, Arnqvist HJ. Assessment of nutritional status using biochemical and anthropometric variables in a nutritional intervention study of women with hip fracture. Clinical nutrition (Edinburgh, Scotland). 2001;20(3):217-223.

5. Kanis JA, Odén A, McCloskey EV, et al. A systematic review of hip fracture incidence and probability of fracture worldwide. Osteoporosis international : a journal established as result of cooperation between the European Foundation for Osteoporosis and the National Osteoporosis Foundation of the USA. 2012;23(9):2239-2256.

6. Dhanwal DK, Cooper C, Dennison EM. Geographic variation in osteoporotic hip fracture incidence: the growing importance of asian influences in coming decades. Journal of osteoporosis. 2010;2010:757102.

7. Leslie WD, O'Donnell S, Jean S, et al. Trends in hip fracture rates in Canada. $J A M A$ : the journal of the American Medical Association. 2009;302(8):883889.

8. Holt G, Smith R, Duncan K, Hutchison JD, Reid D. Changes in population demographics and the future incidence of hip fracture. Injury. 2009;40(7):722-726.

9. Icks A, Arend W, Becker C, Rapp K, Jungbluth $\mathrm{P}$, Haastert B. Incidence of hip fractures in Germany, 1995-2010. Archives of osteoporosis. 2013;8:140.

10. Hartholt KA, van Beeck EF, Polinder $S$, et al. Societal consequences of falls in the older population: injuries, healthcare costs, and long-term reduced quality of life. The Journal of trauma. 2011;71(3):748-753.

11. Johnell O. The socioeconomic burden of fractures: today and in the 21st century. The American journal of medicine. 1997;103(2A).

12. Brainsky A, Glick H, Lydick E, et al. The economic cost of hip fractures in community-dwelling older adults: a prospective study. Journal of the American Geriatrics Society. 1997;45(3):281-287.

13. Haentjens P, Lamraski G, Boonen S. Costs and consequences of hip fracture occurrence in old age: an economic perspective. Disability and rehabilitation. 2005;27(18-19):1129-1141.

14. Haentjens $\mathrm{P}$, Magaziner J, ColónEmeric CS, et al. Meta-analysis: excess mortality after hip fracture among older women and men. Annals of internal medicine. 2010;152(6):380-390.

15. Le Manach Y, Collins G, Bhandari M, et al. Outcomes After Hip Fracture Surgery Compared With Elective Total Hip Replacement. JAMA : the journal of the American Medical Association. 2015;314(11):1159-1166.

16. Foster MR, Heppenstall RB, Friedenberg ZB, Hozack WJ. A prospective assessment of nutritional status and complications in patients with fractures of the hip. Journal of orthopaedic trauma. 1990;4(1):49-57.

17. Mariconda M, Costa GG, Cerbasi S, et al. The determinants of mortality and morbidity during the year following fracture of the hip: a prospective 
study. The bone \& joint journal. 2015;97$\mathrm{B}(3): 383-390$.

18. Haentjens $\mathrm{P}$, Autier $\mathrm{P}$, Barette M, et al. Survival and functional outcome according to hip fracture type: a oneyear prospective cohort study in elderly women with an intertrochanteric or femoral neck fracture. Bone. 2007;41(6):958-964.

19. Braithwaite SR, Col NF, Wong JB. Estimating Hip Fracture Morbidity, Mortality and Costs. Journal of the American Geriatrics Society. 2003;51(3):364-370.

20. Holt G, Smith R, Duncan K, Finlayson DF, Gregori A. Early mortality after surgical fixation of hip fractures in the elderly: an analysis of data from the scottish hip fracture audit. The Journal of bone and joint surgery British volume. 2008;90(10):1357-1363.

21. Kim SM, Moon YW, Lim SJ, et al. Prediction of survival, second fracture, and functional recovery following the first hip fracture surgery in elderly patients. Bone. 2012;50(6):1343-1350.

22. Vochteloo AJ, Borger van der Burg BL, Tuinebreijer WE, et al. Do clinical characteristics and outcome in nonagenarians with a hip fracture differ from younger patients? Geriatrics \& gerontology international. 2013;13(1):190-197.

23. Empana J-PP, Dargent-Molina P, Bréart G, Group E. Effect of hip fracture on mortality in elderly women: the EPIDOS prospective study. Journal of the American Geriatrics Society. 2004;52(5):685-690.

24. Meyer HE, Tverdal A, Falch JA, Pedersen JI. Factors associated with mortality after hip fracture. Osteoporosis international : a journal established as result of cooperation between the European Foundation for Osteoporosis and the National Osteoporosis Foundation of the USA. 2000;11(3):228-232.

25. White BL, Fisher WD, Laurin CA. Rate of mortality for elderly patients after fracture of the hip in the 1980 s. J Bone Joint Surg Am. 1987;69(9):1335-1340.

26. Aharonoff GB, Koval KJ, Skovron ML, Zuckerman JD. Hip fractures in the elderly: predictors of one year mortality. Journal of orthopaedic trauma. 1997;11(3):162-165.

27. Holt G, Smith R, Duncan K, Hutchison JD, Gregori A, Reid D. Outcome after sequential hip fracture in the elderly. The Journal of bone and joint surgery American volume. 2012;94(19):18011808.

28. Gholve PA, Kosygan KP, Sturdee SW, Faraj AA. Multidisciplinary integrated care pathway for fractured neck of femur. A prospective trial with improved outcome. Injury. 2005;36(1):93.

29. Eriksson M, Kelly-Pettersson P, Stark A, Ekman AK, Sköldenberg O. 'Straight to bed' for hip-fracture patients: a prospective observational cohort study of two fast-track systems in 415 hips. Injury. 2012;43(12):21262131.

30. Kehlet H, Wilmore DW. Multimodal strategies to improve surgical outcome. American journal of surgery. 2002;183(6):630-641.

31. Nordström P, Gustafson $Y$, Michaëlsson K, Nordström A. Length of hospital stay after hip fracture and short term risk of death after discharge: a total cohort study in Sweden. BMJ (Clinical research ed). 2015;350.

32. Haentjens $\mathrm{P}$, Autier $\mathrm{P}$, Barette $\mathrm{M}$, Boonen S, Group B. Predictors of functional outcome following intracapsular hip fracture in elderly women. A one-year prospective cohort study. Injury. 2005;36(7):842850.

33. Cranney AB, Coyle D, Hopman WM, Hum V, Power B, Tugwell PS. Prospective evaluation of preferences and quality of life in women with hip fractures. The Journal of rheumatology. 2005;32(12):2393-2399. 
34. Vochteloo AJ, Moerman S, Tuinebreijer WE, et al. More than half of hip fracture patients do not regain mobility in the first postoperative year. Geriatrics $\mathcal{E}$ gerontology international. 2013;13(2):334-341.

35. Zijlstra GAR, Haastregt JCM, Eijk JTM. Prevalence and correlates of fear of falling, and associated avoidance of activity in the general population of community-living older people. Age and .... 2007.

36. Tinetti ME, Williams CS. Falls, injuries due to falls, and the risk of admission to a nursing home. The New England journal of medicine. 1997;337(18):12791284.

37. Vochteloo AJ, van Vliet-Koppert ST, Maier AB, et al. Risk factors for failure to return to the pre-fracture place of residence after hip fracture: a prospective longitudinal study of 444 patients. Archives of orthopaedic and trauma surgery. 2012;132(6):823-830.

38. Parkkari J, Kannus P, Palvanen M, et al. Majority of hip fractures occur as a result of a fall and impact on the greater trochanter of the femur: a prospective controlled hip fracture study with 206 consecutive patients. Calcified tissue international. 1999;65(3):183-187.

39. Tinetti ME, Speechley M, Ginter SF. Risk factors for falls among elderly persons living in the community. The New England journal of medicine. 1988;319(26):1701-1707.

40. Graafmans WC, Ooms ME, Hofstee HM, Bezemer PD, Bouter LM, Lips P. Falls in the elderly: a prospective study of risk factors and risk profiles. American journal of epidemiology. 1996;143(11):1129-1136.

41. Pohl P, Nordin E, Lundquist A, Bergström U, Lundin-Olsson L. Community-dwelling older people with an injurious fall are likely to sustain new injurious falls within 5 years--a prospective long-term followup study. BMC geriatrics. 2014;14:120.
42. Blake AJ, Morgan K, Bendall MJ, et al. Falls by elderly people at home: prevalence and associated factors. Age and ageing. 1988;17(6):365-372.

43. Hartholt KA, Stevens JA, Polinder S, van der Cammen TJ, Patka P. Increase in fall-related hospitalizations in the United States, 2001-2008. The Journal of trauma. 2011;71(1):255-258.

44. Fukagawa NK, Wolfson L, Judge J, Whipple R, King M. Strength Is a Major Factor in Balance, Gait, and the Occurrence of Falls. The Journals of Gerontology Series A: Biological Sciences and Medical Sciences. 1995;50A(Special):64-67.

45. Moreland JD, Richardson JA, Goldsmith $\mathrm{CH}$, Clase CM. Muscle weakness and falls in older adults: a systematic review and meta-analysis. Journal of the American Geriatrics Society. 2004;52(7):1121-1129.

46. Cruz-Jentoft AJ, Baeyens JP, Bauer JM, et al. Sarcopenia: European consensus on definition and diagnosis: Report of the European Working Group on Sarcopenia in Older People. Age and ageing. 2010;39(4):412-423.

47. Fielding RA, Vellas B, Evans WJ, et al. Sarcopenia: an undiagnosed condition in older adults. Current consensus definition: prevalence, etiology, and consequences. International working group on sarcopenia. Journal of the American Medical Directors Association. 2011;12(4):249-256.

48. Bahat G, Tufan A, Tufan F, et al. Cutoff points to identify sarcopenia according to European Working Group on Sarcopenia in Older People (EWGSOP) definition. Clinical nutrition (Edinburgh, Scotland). 2016.

49. Thomas DR. Sarcopenia. Clinics in geriatric medicine. 2010;26(2):331-346.

50. English KL, Paddon-Jones D. Protecting muscle mass and function in older adults during bed rest. Current opinion in clinical nutrition and metabolic care. 2010;13(1):34-39.

51. Calvani R, Martone AM, Marzetti E, et al. Pre-Hospital Dietary Intake 
Correlates with Muscle Mass at the Time of Fracture in Older HipFractured Patients. Frontiers in aging neuroscience. 2014;6:269.

52. Buford TW, Anton SD, Judge AR, et al. Models of accelerated sarcopenia: critical pieces for solving the puzzle of age-related muscle atrophy. Ageing research reviews. 2010;9(4):369-383.

53. Sousa AS, Guerra RS, Fonseca I, Pichel F, Amaral TF. Sarcopenia and length of hospital stay. European journal of clinical nutrition. 2015.

54. Kimyagarov S, Klid R, Fleissig Y, Kopel B, Arad M, Adunsky A. Skeletal muscle mass abnormalities are associated with survival rates of institutionalized elderly nursing home residents. The journal of nutrition, health E aging. 2012;16(5):432-436.

55. Gariballa S, Alessa A. Sarcopenia: prevalence and prognostic significance in hospitalized patients. Clinical nutrition (Edinburgh, Scotland). 2013;32(5):772-776.

56. Sousa AS, Guerra RS, Fonseca I, Pichel F, Amaral TF. Sarcopenia among hospitalized patients - A crosssectional study. Clinical nutrition (Edinburgh, Scotland). 2014.

57. Martinez BP, Batista AK, Gomes IB, Olivieri FM, Camelier FW, Camelier AA. Frequency of sarcopenia and associated factors among hospitalized elderly patients. BMC musculoskeletal disorders. 2015;16(1):108.

58. Hida $\mathrm{T}$, Ishiguro $\mathrm{N}$, Shimokata $\mathrm{H}$, et al. High prevalence of sarcopenia and reduced leg muscle mass in Japanese patients immediately after a hip fracture. Geriatrics \& Gerontology International. 2013;13(2):413-420.

59. González-Montalvo JI, Alarcón T, Gotor P, et al. Prevalence of sarcopenia in acute hip fracture patients and its influence on shortterm clinical outcome. Geriatrics \& gerontology international. 2015.

60. Di Monaco M, Castiglioni C, De Toma E, et al. Presarcopenia and sarcopenia in hip-fracture women: prevalence and association with ability to function in activities of daily living. Aging clinical and experimental research. 2015;27(4):465-472.

61. Singh FMA, Singh NA, Hansen RD, et al. Methodology and Baseline Characteristics for the Sarcopenia and Hip Fracture Study: A 5-Year Prospective Study. The Journals of Gerontology Series A: Biological Sciences and Medical Sciences. 2009;64A(5):568574.

62. D'Adamo C, Hawkes WG, Miller R, et al. Short-term changes in body composition after surgical repair of hip fracture. Age and Ageing. 2014;43(2):275-280.

63. Kramer IF, Snijders T, Smeets JS, et al. Extensive Type II Muscle Fiber Atrophy in Elderly Female Hip Fracture Patients. The journals of gerontology Series A, Biological sciences and medical sciences. 2017.

64. Landi F, Liperoti R, Russo A, et al. Sarcopenia as a risk factor for falls in elderly individuals: results from the ilSIRENTE study. Clinical nutrition. 2012;31(5):652-658.

65. Lang T, Cauley JA, Tylavsky F, Bauer D, Cummings S, Harris TB. Computed Tomographic Measurements of Thigh Muscle Cross-Sectional Area and Attenuation Coefficient Predict Hip Fracture: The Health, Aging, and Body Composition Study. Journal of Bone and Mineral Research. 2010;25(3):513-519.

66. Lang T, Koyama A, Li C, et al. Pelvic body composition measurements by quantitative computed tomography: association with recent hip fracture. Bone. 2008;42(4):798-805.

67. Malkov S, Cawthon PM, Peters KW, et al. Hip Fractures Risk in Older Men and Women Associated with DXADerived Measures of Thigh Subcutaneous Fat Thickness, CrossSectional Muscle Area, and Muscle Density. Journal of bone and mineral research : the official journal of the American Society for Bone and Mineral Research. 2015. 
68. Vetrano DL, Landi F, Volpato S, et al. Association of sarcopenia with shortand long-term mortality in older adults admitted to acute care wards: results from the CRIME study. The journals of gerontology Series $A$, Biological sciences and medical sciences. 2014;69(9):1154-1161.

69. Landi F, Calvani R, Ortolani E, et al. The association between sarcopenia and functional outcomes among older patients with hip fracture undergoing in-hospital rehabilitation. Osteoporosis international : a journal established as result of cooperation between the European Foundation for Osteoporosis and the National Osteoporosis Foundation of the USA. 2017.

70. Cederholm T, Barazzoni R, Austin P, et al. ESPEN guidelines on definitions and terminology of clinical nutrition. Clinical nutrition (Edinburgh, Scotland). 2017;36(1):49-64.

71. Bauer J, Biolo G, Cederholm T, et al. Evidence-based recommendations for optimal dietary protein intake in older people: a position paper from the PROT-AGE Study Group. Journal of the American Medical Directors Association. 2013;14(8):542-559.

72. Nowson C, O'Connell S. Protein Requirements and Recommendations for Older People: A Review. Nutrients. 2015;7(8):6874-6899.

73. Rodriguez NR. Introduction to Protein Summit 2.0: continued exploration of the impact of high-quality protein on optimal health. The American journal of clinical nutrition. 2015.

74. Weimann A, Braga M, Carli F, et al. ESPEN guideline: Clinical nutrition in surgery. Clinical nutrition (Edinburgh, Scotland). 2017;36(3):623-650.

75. Sullivan DH, Sun S, Walls RC. Proteinenergy undernutrition among elderly hospitalized patients: a prospective study. JAMA : the journal of the American Medical Association. 1999;281(21):2013-2019.

76. Allison SP, Rawlings J, Field J, Bean N, Stephen AD. Nutrition in the elderly hospital patient Nottingham studies. The journal of nutrition, health $\mathcal{E}$ aging. 2000;4(1):54-57.

77. Keys A. The residues of malnutrition and starvation. Science (New York, NY). 1950;112(2909):371-373.

78. Lesourd BM. Nutrition and immunity in the elderly: modification of immune responses with nutritional treatments. The American journal of clinical nutrition. 1997;66(2).

79. Lindholm C, Sterner E, Romanelli M, et al. Hip fracture and pressure ulcers - the Pan-European Pressure Ulcer Study - intrinsic and extrinsic risk factors. International wound journal. 2008;5(2):315-328.

80. Allard JP, Keller H, Jeejeebhoy KN, et al. Malnutrition at Hospital Admission-Contributors and Effect on Length of Stay. Journal of Parenteral and Enteral Nutrition. 2015;40(4):487497.

81. Houwing $\mathrm{RH}$, Mathus-Vliegen EM. [Dietary supplements such as nutrient drinks have no role in the prevention of pressure sores]. Nederlands tijdschrift voor geneeskunde. 2007;151(18):1015.

82. Eneroth M, Olsson U-BB, Thorngren K-GG. Nutritional supplementation decreases hip fracture-related complications. Clinical orthopaedics and related research. 2006;451:212-217.

83. Patterson BM, Cornell CN, Carbone B, Levine B, Chapman D. Protein depletion and metabolic stress in elderly patients who have a fracture of the hip. The Journal of bone and joint surgery American volume. 1992;74(2):251-260.

84. Fabian E, Gerstorfer I, Thaler HW, Stundner H, Biswas P, Elmadfa I. Nutritional supplementation affects postoperative oxidative stress and duration of hospitalization in patients with hip fracture. Wiener klinische Wochenschrift. 2011;123(3-4):88-93.

85. Bell JJ, Pulle RC, Crouch AM, Kuys SS, Ferrier RL, Whitehouse SL. Impact of malnutrition on 12-month mortality 
following acute hip fracture. ANZ journal of surgery. 2016;86(3):157-161.

86. Bachrach-Lindström $\mathrm{M}$, Johansson $\mathrm{T}$, Unosson M, Ek AC, Wahlström $\mathrm{O}$. Nutritional status and functional capacity after femoral neck fractures: a prospective randomized one-year follow-up study. Aging (Milan, Italy). 2000;12(5):366-374.

87. Bastow MD, Rawlings J, Allison SP. Undernutrition, hypothermia, and injury in elderly women with fractured femur: an injury response to altered metabolism? Lancet (London, England). 1983;1(8317):143-146.

88. Chwals WJ, Bistrian BR. Role of exogenous growth hormone and insulin-like growth factor $I$ in malnutrition and acute metabolic stress: a hypothesis. Critical care medicine. 1991;19(10):1317-1322.

89. Fleck A. Clinical and nutritional aspects of changes in acute-phase proteins during inflammation. The Proceedings of the Nutrition Society. 1989;48(3):347-354.

90. Volkert D, Berner YN, Berry E, et al. ESPEN Guidelines on Enteral Nutrition: Geriatrics. Clinical nutrition (Edinburgh, Scotland). 2006;25(2):330360.

91. Cederholm T, Bosaeus I, Barazzoni R, et al. Diagnostic criteria for malnutrition, an ESPEN consensus statement. Clinical nutrition. 2015;34(3):335-340.

92. Martínez-Ramírez MJ, DelgadoMartínez AD, Ruiz-Bailén $M$, de la Fuente C, Martínez-González MÁ, Delgado-Rodríguez M. Protein intake and fracture risk in elderly people: a case-control study. Clinical nutrition (Edinburgh, Scotland). 2012;31(3):391395.

93. Delmi $\mathrm{M}$, Rapin $\mathrm{CH}$, Bengoa JM, Delmas PD, Vasey H, Bonjour JP. Dietary supplementation in elderly patients with fractured neck of the femur. Lancet (London, England). 1990;335(8696):1013-1016.
94. Nematy M, Hickson M, Brynes AE, Ruxton $\mathrm{CH}$, Frost GS. Vulnerable patients with a fractured neck of femur: nutritional status and support in hospital. Journal of human nutrition and dietetics: the official journal of the British Dietetic Association. 2006;19(3):209-218.

95. Koval KJ, Maurer SG, Su ET, Aharonoff GB. The effects of nutritional status on outcome after hip fracture.... of orthopaedic trauma. 1999.

96. Lumbers M, New SA, Gibson S, Murphy MC. Nutritional status in elderly female hip fracture patients: comparison with an age-matched home living group attending day centres. The British journal of nutrition. 2001;85(6):733-740.

97. Li H-JJ, Cheng H-SS, Liang J, Wu CCC, Shyu Y-ILI. Functional recovery of older people with hip fracture: does malnutrition make a difference? Journal of advanced nursing. 2013;69(8):1691-1703.

98. Eneroth M, Olsson U-BB, Thorngren K-GG. Insufficient fluid and energy intake in hospitalised patients with hip fracture. A prospective randomised study of 80 patients. Clinical nutrition (Edinburgh, Scotland). 2005;24(2):297-303.

99. Carlsson P, Tidermark J, Ponzer S, Söderqvist A, Cederholm T. Food habits and appetite of elderly women at the time of a femoral neck fracture and after nutritional and anabolic support. Journal of human nutrition and dietetics : the official journal of the British Dietetic Association. 2005;18(2):117-120.

100. Jallut D, Tappy L, Kohut M, Bloesch D. Energy balance in elderly patients after surgery for a femoral neck fracture. ... of Parenteral and .... 1990.

101. Paillaud E, Bories PN, Le Parco JC, Campillo B. Nutritional status and energy expenditure in elderly patients with recent hip fracture during a 2month follow-up. The British journal of nutrition. 2000;83(2):97-103. 
102. Miller MD, Bannerman E, Daniels LA, Crotty M. Lower limb fracture, cognitive impairment and risk of subsequent malnutrition: a prospective evaluation of dietary energy and protein intake on an orthopaedic ward. European journal of clinical nutrition. 2006;60(7):853-861.

103. Stableforth PG. Supplement feeds and nitrogen and calorie balance following femoral neck fracture. The British journal of surgery. 1986;73(8):651-655.

104. Hessov I. Energy and protein intake in elderly patients in an orthopedic surgical ward. Acta chirurgica Scandinavica. 1977;143(3):145-149.

105. Bastow MD, Rawlings J, Allison SP. Benefits of supplementary tube feeding after fractured neck of femur: a randomised controlled trial. British medical journal. 1983;287(6405):15891592.

106. Hartgrink $\mathrm{HH}$, Wille J, König $\mathrm{P}$, Hermans J, Breslau PJ. Pressure sores and tube feeding in patients with a fracture of the hip: a randomized clinical trial. Clinical nutrition (Edinburgh, Scotland). 1998;17(6):287292.

107. Sullivan DH, Nelson CL, Klimberg VS, Bopp MM. Nightly enteral nutrition support of elderly hip fracture patients: a pilot study. Journal of the American College of Nutrition. 2004;23(6):683-691.

108. Sullivan DH, Nelson CL, Bopp MM, Puskarich-May CL, Walls RC. Nightly enteral nutrition support of elderly hip fracture patients: a phase I trial. Journal of the American College of Nutrition. 1998;17(2):155-161.

109. Anbar R, Beloosesky Y, Cohen J, et al. Tight calorie control in geriatric patients following hip fracture decreases complications: a randomized, controlled study. Clinical nutrition (Edinburgh, Scotland). 2014;33(1):23-28.

110. Botella-Carretero JII, Iglesias B, Balsa JAA, Arrieta F, Zamarrón I, Vázquez C. Perioperative oral nutritional supplements in normally or mildly undernourished geriatric patients submitted to surgery for hip fracture: a randomized clinical trial. Clinical nutrition (Edinburgh, Scotland). 2010;29(5):574-579.

111. Botella-Carretero JII, Iglesias B, Balsa JAA, Zamarrón I, Arrieta F, Vázquez C. Effects of oral nutritional supplements in normally nourished or mildly undernourished geriatric patients after surgery for hip fracture: a randomized clinical trial. JPEN Journal of parenteral and enteral nutrition. 2008;32(2):120-128.

112. Bruce D, Laurance I, McGuiness M, Ridley M, Goldswain P. Nutritional supplements after hip fracture: poor compliance limits effectiveness. Clinical nutrition (Edinburgh, Scotland). 2003;22(5):497-500.

113. Myint MWW, Wu J, Wong E, et al. Clinical benefits of oral nutritional supplementation for elderly hip fracture patients: a single blind randomised controlled trial. Age and ageing. 2013;42(1):39-45.

114. Tidermark J, Ponzer S, Carlsson P, et al. Effects of protein-rich supplementation and nandrolone in lean elderly women with femoral neck fractures. Clinical nutrition. 2004;23(4):587-596.

115. Tkatch L, Rapin CH, Rizzoli R, et al. Benefits of oral protein supplementation in elderly patients with fracture of the proximal femur. Journal of the American College of Nutrition. 1992;11(5):519-525.

116. Schürch MA, Rizzoli R, Slosman D, Vadas L, Vergnaud P, Bonjour JP. Protein supplements increase serum insulin-like growth factor-I levels and attenuate proximal femur bone loss in patients with recent hip fracture. A randomized, double-blind, placebocontrolled trial. Annals of internal medicine. 1998;128(10):801-809.

117. Espaulella J, Guyer H, Diaz-Escriu F, Mellado-Navas JA, Castells M, Pladevall M. Nutritional 
supplementation of elderly hip fracture patients. A randomized, double-blind, placebo-controlled trial. Age and ageing. 2000;29(5):425-431 .

118. Neumann M, Friedmann J, Roy MAA, Jensen GL. Provision of highprotein supplement for patients recovering from hip fracture. Nutrition (Burbank, Los Angeles County, Calif). 2004;20(5):415-419.

119. Duncan DG, Beck SJ, Hood K, Johansen A. Using dietetic assistants to improve the outcome of hip fracture: a randomised controlled trial of nutritional support in an acute trauma ward. Age and ageing. 2006;35(2):148-153.

120. Hoekstra JC, Goosen JH, de Wolf GS, Verheyen CC. Effectiveness of multidisciplinary nutritional care on nutritional intake, nutritional status and quality of life in patients with hip fractures: a controlled prospective cohort study. Clinical nutrition
(Edinburgh, Scotland). 2011;30(4):455461.

121. Bell JJ, Bauer JD, Capra S, Pulle RC. Multidisciplinary, multi-modal nutritional care in acute hip fracture inpatients - results of a pragmatic intervention. Clinical nutrition (Edinburgh, Scotland). 2014;33(6):11011107.

122. Breedveld-Peters JJJ, Reijven PL, Wyers CE, et al. Integrated nutritional intervention in the elderly after hip fracture. A process evaluation. Clinical nutrition (Edinburgh, Scotland). 2012;31(2):199-205.

123. Wyers CE, Reijven PL, Evers SM, et al. Cost-effectiveness of nutritional intervention in elderly subjects after hip fracture. A randomized controlled trial. Osteoporosis international : a journal established as result of cooperation between the European Foundation for Osteoporosis and the National Osteoporosis Foundation of the USA. 2013;24(1):151-162. 




\section{CHAPTER 6}

Impact of the macronutrient composition of a nutritional supplement on muscle protein synthesis rates in elderly men: a randomised, double blind, controlled trial

I.F. Kramer, L.B. Verdijk, H.M. Hamer, S. Verlaan, Y.C. Luiking, I.W.K. Kouw, J.M. Senden, J. van Kranenburg, A.P. Gijsen, M. Poeze, L.J.C. van Loon 


\section{Abstract}

\section{Background}

An impaired muscle protein synthetic response to feeding likely contributes to muscle loss with aging. There are few data available on the effect of the macronutrient composition of clinical supplements on the postprandial muscle protein synthetic response in older subjects. In this study, our objective is to determine the impact of the macronutrient composition of a nutritional supplement on the postprandial muscle protein synthetic response in elderly men.

\section{Methods}

A total of 45 non-sarcopenic elderly men (age: $69 \pm 1$ year; BMI: $25.7 \pm 0.3 \mathrm{~kg} / \mathrm{m}^{2}$ ) were randomly assigned to ingest $21 \mathrm{~g}$ of leucine-enriched whey protein with carbohydrate $(9 \mathrm{~g})$ and fat ( $3 \mathrm{~g}$ ) (Pro-En), an isonitrogenous amount of $21 \mathrm{~g}$ of leucine-enriched whey protein without carbohydrate and fat (Pro), or an isocaloric mixture $(628 \mathrm{~kJ})$ containing carbohydrate and fat only (En). Stable isotope tracer methodology was applied to assess basal as well as postprandial muscle protein synthesis rates in the three groups.

\section{Results}

Ingestion of protein in the Pro-En and Pro groups significantly increased muscle protein synthesis rates when compared with basal rates (from $0.032 \pm 0.003$ to $0.053 \pm 0.004$ and $0.040 \pm 0.003$ to $0.049 \pm 0.003 \% / h$, respectively; $\mathrm{P}<0.05$ ), whereas ingestion of carbohydrate and fat did not increase muscle protein synthesis rates in the En group (from $0.039 \pm 0.004$ to $0.040 \pm 0.003 \% / h ; P=0.60$ ). Despite the greater postprandial rise in circulating insulin concentration in the Pro-En group, no significant differences were observed in postprandial muscle protein synthesis rates between the Pro-En and Pro groups $(\mathrm{P}=0.32)$. Postprandial muscle protein synthesis rates were higher in the Pro-En vs En group $(\mathrm{P}=0.01)$.

\section{Conclusions}

The ingestion of a nutritional supplement containing $21 \mathrm{~g}$ of leucine-enriched whey protein significantly raises muscle protein synthesis rates in non-sarcopenic elderly men, but co-ingestion of carbohydrate and fat does not modulate the postprandial muscle protein synthetic response to protein ingestion in elderly men. 


\section{Introduction}

Aging is accompanied by the involuntary loss of skeletal muscle mass, strength and function, which has been named sarcopenia ${ }^{1}$. The gradual loss of muscle mass with aging is the result of a structural imbalance between muscle protein synthesis and degradation rates ${ }^{2}$. Basal muscle protein synthesis rates do not seem to differ between healthy young and older adults ${ }^{3,4}$. Therefore, researchers have started to focus on potential age-related differences in the capacity to increase muscle protein synthesis following anabolic stimuli. Food intake (protein and amino acids in particular) is a strong anabolic stimulus ${ }^{5}$, but several studies have shown an attenuated muscle protein synthetic response in the elderly population when compared with young adults ${ }^{6,7}$. Consequently, many research groups in the field of age-related muscle loss are now trying to understand the various factors that modulate the postprandial increase in muscle protein synthesis rates.

The postprandial rise in muscle protein synthesis rate in elderly has been shown to depend on the amount ${ }^{8-10}$, type ${ }^{11,12}$, and amino acid composition of the ingested protein ${ }^{13,14}$. Furthermore, addition of free leucine with protein has been shown to further increase post-prandial muscle protein synthesis rates in elderly men ${ }^{15}$. Co-ingestion of other macronutrients with protein may alter protein digestion and absorption kinetics as well as the endocrine response to feeding, thereby modulating the postprandial rise in muscle protein synthesis rate in elderly. It has previously been demonstrated that the macronutrient composition of a meal does not affect the postprandial muscle protein synthetic response following the ingestion of more slowly digestible protein, such as casein in both old and young 16,17, but it is unclear if similar results can be expected following the ingestion of more rapidly digestible proteins.

Nutritional supplements generally provide all macronutrients and are supplied with the purpose of improving or maintaining the nutritional status of patients. Though even in healthy elderly adults muscle mass slowly declines, this process is accelerated in situations of acute sickness, systemic inflammation, bed rest, or immobilisation ${ }^{18-20}$. In all these cases, nutritional support is specifically required to counteract the loss of muscle mass, thereby reducing the prevalence of complications, preserve quality of life, and improve longevity ${ }^{21-23}$. Additionally, preserving muscle mass in elderly may be equally important to prevent the development of sarcopenia. It might be suitable to use tailored high protein supplements, aimed at stimulating muscle protein synthesis rates to preserve muscle mass in the elderly, without the need for a high energy content ${ }^{24}$. However, the 
effect of the simultaneous ingestion of carbohydrate and fat in such nutritional supplements remains to be elucidated.

The present study investigates the impact of the macronutrient composition of a protein supplement on the postprandial increase in muscle protein synthesis rates in non-sarcopenic elderly men. Stable isotope methodology was applied to assess basal and postprandial muscle protein synthesis rates following the ingestion of a leucine-enriched whey protein supplement plus energy in the form of carbohydrate and fat (Pro-En), an isonitrogenous supplement containing the leucineenriched whey protein only (Pro), and an isocaloric supplement containing only carbohydrate and fat (En). We hypothesised that protein ingestion would result in an increase in muscle protein synthesis rates and that carbohydrate and fat coingestion would further augment this muscle protein synthetic response to protein feeding in the elderly population.

\section{Methods}

\section{Subjects}

A total of 45 healthy, elderly men aged $\geq 65$ year participated in this randomised, double blind, controlled trial. All experiments and analyses were conducted at the Maastricht University Medical Centre+, the Netherlands, unless stated otherwise. All subjects were informed about the experimental procedures and its possible risks prior to providing written consent. The Medical Ethical Committee of the Maastricht University Medical Centre approved this study. The study was conducted in accordance with the Declaration of Helsinki and the International Conference on Harmonisation guidelines for Good Clinical Practice as appropriate for nutritional products. This trial was registered at trialregister.nl as NTR3047.

\section{Pretesting}

All subjects underwent a medical screening. Inclusion criteria were male sex, age 65 year or older, and a BMI from 20 through $30 \mathrm{~kg} / \mathrm{m}^{2}$. Glucose tolerance was assessed by a 2-hour oral glucose tolerance test ${ }^{25}$. Exclusion criteria included all comorbidities and use of medication affecting muscle metabolism and mobility of the limbs, co-morbidities and use of medication interfering with gastric-intestinal function, Diabetes Mellitus, smoking, weight loss $>3 \mathrm{~kg}$ in the last three months, use of protein supplements, participation in an exercise program, and coagulation diseases. Only non-sarcopenic subjects were included, based on the criteria derived from Cruz-Jentoft et al. ${ }^{26}$ and the International Working group on Sarcopenia ${ }^{27}$. 
Subjects were considered to be healthy with a gait speed of $>1.0 \mathrm{~m} / \mathrm{s}$ and a handgrip strength $\geq 30 \mathrm{~kg}$, or $S M M I>8.4 \mathrm{~kg} / \mathrm{m}^{2}$. Gait speed was determined over a $4-\mathrm{m}$ interval, handgrip strength was assessed using a hydraulic handheld dynamometer (Jamar, Jackson, MI), and body composition was determined by dual-energy X-ray absorptiometry (DXA, Hologic Discovery A, Bedford, MA). Skeletal muscle mass index (SMMI) was calculated as appendicular lean mass divided by body height squared. After inclusion, participants were randomly assigned to one of three different groups. Randomisation was computer-generated and all procedures and analysis were performed in a double blind manner. Beverages were prepared by an independent research assistant and coded.

\section{Diet and activity prior to testing}

All subjects consumed the same standardised meal containing $2385 \mathrm{~kJ}$ providing 35 Energy\% (En\%) as carbohydrate, $49 \mathrm{En} \%$ as fat, and $16 \mathrm{En} \%$ as protein, the evening prior to testing All participants were instructed to refrain from any sort of exhaustive physical activity and to keep their diet as constant as possible during three days preceding testing.

\section{Design}

Subjects participated in a single test day during which they ingested a single bolus of one of three test drinks. A primed continuous infusion of L-[ring- $\left.{ }^{13} \mathrm{C}_{6}\right]$-phenylalanine (Cambridge Isotopes Laboratories, Andover, MA) combined with the collection of multiple plasma and muscle biopsy samples before and after the ingestion of the test drink was used to determine both basal and postprandial muscle protein synthesis rates.

\section{Experimental protocol}

Subjects arrived at the laboratory by car or public transport after an overnight fast. A catheter was inserted in an antecubital vein for stable-isotope infusion. A second catheter was inserted in a dorsal hand vein of the contralateral arm and placed in a hot box $\left(60^{\circ} \mathrm{C}\right)$ for arterialised blood sampling ${ }^{28}$. After the collection of a basal plasma and serum sample ( $\mathrm{t}=-240 \mathrm{~min}$ ), the plasma phenylalanine pool was primed with a single dose of intravenously administered L-[ring- $\left.{ }^{13} \mathrm{C}_{6}\right]$-phenylalanine (2 $\mu \mathrm{mol} / \mathrm{kg}$ ). Thereafter, continuous tracer infusion was started with an infusion rate of $0.045 \mu \mathrm{mol} / \mathrm{kg} / \mathrm{min}$ for $\mathrm{L}-\left[\right.$ ring- $\left.{ }^{13} \mathrm{C}_{6}\right]$-phenylalanine. The first muscle biopsy was collected from the vastus lateralis muscle at $\mathrm{t}=-150 \mathrm{~min}$, marking the end of the preinfusion period and the start of the basal period. Subsequently, arterialised blood 
samples were collected every $30 \mathrm{~min}$, and a second muscle biopsy was taken at $\mathrm{t}=0$ min, the end of the basal period. Directly following the second biopsy, subjects ingested a single bolus of one of three test drinks. Blood samples were drawn at $\mathbf{t}=15$, $30,45,60,75,90,105,120,135,150,165,180,210,240,270$ en $300 \mathrm{~min}$. A third and fourth muscle biopsy were taken from the contralateral limb at $t=120 \mathrm{~min}$ and at $\mathrm{t}=300 \mathrm{~min}$. Blood samples were collected in EDTA-containing tubes and centrifuged at $1000 \mathrm{~g}$ for $10 \mathrm{~min}$ at $4^{\circ} \mathrm{C}$. Aliquots of plasma were frozen in liquid nitrogen and stored at $-80{ }^{\circ} \mathrm{C}$. Muscle biopsies were obtained using the percutaneous needle biopsy technique ${ }^{29}$. Muscle samples were dissected carefully and immediately frozen in liquid nitrogen and stored at $-80^{\circ} \mathrm{C}$ until further analysis.

\section{Test drinks}

The test drinks consisted of either a leucine-enriched whey protein nutritional supplement containing carbohydrate, and fat, with an energetic value of $628 \mathrm{~kJ}$ (ProEn); or an isocaloric, non-protein control drink (En); or an isonitrogenous control drink, containing the same amount and type of protein as the Pro-En drink, but without the carbohydrate and fat $390 \mathrm{~kJ}$ (Pro) (table 1). The drinks were manufactured and provided by Nutricia Advanced Medical Nutrition, the Netherlands. A small amount of $\mathrm{L}-\left[\right.$ ring $\left.-{ }^{13} \mathrm{C}_{6}\right]$-phenylalanine was added to the protein containing beverages to maintain a steady state in $\mathrm{L}$-[ring- $\left.{ }^{13} \mathrm{C}_{6}\right]-$ phenylalanine plasma enrichments.

\section{Plasma analyses}

Plasma glucose and insulin concentrations were analysed at Stein Medical Laboratory, Maastricht, using commercially available kits (GLUC3, Roche, Ref: 05168791190, 0.11-41.6 mmol/L, CV 0.7\%; Immunologic, Roche, Ref: 12017547122, $0.2-1000 \mu \mathrm{U} / \mathrm{mL}, \mathrm{CV} 1.9 \%$, respectively). HbA1c content was determined in $3 \mathrm{~mL}$ venous blood samples by high-performance liquid chromatography (Bio-Rad Diamat, Munich, Germany). To determine the plasma concentrations of all essential and non-essential amino acids, $10 \mu \mathrm{L}$ of plasma was mixed with $1500 \mu \mathrm{L}$ of $0.5 \mathrm{mM}$ tridecafluoroheptanoic acid (TDFHA) (Sigma, Zwijndrecht, The Netherlands) in water and $10 \mu \mathrm{L}$ of the internal standard solution containing stable isotope-labelled amino acids (Cambridge Isotopes Laboratories, Andover, MA) in $0.1 \mathrm{M} \mathrm{HCl}$. Amino acid concentrations were determined using ultra-performance liquid chromatography tandem mass spectrometry (UPLC-MS/MS) as described previously ${ }^{30}$. For plasma L-[ring- $\left.{ }^{-13} \mathrm{C}_{6}\right]$-phenylalanine enrichment measurements, plasma phenylalanine was derivatised to the tert-butyldimethylsilyl (TBDMS) derivative, 
Table 1 | Composition of the test drinks

\begin{tabular}{|c|c|c|c|c|}
\hline Component & & Pro-En & En & Pro \\
\hline Energy (kJ) & & 628 & 628 & 390 \\
\hline Protein (g) & Total & 21 & -- & 21 \\
\hline Total leucine* & & 2.8 & -- & 2.8 \\
\hline Total EAA* & & 10.6 & -- & 10.6 \\
\hline Total phenylalanine & & 0.6 & -- & 0.6 \\
\hline Carbohydrate (g) & Total & 9 & 30 & -- \\
\hline Fat $(g)$ & & 3 & 3 & -- \\
\hline Fibres (g) & & 1.3 & 1.3 & -- \\
\hline \multicolumn{5}{|l|}{ Minerals } \\
\hline & Sodium (mg) & 150 & 150 & 150 \\
\hline & Potassium (mg) & 279 & 298 & 296 \\
\hline & Chloride (mg) & 70 & 2 & 23 \\
\hline & Calcium (mg) & 500 & 500 & 500 \\
\hline & Phosphorus (mg) & 250 & 250 & 250 \\
\hline & Magnesium (mg) & 37 & 37 & 37 \\
\hline \multirow[t]{9}{*}{ Trace elements } & Iron (mg) & 2.4 & 2.4 & 2.4 \\
\hline & Zinc (mg) & 2.2 & 2.2 & 2.2 \\
\hline & Copper $(\mu g)$ & 270 & 270 & 268 \\
\hline & Manganese (mg) & 0.5 & 10 & 11 \\
\hline & Fluoride (mg) & 0.15 & 0 & 0 \\
\hline & Molybdenum ( $\mu \mathrm{g})$ & 15 & 0 & 0 \\
\hline & Selenium $(\mu \mathrm{g})$ & 15 & 15 & 15 \\
\hline & Chromium $(\mu \mathrm{g})$ & 7.5 & 0.1 & 0 \\
\hline & Iodine $(\mu \mathrm{g})$ & 20 & 20 & 19 \\
\hline \multirow[t]{13}{*}{ Vitamins } & Vitamin A $(\mu g)$ & 152 & 0 & 0 \\
\hline & Vitamin $D_{3}(\mu g)$ & 20 & 20 & 20 \\
\hline & Vitamin E (mg) & 7.5 & 7.5 & 7.5 \\
\hline & Vitamin $K_{1}(\mu g)$ & 12 & 12 & 12 \\
\hline & Vitamin B1 (mg) & 0.23 & 0.23 & 0.23 \\
\hline & Vitamin B2 (mg) & 0.25 & 0 & 0 \\
\hline & Niacin (mg) & 8.8 & 8.8 & 8.8 \\
\hline & Pantothenic acid (mg) & 0.81 & 0.81 & 0.81 \\
\hline & Vitamin B6 (mg) & 0.76 & 0.76 & 0.76 \\
\hline & Folic acid $(\mu \mathrm{g})$ & 203 & 203 & 203 \\
\hline & Vitamin B12 ( $\mu \mathrm{g})$ & 3.0 & 3.0 & 3.0 \\
\hline & Biotin $(\mu g)$ & 6.1 & 0 & 0 \\
\hline & Vitamin C (mg) & 32 & 32 & 32 \\
\hline
\end{tabular}

All drinks were manufactured and provided by Nutricia Advanced Medical Nutrition, Danone, the Netherlands. The whey protein source is a whey protein isolate containing $87 \mathrm{~g}$ protein in $100 \mathrm{~g}$ of raw material. * Provided by protein and free amino acids.

and the ${ }^{13} \mathrm{C}$ enrichments were determined by electron ionization gas chromatography-mass spectrometry (GC-MS; Agilent 6890N GC/5973N MSD) using selected ion monitoring of masses 336 and 342 for unlabelled and labelled (ring- ${ }^{13} \mathrm{C}_{6}$ ) 
phenylalanine, respectively. We applied standard regression curves in all isotopic enrichment analyses to assess linearity of the mass spectrometer and to control for loss of tracer. Through the addition of an internal standard $(\mathrm{m}+10$ or $\mathrm{m}+6)$, concentrations of phenylalanine, tyrosine and leucine were determined in the same run. Enrichments (MPE) were calculated according to Biolo et al. ${ }^{31}$ to correct for the natural presence of ${ }^{13} \mathrm{C}$ isotopes.

\section{Muscle analyses}

To measure L-[ring ${ }^{13} \mathrm{C}_{6}$ ]-phenylalanine enrichment in the free amino acid pool and mixed muscle protein, 35-60 mg wet muscle was freeze-dried. Collagen, blood and other non-muscle fibre material were removed from the muscle fibres under a light microscope. The isolated muscle fibre mass $(7-12 \mathrm{mg})$ was weighed and 35 volumes ( 7 - dry weight of isolated muscle fibres · wet/dry ratio) of ice-cold $2 \%$ perchloric acid (PCA) were added. The tissue was then homogenised and centrifuged. The supernatant was collected and processed in the same manner as the plasma samples, so that intracellular free L-[ring- ${ }^{13} \mathrm{C}_{6}$ ]-phenylalanine enrichment could be measured using the tert-butyldymethylsilyl derivatives on a GC-MS. The protein pellet was washed three times with $1.5 \mathrm{~mL}$ of $2 \% \mathrm{PCA}$, dried, and hydrolysed in $6 \mathrm{M} \mathrm{HCl}$ at 120 ${ }^{\circ} \mathrm{C}$ for 15-18 $\mathrm{h}$. The hydrolysed protein fraction was dried under a nitrogen stream while heated to $120^{\circ} \mathrm{C}$, then dissolved in a $50 \%$ acetic acid solution, and was passed over a Dowex exchange resin (AG 50W-X8, 100-200 mesh hydrogen form; Bio-Rad, Hercules, CA, USA) using $2 \mathrm{M} \mathrm{NH}_{4} \mathrm{OH}$. The eluate was dried and the purified amino acid fraction of ${ }^{13} \mathrm{C}$-phenylalanine was derivatised to its $\mathrm{N}(\mathrm{O}, \mathrm{S})$-ethoxycarbonylethylesters. The ratio ${ }^{13} \mathrm{C} /{ }^{12} \mathrm{C}$ of the muscle protein-bound phenylalanine was determined by using gas chromatography-combustion-isotope ratio mass spectrometry (GC-IRMS; MAT 253, Thermo-Finnigan, Bremen, Germany) by monitoring ion masses 44,45 and 46. Standard regression curves were applied to assess linearity of the mass spectrometer and to control for the loss of tracer.

\section{Calculations}

Fractional synthesis rate (FSR) of mixed muscle protein was calculated by dividing the increment in enrichment of the product, i.e. protein-bound L-[ring- $\left.{ }^{-13} \mathrm{C}_{6}\right]-$ phenylalanine, by the enrichment of the precursor, i.e. plasma L-[ring- $\left.{ }^{13} \mathrm{C}_{6}\right]-$ phenylalanine enrichment. Muscle FSR was calculated as follows:

$$
F S R=\frac{\Delta E_{p}}{E_{\text {precursor }} \times t} \times 100
$$


In this formula, $\Delta E_{p}$ is the increment in protein-bound L-[ring- $\left.{ }^{13} \mathrm{C}_{6}\right]$-phenylalanine after an incorporation period, $E_{\text {precursor }}$ is the weighted mean plasma L-[ring- $\left.{ }^{13} \mathrm{C}_{6}\right]-$ phenylalanine enrichment during that incorporation period, $t$ indicates the incorporation period $(\mathrm{h})$ between biopsies, and the factor 100 is needed to express the FSR in percent per hour $(\% / h)$. For basal FSR, muscle biopsies at $t=-2,5$ and $0 \mathrm{~h}$ were used, and for postprandial FSR, biopsies at $\mathrm{t}=0,2$ and $5 \mathrm{~h}$ were used.

\section{Statistics}

All data are expressed as mean \pm standard error (SEM). A sample size of 15 subjects per group including a $20 \%$ dropout rate was calculated with a power of $90 \%$ and an alpha level of 0.05 to detect a difference in FSR between groups. No dropouts occurred in any of the three groups. For all outcome measures, the Pro-En group was compared with the PRO group and compared with En group. Subjects' characteristics were compared between groups using a two-sample t-test, nonparametric Wilcoxon rank sum test, or Fisher's Exact test. The concentrations of the plasma total amino acids (AA), essential AA (EAA), phenylalanine, and leucine at different time points were compared between groups using a mixed model for repeated measures (MMRM) with "product", "time", and their interaction as fixed effects, and "subject" as a random effect, and using the baseline value as covariate. In addition, peak concentrations and incremental area under the curve above baseline values (iAUC) of plasma amino acids were calculated and were compared between groups using ANCOVA with "product" as factor and using the baseline value as covariate. Insulin and glucose responses and plasma L-[ring- $\left.{ }^{13} \mathrm{C}_{6}\right]-$ phenylalanine enrichments were analysed in the same way as the amino acid concentrations.

The postprandial muscle fractional synthesis rates (FSR), which was the primary outcome measure, and the postprandial muscle enrichments were analysed using ANCOVA with basal as covariate to determine differences with basal FSR within study groups. Basal FSR and muscle enrichment were pair-wise compared between groups using two-tailed t-tests. For the comparison of FSR and muscle enrichments between groups, an ANCOVA was used combining the postprandial time points/ periods as dependent variables, with baseline as covariate and with "product" and "time" as factor. Statistical significance was set at $p<0.05$. All calculations were performed using $\mathrm{SAS}{ }$ ) software (SAS Enterprise Guide 4.3 for Windows, SAS Institute Inc., USA). 


\section{Results}

\section{Participants}

A total of 45 healthy, non-sarcopenic, elderly men (age: 69 \pm 1 year; body mass: $80.1 \pm 1.0 \mathrm{~kg}$; body mass index (BMI): $25.7 \pm 0.3 \mathrm{~kg} / \mathrm{m}^{2}$ ) were included and randomised to intervention between December 2011 and May 2012. Subjects' characteristics and demographics are displayed in table 2. None of the baseline characteristics were identified as confounders for the FSR outcome measures.

\section{Safety and tolerance}

The test drinks were well tolerated, with no relevant gastro-intestinal complaints such as diarrhoea or emesis observed. The recorded adverse events did not differ between the groups, and consisted of minor events such as a headache during the test day. No serious adverse events occurred in this study.

Table 2 | Subjects' characteristics

\begin{tabular}{|c|c|c|c|}
\hline & $\begin{array}{c}\text { Pro-En } \\
n=15\end{array}$ & $\begin{array}{c}\text { En } \\
n=15\end{array}$ & $\begin{array}{c}\text { Pro } \\
n=15\end{array}$ \\
\hline $\operatorname{Age}(y)^{2}$ & $69 \pm 1$ & $70 \pm 1$ & $69 \pm 1$ \\
\hline Height (m) ${ }^{1}$ & $1.77 \pm 0.02$ & $1.76 \pm 0.02$ & $1.76 \pm 0.02$ \\
\hline Weight (kg) ${ }^{1}$ & $79.5 \pm 1.9$ & $81.0 \pm 1.6$ & $79.7 \pm 2.0$ \\
\hline BMI $\left(\mathrm{kg} / \mathrm{m}^{2}\right)^{1}$ & $25.5 \pm 0.3$ & $26.1 \pm 0.7$ & $25.6 \pm 0.5$ \\
\hline Lean body mass $(\mathrm{kg})^{1}$ & $61.1 \pm 1.5$ & $62.5 \pm 1.4$ & $60.1 \pm 1.4$ \\
\hline Body fat $(\%)^{1}$ & $20.2 \pm 0.8$ & $20.2 \pm 0.9$ & $22.1 \pm 0.8$ \\
\hline $\operatorname{ALM}(\mathbf{k g})^{1}$ & $26.8 \pm 0.7$ & $27.0 \pm 0.7$ & $26.3 \pm 0.8$ \\
\hline $\operatorname{SMMI}\left(\mathrm{kg} / \mathrm{m}^{2}\right)^{1}$ & $8.6 \pm 0.1$ & $8.7 \pm 0.2$ & $8.4 \pm 0.2$ \\
\hline Handgrip strength $(\mathbf{k g})^{1}$ & $43 \pm 2$ & $45 \pm 2$ & $43 \pm 1$ \\
\hline Gait speed $(\mathrm{m} / \mathrm{sec})^{1}$ & $1.3 \pm 0.04$ & $1.3 \pm 0.03$ & $1.3 \pm 0.04$ \\
\hline Total balance score $4(\%)^{3}$ & 93 & 93 & 93 \\
\hline Time to complete 5 chair stands (s) ${ }^{1}$ & $10.0 \pm 0.3$ & $10.1 \pm 0.3$ & $10.0 \pm 0.2$ \\
\hline Total SPPB score $12(\%)^{3}$ & 80 & 67 & 87 \\
\hline Fasting glucose $(\mathrm{mmol} / \mathrm{L})^{1}$ & $5.3 \pm 0.2$ & $5.1 \pm 0.1$ & $5.0 \pm 0.2$ \\
\hline 2-hour glucose $(\mathrm{mmol} / \mathrm{L})^{2}$ & $5.7 \pm 0.3$ & $5.6 \pm 0.6$ & $5.9 \pm 0.5$ \\
\hline Glycated haemoglobin (\%) ${ }^{1}$ & $5.7 \pm 0.1$ & $5.8 \pm 0.1$ & $5.6 \pm 0.1$ \\
\hline HOMA-IR index ${ }^{2}$ & $2.37 \pm 0.51$ & $2.04 \pm 0.21$ & $2.28 \pm 0.22$ \\
\hline OGIS index ${ }^{2}$ & $324 \pm 22$ & $374 \pm 13$ & $370 \pm 11$ \\
\hline \multicolumn{4}{|c|}{$\begin{array}{l}\text { Values are means } \pm \text { SEM. Abbreviations: ALM, Appendicular Lean Mass; HOMA-IR, Homeostatic Model } \\
\text { Assessement - Insulin Resistance; OGIS, Oral Glucose Insulin Sensitivity; SMMI, Skeletal Muscle Mass Index; } \\
\text { SPPB, Short Physical Performance Battery. Data were analysed using two-tailed t-test }{ }^{1} \text {, non-parametric Wilcoxon } \\
\text { rank sum test }{ }^{2} \text {, or Fisher's Exact test }{ }^{3} \text { where applicable. No significant differences were present between groups. } \\
\text { Characteristics were tested as potential confounders, which did not reveal any significant effect. }\end{array}$} \\
\hline
\end{tabular}




\section{Plasma glucose and insulin}

Baseline plasma glucose concentrations did not differ significantly between groups. Plasma glucose concentrations were significantly higher in the En vs Pro-En group from time point $\mathrm{t}=15$ until $\mathrm{t}=120 \mathrm{~min}(\mathrm{MMRM}, \mathrm{p}<0.001$, figure 1A). Plasma glucose concentrations were significantly higher in the Pro-En vs Pro group only at time points $\mathrm{t}=30$ and $45 \mathrm{~min}(\mathrm{p}<0.05)$. Significantly higher peak glucose concentration was reached in the En versus Pro-En group $(10.9 \pm 0.4$ vs $7.1 \pm 0.1 \mathrm{mmol} / \mathrm{L}$, ANCOVA, $\mathrm{p}<0.001)$, and in the Pro-En vs Pro group $(7.1 \pm 0.1$ vs $6.3 \pm 0.1 \mathrm{mmol} / \mathrm{L}, \mathrm{p}=0.04)$. In agreement, iAUC above fasting plasma glucose concentration was significantly greater in En vs Pro-En $(407 \pm 34$ vs $92 \pm 12 \mathrm{mmol} / \mathrm{L} / 5 \mathrm{~h}, \mathrm{p}<0.001)$, but not in the Pro-En vs Pro group ( $92 \pm 12$ vs $53 \pm 14 \mathrm{mmol} / \mathrm{L} / 5 \mathrm{~h}, \mathrm{p}=0.22$ ).

Plasma insulin concentrations did not differ at any time point between the Pro-En and En group (figure 1B). Plasma insulin concentrations were significantly higher in the Pro-En vs Pro group from time point $t=30$ until 90 min (MMRM, $\mathrm{p}<0.05)$. Peak plasma insulin concentrations in the Pro-En group were significantly higher when compared to the Pro group ( $63 \pm 13$ vs $32 \pm 3 \mathrm{mU} / \mathrm{L}$, ANCOVA, $\mathrm{p}<0.001$ ), but not when compared to the En group $(63 \pm 13$ vs $51 \pm 4 \mathrm{mU} / \mathrm{L}, \mathrm{p}=0.66)$. These results were in line with the statistical results of the comparison of iAUC above fasting insulin concentration between groups $(3455 \pm 776$ vs $1558 \pm 176 \mathrm{mU} / \mathrm{L} / 5 \mathrm{~h}, \mathrm{p}<0.001$ ProEn vs Pro, and $3455 \pm 776$ vs $3257 \pm 239 \mathrm{mU} / \mathrm{L} / 5 \mathrm{~h}, \mathrm{p}=0.33$, in the Pro-En vs En group, respectively; figure $\mathbf{1 B}$ ).

Figure 1 I Plasma glucose and insulin concentrations

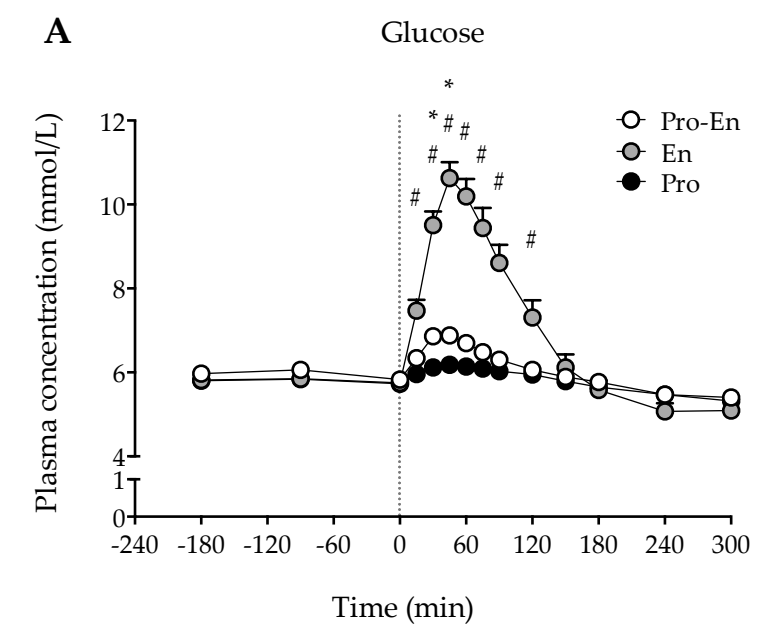

B Insulin

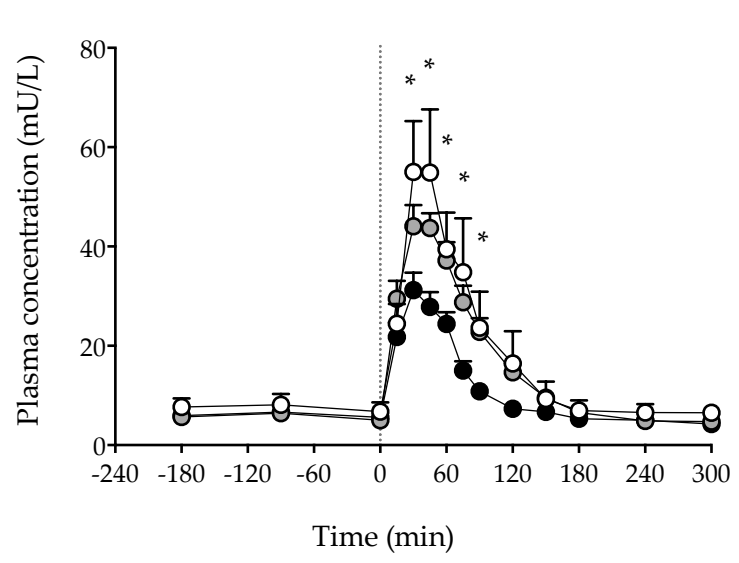

Mean ( \pm SEM) plasma glucose (A) and insulin (B) concentrations following ingestion of $21 \mathrm{~g}$ of leucine-enriched whey protein with carbohydrate and fat (Pro-En, $n=15$ ), an isonitrogenous variant (Pro, $n=15$ ), or an isocaloric variant containing carbohydrate and fat but without protein $(E n, n=15)$ * Significant difference between Pro-En and Pro group. \# Significant difference between Pro-En and En group. Glucose: iAUC Pro-En vs En p $<0.001$, ProEn vs Pro $\mathrm{p}=0.22$, peak-value Pro-En vs En $\mathrm{p}<0.001$, Pro-En vs Pro $\mathrm{p}=0.04$; Insulin: iAUC Pro-En vs En $\mathrm{p}=0.33$, Pro-En vs Pro $\mathrm{p}<0.001$, peak-value Pro-En vs En $\mathrm{p}=0.66$, Pro-En vs Pro $\mathrm{p}<0.001$. 


\section{Plasma amino acids}

Figure 2 I Plasma amino acid concentrations
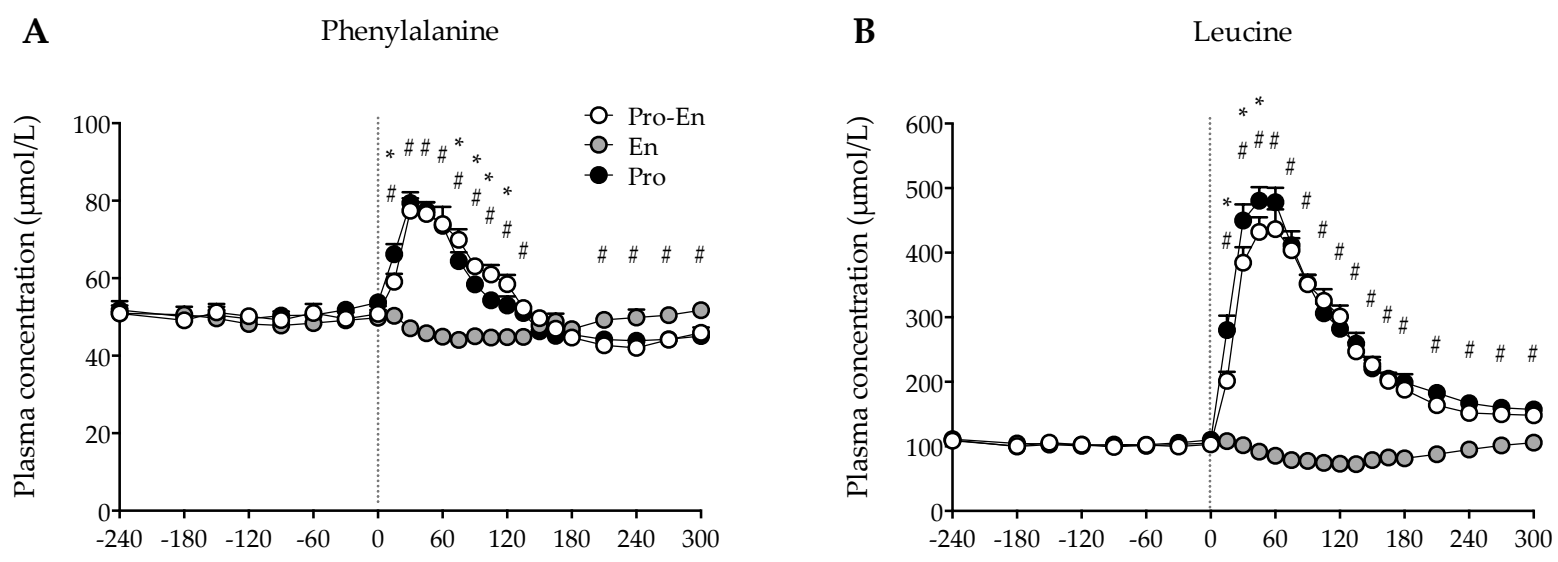

C

EAA

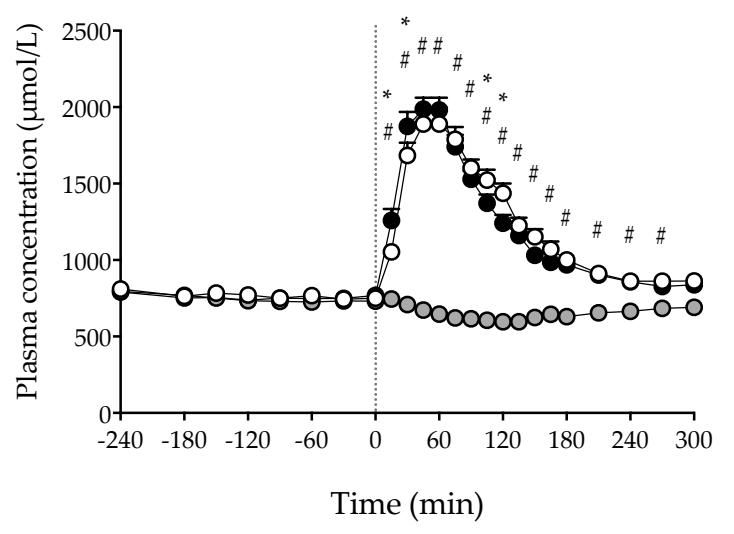

D

AA

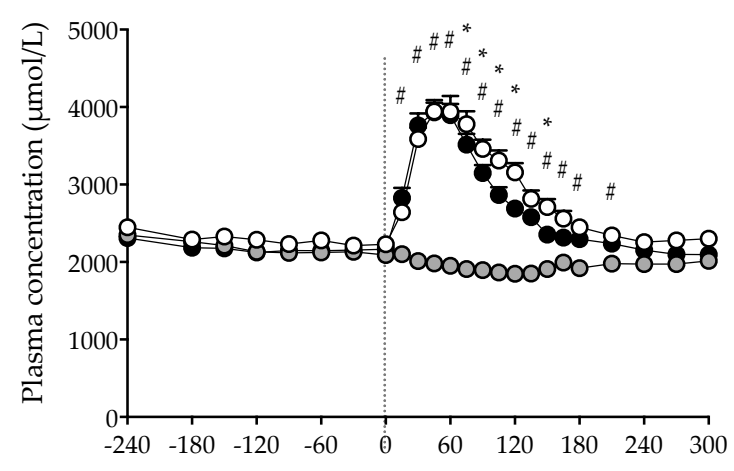

Mean ( \pm SEM) plasma phenylalanine (A), leucine (B), essential amino acid (C), and total amino acid (D) concentration $(\mu \mathrm{mol} / \mathrm{L})$ following ingestion of $21 \mathrm{~g}$ of leucine-enriched whey protein with carbohydrate and fat (Pro-En, $n=15$ ), an isonitrogenous variant (Pro, $n=15)$, or an isocaloric variant containing carbohydrate and fat but without protein (En, n=15). * Significant difference between Pro-En and Pro group. \# Significant difference between Pro-En and En group. Phenylalanine: iAUC Pro-En vs En $\mathrm{p}<0.001$, Pro-En vs Pro p=0.11, peak-value ProEn vs En p<0.001, Pro-En vs Pro p=0.85; Leucine: iAUC Pro-En vs En $\mathrm{p}<0.001$, Pro-En vs Pro p=0.31, peak-value Pro-En vs En p<0.001, Pro-En vs Pro p=0.29; EAA: iAUC Pro-En vs En p<0.001, Pro-En vs Pro p=0.26, peak-value Pro-En vs En p<0.001, Pro-En vs Pro p=0.62; AA: iAUC Pro-En vs En p<0.001, Pro-En vs Pro p=0.28, peak-value Pro-En vs En $\mathrm{p}<0.001$, Pro-En vs Pro $\mathrm{p}=0.86$.

Plasma phenylalanine (A), leucine (B), total essential amino acid (EAA; C), total amino acid (AA; D) concentrations are illustrated in figure 2A-D. Minimal differences were observed between postprandial amino acid concentrations in the Pro-En and Pro groups at all time points. No differences in iAUC and/or peak values for any of the amino acids were observed between the Pro-En and Pro group. In the Pro-En vs En group, plasma phenylalanine concentrations were significantly higher from $t=15$ until $t=135$ min and $t=210$ until $t=300$ min (MMRM, $p<0.02$ ). Furthermore, plasma leucine concentrations were significantly higher in the Pro-En versus the En 
group from $\mathrm{t}=15$ until $\mathrm{t}=300 \mathrm{~min}(\mathrm{MMRM}, \mathrm{p}<0.05)$. Likewise, plasma EAA and total AA were significantly higher in the Pro-En group compared with the En group at the far majority of the time points $(\mathrm{p}<0.05$, figure $2 \mathrm{~B}-\mathrm{C})$. Peak concentrations and iAUC of plasma phenylalanine, leucine, essential amino acids and total amino acids were significantly higher in the Pro-En vs En group (ANCOVA, all p<0.001).

\section{Plasma tracer analyses}

Plasma L-[ring- $\left.{ }^{13} \mathrm{C}_{6}\right]$-phenylalanine enrichments (MPE) in time are depicted in figure 3. Plasma L-[ring- $\left.{ }^{13} \mathrm{C}_{6}\right]$-phenylalanine enrichment was only significantly higher in the Pro vs the Pro-En group at time point $\mathrm{t}=15$, but did not differ significantly between these groups at any other time point.

Figure 3 I Plasma L-[ring-13 $\left.\mathrm{C}_{6}\right]$-phenylalanine enrichments

L-[ring ${ }^{13} \mathrm{C}_{6}$-phenylalanine

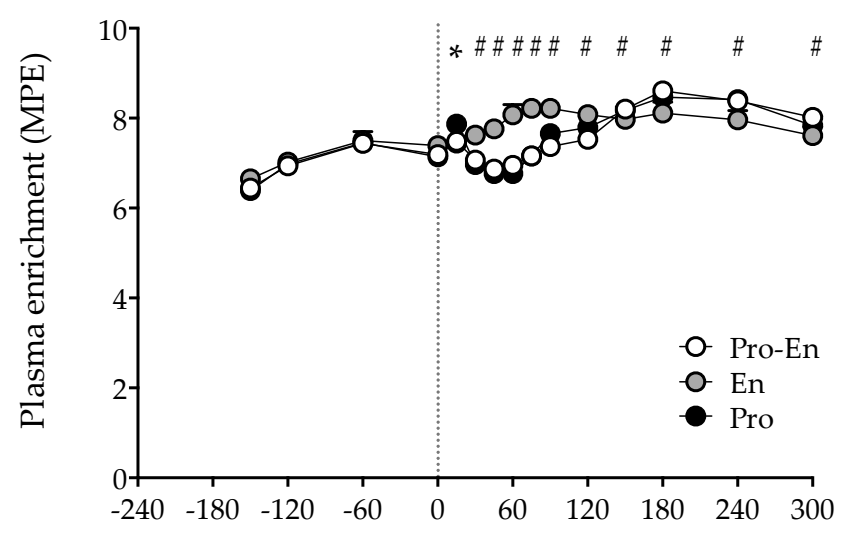

Time (min)

Mean $\left( \pm\right.$ SEM) plasma L-[ring-13 $\left.\mathrm{C}_{6}\right]$-phenylalanine enrichments (MPE) following ingestion of $21 \mathrm{~g}$ of leucineenriched whey protein with carbohydrate and fat (Pro-En, n=15), an isonitrogenous variant (Pro, n=15), or an isocaloric variant containing carbohydrate and fat but without protein $(E n, n=15) .{ }^{*}$ Significant difference between Pro-En and Pro group. \# Significant difference between Pro-En and En group. iAUC Pro-En vs En $\mathrm{p}=0.20$, Pro-En vs Pro $\mathrm{p}=0.40$, peak-value Pro-En vs En $\mathrm{p}=0.03$, Pro-En vs Pro $\mathrm{p}=0.87$.

\section{Muscle analyses}

Muscle tissue-free and muscle protein-bound L-[ring- $\left.{ }^{13} \mathrm{C}_{6}\right]$-phenylalanine enrichments at baseline, 2 and $5 \mathrm{~h}$ after ingestion of the drink are displayed in table 3. Muscle tissue-free L-[ring- $\left.{ }^{13} \mathrm{C}_{6}\right]$-phenylalanine enrichments did not differ significantly between groups at baseline. In the Pro-En and Pro groups, muscle tissue-free L-[ring- $\left.{ }^{13} \mathrm{C}_{6}\right]$-phenylalanine enrichments showed a significant rise following drink ingestion, with significantly higher enrichments at $2 \mathrm{~h}$ (ANCOVA, $p=0.002$ and $p=0.002$, respectively) and $5 \mathrm{~h}$ ( $\mathrm{p}<0.0001$ and $\mathrm{p}=0.03$, respectively) when 
compared with baseline values. In the En group, muscle tissue-free L-[ring- $\left.{ }^{13} \mathrm{C}_{6}\right]-$ phenylalanine enrichments at 2 and $5 \mathrm{~h}$ did not significantly differ from basal values. Muscle protein-bound L-[ring- $\left.{ }^{13} \mathrm{C}_{6}\right]$-phenylalanine enrichments within the groups showed a significant increase compared with baseline in all three groups, with higher enrichments observed at 2 and $5 \mathrm{~h}$ when compared with baseline values (ANCOVA, $\quad \mathrm{p}<0.001)$. Postprandial muscle protein-bound L-[ring- $\left.{ }^{13} \mathrm{C}_{6}\right]-$ phenylalanine enrichments were significantly higher in the Pro-En group when compared with the En group, but did not differ between the Pro-En and Pro group at $5 \mathrm{~h}$ (ANCOVA, $\mathrm{p}=0.01$ and $\mathrm{p}=0.29$, respectively).

Table 3 | Muscle tissue-free and protein-bound L-[ring- $\left.{ }^{13} \mathrm{C}_{6}\right]$-phenylalanine enrichments

\begin{tabular}{|c|c|c|c|c|}
\hline & Time (h) & $\begin{array}{c}\text { Pro-En } \\
n=15\end{array}$ & $\begin{array}{c}\text { En } \\
n=15\end{array}$ & $\begin{array}{c}\text { Pro } \\
n=15\end{array}$ \\
\hline \multirow[t]{3}{*}{ Muscle tissue-free } & 0 & $4.49 \pm 0.20$ & $4.95 \pm 0.25$ & $5.01 \pm 0.22$ \\
\hline & 2 & $5.44 \pm 0.25^{*}$ & $4.90 \pm 0.22 \#$ & $5.56 \pm 0.16^{*}$ \\
\hline & 5 & $5.21 \pm 0.15^{*}$ & $5.12 \pm 0.18$ & $5.48 \pm 0.23^{*}$ \\
\hline \multirow{3}{*}{$\begin{array}{l}\text { Muscle protein- } \\
\text { bound }\end{array}$} & 0 & $0.0058 \pm 0.0005$ & $0.0072 \pm 0.0007$ & $0.0071 \pm 0.0005$ \\
\hline & 2 & $0.0150 \pm 0.0013^{*}$ & $0.0146 \pm 0.0009^{*}$ & $0.0158 \pm 0.0010^{*}$ \\
\hline & 5 & $0.0268 \pm 0.0014^{*}$ & $0.0234 \pm 0.0013^{*} \#$ & $0.0265 \pm 0.0015^{*}$ \\
\hline
\end{tabular}

Mean ( \pm SEM) muscle tissue-free and muscle protein-bound L-[ring- $\left.{ }^{13} \mathrm{C}_{6}\right]$-phenylalanine enrichments (MPE) during the fasting $(t=0 \mathrm{~min})$ and postprandial period $(t=120$ and $t=300 \mathrm{~min})$ following ingestion of $21 \mathrm{~g}$ of a leucine-enriched whey protein supplement with carbohydrate and fat (Pro-En), an isonitrogenous variant without carbohydrate and fat (Pro), or an isocaloric variant without the protein (En). * Significant increase compared with basal $(\mathrm{t}=0 \mathrm{~h})$ muscle enrichment. \# Significant difference compared with corresponding time point in the Pro-En group. An ANCOVA with basal values as covariate was used to compare the postprandial enrichments between groups: Muscle tissue-free ( 2 h: Pro-En vs Pro p=0.61; Pro-En vs En p=0.002; 5 h: Pro-En vs Pro p=0.85; Pro-En vs En p=0.11), muscle protein-bound ( 2 h: Pro-En vs Pro p=0.74; Pro-En vs En p=0.32; 5 h: ProEn vs Pro p=0.29; Pro-En vs En p=0.01).

Mixed muscle protein synthesis rates, expressed as FSR, are presented in figure 4. FSR was calculated for the basal period $(-2.5-0 \mathrm{~h})$, the early $(0-2 \mathrm{~h})$ and the entire postprandial period $(0-5 \mathrm{~h})$ using plasma L-[ring- $\left.{ }^{13} \mathrm{C}_{6}\right]$-phenylalanine enrichments as precursor. Mixed muscle protein FSR in the entire postprandial period increased significantly from basal FSR in the Pro-En (from $0.032 \pm 0.003$ to $0.053 \pm 0.004 \% / \mathrm{h}$ ) and Pro (from $0.040 \pm 0.003$ to $0.049 \pm 0.003 \% / h$ ) group (ANCOVA, $p<0.001$ and $p=0.02$, respectively). Postprandial muscle protein FSR in the En group did not differ from basal FSR (from $0.039 \pm 0.004$ to $0.040 \pm 0.003 \% / \mathrm{h}, \mathrm{p}=0.60$; figure $4 \mathrm{~A}$ ).

In addition, basal and postprandial FSR (0-2h and $0-5 h)$ were compared between the three groups. Basal FSR did not significantly differ between groups (Pro-En vs En and Pro-En vs Pro group, t-test, $\mathrm{p}=0.15$ and $\mathrm{p}=0.06$, respectively, figure 4B). The entire postprandial FSR was significantly higher in the Pro-En when compared with 
the En group (estimate of difference $0.013 \% / \mathrm{h}$; 95\% confidence interval (CI) [0.003; 0.023]; ANCOVA, $\mathrm{p}=0.01$ ), and there was no difference between the Pro-En and Pro group (estimate of difference $0.006 \% / h ; 95 \%$ CI [-0.006; 0.017]; $\mathrm{p}=0.32$ ). Similar results were obtained when calculating mixed muscle FSRs using muscle tissue-free L-[ring- $\left.{ }^{13} \mathrm{C}_{6}\right]$-phenylalanine enrichments as precursor (data not shown). Also in the early postprandial period, muscle protein synthesis rates were significantly different between the Pro-En and En group, but not between the Pro-En and Pro groups (ANCOVA, $\mathrm{p}=0.03$ and $\mathrm{p}=0.24$ respectively). Again, similar findings were obtained when calculating mixed muscle FSRs using muscle tissue-free L-[ring- $\left.{ }^{13} \mathrm{C}_{6}\right]-$ phenylalanine enrichments as precursor, but the difference between Pro-En and En did not reach statistical significance $(\mathrm{p}=0.17)$.

Figure 4 I Mixed-muscle protein synthesis rates

A

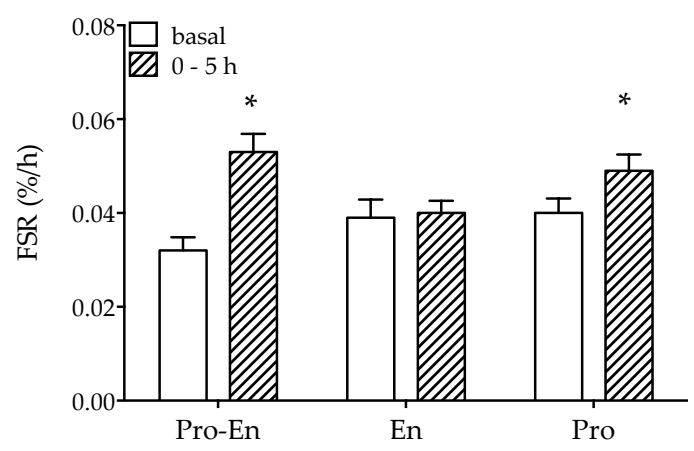

B

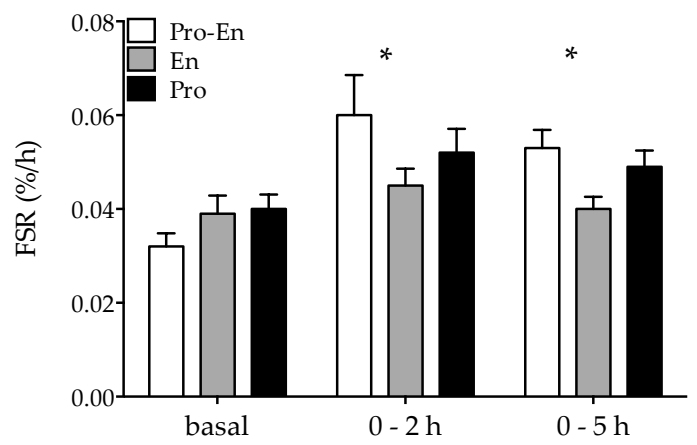

Mean $( \pm$ SEM) mixed muscle protein FSR $(\% / \mathrm{h})$ following ingestion of $21 \mathrm{~g}$ of leucine-enriched whey protein with carbohydrate and fat (Pro-En), an isonitrogenous variant (Pro), or an isocaloric variant containing carbohydrate and fat but without protein (En). FSR was calculated using plasma and muscle protein-bound L-[ring- $\left.{ }^{13} \mathrm{C}_{6}\right]-$ phenylalanine enrichments (MPE). A: Postprandial muscle FSR compared with basal FSR in each treatment group (Pro-En: $n=15$, Pro: $n=14$, En: $n=15) .{ }^{*}$ Significant increase compared with basal FSR. Pro-En $\mathrm{p}<0.001$, En $\mathrm{p}=0.60$, Pro $\mathrm{p}=0.02$. B: Basal, early postprandial $(0-2 \mathrm{~h}$ ) (Pro-En: $n=14$, Pro: $n=14$, En: $n=15$ ), and entire postprandial $(0-5 \mathrm{~h}$ ) (Pro-En: $n=15$, Pro: $n=14$, En: $n=15)$ muscle protein FSR compared between groups. * Significant difference when compared with Pro-En group. Basal: Pro-En vs En p=0.15, Pro-En vs Pro p=0.06; $0-2$ h: Pro-En vs En p=0.03, Pro-En vs Pro p=0.24; 0 - 5 h: Pro-En vs En p=0.01, Pro-En vs Pro p=0.32. 


\section{Discussion}

In this study, we demonstrate that the ingestion of a nutritional supplement containing $21 \mathrm{~g}$ of leucine-enriched whey protein significantly raises muscle protein synthesis rates in non-sarcopenic elderly men. Co-ingestion of carbohydrate and fat with the leucine-enriched whey protein did not modulate the postprandial muscle protein synthetic response.

The ingestion of protein has been well established as a key regulator of postprandial muscle protein synthesis ${ }^{32,33}$. Previous work from our lab clearly indicated that ingestion of whey protein, when compared with intact micellar casein, more effectively stimulates muscle protein synthesis in the elderly ${ }^{11}$ and addition of free leucine to protein can further increase post-prandial muscle protein accretion in elderly men ${ }^{15}$. Likewise, the modulation of this muscle protein synthetic response through the co-ingestion of other macronutrients with protein has been previously suggested ${ }^{34,35}$. However, the effect of adding other macronutrients to a leucineenriched whey protein supplement has, to the authors' knowledge, not been assessed before. Therefore, we compared muscle protein fractional synthesis rates in response to the ingestion of a nutritional supplement containing $21 \mathrm{~g}$ of leucineenriched whey protein plus carbohydrate and fat (Pro-En) with a drink containing the same $21 \mathrm{~g}$ of leucine-enriched whey protein without carbohydrate and fat (Pro) or an isocaloric amount of carbohydrate and fat only (En).

Following ingestion of the Pro-En supplement, we observed a substantial increase in muscle protein synthesis rate when compared with basal protein synthesis rates $(p<0.001$; figure $4 \mathbf{A})$. This anabolic response did not seem to be modified by the added carbohydrate and fat, as the ingestion of the nitrogenous supplement (Pro) resulted in a similar anabolic response. No significant differences were observed in the postprandial muscle protein synthesis rates between the ProEn and Pro groups ( $p=0.32$; figure $4 B$ ). No anabolic response was observed after ingestion of the isocaloric control supplement (En) ( $p=0.60$; figure $4 \mathrm{~A})$. These data show that carbohydrate and fat do not modulate the muscle protein synthetic response to a leucine-enriched whey protein ingestion in elderly men, and shows that dietary protein is required to elevate protein synthesis rates.

We hypothesised that carbohydrate and fat co-ingestion could augment the muscle protein synthetic response to protein feeding by stimulating postprandial endogenous insulin release. The postprandial release of insulin into the plasma is often suggested to have a positive effect on muscle protein synthesis by enlargement of the local availability of amino acids in muscle through stimulation of muscle 
perfusion, while simultaneously decreasing the rates of muscle protein breakdown ${ }^{36-}$ 38. Carbohydrate plus fat co-ingestion strongly increased the postprandial rise in plasma insulin concentrations in the Pro-En and En groups (figure 1B). These concentrations were significantly higher than following protein ingestion only (figure 1B). Although the circulating insulin concentrations were significantly higher in the Pro-En when compared with the Pro group, it did not result in significantly greater postprandial muscle protein accretion. Furthermore, both muscle proteinbound L-[ring- $\left.{ }^{13} \mathrm{C}_{6}\right]$-phenylalanine enrichments at $5 \mathrm{~h}$ and muscle protein synthesis rates during 0-5h (figure 4B) did not significantly differ between the Pro-En and Pro group, but were significantly lower in the En vs the Pro-En group for this time period. This further supports the concept that the presence of insulin is more permissive than stimulatory, and that even a moderate rise in circulating insulin concentration is sufficient in increasing muscle protein synthesis rates following protein ingestion 16,17,39. However, enhancing plasma insulin concentrations might benefit the net muscle protein balance by further inhibiting muscle protein breakdown ${ }^{40}$.

Nutritional supplements designed to support nutritional status generally contain a combination of all macronutrients. These supplements are usually offered to the elderly population in clinical or home-care settings to reach targets set for both total energy, as well as protein intake. However, nutritional supplementation may be specifically used for the preservation of muscle mass both in the general ageing population and in elderly specifically at risk for accelerated muscle loss due to immobilisation, illness, or injury, a factor which is of great influence on mortality and morbidity rates in elderly ${ }^{21,23,41}$. Supplementation of an adequate amount of dietary protein could be essential to preserve muscle mass in elderly, independent of additional energy. The present work expands on previous observations 16,17,42, showing that the ingestion of leucine-enriched whey protein effectively stimulates postprandial muscle protein synthesis rates in elderly men, and demonstrating that the energy content per se of a supplement is not the modulating factor. Obviously, it remains to be established to what extent repeated ingestion of such supplements effectively supports the maintenance of muscle mass, thereby preventing the development of sarcopenia. Moreover, as we included only non-sarcopenic elderly men in the present study, future work should further assess the effect of the macronutrient composition of nutritional supplements on the muscle anabolic response in elderly females as well as in more clinically compromised frail or sarcopenic elderly. 


\section{Conclusions}

In conclusion, the ingestion of a nutritional supplement containing $21 \mathrm{~g}$ of a leucineenriched whey protein significantly increases muscle protein synthesis rates in nonsarcopenic elderly men. Co-ingestion of carbohydrate and fat with such a bolus of protein does not modulate the postprandial muscle protein synthetic response. These findings imply that nutritional supplements designed to help prevent muscle loss at least require protein to stimulate skeletal muscle protein synthesis in elderly individuals. 


\section{References}

1. Rosenberg IH. Sarcopenia: origins and clinical relevance. The Journal of nutrition. May 1997;127(5 Suppl):990S991S.

2. Short KR, Vittone JL, Bigelow ML, Proctor DN, Nair KS. Age and aerobic exercise training effects on whole body and muscle protein metabolism. American journal of physiology. Endocrinology and metabolism. Jan 2004;286(1):E92-101.

3. Volpi E, Sheffield-Moore M, Rasmussen BB, Wolfe RR. Basal muscle amino acid kinetics and protein synthesis in healthy young and older men. JAMA : the journal of the American Medical Association. Sep 12 2001;286(10):1206-1212.

4. Paddon-Jones D, Sheffield-Moore M, Zhang XJ, et al. Amino acid ingestion improves muscle protein synthesis in the young and elderly. American journal of physiology. Endocrinology and metabolism. Mar 2004;286(3):E321-328.

5. Irving BA, Robinson MM, Nair KS. Age effect on myocellular remodeling: response to exercise and nutrition in humans. Ageing research reviews. Jul 2012;11(3):374-389.

6. Katsanos CS, Kobayashi H, SheffieldMoore M, Aarsland A, Wolfe RR. Aging is associated with diminished accretion of muscle proteins after the ingestion of a small bolus of essential amino acids. The American journal of clinical nutrition. Nov 2005;82(5):10651073.

7. Cuthbertson D, Smith K, Babraj J, et al. Anabolic signaling deficits underlie amino acid resistance of wasting, aging muscle. FASEB journal : official publication of the Federation of American Societies for Experimental Biology. Mar 2005;19(3):422-424.

8. Volpi E, Ferrando AA, Yeckel CW, Tipton KD, Wolfe RR. Exogenous amino acids stimulate net muscle protein synthesis in the elderly. The
Journal of clinical investigation. May 1 1998;101(9):2000-2007.

9. Pennings B, Groen B, de Lange A, et al. Amino acid absorption and subsequent muscle protein accretion following graded intakes of whey protein in elderly men. American journal of physiology. Endocrinology and metabolism. Apr 2012;302(8):E992-999.

10. Yang Y, Breen L, Burd NA, et al. Resistance exercise enhances myofibrillar protein synthesis with graded intakes of whey protein in older men. The British journal of nutrition. Nov 28 2012;108(10):17801788.

11. Pennings B, Boirie $\mathrm{Y}$, Senden JM, Gijsen AP, Kuipers H, van Loon LJ. Whey protein stimulates postprandial muscle protein accretion more effectively than do casein and casein hydrolysate in older men. The American journal of clinical nutrition. May 2011;93(5):997-1005.

12. Burd NA, Yang Y, Moore DR, Tang JE, Tarnopolsky MA, Phillips SM. Greater stimulation of myofibrillar protein synthesis with ingestion of whey protein isolate v. micellar casein at rest and after resistance exercise in elderly men. The British journal of nutrition. Sep 28 2012;108(6):958-962.

13. Rieu I, Balage $M$, Sornet $C$, et al. Leucine supplementation improves muscle protein synthesis in elderly men independently of hyperaminoacidaemia. The Journal of physiology. Aug 15 2006;575(Pt 1):305315.

14. Volpi E, Kobayashi H, SheffieldMoore M, Mittendorfer B, Wolfe RR. Essential amino acids are primarily responsible for the amino acid stimulation of muscle protein anabolism in healthy elderly adults. The American journal of clinical nutrition. Aug 2003;78(2):250-258.

15. Wall BT, Hamer HM, de Lange A, et al. Leucine co-ingestion improves 
post-prandial muscle protein accretion in elderly men. Clinical nutrition. Jun 2013;32(3):412-419.

16. Gorissen $\mathrm{SH}$, Burd NA, Hamer HM, Gijsen AP, Groen BB, van Loon LJ. Carbohydrate coingestion delays dietary protein digestion and absorption but does not modulate postprandial muscle protein accretion. The Journal of clinical endocrinology and metabolism. Jun 2014;99(6):2250-2258.

17. Hamer HM, Wall BT, Kiskini A, et al. Carbohydrate co-ingestion with protein does not further augment post-prandial muscle protein accretion in older men. Nutrition \& metabolism. 2013;10(1):15.

18. Wall BT, Dirks ML, van Loon LJ. Skeletal muscle atrophy during shortterm disuse: implications for agerelated sarcopenia. Ageing research reviews. Sep 2013;12(4):898-906.

19. Kortebein P, Ferrando A, Lombeida J, Wolfe R, Evans WJ. Effect of 10 days of bed rest on skeletal muscle in healthy older adults. JAMA : the journal of the American Medical Association. Apr 25 2007;297(16):17721774.

20. Klaude M, Mori M, Tjader I, Gustafsson T, Wernerman J, Rooyackers O. Protein metabolism and gene expression in skeletal muscle of critically ill patients with sepsis. Clinical science. Feb 2012;122(3):133142.

21. Kimyagarov S, Klid R, Fleissig $\mathrm{Y}$, Kopel B, Arad M, Adunsky A. Skeletal muscle mass abnormalities are associated with survival rates of institutionalized elderly nursing home residents. The journal of nutrition, health $\mathcal{E}$ aging. May 2012;16(5):432-436.

22. Hartholt KA, van Beeck EF, Polinder $\mathrm{S}$, et al. Societal consequences of falls in the older population: injuries, healthcare costs, and long-term reduced quality of life. The Journal of trauma. Sep 2011;71(3):748-753.

23. Janssen I, Heymsfield SB, Ross R. Low relative skeletal muscle mass (sarcopenia) in older persons is associated with functional impairment and physical disability. Journal of the American Geriatrics Society. May 2002;50(5):889-896.

24. Ferrando AA, Paddon-Jones D, Hays $\mathrm{NP}$, et al. EAA supplementation to increase nitrogen intake improves muscle function during bed rest in the elderly. Clinical nutrition. Feb 2010;29(1):18-23.

25. Alberti KG, Zimmet PZ. Definition, diagnosis and classification of diabetes mellitus and its complications. Part 1: diagnosis and classification of diabetes mellitus provisional report of a WHO consultation. Diabetic medicine : a journal of the British Diabetic Association. Jul 1998;15(7):539-553.

26. Cruz-Jentoft AJ, Baeyens JP, Bauer JM, et al. Sarcopenia: European consensus on definition and diagnosis: Report of the European Working Group on Sarcopenia in Older People. Age and ageing. Jul 2010;39(4):412-423.

27. Fielding RA, Vellas B, Evans WJ, et al. Sarcopenia: an undiagnosed condition in older adults. Current consensus definition: prevalence, etiology, and consequences. International working group on sarcopenia. Journal of the American Medical Directors Association. 2011;12(4):249-256.

28. Abumrad NN, Rabin D, Diamond MP, Lacy WW. Use of a heated superficial hand vein as an alternative site for the measurement of amino acid concentrations and for the study of glucose and alanine kinetics in man. Metabolism: clinical and experimental. Sep 1981;30(9):936-940.

29. Bergstrom J. Percutaneous needle biopsy of skeletal muscle in physiological and clinical research. Scandinavian journal of clinical and laboratory investigation. Nov 1975;35(7):609-616.

30. Waterval WA, Scheijen JL, OrtmansPloemen MM, Habets-van der Poel $\mathrm{CD}$, Bierau J. Quantitative UPLCMS/MS analysis of underivatised 
amino acids in body fluids is a reliable tool for the diagnosis and follow-up of patients with inborn errors of metabolism. Clinica chimica acta; international journal of clinical chemistry. Sep 2009;407(1-2):36-42.

31. Biolo G, Tessari P, Inchiostro S, et al. Leucine and phenylalanine kinetics during mixed meal ingestion: a multiple tracer approach. The American journal of physiology. Apr 1992;262(4 Pt 1):E455-463.

32. Biolo G, Tipton KD, Klein S, Wolfe RR. An abundant supply of amino acids enhances the metabolic effect of exercise on muscle protein. The American journal of physiology. Jul 1997;273(1 Pt 1):E122-129.

33. Rennie MJ, Edwards RH, Halliday D, Matthews DE, Wolman SL, Millward DJ. Muscle protein synthesis measured by stable isotope techniques in man: the effects of feeding and fasting. Clinical science. Dec 1982;63(6):519-523.

34. Miller SL, Tipton KD, Chinkes DL, Wolf SE, Wolfe RR. Independent and combined effects of amino acids and glucose after resistance exercise. Med Sci Sports Exerc. Mar 2003;35(3):449455.

35. Fujita S, Rasmussen BB, Cadenas JG, Grady JJ, Volpi E. Effect of insulin on human skeletal muscle protein synthesis is modulated by insulininduced changes in muscle blood flow and amino acid availability. American journal of physiology. Endocrinology and metabolism. Oct 2006;291(4):E745-754.

36. Gelfand RA, Barrett EJ. Effect of physiologic hyperinsulinemia on skeletal muscle protein synthesis and breakdown in man. J Clin Invest. Jul 1987;80(1):1-6.
37. Denne SC, Liechty EA, Liu YM, Brechtel G, Baron AD. Proteolysis in skeletal muscle and whole body in response to euglycemic hyperinsulinemia in normal adults. The American journal of physiology. Dec 1991;261(6 Pt 1):E809-814.

38. Timmerman KL, Lee JL, Dreyer HC, et al. Insulin stimulates human skeletal muscle protein synthesis via an indirect mechanism involving endothelial-dependent vasodilation and mammalian target of rapamycin complex 1 signaling. The Journal of clinical endocrinology and metabolism. Aug 2010;95(8):3848-3857.

39. Greenhaff PL, Karagounis LG, Peirce $\mathrm{N}$, et al. Disassociation between the effects of amino acids and insulin on signaling, ubiquitin ligases, and protein turnover in human muscle. American journal of physiology. Endocrinology and metabolism. Sep 2008;295(3):E595-604.

40. Borsheim E, Cree MG, Tipton KD, Elliott TA, Aarsland A, Wolfe RR. Effect of carbohydrate intake on net muscle protein synthesis during recovery from resistance exercise. Journal of applied physiology. Feb 2004;96(2):674-678.

41. Landi F, Liperoti R, Fusco D, et al. Sarcopenia and mortality among older nursing home residents. Journal of the American Medical Directors Association. Feb 2012;13(2):121-126.

42. Glynn EL, Fry CS, Timmerman KL, Drummond MJ, Volpi E, Rasmussen BB. Addition of carbohydrate or alanine to an essential amino Acid mixture does not enhance human skeletal muscle protein anabolism. The Journal of nutrition. Mar 2013;143(3):307-314. 



\section{CHAPTER 7}

\section{Both basal and post-prandial muscle protein synthesis rates, following the ingestion of a leucine-enriched whey protein supplement, are not impaired in sarcopenic elderly males}

I.F. Kramer, L.B Verdijk, H.M. Hamer, S. Verlaan, Y.C. Luiking, I.W.K. Kouw, J.M. Senden, J. van Kranenburg, A.P. Gijsen, J.Bierau, M. Poeze, L.J.C. van Loon 


\section{Abstract}

\section{Background}

Studying the muscle protein synthetic response to food intake in elderly is important, as it aids the development of interventions to combat sarcopenia. Although sarcopenic elderly are the target group for many of these nutritional interventions, no studies have assessed basal or post-prandial muscle protein synthesis rates in this population. The objective of this study was to assess the basal and post-prandial muscle protein synthesis rates between healthy and sarcopenic elderly men.

\section{Design}

A total of 15 healthy $(69 \pm 1$ y) and 15 sarcopenic $(81 \pm 1$ y) elderly men ingested a leucine-enriched whey protein nutritional supplement containing 21 gram of protein, 9 gram of carbohydrate, and 3 gram of fat. Stable isotope methodology combined with frequent collection of blood and muscle samples was applied to assess basal and post-prandial muscle protein fractional synthetic rates. Handgrip strength, muscle mass, and gait speed were assessed to identify sarcopenia, according to international criteria.

\section{Results}

Basal mixed muscle protein fractional synthetic rates (FSR) averaged $0.040 \pm 0.005$ and $0.032 \pm 0.003 \% / \mathrm{h}($ mean \pm SEM) in the sarcopenic and healthy group, respectively $(p=0.14)$. Following protein ingestion, FSR increased significantly to $0.055 \pm 0.004$ and $0.053 \pm 0.004 \% / \mathrm{h}$ in the post-prandial period in the sarcopenic $(\mathrm{p}=0.003)$ and healthy groups $(p<0.001)$, respectively, with no differences between groups $(p=0.45)$. Furthermore, no differences were observed between groups in muscle protein synthesis rates during the early $(0.058 \pm 0.007$ vs $0.060 \pm 0.008 \% / h$, sarcopenic vs healthy, respectively) and late $(0.052 \pm 0.004$ vs $0.048 \pm 0.003 \% / h)$ stages of the postprandial period ( $\mathrm{p}=0.93$ and $\mathrm{p}=0.34$, respectively).

\section{Conclusions}

Basal muscle protein synthesis rates are not lower in sarcopenic elderly men compared to healthy elderly men. The ingestion of 21 gram of a leucine-enriched whey protein effectively increases muscle protein synthesis rates in both sarcopenic and healthy elderly men. 


\section{Introduction}

Skeletal muscle mass, function and strength decline with an increasing age, a syndrome that has been coined sarcopenia. The decline in muscle strength and function leads to a reduced ability to perform activities of daily living, and are associated with an increased risk of adverse musculoskeletal outcomes such as falls and fractures ${ }^{1,2}$. Since sarcopenia is a strong predictor for mortality ${ }^{3}$, it is clinically relevant to unravel the mechanisms underlying the age-related loss of skeletal muscle tissue.

Muscle mass maintenance is believed to be regulated mainly by changes in basal and post-prandial muscle protein synthesis rates (MPS). Age-related declines in basal or post-prandial muscle protein synthesis rates may be responsible for the progressive loss of skeletal muscle mass throughout the lifespan. So far, studies investigating basal muscle protein synthesis rates in older individuals have shown conflicting results. Lower basal muscle protein synthesis rates have been observed in the older populations when compared with younger populations in some studies ${ }^{4-7}$. In contrast, more recent work has been unable to detect significant differences in basal muscle protein synthesis rates between young and elderly individuals ${ }^{8-12}$. However, none of these studies specifically included elderly men and women suffering from sarcopenia. Therefore, it is likely that potential differences in basal muscle protein synthesis rates between the young and old have remained undetected, because a heterogeneous elderly population was selected that included many individuals who had not (yet) shown any signs of (substantial) muscle loss.

In addition to basal muscle protein synthesis, muscle maintenance is also largely determined by the muscle protein synthetic response to food intake. Because of the apparent absence of measurable differences in basal muscle protein synthesis rates between young and elderly populations, many research groups have shifted their focus to the muscle protein synthetic response to the main anabolic stimuli, such as food intake and physical activity. One of the primary anabolic stimuli for muscle protein synthesis is a systemic hyperaminoacidemia, resulting from the ingestion of dietary protein or essential amino acids ${ }^{13-17}$. A reduced sensitivity of senescent muscle to the anabolic properties of amino acid exposure has been reported by various research groups $8,10,18,19$. The post-prandial muscle protein synthetic response has been shown to be modulated by the type ${ }^{20}$, amount ${ }^{21}$ and total leucine content ${ }^{9,22,23}$ of the protein ingested. Ingestion of $\sim 20 \mathrm{~g}$ whey protein has been shown to increase muscle protein synthesis rates in healthy elderly individuals 17,24-26. However, the post-prandial muscle protein synthetic response to protein 
ingestion may be blunted in the sarcopenic compared with the healthy elderly population. In the present study, we assessed if ingestion of a leucine-enriched whey protein can effectively increase the post-prandial muscle protein synthetic response in both healthy and sarcopenic elderly men.

We selected 15 healthy and 15 sarcopenic elderly males to participate in an experiment where we assessed basal and post-prandial muscle protein synthesis rates. Primed continuous infusions with L-[ring- $\left.{ }^{13} \mathrm{C}_{6}\right]$-phenylalanine were applied with the collection of blood samples and muscle tissue to assess both basal as well as post-prandial muscle protein synthesis rates following the ingestion of a supplement containing $21 \mathrm{~g}$ of leucine-enriched whey protein. This is the first study to investigate post-prandial muscle protein synthesis in diagnosed ${ }^{27}$ sarcopenic elderly males and to compare basal and post-prandial muscle protein synthesis rates between healthy and sarcopenic elderly males.

\section{Methods}

\section{Subjects}

A total of 15 sarcopenic elderly men ( $\geq 65$ year) and 15 healthy elderly men ( $\geq 65$ year) were selected to participate in this study. Subjects responded to advertisements in newspapers and were screened for eligibility at Maastricht University, the Netherlands. We informed all subjects on the nature and possible risks of the experimental procedures before we obtained written informed consent was. This study was approved by the Medical Ethical Committee of the Maastricht University Medical Centre, the Netherlands. The study was conducted in accordance with the Declaration of Helsinki and the International Conference on Harmonization guidelines for Good Clinical Practice as appropriate for nutritional products. The Trial Registration number for this study is NTR3047.

\section{Pre-testing}

All subjects participated in a screening session to determine their eligibility for inclusion. The inclusion criteria were male sex, age 65 years or older, and a BMI from 20 through $30 \mathrm{~kg} / \mathrm{m}^{2}$. Medical history, medication use, body weight, height, and alcohol use were recorded, and glucose tolerance was assessed by a 2-hour oral glucose tolerance test. A basal blood sample was drawn to determine glycated haemoglobin $\left(\mathrm{HbA} 1_{\mathrm{c}}\right)$, calcidiol and C-reactive protein (CRP) concentrations. Exclusion criteria included: all co-morbidities, the use of medication interacting with muscle metabolism and mobility of the limbs, co-morbidities interacting with 
gastric-intestinal function, inadequate glycaemic control and diabetes mellitus, smoking, weight loss of more than $3 \mathrm{~kg}$ in the last three months, the use of protein supplements, and participation in an exercise program. In addition, the criteria derived from the European Working Group on Sarcopenia in Older People ${ }^{27}$ and the International Working Group on Sarcopenia ${ }^{28}$ were used to determine the presence (or absence) of sarcopenia. The presence of both low skeletal muscle mass index (SMMI, i.e. appendicular lean mass divided by height by meters squared $\left(\mathrm{kg} / \mathrm{m}^{2}\right)$ ) and low muscle function (gait speed and/or grip strength) was mandatory for the diagnosis of sarcopenia. Subjects were considered to be sarcopenic with a gait speed of $\leq 1.0 \mathrm{~m} / \mathrm{s}$ or a handgrip strength $<30 \mathrm{~kg}$, in combination with a SMMI $<8.4 \mathrm{~kg} / \mathrm{m}^{2}$ (figure 1). Gait speed was determined over a $4 \mathrm{~m}$ interval. We assessed handgrip strength using a hydraulic handheld dynamometer (Jamar, Jackson, MI), and determined body composition by dual-energy X-ray absorptiometry (DEXA, Hologic Discovery A, Bedford, MA). ${ }^{29}$.

Figure 1 | Group selection algorithm

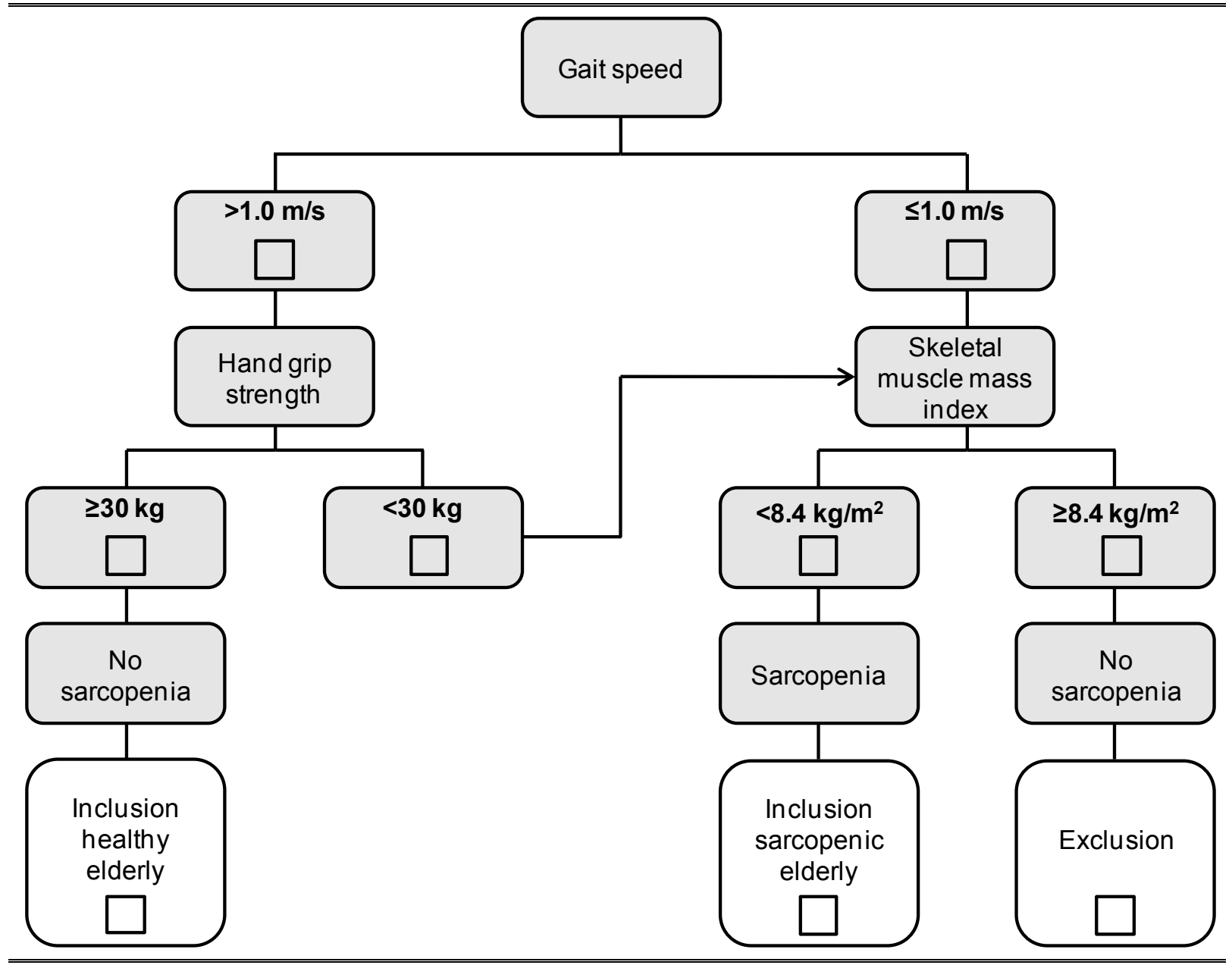

Algorithm used to identify healthy and sarcopenic subjects, according to the criteria formulated by the European Working Group on Sarcopenia in Older People and the International Working group on Sarcopenia. 


\section{Diet and activity prior to testing}

The same standardised meal was consumed by all subjects the evening prior to testing, containing $2385 \mathrm{~kJ}$ providing 35 Energy\% (En\%) as carbohydrate, $49 \mathrm{En} \%$ as fat, and $16 \mathrm{En} \%$ as protein. We instructed all participants to omit any exhaustive physical activity and to keep the diet as constant as possible during three days preceding testing.

\section{Design}

After the screening session, all eligible subjects participated in a single test day during which they ingested a single bolus of a given test drink. A primed, continuous infusion of $\mathrm{L}-\left[\right.$ ring $\left.{ }^{13} \mathrm{C}_{6}\right]$-phenylalanine and $\mathrm{L}-\left[\right.$ ring- $\left.{ }^{2} \mathrm{H}_{2}\right]$-tyrosine (Cambridge Isotopes Laboratories, Andover, MA) combined with the collection of plasma samples and muscle biopsies before and after the intake of the test drink was used to determine both basal and post-prandial muscle protein synthesis rates and basal whole-body protein balance.

\section{Experimental protocol}

Subjects arrived at the laboratory after an overnight fast by car or public transport in the early morning. We inserted a Teflon catheter in an antecubital vein to allow infusion of stable-isotopes. A second catheter was inserted in a vein on the hand of the contralateral arm and was placed in a hot box $\left(60^{\circ} \mathrm{C}\right)$ for arterialised blood sampling ${ }^{30}$. First, a basal plasma sample and a basal serum sample were collected ( $t$ $=-240 \mathrm{~min}$ ), after which the plasma phenylalanine and tyrosine pools were primed with a single dose of intravenously administered L-[ring- $\left.{ }^{13} \mathrm{C}_{6}\right]$-phenylalanine (2 $\mu \mathrm{mol} / \mathrm{kg})$ and L-[ring- $\left.{ }^{2} \mathrm{H}_{2}\right]$-tyrosine $(0.775 \mu \mathrm{mol} / \mathrm{kg})$. Thereafter, continuous tracer infusion was started with an infusion rate of $0.045 \mu \mathrm{mol} / \mathrm{kg} / \mathrm{min}$ for L-[ring- $\left.{ }^{13} \mathrm{C}_{6}\right]-$ phenylalanine and $0.020 \mu \mathrm{mol} / \mathrm{kg} / \mathrm{min}$ for L-[ring- ${ }^{2} \mathrm{H}_{2}$ ]-tyrosine using a calibrated infusion pump (IVAC). Subjects rested in a supine position for 90 minutes, after which we collected the first muscle biopsy from the vastus lateralis muscle $(t=-150$ min), marking the end of the pre-infusion period and the beginning of the basal period. Subsequently, arterialised blood samples were collected every 30 minutes, and the second muscle biopsy was collected at $t=0$ min, marking the end of the basal period. Following directly after the second biopsy, a single bolus of the test drink was ingested by the subjects. The third and fourth muscle biopsy were taken at $\mathrm{t}=120 \mathrm{~min}$ and at $\mathrm{t}=300 \mathrm{~min}$ from the contralateral limb. Arterialised blood samples $(8 \mathrm{~mL})$ were taken at $\mathrm{t}=15,30,45,60,75,90,105,120,135,150,165,180,210,240,270$ 
en $300 \mathrm{~min}$, and were collected in EDTA-containing tubes. They were centrifuged at $1000 \mathrm{~g}$ for $10 \mathrm{~min}$ at $4^{\circ} \mathrm{C}$. Aliquots of plasma were frozen in liquid nitrogen and were stored at $-80^{\circ} \mathrm{C}$. We obtained muscle biopsies using the percutaneous needle biopsy technique, entering the muscle $\pm 15 \mathrm{~cm}$ cranial of the patella and placing the needle $\pm 3 \mathrm{~cm}$ below the fascia ${ }^{31}$. Muscle samples were first dissected carefully and any visible non-muscle material was removed, and were then frozen in liquid nitrogen and stored until further analysis at $-80^{\circ} \mathrm{C}$.

\section{Drinks}

All subjects received a single bolus of a $21 \mathrm{~g}$ leucine-enriched whey protein nutritional supplement containing 3 gram of total leucine, 9 gram of carbohydrate and 3 gram of fat with an energetic value of $628 \mathrm{~kJ}$ (produced by Nutricia Advanced Medical Nutrition, the Netherlands). For an overview of the composition of this supplement, see chapter 6 (Kramer $2015{ }^{26}$ ). A small amount of tracer was added to the drink to prevent dilution of the L-[ring- $\left.{ }^{13} \mathrm{C}_{6}\right]$-phenylalanine plasma enrichment.

\section{Plasma analyses}

Concentrations of plasma glucose and insulin were analysed using commercially available kits (GLUC3, Roche, Ref: 05168791190, and Immunologic, Roche, Ref: 12017547122, respectively). High-performance liquid chromatography (Bio-Rad Diamat, Munich, Germany) was used to determine HbA1c content in venous blood samples. To measure the plasma concentrations of all essential and non-essential amino acids, $1500 \mu \mathrm{L}$ of $0.5 \mathrm{mM}$ Tridecafluoroheptanoic acid (TDFHA) (Sigma, Zwijndrecht, The Netherlands) was mixed with $10 \mu \mathrm{L}$ of plasma in water and $10 \mu \mathrm{L}$ of the internal standard solution containing stable isotope-labelled amino acids (Cambridge Isotope Laboratories, Inc., Andover, USA) was mixed in $0.1 \mathrm{M} \mathrm{HCl}$. Ultra-performance liquid chromatography tandem mass spectrometry (UPLCMS/MS) was used to determine amino acid concentrations, as described previously 32. For plasma L-[ring- ${ }^{13} \mathrm{C}_{6}$ ]-phenylalanine and L-[ring- $\left.{ }^{2} \mathrm{H}_{2}\right]$-tyrosine enrichment measurements, we derivatised plasma phenylalanine and tyrosine to their tertbutyldimethylsilyl (TBDMS) derivatives, and determined their ${ }^{13} \mathrm{C}$ and/or ${ }^{2} \mathrm{H}$ enrichments by electron ionisation gas chromatography-mass spectrometry (GC-MS; Agilent $6890 \mathrm{~N} \mathrm{GC/5973N} \mathrm{MSD)} \mathrm{using} \mathrm{selected} \mathrm{ion} \mathrm{monitoring} \mathrm{of} \mathrm{masses} 336$ and 342 for unlabelled and labelled (ring- ${ }^{13} \mathrm{C}_{6}$ ) phenylalanine, respectively. Masses 466, 468 and 472 were assessed for unlabelled and labelled (ring- ${ }^{2} \mathrm{H}_{2}$ and ring- ${ }^{13} \mathrm{C}_{6}$ ) tyrosine, respectively. Standard regression curves were applied in all isotopic enrichment analyses to assess the linearity of the mass spectrometer and to control for loss of 
tracer. By adding an internal standard $(m+10$ or $m+6)$, concentrations of phenylalanine, tyrosine and leucine were determined in the same run. We calculated enrichments (MPE) according to the work of Biolo et al ${ }^{33}$, to correct for the presence of both the ${ }^{13} \mathrm{C}$ and ${ }^{2} \mathrm{H}$ isotopes.

\section{Muscle analyses}

$\mathrm{L}-\left[\right.$ ring $\left.-{ }^{13} \mathrm{C}_{6}\right]$-phenylalanine enrichments were measured in the free amino acid pool and in mixed muscle protein, for which first 35-60 mg wet muscle was freeze-dried. Non- muscle fibre material such as collagen and blood was removed from the muscle fibres under a light microscope. The mass of isolated muscle fibres (7-12 mg) was weighed and 35 volumes $(7$ - dry weight of isolated muscle fibres - wet/dry ratio) of ice-cold $2 \%$ perchloric acid (PCA) were added. This was then homogenised and centrifuged. We collected the supernatant and processed this in the same way as the plasma samples, thereby allowing for measurement of intracellular free L-[ring${ }^{13} \mathrm{C}_{6}$ - -phenylalanine, L-[ring- $\left.{ }^{13} \mathrm{C}_{6}\right]$-tyrosine, and L-[ring- $\left.{ }^{2} \mathrm{H}_{2}\right]$-tyrosine enrichments on a GC-MS using their tert-butyldymethylsilyl derivatives. The protein pellet was washed with three additional $1.5 \mathrm{~mL}$ washes of $2 \%$ PCA, dried, and hydrolysed in 6 $\mathrm{M} \mathrm{HCl}$ at $120^{\circ} \mathrm{C}$ for $15-18 \mathrm{~h}$. The hydrolysed protein fraction was then dried under a nitrogen stream while being heated to $120^{\circ} \mathrm{C}$, and then dissolved in a $50 \%$ acetic acid solution. It was passed over a Dowex exchange resin (AG 50W-X8, 100-200 mesh hydrogen form; Bio-Rad, Hercules, CA, USA) using $2 \mathrm{M} \mathrm{NH} 4 \mathrm{OH}$. After this, the eluate was dried and the purified amino acid fraction of ${ }^{13} \mathrm{C}$-phenylalanine was derivatised to its $\mathrm{N}(\mathrm{O}, \mathrm{S})$-ethoxycarbonyl-ethylesters. The ratios ${ }^{13} \mathrm{C} /{ }^{12} \mathrm{C}$ of the muscle protein-bound phenylalanine were determined using gas chromatographycombustion-isotope ratio mass spectrometry (GC-IRMS) (MAT 253, ThermoFinnigan, Bremen, Germany) by monitoring ion masses 44, 45 and 46. We applied standard regression curves to assess linearity of the mass spectrometer and to control for the loss of tracer.

\section{Calculations}

Infusion of L-[ring- $\left.{ }^{13} \mathrm{C}_{6}\right]$-phenylalanine and L-[ring- $\left.{ }^{2} \mathrm{H}_{2}\right]$-tyrosine with the collection of muscle biopsies and arterialised blood sampling were used to assess whole-body amino acid kinetics during basal state and fractional synthetic rate (FSR) of mixed muscle protein during both basal and post-prandial states.

The calculation of the whole body rate of phenylalanine appearance (Ra) and rate of phenylalanine disappearance $(\mathrm{Rd})$ is summarised in the following equations: 


$$
\begin{gathered}
R_{a}=\frac{F-V\left[\frac{\left(C_{1}+C_{2}\right)}{2}\right] \times\left[\frac{E_{2}-E_{1}}{t_{2}-t_{1}}\right]}{\frac{E_{1}+E_{2}}{2}} \\
R_{d}=R_{a}-V \times \frac{C_{2}-C_{1}}{t_{2}-t_{1}}
\end{gathered}
$$

In this formula, $\mathrm{F}$ is the intravenous tracer infusion rate $(\mu \mathrm{mol} / \mathrm{kg} / \mathrm{min}), \mathrm{V}$ is the distribution volume for phenylalanine $(=0.125 \mathrm{~L} / \mathrm{kg}), \mathrm{C}_{1}$ and $\mathrm{C}_{2}$ are the phenylalanine concentrations $(\mu \mathrm{M})$ at time point $1\left(t_{1}\right)$ and $2\left(t_{2}\right)$, respectively, and $E_{1}$ and $E_{2}$ are the plasma L-[ring- ${ }^{13} \mathrm{C}_{6}$ ]-phenylalanine enrichments at time point $1\left(\mathrm{t}_{1}\right)$ and $2\left(\mathrm{t}_{2}\right)$, respectively. At steady state, the phenylalanine concentrations at time point 1 and 2 are equal $\left(C_{1}=C_{2}\right)$, so rate of phenylalanine appearance $\left(R_{a}\right)$ and disappearance $\left(R_{d}\right)$ are equal.

$$
R_{a}=R_{d}
$$

The rate of phenylalanine appearance equals the breakdown and intake, and the rate of disappearance equals the synthesis and oxidation of amino acids. Thus:

$$
\begin{aligned}
& R_{a}=B+I \\
& R_{d}=S+O
\end{aligned}
$$

Whole body protein turnover was calculated for the basal state, before intake of amino acids. Thus, intake (I) is zero and therefore changes in protein breakdown (B) equals the change in $R_{a}$.

$$
S=R_{d}-O
$$

Whole-body oxidation $(\mathrm{O})$ can be determined from the conversion (hydroxylation) of $\mathrm{L}-\left[\right.$ ring- $\left.{ }^{13} \mathrm{C}_{6}\right]$-phenylalanine to $\mathrm{L}-\left[\right.$ ring- $\left.{ }^{13} \mathrm{C}_{6}\right]$-tyrosine. The rate of hydroxylation can be calculated as follows:

$$
O=\operatorname{Tyr} R_{a} \times \frac{E_{t(t)}}{E_{p(t)}} \times \frac{\text { Phe } R_{d}}{F_{p}+\text { Phe } R_{d}}
$$

In this formula, $\mathrm{E}_{\mathrm{t}}$ is the weighted mean plasma enrichment of $\mathrm{L}-\left[\right.$ ring- $\left.{ }^{13} \mathrm{C}_{6}\right]-$ tyrosine during the incorporation period, $E_{p}$ is the weighted mean plasma enrichment of L- 
[ring- ${ }^{13} \mathrm{C}_{6}$ ]-phenylalanine $(\mathrm{MPE})$ during the incorporation period, and $\mathrm{F}_{\mathrm{p}}$ is the infusion rate of L-[ring- $\left.{ }^{13} \mathrm{C}_{6}\right]-$ phenylalanine $(\mu \mathrm{mol} / \mathrm{kg} / \mathrm{min})$.

Fractional synthesis rate (FSR) of mixed muscle protein was calculated by dividing the increment in enrichment of the product, i.e. protein-bound L-[ring- $\left.{ }^{13} \mathrm{C}_{6}\right]-$ phenylalanine, by the enrichment of the precursor, i.e. plasma L-[ring- $\left.{ }^{13} \mathrm{C}_{6}\right]-$ phenylalanine enrichment. Muscle FSR was calculated as follows:

$$
\mathrm{FSR}=\frac{\Delta E_{p}}{E_{\text {precursor }} \times t} \times 100
$$

In this formula, $\Delta E_{p}$ is the increment in protein-bound L-[ring- $\left.{ }^{13} \mathrm{C}_{6}\right]$-phenylalanine after an incorporation period, $E_{\text {precursor }}$ is the weighted mean plasma L-[ring- $\left.{ }^{13} \mathrm{C}_{6}\right]-$ phenylalanine enrichment (TTR) during that incorporation period, $t$ indicates the incorporation period $(\mathrm{h})$ between biopsies, and the factor 100 is needed to express the FSR in percent per hour $(\% / h)$. For basal FSR, muscle biopsies at $t=-2.5$ and $0 \mathrm{~h}$ were used, and for post-prandial FSR, biopsies at $t=0,2$ and $5 \mathrm{~h}$ were used.

\section{Statistics}

Sample size calculation for the part of the study in which study groups healthy elderly men resulted in a number of 15 subjects per group ${ }^{26}$. Therefore, also 15 sarcopenic subjects were included in the study.

All data are expressed as mean \pm standard error (SEM). Subjects' characteristics were compared between groups using a two-sample t-test, nonparametric Wilcoxon rank sum test, or Fisher's Exact test where appropriate. The concentrations of the plasma total amino acids (AA), essential AA (EAA), phenylalanine, and leucine at different time points were compared between groups using a mixed model for repeated measures (MMRM) with "group", "time", and their interaction as fixed effects, and "subject" as a random effect, and using the baseline value as covariate. In addition, peak concentrations and incremental area under the curve above baseline values (iAUC) of plasma total AA, EAA, phenylalanine and leucine were calculated and were compared between groups using ANCOVA with "group" as factor and using the baseline value as covariate. Insulin and glucose responses and plasma L-[ring- $\left.{ }^{13} \mathrm{C}_{6}\right]$-phenylalanine enrichments were analysed in the same way as the amino acid concentrations.

Whole-body phenylalanine kinetics were analysed using unpaired two-sample ttests to determine differences between the two groups. The post-prandial muscle 
fractional synthesis rates (FSR), which was the primary outcome measure, and the post-prandial muscle enrichments were analysed using ANCOVA with baseline as covariate to determine differences with basal FSR within study groups. Basal FSR and muscle enrichment were compared between groups using two-sample t-tests. For the comparison of FSR and muscle enrichments between groups, an ANCOVA was used combining the post-prandial time points/ periods as depending variables, with baseline as covariate and with "group" and "time" as factor. Statistical significance was set at $\mathrm{P}<0.05$. We performed all calculations using $\mathrm{SAS} \AA$ software (SAS Enterprise Guide 4.3 for Windows, SAS Institute Inc., Cary, NC, USA).

\section{Results}

Table 1 I Subjects' characteristics.

\begin{tabular}{|c|c|c|c|}
\hline & $\begin{array}{c}\text { Healthy } \\
n=15\end{array}$ & $\begin{array}{c}\text { Sarcopenic } \\
\quad n=15\end{array}$ & $p$ value \\
\hline Age $(y)^{2}$ & $69 \pm 1$ & $81 \pm 1$ & $<0.001$ \\
\hline Height (m) ${ }^{1}$ & $1.77 \pm 0.02$ & $1.72 \pm 0.02$ & 0.09 \\
\hline Weight (kg) ${ }^{1}$ & $79.5 \pm 1.9$ & $74.1 \pm 2.7$ & 0.11 \\
\hline BMI $\left(\mathrm{kg} / \mathrm{m}^{2}\right)^{1}$ & $25.5 \pm 0.3$ & $25.1 \pm 0.6$ & 0.65 \\
\hline Lean body mass $(\mathrm{kg})^{1}$ & $61.1 \pm 1.5$ & $54.2 \pm 1.9$ & 0.01 \\
\hline Body fat $(\%)^{1}$ & $20.2 \pm 0.8$ & $23.5 \pm 1.2$ & 0.03 \\
\hline $\operatorname{ALM}(\mathbf{k g})^{1}$ & $26.8 \pm 0.7$ & $22.5 \pm 0.8$ & $<0.001$ \\
\hline $\operatorname{SMMI}\left(\mathrm{kg} / \mathrm{m}^{2}\right)^{1}$ & $8.6 \pm 0.1$ & $7.6 \pm 0.2$ & $<0.001$ \\
\hline Handgrip strength (kg) ${ }^{1}$ & $43.4 \pm 1.9$ & $26.1 \pm 2.0$ & $<0.001$ \\
\hline Gait speed $(\mathrm{m} / \mathrm{sec})^{1}$ & $1.3 \pm 0.04$ & $0.7 \pm 0.05$ & $<0.001$ \\
\hline Total Balance score $(0-4)^{3}$ & $3.9 \pm 0.1$ & $2.3 \pm 0.3$ & $<0.001$ \\
\hline Time to complete 5 chair stands (s) ${ }^{1}$ & $10.0 \pm 0.3$ & $18.3 \pm 1.9$ & 0.001 \\
\hline Total SPPB score $(0-12)^{1}$ & $11.8 \pm 0.1$ & $6.1 \pm 0.5$ & $<0.001$ \\
\hline Fasting glucose $(\mathrm{mmol} / \mathrm{L})^{1}$ & $5.3 \pm 0.2$ & $5.6 \pm 0.2$ & 0.17 \\
\hline 2-hour glucose $(\mathrm{mmol} / \mathrm{L})^{2}$ & $5.7 \pm 0.3$ & $6.8 \pm 0.4$ & 0.06 \\
\hline Glycated haemoglobin $(\%)^{1}$ & $5.7 \pm 0.1$ & $5.7 \pm 0.1$ & 0.90 \\
\hline HOMA-IR index ${ }^{2}$ & $2.37 \pm 0.51$ & $2.49 \pm 0.33$ & 0.25 \\
\hline OGIS index ${ }^{2}$ & $324 \pm 22$ & $336 \pm 15$ & 0.63 \\
\hline Baseline hsCRP level (mg/L)² & $1.2 \pm 0.2$ & $4.6 \pm 1.1$ & 0.004 \\
\hline Baseline Calcidiol level (nmol/L) ${ }^{1}$ & $68.3 \pm 6$ & $58.8 \pm 8$ & 0.33 \\
\hline
\end{tabular}

Abbreviations: BMI= Body Mass Index; ALM= Appendicular Lean Mass; SMMI= Skeletal Muscle Mass Index; $\mathrm{SPPB}=$ Short Physical Performance Battery; HOMA-IR= Homeostatic Model Assessement - Insulin Resistance; OGIS $=$ Oral Glucose Insulin Sensitivity. Values are means \pm SEM. Data were analysed using two-sample t-test ${ }^{1}$, non-parametric Wilcoxon rank sum test ${ }^{2}$, or Fisher's Exact test ${ }^{3}$. Characteristics were tested as potential confounders, which did not reveal any significant effect.

\section{Participants}

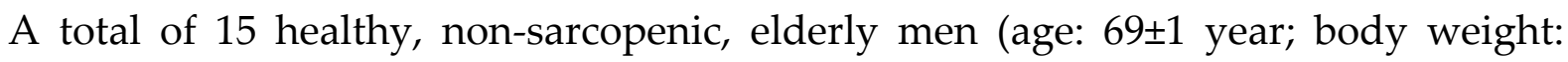
$79.5 \pm 1.9 \mathrm{~kg}$; BMI: $25.5 \pm 0.3 \mathrm{~kg} / \mathrm{m}^{2}$ ) and 15 sarcopenic elderly men (age: $81 \pm 1 \mathrm{y}$; body 
weight: $74.1 \pm 2.7 \mathrm{~kg}$; BMI: $25.1 \pm 0.6 \mathrm{~kg} / \mathrm{m}^{2}$ ) were included and participated in the experiment between December 2011 and April 2013. Participants' characteristics are shown in table 1 . The group of sarcopenic elderly differed significantly from the group of healthy elderly regarding the physical tests (SPPB and handgrip strength) and DEXA results, which confirms that the selection of subjects was done adequately. Age, alcohol consumption, BMI, lean body mass, skeletal muscle mass, weight, hsCRP and calcidiol were tested as possible confounders, but did not significantly influence the results of the between-group analyses of the FSR outcome parameters. There were no dropouts during the study.

\section{Safety and tolerance}

No gastro-intestinal complaints were observed after intake of the drinks in any of the two groups. The recorded adverse events did not differ between the groups and were not considered to be related to the use of the study product. No serious adverse events occurred during the execution of this study.

\section{Plasma glucose and insulin}

Figure 2 | Plasma glucose and insulin concentrations

A

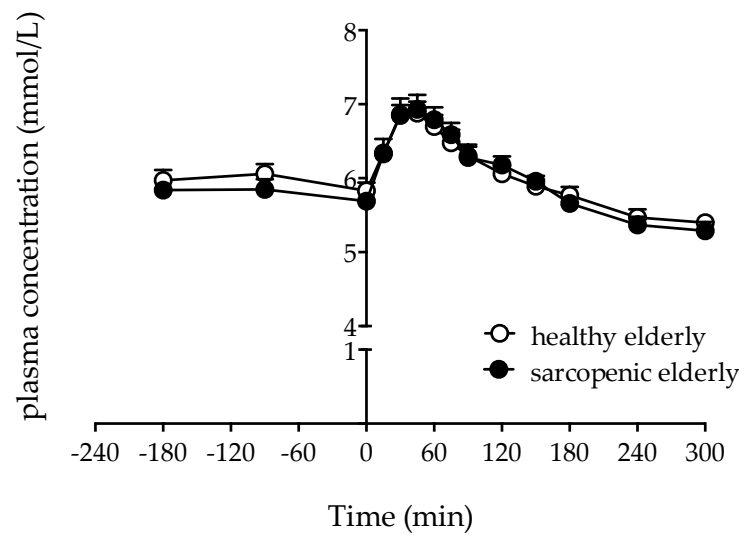

B

Insulin

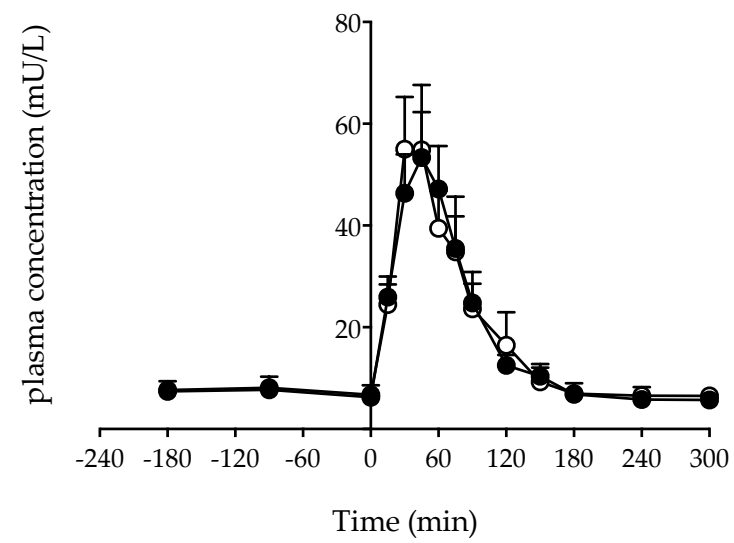

Mean ( \pm SEM) plasma glucose (A) and insulin (B) concentrations (mmol/L and $\mathrm{mU} / \mathrm{L}$, respectively) in healthy $(n=15)$ en sarcopenic $(n=15)$ subjects during the fasting period and after ingestion of $21 \mathrm{~g}$ of leucine-enriched whey protein supplement. Comparisons between groups at specific time points were done using mixed model repeated measures (MMRM) analyses; no significant differences between groups. Glucose: iAUC p=0.15, peakvalue $\mathrm{p}=0.38$; Insulin: iAUC $\mathrm{p}=0.74$, peak-value $\mathrm{p}=0.77$ (all ANCOVA).

Plasma glucose and insulin concentrations in the healthy and sarcopenic group are displayed in figure 2. For glucose, a significant time effect was observed in both groups (MMRM model, $\mathrm{p}<0.0001$ ), without a group effect or group $\mathrm{x}$ time effect 
$(p=0.11$ and $p=0.92$, respectively). No significant differences in glucose concentrations were seen between the groups at any time point. No difference in glucose peak concentration or incremental area under the curve (iAUC) above baseline levels was seen between the healthy and sarcopenic group (7.1 \pm 0.2 and $7.0 \pm 0.2 \mathrm{mmol} / \mathrm{L}$, ANCOVA $\mathrm{p}=0.38$, and $92 \pm 12$ and $117 \pm 10 \mathrm{mmol} / \mathrm{L} / 5 \mathrm{~h}, \mathrm{p}=0.15$, respectively). Plasma insulin concentrations also significantly increased after ingestion of the supplement (MMRM model, significant time effect $(p<0.0001)$, no interaction $(p=0.92)$ effect, no group effect $(p=0.78)$ ). Again, no significant differences in insulin concentrations were seen between the groups at any time point. Furthermore, no difference was seen between the healthy and sarcopenic group in terms of insulin peak concentration or iAUC $(63 \pm 13$ and $57 \pm 9 \mathrm{mU} / \mathrm{L}, \mathrm{p}=0.77$ and $3455 \pm 776$ and $3475 \pm 623 \mathrm{mU} / \mathrm{L} / 5 \mathrm{~h}, \mathrm{p}=0.74$, respectively).

\section{Plasma amino acids}

The time course of plasma phenylalanine (A), leucine (B), total essential amino acid $($ EAA; $)$, and total amino acid (AA; D) concentrations over time are depicted in figure 3. Total plasma amino acid concentrations increased after ingestion of the supplement in both groups (MMRM model, time effect $\mathrm{p}<0.001$, group effect $\mathrm{p}=0.08$, interaction effect $p=0.91$ ). No difference in peak concentration of any of the amino acids was seen between the two groups. Plasma phenylalanine concentrations were higher in the sarcopenic group during a part of the post-prandial period, i.e. at time point $\mathrm{t}=45,60,75,90,135$ and $150 \mathrm{~min}$ (MMRM, $\mathrm{p}<0.05$, figure 3A). Leucine concentrations were higher in the sarcopenic group for time points $t=75$ until $t=105$ $\min$ and $t=135(p<0.05$; figure $3 \mathbf{B})$. Total essential amino acid concentration were higher in the sarcopenic group at $t=75, t=90$ and $t=135 \min (M M R M, p<0.05$, figure $3 \mathrm{C}$ ). In addition, higher iAUC were seen for plasma phenylalanine, leucine and EAA concentrations in the sarcopenic group when compared with the healthy group (ANCOVA, $3.1 \pm 0.3$ vs $2.1 \pm 0.1 \mathrm{mmol} / \mathrm{L} / 5 \mathrm{~h}, \mathrm{p}=0.006 ; 51.2 \pm 2.3$ vs $42.5 \pm 1.7$ $\mathrm{mmol} / \mathrm{L} / 5 \mathrm{~h}, \mathrm{p}=0.01$; and $161.4 \pm 8.4$ vs $136.0 \pm 7.0 \mathrm{mmol} / \mathrm{L} / 5 \mathrm{~h}, \mathrm{p}=0.03$, respectively). Total plasma amino acid concentration only differed between the groups at $t=90$ min (figure 3D).

\section{Plasma L-[ring- $\left.{ }^{13} \mathrm{C}_{6}\right]$-phenylalanine}

Figure 4 shows the plasma L-[ring- $\left.{ }^{13} \mathrm{C}_{6}\right]$-phenylalanine enrichments. No significant differences in L-[ring- $\left.{ }^{13} \mathrm{C}_{6}\right]$-phenylalanine enrichments were seen between the groups at any time point. After ingestion of the supplement, a small decrease in L-[ring${ }^{13} \mathrm{C}_{6}$ ]-phenylalanine enrichments was observed in both groups. 
Figure 3 | Plasma amino acid concentrations
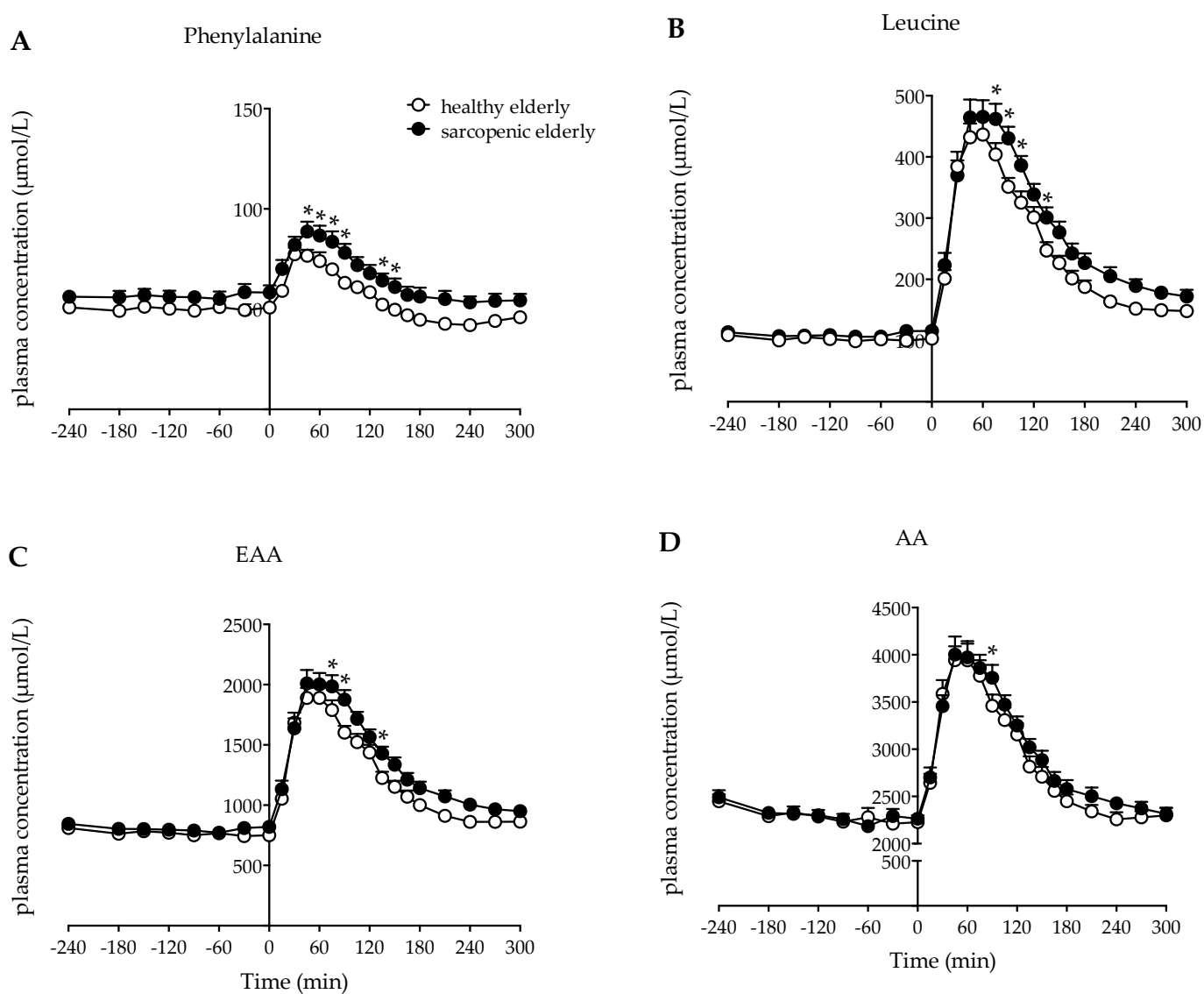

Mean ( \pm SEM) plasma phenylalanine (A), leucine (B), essential amino acid (C), and total amino acid (D) concentration $(\mu \mathrm{mol} / \mathrm{L})$ in healthy $(n=15)$ and sarcopenic $(n=15)$ subjects during the fasting period and after ingestion of $21 \mathrm{~g}$ of leucine-enriched whey protein supplement. * Significant difference between groups. Phenylalanine: iAUC $p=0.006$, peak-value $p=0.45$; Leucine: iAUC $p=0.01$, peak-value $p=0.47$; EAA: iAUC $p=0.03$, peak-value $\mathrm{p}=0.62$; AA: iAUC $\mathrm{p}=0.16$, peak-value $\mathrm{p}=0.86$ (all ANCOVA).

Figure 4 | Plasma L-[ring-13 $\left.\mathrm{C}_{6}\right]$-phenylalanine

\section{L-[ring- ${ }^{13} \mathrm{C}_{6}$ ]-phenylalanine}

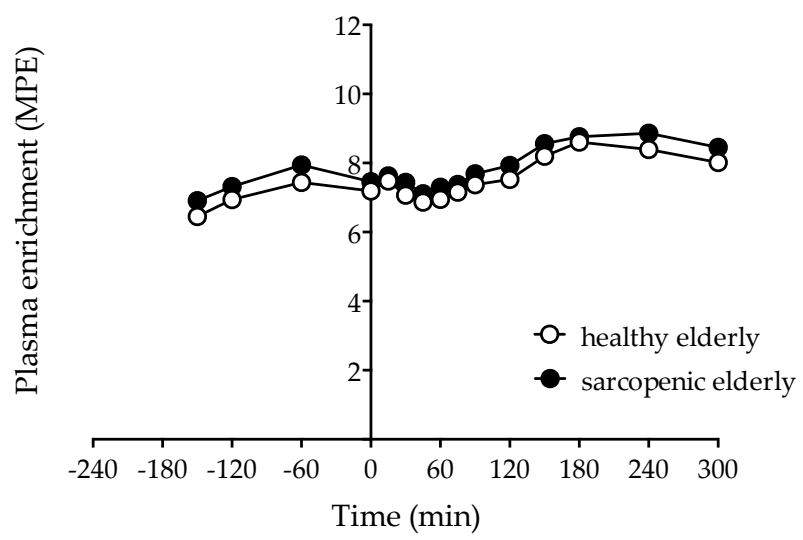

Mean ( \pm SEM) plasma L-[ring-13 ${ }^{13}$ ]-phenylalanine enrichments (MPE) in healthy $(n=15)$ and sarcopenic $(n=15)$ subjects during the fasting period and after ingestion of $21 \mathrm{~g}$ of leucine-enriched whey protein supplement. no significant differences between groups. iAUC $\mathrm{p}=0.60$, peak-value $\mathrm{p}=0.74$ (all ANCOVA). 


\section{Whole-body phenylalanine kinetics}

During the basal period, whole-body protein breakdown measured by phenylalanine appearance averaged $38.1 \pm 0.7$ and $36.0 \pm 0.8 \mu \mathrm{mol} / \mathrm{kg} / \mathrm{h}$ in the healthy and sarcopenic group, respectively, without significant differences between the groups ( $\mathrm{t}$-test, $\mathrm{p}=0.06$ ). Whole-body protein synthesis measured by phenylalanine disappearance corrected for amino acid oxidation neither differed between the groups (t-test, $\mathrm{p}=0.13$ ), with an average rate of $35.0 \pm 0.7$ and $33.4 \pm 0.7 \mu \mathrm{mol} / \mathrm{kg} / \mathrm{h}$, respectively. However, whole-body phenylalanine hydroxylation did show a significant group effect (t-test, $\mathrm{p}<0.01,3.3 \pm 0.2 \mathrm{vs} 2.5 \pm 0.2 \mu \mathrm{mol} / \mathrm{kg} / \mathrm{h}$, in the healthy and sarcopenic group, respectively). In total, basal whole-body net protein balance was negative in both groups, but significantly higher in the sarcopenic elderly ($2.0 \pm 0.2 \mu \mathrm{mol} / \mathrm{kg} / \mathrm{h})$ when compared with the healthy elderly $(-2.6 \pm 0.2 \mu \mathrm{mol} / \mathrm{kg} / \mathrm{h})(\mathrm{t}-$ test, $\mathrm{p}<0.01)$.

\section{Muscle tracer analyses}

Table 2 I Muscle tissue-free and protein-bound L-[ring- $\left.{ }^{13} \mathrm{C}_{6}\right]$-phenylalanine enrichments

\begin{tabular}{|c|c|c|c|c|}
\hline & Time (min) & $\begin{array}{l}\text { Healthy elderly } \\
\qquad n=15\end{array}$ & $\begin{array}{c}\text { Sarcopenic elderly } \\
n=15 \\
\end{array}$ & $p$ value \\
\hline \multirow{4}{*}{$\begin{array}{l}\text { Muscle tissue-free } \\
\text { enrichments }\end{array}$} & 0 & $4.49 \pm 0.20$ & $5.54 \pm 0.19$ & $<0.001^{1}$ \\
\hline & 120 & $5.44 \pm 0.25^{*}$ & $5.92 \pm 0.21^{*}$ & $0.68^{2}$ \\
\hline & 300 & $5.21 \pm 0.15^{*}$ & $6.07 \pm 0.16^{*}$ & \\
\hline & & & & $0.25^{2}$ \\
\hline \multirow{3}{*}{$\begin{array}{l}\text { Muscle protein-bound } \\
\text { enrichments }\end{array}$} & 0 & $0.0058 \pm 0.0005$ & $0.0072 \pm 0.0009$ & $0.18^{1}$ \\
\hline & 120 & $0.0150 \pm 0.0013^{*}$ & $0.0164 \pm 0.0008^{*}$ & $0.55^{2}$ \\
\hline & 300 & $0.0268 \pm 0.0014^{*}$ & $0.0295 \pm 0.0015^{*}$ & $0.25^{2}$ \\
\hline
\end{tabular}

Mean ( \pm SEM) muscle tissue-free and muscle protein-bound L-[ring-13 $\left.\mathrm{C}_{6}\right]$-phenylalanine enrichments (MPE) during the fasting $(t=0 \mathrm{~h})$ and post-prandial period $(t=2$ and $t=5 \mathrm{~h})$ following ingestion of $21 \mathrm{~g}$ of leucineenriched whey protein supplement in healthy $(n=15)$ and sarcopenic $(n=15)$ subjects. Data were analysed to compare the post-prandial enrichments between groups using Two-sample t-test ${ }^{1}$, or ANCOVA with basal values as covariate ${ }^{2}$. Comparisons within the groups between the post-prandial time point and basal values were done using ANCOVA. * Significant increase compared with basal $(\mathrm{t}=0 \mathrm{~h})$ muscle enrichment.

Muscle tissue-free and protein-bound L-[ring- $\left.{ }^{13} \mathrm{C}_{6}\right]$-phenylalanine enrichments are presented in table 2 . In the two groups, a significant rise in muscle tissue-free L[ring- ${ }^{13} \mathrm{C}_{6}$ ]-phenylalanine was observed at both $2 \mathrm{~h}$ and $5 \mathrm{~h}$ following ingestion of the supplement compared with basal values (ANCOVA, $p<0.0001$ and $p<0.001$ in the healthy and sarcopenic group, respectively). Muscle tissue-free L-[ring- $\left.{ }^{13} \mathrm{C}_{6}\right]-$ phenylalanine enrichments were significantly higher in the sarcopenic elderly group at baseline in comparison with the healthy elderly group ( $t$-test, $\mathrm{p}<0.001$ ), while there 
was no difference between groups at 2 and $5 \mathrm{~h}$ (ANCOVA, $\mathrm{p}=0.68$ and $\mathrm{p}=0.25$, respectively). Mixed muscle protein-bound L-[ring- $\left.{ }^{13} \mathrm{C}_{6}\right]$-phenylalanine enrichments showed a significant rise in both groups at $2 \mathrm{~h}$ and $5 \mathrm{~h}$ compared with basal values (ANCOVA, $\mathrm{p}<0.0001$ for both time points for each group). There were no statistical differences between the two groups at any specific time point.

\section{Mixed-muscle protein synthesis rates}

Figure 5 | Mixed-muscle protein synthesis rates
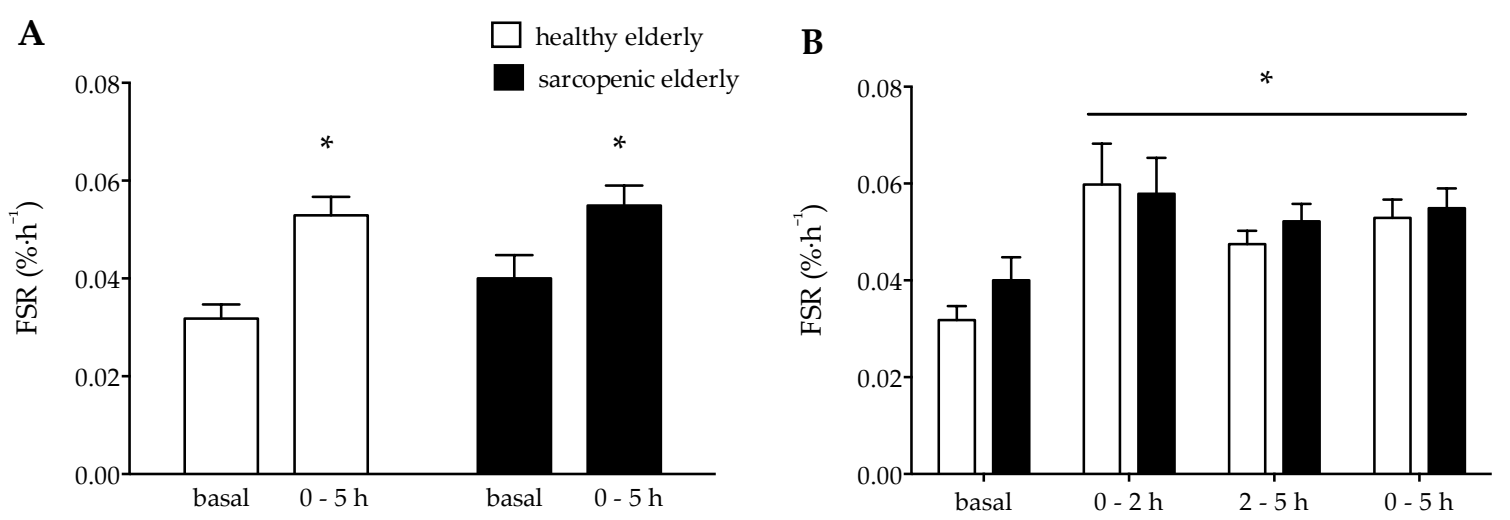

Mean ( \pm SEM) mixed muscle protein FSR (percentage per hour) in healthy $(n=15)$ and sarcopenic $(n=13)$ subjects during the basal period and post-prandial period after ingestion of $21 \mathrm{~g}$ of leucine-enriched whey protein supplement. Comparisons within and between groups were done using ANCOVA. * Significantly different when compared with basal rates. A: comparison of muscle FSR in the cumulative post-prandial period $(0-5 \mathrm{~h})$ with basal period within groups; healthy $(p<0.001)$; sarcopenic $(p=0.003)$. B: comparison of muscle FSR in the basal period, early post-prandial period $(0-2 \mathrm{~h})$, late post-prandial period $(2-5 \mathrm{~h})$, and cumulative post-prandial period $(0-5 \mathrm{~h})$ between groups; basal ( $\mathrm{p}=0.14) ; 0-2 \mathrm{~h}(\mathrm{p}=0.93) ; 2-5 \mathrm{~h}(\mathrm{p}=0.34) ; 0-5 \mathrm{~h}(\mathrm{p}=0.45)$.

Mixed-muscle protein synthesis rates, expressed as fractional synthesis rates (FSR) with plasma L-[ring- $\left.{ }^{13} \mathrm{C}_{6}\right]$-phenylalanine enrichments as precursor, are shown in figure 5. FSR values were calculated for the basal period $(-2.5-0 \mathrm{~h})$, the early postprandial period $(0-2 \mathrm{~h})$, the late post-prandial period $(2-5 \mathrm{~h})$, and the cumulative post-prandial period $(0-5 \mathrm{~h})$. A significant rise in mixed-muscle FSR was seen in both healthy and sarcopenic elderly in the cumulative post-prandial period (ANCOVA, $\mathrm{p}<0.001$ and $\mathrm{p}=0.003$, respectively, figure 5A). Furthermore, mixedmuscle FSR was significantly higher than basal FSR in the healthy and sarcopenic group in both the early (ANCOVA, $\mathrm{p}=0.009$ and $\mathrm{p}=0.004$, respectively) and late $(\mathrm{p}<0.001$ and $\mathrm{p}=0.008$, respectively) post-prandial period. No significant difference was observed for basal FSR between the two groups ( $t$-test, $0.032 \pm 0.003$ and $0.040 \pm 0.005 \% / h$, in the healthy and sarcopenic group, respectively, $\mathrm{p}=0.14$; figure 5B). Both the early and late post-prandial muscle protein synthesis rates did not 
differ significantly between the two groups (ANCOVA, $0.060 \pm 0.008$ vs $0.058 \pm 0.007$ $\% / \mathrm{h}$ and $0.048 \pm 0.003$ vs $0.052 \pm 0.004 \% / \mathrm{h} ; \mathrm{p}=0.93$ and $\mathrm{p}=0.34$, respectively). Likewise, no significant difference was observed for the cumulative post-prandial FSR between the healthy and sarcopenic group (ANCOVA, $0.053 \pm 0.004$ and $0.055 \pm 0.004$ $\% / h$, respectively, $\mathrm{p}=0.45$ ). Similar results were obtained using the muscle tissue-free L-[ring- $\left.{ }^{13} \mathrm{C}_{6}\right]$-phenylalanine enrichments as precursor pool (data not shown).

\section{Discussion}

We demonstrated that muscle protein synthesis rates in sarcopenic elderly men were effectively increased by the ingestion of $21 \mathrm{~g}$ of a leucine-enriched whey protein. Basal muscle protein synthesis rates and post-prandial muscle protein synthesis rates did not differ between sarcopenic and healthy elderly men.

Elderly individuals with diagnosed sarcopenia have lost substantial amounts of skeletal muscle mass and strength when compared with their healthy elderly controls. We hypothesised that this loss of muscle mass is attributed to a decline in basal muscle protein synthesis rates and/or a blunted muscle protein synthetic response to feeding. We selected a group of 15 sarcopenic elderly males $(81 \pm 1 \mathrm{y})$ from a total of 161 potential subjects who responded to advertisements placed in local newspapers aimed at elderly males who had been experiencing signs of muscle loss and an incipient decline in mobility. Sarcopenia was diagnosed using the criteria as formulated by the EWGSOP 27 and the International Working Group on Sarcopenia ${ }^{28}$ in an algorithm including gait speed, handgrip strength and skeletal muscle mass index (figure 1). The presence of both low SMMI $\left(<8.4 \mathrm{~kg} / \mathrm{m}^{2}\right)$ and low muscle function (gait speed $\leq 1.0 \mathrm{~m} / \mathrm{s}$ and/or grip strength $<30 \mathrm{~kg}$ ) was required for the diagnosis of sarcopenia. A control group of 15 healthy elderly males $(69 \pm 1$ year) were recruited from a pool of independently living elderly who responded to an advertisement in the local newspaper. As expected, the sarcopenic elderly showed significantly lower skeletal muscle mass when compared with the healthy controls (table 1).

Previous work has suggested lower basal muscle protein synthesis rates in elderly compared with younger individuals as a rationale for the age-related loss of skeletal muscle mass and strength ${ }^{4-7}$. We hypothesised that basal muscle protein synthesis rates are reduced in sarcopenic when compared with healthy elderly men. However, our data showed no significant differences in basal muscle protein synthesis rates between groups ( $p=0.14$, figure $5 \mathbf{B}$ ). In fact, the basal muscle protein synthesis rates tended to be higher as opposed to lower in the sarcopenic elderly 
subjects compared with the healthy controls. These data tend to be in line with more recent reports showing no detectable differences in basal muscle protein synthesis rates between the young and elderly $8,10,11$ and the observation of rather higher than lower basal muscle protein synthesis rates in the elderly compared the young ${ }^{34}$. Consequently, a structural decline in basal muscle protein synthesis rate does not same to be the underlying mechanism of the difference in skeletal muscle mass between sarcopenic and non-sarcopenic elderly.

In addition to basal muscle protein synthesis rates, post-prandial stimulation of muscle protein synthesis has been identified as an important component in the regulation of muscle mass maintenance. It has been well established that the elderly population shows an impaired muscle protein synthetic response to anabolic stimuli such as food intake and physical activity $8,18,35,36$. The mechanisms responsible for this anabolic resistance may be multifactorial and may include impairments in protein digestion and amino acid absorption ${ }^{37}$, increased extraction of plasma amino acids into the splanchnic tissues ${ }^{15}$, reduced amino acid delivery to skeletal muscle tissue ${ }^{38}$, reduced amino acid uptake in muscle ${ }^{39}$, and impaired intramuscular anabolic signalling ${ }^{8}$. As sarcopenic elderly have experienced loss of skeletal muscle mass and strength, we hypothesised that these sarcopenic elderly show an attenuated muscle protein synthetic response to feeding when compared with healthy controls. Following ingestion of the $21 \mathrm{~g}$ bolus of leucine-enriched whey protein supplement, we observed a rapid post-prandial rise in plasma amino acid and insulin concentrations in both groups (figure 2 B and 3A-D). This resulted in $\sim 35-65 \%$ higher muscle protein synthesis rates when compared with basal values in the healthy and sarcopenic elderly $(\mathrm{p}<0.005$; figure $5 \mathbf{A})$. No differences were observed in muscle protein synthesis rates calculated during the early (0-2 h), late (2-5 h) or entire $5 \mathrm{~h}$ post-prandial phase between groups $(\mathrm{p}=0.93, \mathrm{p}=0.34$, and $\mathrm{p}=0.45$, respectively, figure 5B). This shows that there are no impairments in the post-prandial muscle protein synthetic response to the ingestion of a $21 \mathrm{~g}$ bolus of leucine-enriched whey protein in sarcopenic elderly compared with healthy controls. This demonstrates that even in sarcopenic elderly senescent muscle seems to maintain its capability to respond to the ingestion of a bolus of whey protein fortified with free leucine.

The present study expands upon previous work aiming to elucidate the changes in basal and post-prandial muscle protein synthesis rates associated with aging, by comparing both basal and post-prandial muscle protein synthesis rates between healthy and sarcopenic elderly men. Despite the substantial differences in muscle mass and strength between the sarcopenic elderly and their healthy controls, we could not detect any differences in basal or post-prandial muscle protein 
synthesis rates between groups. This raises the question what (other) mechanisms may be responsible for the substantial loss of skeletal muscle mass in the sarcopenic geriatric population. We have recently reported substantial muscle loss after merely 5-14 days of muscle disuse, attributed to both a decline in basal muscle protein synthesis and impairments in the anabolic response to feeding ${ }^{40}$. This work, as well as work from others ${ }^{41-43}$, suggests that muscle mass loss with aging may be largely attributed to muscle loss experienced during short, successive periods of bed rest following injury or disease, characterised by muscle disuse and malnutrition. This catabolic crisis theory ${ }^{44}$ implies that the substantial loss of muscle mass and strength experienced during such episodes is not regained during recovery from injury or disease in the elderly population, resulting in a progressive loss of muscle mass throughout the later stages of the lifespan. In support of this theory, the medical history of our sarcopenic elderly showed multiple reports of hospitalisation and surgery over (at least) the preceding 5 years with multiple co-morbidities. We believe more focus is needed to address the impact of such periods of accelerated muscle loss following injury, surgery or disease on the development of sarcopenia in the elderly population.

In the present study, we compared the post-prandial muscle protein synthetic response following the ingestion of $21 \mathrm{~g}$ of a leucine-enriched whey protein nutritional supplement between healthy and sarcopenic elderly men. Ingestion of 20 $\mathrm{g}$ whey protein has previously been shown to represent an effective anabolic stimulus in the elderly population ${ }^{24}$ and was, therefore, applied in this study. In agreement, a $\sim 35-65 \%$ increase in muscle protein synthesis rate was observed following protein ingestion in the elderly volunteers included in the present study. The absence of any structural differences in the post-prandial muscle protein synthetic response to feeding between the healthy and sarcopenic elderly indicates that there are no substantial impairments in anabolic sensitivity in sarcopenic elderly to the anabolic stimulus provided in the study (figure 5B). However, we cannot rule out that some level of anabolic resistance may be evident following ingestion of small(er), more meal-like amounts of dietary protein in sarcopenic versus healthy elderly. Nonetheless, our data clearly show that there is still remarkable responsiveness to proper anabolic stimuli in the compromised elderly sarcopenic patient, providing important leads to targeted nutritional intervention and dietary support. 


\section{Conclusions}

In conclusion, basal muscle protein synthesis rates are not reduced in sarcopenic elderly men compared to healthy elderly men. The ingestion of $21 \mathrm{~g}$ of a leucineenriched whey protein effectively increases muscle protein synthesis rates in healthy as well as sarcopenic elderly men. 


\section{References}

1. Cooper C, Dere W, Evans W, et al. Frailty and sarcopenia: definitions and outcome parameters. Osteoporos Int. 2012;23(7):1839-1848.

2. Landi F, Liperoti R, Russo A, et al. Sarcopenia as a risk factor for falls in elderly individuals: results from the ilSIRENTE study. Clinical nutrition. 2012;31(5):652-658.

3. Genton L, Graf CE, Karsegard VL, et al. Low fat-free mass as a marker of mortality in community-dwelling healthy elderly subjects. Age and ageing. 2013;42(1):33-39.

4. Balagopal P, Rooyackers OE, Adey $\mathrm{DB}$, et al. Effects of aging on in vivo synthesis of skeletal muscle myosin heavy-chain and sarcoplasmic protein in humans. The American journal of physiology. 1997;273(4):790-800.

5. Rooyackers OE, Adey DB, Ades PA, et al. Effect of age on in vivo rates of mitochondrial protein synthesis in human skeletal muscle. Proceedings of the National Academy of Sciences of the United States of America. 1996;93(26):15364-15369.

6. Welle S, Thornton C, Jozefowicz R, et al. Myofibrillar protein synthesis in young and old men. The American journal of physiology. 1993;264(5):693698.

7. Yarasheski KE, Zachwieja JJ, Bier DM. Acute effects of resistance exercise on muscle protein synthesis rate in young and elderly men and women. The American journal of physiology. 1993;265(2):210-214.

8. Cuthbertson D, Smith K, Babraj J, Leese G, Waddell T, Atherton P, et al. Anabolic signaling deficits underlie amino acid resistance of wasting, aging muscle. FASEB journal : official publication of the Federation of American Societies for Experimental Biology. 2005;19(3):422-424.

9. Katsanos CS, Kobayashi H, SheffieldMoore M, et al. A high proportion of leucine is required for optimal stimulation of the rate of muscle protein synthesis by essential amino acids in the elderly. American journal of physiology Endocrinology and metabolism. 2006;291(2):381-387.

10. Paddon-Jones D, Sheffield-Moore M, Zhang $\mathrm{XJ}$, et al. Amino acid ingestion improves muscle protein synthesis in the young and elderly. American journal of physiology Endocrinology and metabolism. 2004;286(3):321-328.

11. Volpi E, Sheffield-Moore M, Rasmussen BB, Wolfe RR. Basal muscle amino acid kinetics and protein synthesis in healthy young and older men. JAMA : the journal of the American Medical Association. 2001;286(10):1206-1212.

12. Kumar V, Selby A, Rankin D, et al. Age-related differences in the doseresponse relationship of muscle protein synthesis to resistance exercise in young and old men. The Journal of physiology. 2009;587(1):211-217.

13. Volpi E, Kobayashi H, SheffieldMoore $\mathrm{M}$, et al. Essential amino acids are primarily responsible for the amino acid stimulation of muscle protein anabolism in healthy elderly adults. Am J Clin Nutr. 2003;78(2):250258.

14. Volpi E, Ferrando AA, Yeckel CW, et al. Exogenous amino acids stimulate net muscle protein synthesis in the elderly. The Journal of clinical investigation. 1998;101(9):2000-2007.

15. Volpi E, Mittendorfer B, Wolf SE, et al. Oral amino acids stimulate muscle protein anabolism in the elderly despite higher first-pass splanchnic extraction. The American journal of physiology. 1999;277(3):E513-520.

16. Rennie MJ, Edwards RH, Halliday D, et al. Muscle protein synthesis measured by stable isotope techniques in man: the effects of feeding and 
fasting. Clinical science. 1982;63(6):519523.

17. Paddon-Jones D, Sheffield-Moore M, Katsanos CS, et al. Differential stimulation of muscle protein synthesis in elderly humans following isocaloric ingestion of amino acids or whey protein. Experimental gerontology. 2006;41(2):215-219.

18. Katsanos CS, Kobayashi H, SheffieldMoore $\mathrm{M}$, et al. Aging is associated with diminished accretion of muscle proteins after the ingestion of a small bolus of essential amino acids. The American journal of clinical nutrition. 2005;82(5):1065-1073.

19. Volpi E, Mittendorfer B, Rasmussen $\mathrm{BB}$, et al. The response of muscle protein anabolism to combined hyperaminoacidemia and glucoseinduced hyperinsulinemia is impaired in the elderly. The Journal of clinical endocrinology and metabolism. 2000;85(12):4481-4490.

20. Pennings B, Boirie $Y$, Senden JM, et al. Whey protein stimulates postprandial muscle protein accretion more effectively than do casein and casein hydrolysate in older men. The American journal of clinical nutrition. 2011;93(5):997-1005.

21. Pennings B, Groen B, de Lange A, et al. Amino acid absorption and subsequent muscle protein accretion following graded intakes of whey protein in elderly men. American journal of physiology Endocrinology and metabolism. 2012;302(8):E992-999.

22. Wall BT, Hamer HM, de Lange A, et al. Leucine co-ingestion improves post-prandial muscle protein accretion in elderly men. Clinical nutrition. 2013;32(3):412-419.

23. Rieu I, Balage $M$, Sornet $C$, et al. Leucine supplementation improves muscle protein synthesis in elderly men independently of hyperaminoacidaemia. The Journal of physiology. 2006;575(1):305-315.

24. Burd NA, Yang Y, Moore DR, et al. Greater stimulation of myofibrillar protein synthesis with ingestion of whey protein isolate $\mathrm{v}$. micellar casein at rest and after resistance exercise in elderly men. The British journal of nutrition. 2012;108(6):958-962.

25. Katsanos CS, Chinkes DL, PaddonJones $\mathrm{D}$, et al. Whey protein ingestion in elderly persons results in greater muscle protein accrual than ingestion of its constituent essential amino acid content. Nutrition research (New York, NY). 2008;28(10):651-658.

26. Kramer IF, Verdijk LB, Hamer HM, et al. Impact of the Macronutrient Composition of a Nutritional Supplement on Muscle Protein Synthesis Rates in Older Men: A Randomized, Double Blind, Controlled Trial. The Journal of clinical endocrinology and metabolism. 2015;100(11):4124-4132.

27. Cruz-Jentoft AJ, Baeyens JP, Bauer JM, et al. Sarcopenia: European consensus on definition and diagnosis: Report of the European Working Group on Sarcopenia in Older People. Age and ageing. 2010;39(4):412-423.

28. Fielding RA, Vellas B, Evans WJ, et al. Sarcopenia: an undiagnosed condition in older adults. Current consensus definition: prevalence, etiology, and consequences. International working group on sarcopenia. Journal of the American Medical Directors Association. 2011;12(4):249-256.

29. Baumgartner RN, Koehler KM, Gallagher D, et al. Epidemiology of sarcopenia among the elderly in New Mexico. American journal of epidemiology. 1998;147(8):755-763.

30. Abumrad NN, Rabin D, Diamond MP, et al. Use of a heated superficial hand vein as an alternative site for the measurement of amino acid concentrations and for the study of glucose and alanine kinetics in man. Metabolism: clinical and experimental. 1981;30(9):936-940.

31. Bergstrom J. Percutaneous needle biopsy of skeletal muscle in physiological and clinical research. 
Scandinavian journal of clinical and laboratory investigation. 1975;35(7):609616.

32. Waterval WA, Scheijen JL, OrtmansPloemen MM, et al. Quantitative UPLC-MS/MS analysis of underivatised amino acids in body fluids is a reliable tool for the diagnosis and follow-up of patients with inborn errors of metabolism. Clinica chimica acta; international journal of clinical chemistry. 2009;407(1-2):36-42.

33. Biolo G, Tessari P, Inchiostro $S$, et al. Leucine and phenylalanine kinetics during mixed meal ingestion: a multiple tracer approach. The American journal of physiology. 1992;262(4 Pt 1):E455-463.

34. Wall BT, Gorissen SH, Pennings B, et al. Aging Is Accompanied by a Blunted Muscle Protein Synthetic Response to Protein Ingestion. PloS one. 2015;10(11).

35. Fry CS, Drummond MJ, Glynn EL, et al. Aging impairs contraction-induced human skeletal muscle mTORC1 signaling and protein synthesis. Skelet Muscle. 2011;1(1):11-21.

36. Burd NA, Gorissen SH, van Loon LJ. Anabolic resistance of muscle protein synthesis with aging. Exerc Sport Sci Rev. 2013;41(3):169-173.

37. Boirie Y, Gachon P, Beaufrere B. Splanchnic and whole-body leucine kinetics in young and elderly men. The American journal of clinical nutrition. 1997;65(2):489-495.

38. Rasmussen BB, Fujita S, Wolfe RR, et al. Insulin resistance of muscle protein metabolism in aging. FASEB journal : official publication of the Federation of American Societies for Experimental Biology. 2006;20(6):768-769.

39. Drummond MJ, Coben JR, Volpi E, et al. Aging differentially affects human skeletal muscle amino acid transporter expression when essential amino acids are ingested after exercise. Clinical nutrition. 2013.

40. Wall BT, Dirks ML, Snijders T, et al. Substantial skeletal muscle loss occurs during only 5 days of disuse. Acta physiologica (Oxford, England). 2014;210(3):600-611.

41. Paddon-Jones D, Sheffield-Moore M, Cree MG, et al. Atrophy and impaired muscle protein synthesis during prolonged inactivity and stress. The Journal of clinical endocrinology and metabolism. 2006;91(12):4836-4841.

42. Glover EI, Phillips SM, Oates BR, et al. Immobilization induces anabolic resistance in human myofibrillar protein synthesis with low and high dose amino acid infusion. The Journal of physiology. 2008;586(Pt 24):60496061.

43. Kortebein P, Ferrando A, Lombeida J, et al. Effect of 10 days of bed rest on skeletal muscle in healthy older adults. JAMA : the journal of the American Medical Association. 2007;297(16):1772-1774.

44. English KL, Paddon-Jones D. Protecting muscle mass and function in older adults during bed rest. Current opinion in clinical nutrition and metabolic care. 2010;13(1):34-39. 

CHAPTER 8

General discussion 



\section{Surgery in the elderly patient}

Human life expectancy has been increasing at a rapid rate ${ }^{1}$. The aged population is growing, driven by a remarkable rise in life expectancy in combination with falling birth rates. In 2010, an estimated 524 million people were aged 65 years and older, accounting for 8 percent of the world's population. By 2050, this number is expected to nearly triple to about 1.5 billion, representing 16 percent of the world's population 2. New health care challenges have emerged in the context of rapid aging of the worldwide population. With declining mortality rates, the accompanied socioeconomic development leads to differences in causes of death and disease. While infectious and acute diseases are waning in Western societies, frailty and degenerative diseases have emerged as significant health care problems ${ }^{3}$. Ageing is a multidimensional process of change with both physical and mental aspects, leading to functional decline. Injuries account for a large and growing amount of the disease burden in elderly ${ }^{4}$. Of these, fall-related injuries are a significant problem for elderly individuals, sometimes requesting surgical treatment ${ }^{5}$, and affecting functional capacity, habitual physical activity, and quality of life.

Surgery is an essential component of the public-health system. Expansion of the worldwide population of elderly and shifting patterns of disease lead to enlargement of the elderly surgical patient population ${ }^{6}$, and over the last 20 years, the number of elderly people undergoing surgical procedures has increased faster than the rate of population ageing 7 . Although surgery is used to treat a diverse range of conditions and can even prevent the loss of life, it also is associated with a considerable risk of complications and death. The mortality rates between countries and surgical specialities greatly varies and is overall estimated between 0.1 and $4 \%{ }^{8}$. Multiple factors are considered to have impact on perioperative survival, of which co-morbidity is one of the most intensively studied ${ }^{9-11}$. Despite the accelerating ageing of the worldwide population, the impact of advanced age on survival has not been fully understood. The group of elderly patients in need of surgery for fallrelated injuries will continue to grow in the next decades ${ }^{12,13}$. Elderly fracture patients can be more vulnerable due to interplay of multiple comorbidities, reduced cardiovascular fitness, and functional decline. In chapter 2, we analysed data of the European Surgical Outcomes Study (EuSOS), of which the objective was to describe mortality rates and patterns of intensive care resource use for patients undergoing non-cardiac and non-neurological surgery across several European nations. We were specifically interested in the patient group receiving orthopaedic care, especially to compare elderly patients undergoing surgery for acute orthopaedic injuries with 
patients undergoing elective surgery for the musculoskeletal system. Our analysis therefore aimed to identify patient-related factors that mark for a greater risk of unfavourable outcomes after surgery, and to see whether the elderly non-elective patient undergoing orthopaedic surgery would indeed have a higher risk of complications and death. In our study, patients that died during hospital admission were significantly older than patients that survived. Furthermore, we observed significantly higher crude mortality odds ratios in the octogenarian and nonagenarian orthopaedic patients than in the young age group. This is in line with other literature, showing higher mortality rates among the oldest patients. In a large national database study of Bhattacharyya et al ${ }^{11}$, a significant rise of mortality was observed after 80 years of age. A multicentre study of Khuri et al found that age is the most important preoperative variable determining long-term survival, and is one of the five most important preoperative variables determining 30-day mortality ${ }^{14}$. A study of Holt et al showed that even in the extremely old surgical patient, age is an isolated variable associated with mortality, irrespective of comorbidities ${ }^{15}$. Our findings in combination with existing literature point towards an increased risk of mortality among the oldest patients. However, chronological age alone is not a complete reflection of one's medical condition.

Elderly patients can be more vulnerable due to interplay of multiple comorbidities, reduced cardiovascular fitness, and functional decline. Frailty in elderly patients can contribute to a higher risk of adverse outcomes and consequently requires customised care ${ }^{16,17}$. In the study of Bhattacharyya et al, hip fracture patients accounted for $50 \%$ of all postoperative deaths, insinuating a certain vulnerability of these patients that is not only age-related. Diverse risk stratification models have been developed over time, in which comorbidities or ASA score take a prominent position. In our study, ASA score is one of the contributing factors for mortality in both the total orthopaedic cohort as well as in the non-elective orthopaedic cohort, and is associated with mortality after adjustment for confounding factors. According to literature, increased comorbidity burden has a greater impact on postoperative mortality and major complications than age alone in elderly adults undergoing (orthopaedic) surgery ${ }^{18}$. The original European Surgical Outcomes Study ${ }^{8}$ also identified increasing ASA scores and the prevalence of comorbid diseases as a factor associated with increased mortality.

In chapter 2, we furthermore showed a significantly higher proportion of deaths in the urgent and emergency patient groups. Patients requiring urgent or emergency surgery are possibly sicker or more severely injured, which is the reason why there is no time for careful preoperative planning and preparation. This is 
reflected in the numbers of critical care admission, need of mechanical ventilation and need of vasopression in the first 24 hours post-surgery in our study. Surgical urgency is indeed identified as a contributing factor for perioperative mortality by previous studies and has therefore been used in diverse risk stratification models ${ }^{19-}$ ${ }^{21}$. In summary, our study shows that age is one of the factors influencing patient outcomes after surgery. However, not every elderly patient ( $>65$ years) is a geriatric patient with limited capacity to effectively compensate for external stressors, as is emphasised by the influence of ASA scores, comorbidities, and urgency of care in our and other studies.

\section{Sarcopenia in elderly hip fracture patients}

With global aging, falls and fall-related injuries among the elderly have become a major public health burden ${ }^{22,23}$. Hip fractures in the elderly are often the result of a simple fall ${ }^{24}$. The ability of skeletal muscle to generate an adequate amount of force is fundamental for recovering posture to prevent a fall. Skeletal muscle weakness and declined balance performance are independent risk factors for falls and fallrelated injuries in the elderly ${ }^{25-27}$.

The decline in skeletal muscle mass, strength, and/or functional performance with advancing age is termed sarcopenia. Although there is no universal definition, several working groups have published definitions that differ mainly in the cut-offs points for skeletal muscle strength or mass ${ }^{28-30}$. The European Working Group on Sarcopenia in Older People (EWGSOP) recommends using the presence of both low muscle mass and low muscle function (strength or performance) for the diagnosis of sarcopenia ${ }^{28}$, since muscle strength does not depend solely on muscle mass. Data on the prevalence of sarcopenia in community-dwelling residents or nursing homes are widely available, with reported frequencies of $1-29 \%$ and $14-33 \%$, respectively, but less information exists on hospitalised elderly people ${ }^{31}$. Among hospitalised patients in general, reported prevalence rates of sarcopenia vary between 10 to $25 \%$ among all patients aged 18 years and older ${ }^{32-34}$. Sarcopenia seems to have the greatest prevalence at the orthopaedic trauma wards among all surgical wards ${ }^{33,35}$. Reported numbers on prevalence of sarcopenia in elderly hip fracture patients differ from $17 \%$ to $71 \%$ in various studies ${ }^{35-38}$. This is due to variable cut off points for skeletal muscle mass indexes to define sarcopenia in these studies. Furthermore, some studies used the concept of sarcopenic staging (pre-sarcopenic and sarcopenic), thereby using heterogeneous definitions of sarcopenia. 
The loss of skeletal muscle mass with aging can mainly be attributed to specific type II muscle fibre atrophy ${ }^{39,40}$. Type II muscle fibres are essential for rapid muscle force production during muscle contraction, thus essential in regaining posture to prevent a fall. In accordance, quadriceps muscle strength correlates positively with type II muscle fibre size ${ }^{41}$. As such, type II muscle fibre atrophy represents an important contributing factor in the development of muscle weakness during aging. However, type II muscle fibre atrophy has been repeatedly shown in healthy elderly subjects in laboratory conditions ${ }^{40}$, but had not been shown in a clinical setting in hip fracture patients. Therefore, we conducted a study to assess if elderly hip fracture patients indeed suffer from type II muscle fibre atrophy. In chapter 3, we report that type II muscle fibres are $\sim 30 \%$ smaller in female hip fracture patients when compared with healthy age-matched controls, and we furthermore observed a significantly greater amount of very small type II muscle fibres. Surprisingly, we observed that the hip fracture patients even show signs of type I muscle fibre atrophy. In addition to the extensive type II muscle fibre atrophy, a reduction in type I muscle fibre sise may further contribute to skeletal muscle loss. It remains to be determined which factors (such as disuse, sedentary lifestyle, and malnutrition ${ }^{28}$ ) play a primary role in the extensive atrophy as observed in the hip fracture patients. Importantly though, the observed smaller type I and type II muscle fibre size and greater percentage of (very) small fibres in muscle samples from the hip fracture patients could be associated with the reduced ability of these women to generate the force required to counteract falls, thereby playing an etiological role in sustaining fall-related fractures.

Changes in skeletal muscle fibre size are dependent on the number of nuclei in a single muscle fibre, the rate of muscle protein synthesis per myonucleus, and the rate of muscle protein breakdown ${ }^{42}$. In theory, every myonucleus determines transcriptional processes in a certain amount of cytoplasm ${ }^{43}$. Accordingly, changes in muscle fibre size (e.g. hypertrophy or atrophy) are accompanied by changes in myonuclear content, myonuclear domain size or both. However, a discrepancy exists in literature about changes in myonuclear content or domain size during aging. Whereas some studies report that the age-related muscle fibre atrophy is accompanied by an increase in myonuclear content in human skeletal muscle ${ }^{44}$, other human studies report no change ${ }^{45,46}$. Part of this discrepancy may be caused by the different age cohorts included in studies, as a reduced myonuclear content has only been observed in very old subjects (70-86 y) when compared with old (50-69 y) and young (18-49 y) subjects ${ }^{47}$. Furthermore, part of this discrepancy might also be due to determining a mean myonuclear content and domain size for each biopsy 
sample ${ }^{48}$. By using a fibre-size dependent cluster analysis, it seems that smaller fibres have less myonuclei and a smaller myonuclear domain size, independent of the age of the subjects ${ }^{48}$. In chapter 3 , we report a significantly lower number of myonuclei in the type II muscle fibres in healthy elderly women and hip fracture patients compared with healthy young controls. In addition, the healthy young and elderly women show a significant correlation between myonuclear content and muscle fibre size in the type I and type II muscle fibres, in agreement with the recent suggestions of Karlsen et al ${ }^{48}$. These observations suggest that during healthy aging the loss of myonuclear content may be proportional to the age-related decline in muscle fibre size. In contrast to the healthy young and healthy elderly women, no significant correlations were observed between type I and type II muscle fibre myonuclear content and muscle fibre size in the hip fracture patients. The absence of any relation between myonuclear content and muscle fibre size in these patients might indicate that either the loss in myonuclear content or muscle fibre size is occurring at an accelerated pace when compared with healthy controls. In accordance with the latter suggestion, myonuclear domain size was lowest in the type II muscle fibres in the hip fracture patients, implying a disproportionate decline in fibre size versus myonuclear content. It remains to be determined whether there is a causal relationship between fibre atrophy and the reduction in myonuclear content. Alternatively, there may be a preferential loss of large type II muscle fibres, explaining the greater percentage of small muscle fibres in the elderly groups, resulting in both smaller muscle fibre size and lower myonuclear content.

\section{Worsening of sarcopenia after a hip fracture}

Although current levels of care have significantly increased since the introduction of the early recovery after surgery guidelines and multidisciplinary involvement, outcomes in hip fracture patients are still devastating. Hip fracture patients have an increased risk of dying, which persists for several years post-fracture ${ }^{49,50}$. Up to $30 \%$ of the hip fracture patients do not survive the first year following the injury ${ }^{51-54}$. Importantly, more than half of the patients do not regain their pre-fracture mobility in the first year ${ }^{55}$, due to a decline in mobility and functional status $52,5,57$, and become unable of living independently.

Sarcopenia is well known to be an independent marker of poor prognosis among older individuals in general. For example, data show that institutionalised elderly suffering form sarcopenia have higher one year mortality rates compared to elderly habitants with normal skeletal muscle mass. Of hospitalised elderly patients, 
those with sarcopenia have an increased risk of in-hospital mortality as compared with non-sarcopenic patients ${ }^{58}$, an association that holds after adjustment for confounders, including the presence of cancer, cardiovascular disease, chronic obstructive pulmonary disease, dementia, chronic kidney disease, and pre-hospital disability ${ }^{59}$. Since sarcopenia is characterised by the loss of skeletal muscle mass and strength increasing the risk of frailty and predicting physical disability, loss of independence, poor quality of life and death, it is not surprising that it has been recognised as a major predictor for adverse outcomes after a hip fracture. A growing body of evidence suggests that sarcopenia is also associated with longer hospitalisation, physical frailty, disability, and demand for long-term care or institutionalisation in hip fracture patients $32,58,60-62$.

Although sarcopenia is often depicted as a gradual loss of skeletal muscle mass and strength with ageing, periods of physical inactivity and stress-inducing events can exacerbate the muscle loss ${ }^{63}$. Bed rest or immobilisation facilitates inactivity-induced muscle loss. Previous work on muscle disuse indicates that even a short period of 5 days of immobilisation can lead to substantial loss of muscle mass and strength ${ }^{64}$. A decline of lean body mass in hip fracture patient has been shown previously the 2 months following admission ${ }^{65}$. Studies in elderly subjects and studies comparing young and old have shown a larger loss of muscle mass in the young, but an equivalent or even greater negative effect on muscle strength in the old. ${ }^{66-69}$. Furthermore, it seems that elderly individuals have more difficulty regaining the lost amount of muscle when compared to the young ${ }^{70}$. Successive episodes of exacerbated muscle loss are assembled in the concept of the catabolic crisis model ${ }^{63}$. This model proposes that successive periods of short term muscle loss in combination with an inability to fully regain the muscle mass culminate in progressive muscle loss over a longer period of time. The inflammatory response to the injury and operative treatment ${ }^{71}$ and the perioperative immobilisation during hospital admission may further compromise skeletal muscle mass and function in elderly hip fracture patients. Although regeneration of (damaged) muscle involves acute inflammation, hyper-inflammation is a well-known inhibitor of muscle regeneration. Hip fracture patients seem to have substantial hyper-inflammation post-surgery when compared to elderly operated for elective hip replacement, although the surgical insult is comparable ${ }^{72}$. In chapter 4 , we confirm a significant rise in inflammatory markers in hip fracture patients postoperatively, namely IL-6 and CRP. However, we were not able to draw conclusions about the association between the inflammatory response and the loss of muscle mass postoperatively. Previous literature however, shows a markedly depressed rate of muscle protein 
synthesis in hip fracture patients with a high inflammatory burden ${ }^{72}$, suggesting that inflammation may be one of the determinants for recovery potential.

The evaluation of sarcopenia in patients with hip fractures is challenging caused by their mobility problems in testing muscle strength and function $35,38,73,74$. The gold standard for estimating muscle mass is considered to be computed tomography (CT) or magnetic resonance imaging (MRI), although dual energy X-ray absorptiometry (DEXA) and bioelectrical impedance analysis (BIA) are acceptable alternatives. Different methods used can result in different outcomes, especially when only few patients are included in the study ${ }^{35}$. Handgrip strength and walking speed can be used as reliable methods to assess muscle strength and muscle function ${ }^{28}$. In chapter 4 , we conducted a study with the aim to evaluate sarcopenia during hospital admission in elderly hip fracture patients. We assessed the course of skeletal muscle mass, measured with CT scans, and the course of muscle fibre atrophy, by taking muscle biopsies, during hospital stay. We observed a significant decline in whole thigh and quadriceps muscle cross-sectional area of the non-fractured leg over time following operative treatment in elderly hip fracture patients. A $5.5 \pm 1.5 \%$ and $5.1 \pm 1.7 \%$ decline in whole thigh muscle and quadriceps femoris muscle crosssectional area of the non-fractured leg was observed over an average of 7 days when compared to baseline measures, respectively. In contrast to the non-fractured leg, a decline in cross-sectional area was not observed in the fractured leg. The differences between the fractured and non-fractured leg are likely explained by the effect of swelling due to haematoma and oedema. Muscle radiation attenuation values reflect fat and water deposition in tissue visualised with CT scanning ${ }^{75}$. Intra- and extracellular oedema, haematoma, and/or change in fat deposition after injury can influence the muscle radiation attenuation, as reflected by changes mean grey scales of the tissue ${ }^{76}$. In this study, a difference in mean grey scale was seen between the fractured and non-fractured leg at hospital discharge, and a decline in mean grey scale in the fractured leg postoperatively, indicating a change in soft tissue composition, likely attributable to the swelling following the fracture and the operative treatment in one leg. We, therefore, propose that CT-scans in the fractured leg are unreliable to observe changes over time shortly after the trauma and operative treatment.

In chapter 4, we furthermore confirmed the existence of extensive type II muscle fibre atrophy in elderly hip fracture patients. We hypothesised that a decline in skeletal muscle mass during hospitalisation would be accompanied by a reduction in type II muscle fibre size on a histological level. However, both type I and type II muscle fibre size did not significantly change over time. Muscle biopsies were taken 
from the fractured leg. The observed post-traumatic and postoperatively changes on a whole-leg level, as was observed with CT scans, may have caused swelling also on a muscle fibre level. We, therefore, propose that the observed fibre CSA in the fractured leg is not representative for the actual fibre size changes over time accompanying the change in muscle CSA as seen on CT-scan in the control leg. We encourage researchers who aim to address muscle disuse atrophy during hospitalisation to collect muscle biopsies from limbs that have not been operated on.

The loss of skeletal muscle strength and functional performance are more important than changes in skeletal muscle mass only ${ }^{77}$. As stated previously, research indicates that loss of skeletal muscle in elderly has great impact on muscle strength and function. It has been shown that hospitalised elderly spent the majority of the day in bed during their admission ${ }^{78,79}$. Physical activity is one of the most effective interventions to increase muscle mass or attenuate the loss of muscle mass ${ }^{80}$. In addition, exercise increases the anabolic response to protein or food intake ${ }^{81,82}$. Ingestion of protein or amino acids is the other main anabolic stimulus for skeletal muscle tissue ${ }^{83}$. Protein and caloric malnutrition in elderly aggravate muscle loss during a period of bed rest of immobilisation ${ }^{63}$. To counteract the progressive loss of muscle mass in elderly hip fracture patients, whom have proven to be already vulnerable for unfavourable outcomes, effective intervention strategies should be designed. With multidisciplinary integrated care, combining knowledge from surgeons, geriatricians, physiotherapists and dieticians, outcomes for the elderly hip fracture patient may be optimised ${ }^{84}$.

\section{Nutritional interventions to combat sarcopenia}

Deteriorated nutritional status in elderly hospitalised patients at both general and surgical wards is a well-known problem. Low nutrient intake seems to be present among all hospital wards and disease types ${ }^{85}$. Protein-energy malnutrition is present in up to $60 \%$ of the patients at time of admission or nutritional deficiencies develop during hospital stay ${ }^{85,86}$. The influence of malnutrition on postoperative mortality and morbidity has been the topic of a considerable number of retrospective and prospective studies. Malnutrition leads to impaired mobility due to muscle wasting and reduced muscle function ${ }^{87}$. The net loss of muscle mass can be attributed to an imbalance between muscle protein synthesis and muscle protein breakdown rates. The main anabolic stimuli for muscle protein synthesis are food intake and physical activity. Particularly the ingestion of protein is known to stimulate muscle protein synthesis rates. Muscle mass maintenance is influenced by basal muscle protein 
synthesis as well as by the postprandial muscle protein synthetic response to feeding. However, several studies have shown an attenuated muscle protein synthetic response in the elderly population when compared with young adults 88,89 . Consequently, it is needed to understand the various factors that modulate the postprandial increase in muscle protein synthesis rates. Effective nutritional interventions to counteract the loss of skeletal muscle in both non-clinical and clinical situations can then be designed.

Nutritional supplements generally provide all macronutrients and are supplied with the purpose of improving or maintaining the nutritional status of patients. These supplements are usually offered to the elderly population in clinical or home-care settings to reach targets set for both total energy, as well as protein intake. In addition, nutritional supplementation may be specifically used for the preservation of muscle mass both in the general ageing population and in elderly specifically at risk for accelerated muscle loss due to immobilisation, illness, or injury 59,90,91. Supplementation of an adequate amount of dietary protein could be essential to preserve muscle mass in elderly, independent of additional energy. It might be suitable to use tailored high protein supplements, aimed at stimulating muscle protein synthesis rates to preserve muscle mass in the elderly ${ }^{92}$. The postprandial rise in muscle protein synthesis rate in elderly has been shown to depend on the amount ${ }^{93-95}$, type ${ }^{96,97}$, and amino acid composition of the ingested protein 98,99 . Furthermore, addition of free leucine with protein has been shown to further increase post-prandial muscle protein synthesis rates in elderly men ${ }^{100}$. Coingestion of other macronutrients, such as carbohydrates and fat, with protein may modulate the postprandial rise in muscle protein synthesis rate in elderly. In chapter 6, we therefore tested the influence of other macronutrients than protein on the muscle protein synthetic response to a highly potent nutritional supplement in elderly individuals. We demonstrated that the ingestion of a nutritional supplement containing $21 \mathrm{~g}$ of leucine-enriched whey protein significantly raises muscle protein synthesis rates in non-sarcopenic elderly men. Co-ingestion of carbohydrate and fat with the leucine-enriched whey protein did not modulate the postprandial muscle protein synthetic response. We had hypothesised that carbohydrate and fat coingestion could augment the muscle protein synthetic response to protein feeding by providing energy and by stimulating postprandial endogenous insulin release. The postprandial release of insulin into the plasma is often suggested to have a positive effect on muscle protein synthesis by enlargement of the local availability of amino acids in muscle through stimulation of muscle perfusion, while simultaneously decreasing the rates of muscle protein breakdown ${ }^{101-103}$. Although the circulating 
insulin concentrations were significantly higher in the group ingesting the nutritional supplement containing all macronutrients compared with the group ingesting protein only, it did not result in significantly greater postprandial muscle protein accretion. This supports the concept that the presence of insulin is more permissive than stimulatory, and that even a moderate rise in circulating insulin concentration is sufficient in increasing muscle protein synthesis rates following protein ingestion 104-106. However, enhancing plasma insulin concentrations might benefit the net muscle protein balance by further inhibiting muscle protein breakdown ${ }^{107}$. In chapter 6 , we only included non-sarcopenic elderly men, which is neither representative for the general patient population nor for elderly hip fracture patients in particular. Therefore, the effect of the macronutrient composition of nutritional supplements on the muscle anabolic response in elderly females as well as in more clinically compromised frail or sarcopenic elderly still needs to be determined.

\section{Nutritional interventions to combat sarcopenia in hip fracture patients}

Age-related declines in basal or post-prandial muscle protein synthesis rates may be responsible for the progressive loss of skeletal muscle mass throughout the lifespan. So far, studies investigating basal muscle protein synthesis rates in elderly individuals have shown conflicting results. Lower basal muscle protein synthesis rates have been observed in the elderly populations when compared with younger populations in some studies ${ }^{108-111}$. In contrast, more recent work has been unable to detect significant differences in basal muscle protein synthesis rates between young and elderly individuals $83,89,112-114$. A reduced anabolic response of skeletal muscle to amino acid administration has been reported in elderly by various research groups $83,88,89,115$. Immobilisation in elderly could result in a further reduction in the postprandial muscle protein synthetic response. An attenuated protein synthetic response has been outpointed in young individuals during short-term bed rest ${ }^{116}$. Interestingly, bed-rest (further) compromises the anabolic potency to feeding in elderly ${ }^{66,117}$ and is, therefore, of validated concern in hospitalised elderly patients. However, both basal muscle protein synthesis rates as well as the post-prandial muscle protein synthetic response have never directly been compared between sarcopenic and healthy elderly individuals. Therefore, in chapter 7, we selected 15 healthy and 15 diagnosed ${ }^{28}$ sarcopenic elderly males to participate in an experiment where we assessed basal and post-prandial muscle protein synthesis rates. 
In chapter 7, we demonstrated that muscle protein synthesis rates in sarcopenic elderly men could be effectively increased by the ingestion of $21 \mathrm{~g}$ of leucine-enriched whey protein. Post-prandial muscle protein synthesis rates did not differ between the sarcopenic and healthy elderly men. Furthermore, basal muscle protein synthesis rates did not differ between the groups. However, we hypothesised that basal muscle protein synthesis rates would be reduced in the sarcopenic elderly when compared with healthy elderly men as an explanation for the loss of substantial amounts of skeletal muscle mass and strength. In fact, the basal muscle protein synthesis rates tended to be higher as opposed to lower in the sarcopenic elderly subjects compared with the healthy controls. These data tend to be in line with more recent reports showing no detectable differences in basal muscle protein synthesis rates between the young and elderly ${ }^{83,89,113}$ and the observation of rather higher than lower basal muscle protein synthesis rates in the elderly compared the young ${ }^{118}$. Consequently, a structural decline in basal muscle protein synthesis rate does not seem to be the underlying mechanism of the difference in skeletal muscle mass between sarcopenic and non-sarcopenic elderly. Furthermore, the absence of any structural differences in the post-prandial muscle protein synthetic response to feeding between the healthy and sarcopenic elderly indicates that there are no substantial impairments in anabolic sensitivity in sarcopenic elderly to the anabolic stimulus provided in the study. However, we cannot rule out that some level of anabolic resistance may be evident following ingestion of smaller, more meal-like amounts of dietary protein in sarcopenic versus healthy elderly. This demonstrates that even in sarcopenic elderly senescent muscle seems to maintain its capacity to respond to the ingestion of a bolus of whey protein fortified with free leucine.

Modification of nutritional status by using nutritional interventions, during hospital admission and afterwards during the rehabilitation phase, could be beneficial in terms of improving outcomes for hip fracture patients. As shown previously, even senescent muscle seems to be capable of an anabolic response to feeding. However, the effectiveness of oral nutritional supplementation in elderly hip fracture patients remains controversial and is subject of on-going debate. We examined the use of nutritional interventions in this group by reviewing relevant published randomised controlled trials in chapter 5. Nutritional intervention during hospitalisation can be applied in several ways, such as providing protein dense food supplements, enteral feeds, or intravenous amino acids. The measurement of daily intake during nutritional support is a key issue in the design of nutritional intervention trials. This is, however, not always monitored. Any nutritional 
supplement may have impact on the usual food intake and intake of other macronutrients. If daily intake is not measured, it is impossible to assess what factor has produced a positive effect or no effect. Hip fracture patients often have a reduced appetite both prior to their fracture and during hospitalisation. A further negative effect on appetite due to nutritional supplementation was not seen in several studies ${ }^{119,120}$. Dieticians can help in encouraging and assisting patients to eat properly ${ }^{121}$. Feeding support may be especially helpful in patients with cognitive impairments ${ }^{122}$, making up about $40 \%$ of the hip fracture population.

Nutritional studies are challenging because of the complexity of modulating the total daily energy and protein intake. The effectiveness of nutritional interventions may be dependent on individual needs. Trials where energy and protein requirements were individualised, and nutritional supplementation was optimised for the individual patient, more often show positive effects on outcomes ${ }^{123,124}$. A large variation in the composition of nutritional supplementation used in studies exists in literature. Overall, there seems to be some evidence for a benefit in terms of mortality after protein and energy supplementation ${ }^{125-130}$, but various trials did not find a positive effect 120,131,132, although studies are usually not designed to address possible effects on mortality because of a short follow-up. However, improvements in clinical outcome such as less complications and shorter hospital stays were found in several of the studies 120,123-125,127,133,134. Several of the intervention studies using protein-enriched nutritional support have shown a positive effect on either biochemical or anthropometric indicators of nutritional status 120,133,135,136. Outcomes on improvement of functional performance, functional independence and mobility are conflicting, with some studies showing positive results ${ }^{137}$, and some studies showing no effect of the nutritional intervention $126,133,136,138,139$. In the latest meta-analysis update from the Cochrane Collaboration on nutritional supplementation for hip fracture aftercare $(2016)^{128}$, the overall conclusion remained that oral multinutrient feeds may prevent complication rate after hip fracture surgery but may not prevent mortality. However, adequately sized randomised studies with better designs are required. Besides, the heterogeneity of included patients may also be a significant limitation to draw accurate conclusions for the proposed benefits of nutritional support in elderly patients with hip fracture. 


\section{Conclusions and future directions}

Hip fractures, or proximal femur fractures, are a growing concern in modern society due to the rapidly accelerating ageing of our population and the substantial morbidity and mortality in the patients affected. A prominent feature of biological ageing is the deterioration of skeletal muscle mass, strength, and function, coined sarcopenia. The loss of skeletal muscle function predisposes elderly to falls. The current dissertation provides evidence for extensive muscle fibre atrophy in elderly hip fracture patients (chapters 3 and 4). Sarcopenia has been recognised as a major predictor for adverse outcomes after a hip fracture, such as longer hospitalisation, physical frailty, disability, and demand for long-term care or institutionalisation. Although the postoperative course depends in part on functional status before a hip fracture, post-fracture loss of lean body mass and strength can cause further impairments of the already compromised muscle function. An exacerbated loss of skeletal muscle mass in elderly hip fracture patients postoperatively has been shown in chapter 4 . This fits in the catabolic crisis model, which proposes that successive periods of short term muscle loss in combination with an inability to fully regain the muscle mass culminate in progressive muscle loss over a longer period of time.

Although sarcopenia officially has to be diagnosed combining diagnostic imaging for the measurement of muscle mass with muscle strength or function tests, the clinical features are obvious in most of the hip fracture patients. Therefore, for most surgeons, sarcopenia in hip fracture patients can be seen as the 'elephant in the (operating) room': it is easy to spot, but it is often ignored. Since the introduction of fast-track surgical treatment programs in the 1990s, treatment of hip fractures has rapidly evolved to the current levels of care. However, targeted interventions to combat the loss of skeletal muscle mass and strength during hospitalisation and rehabilitation after a hip fracture could contribute to the quality of life of the elderly hip fracture patient.

Skeletal muscle mass is the result of a negative balance between muscle protein synthesis and muscle protein breakdown. One of the key anabolic stimuli for muscle protein synthesis is the intake of protein-rich nutrition. However, up to half of the elderly patients with hip fractures are already malnourished upon hospital admission. As the patients with a hip fracture are already in a catabolic state within minutes of their injury, these patients have a different metabolic situation when compared to elective surgical patients. The injury-related trauma and subsequent operation in hip fracture patients are associated with a major elevation of inflammatory markers and cytokines, thereby activating the molecular pathways 
involved in skeletal muscle wasting, leading to a decrease in muscle protein synthesis rates and an increase in muscle protein breakdown. Moreover, during perioperative immobilisation and hospitalisation, a period of disuse is introduced. Up until now, it was unclear whether individuals suffering from sarcopenia are capable of an effective increase in muscle protein synthesis rates following the ingestion of an adequate nutritional supplement. This dissertation showed in chapter 7 that there are no evident structural differences in the post-prandial muscle protein synthetic response to feeding between the healthy and sarcopenic elderly. This indicates that there are no substantial impairments in anabolic sensitivity in sarcopenic elderly when an adequate nutritional stimulus is provided. Although nutritional interventions have been tested in various randomised trials in elderly hip fracture patients, the results of the effect on outcomes remains conflictive (chapter 5). Adequate long-term intervention studies are needed to give us the much-requested answers and to optimise hip fracture health care. The design of effective nutritional intervention strategies to combat muscle loss and promote favourable outcomes in hip fracture patients is rather complex and some important issues need to be addressed in the future.

- The current dissertation provides evidence that ingestion of $20 \mathrm{~g}$ of a leucine enriched whey protein supplement is effective in stimulating muscle protein synthesis rates in elderly sarcopenic individuals. However, the optimal composition of an effective nutritional supplement for elderly hip fracture patients remains to be determined. Postprandial dietary protein handling may be altered following trauma and surgery.

- It is unlikely that any nutritional intervention in these patients will have the same impact as in the regular elective patient. It would be interesting to set up well-designed tracer studies to compare muscle protein synthesis and muscle protein breakdown rates between hip fracture patients and other patients to gain more insight in the mechanisms responsible for the proposed accelerated muscle loss in the hip fracture versus elective hip surgery patient.

- We need to assess whether effective strategies to prevent or attenuate muscle mass and strength loss in elderly hip fracture patients will also result in more favourable clinical outcomes. 
- Since the loss of skeletal muscle mass and strength is also an important etiological factor in sustaining a hip fracture in elderly people, muscle mass maintenance should be a spearhead in both the primary and secondary healthcare setting. How fast-track programs need to be adjusted in order to facilitate these aims remains to be determined. 


\section{References}

1. Oeppen J, Vaupel JW. Demography. Broken limits to life expectancy. Science (New York, N.Y.). 2002;296(5570):1029-1031.

2. Lutz W, Sanderson W, Scherbov S. The coming acceleration of global population ageing. Nature. 2008;451(7179):716-719.

3. van der Cammen TJ, Albayrak A, Voûte E, Molenbroek JF. New horizons in design for autonomous ageing. Age and ageing. 2017;46(1):1117.

4. The injury chart book: A graphical overview of the global burden of injuries. World Health Organization; 2002.

5. Hartholt KA, van Beeck EF, Polinder $S$, et al. Societal consequences of falls in the older population: injuries, healthcare costs, and long-term reduced quality of life. I Trauma. Sep;71(3):748-753.

6. Weiser TG, Regenbogen SE, Thompson KD, et al. An estimation of the global volume of surgery: a modelling strategy based on available data. Lancet (London, England). 2008;372(9633):139-144.

7. Hamel MB, Henderson WG, Khuri SF, Daley J. Surgical outcomes for patients aged 80 and older: morbidity and mortality from major noncardiac surgery. Journal of the American Geriatrics Society. 2005;53(3):424-429.

8. Pearse RM, Moreno RP, Bauer P, et al. Mortality after surgery in Europe: a 7 day cohort study. Lancet (London, England). 2012;380(9847):1059-1065.

9. Menendez ME, Neuhaus V, Ring D. Inpatient mortality after orthopaedic surgery. International orthopaedics. 2015;39(7):1307-1314.

10. Austin SR, Wong Y-N, Uzzo RG, Beck RJ, Egleston BL. Why Summary Comorbidity Measures Such As the Charlson Comorbidity Index and Elixhauser Score Work. Medical Care. 2015;53(9).
11. Bhattacharyya T, Iorio R, Healy WL. Rate of and risk factors for acute inpatient mortality after orthopaedic surgery. The Journal of bone and joint surgery. American volume. 2002;84$\mathrm{A}(4): 562-572$.

12. Holt G, Smith R, Duncan K, Hutchison JD, Reid D. Changes in population demographics and the future incidence of hip fracture. Injury. 2009;40(7):722-726.

13. Icks A, Arend W, Becker C, Rapp K, Jungbluth $\mathrm{P}$, Haastert B. Incidence of hip fractures in Germany, 1995-2010. Archives of osteoporosis. 2013;8:140.

14. Khuri SF, Henderson WG, DePalma RG, Mosca C, Healey NA, Kumbhani DJ. Determinants of long-term survival after major surgery and the adverse effect of postoperative complications. Annals of surgery. 2005;242(3):326-343.

15. Holt G, Smith R, Duncan K, Hutchison JD, Gregori A. Outcome after surgery for the treatment of hip fracture in the extremely elderly. The Journal of bone and joint surgery. American volume. 2008;90(9):1899-1905.

16. Partridge JS, Harari D, Dhesi JK. Frailty in the older surgical patient: a review. Age and ageing. 2012;41(2):142147.

17. Fried LP, Tangen CM, Walston J, et al. Frailty in older adults: evidence for a phenotype. The journals of gerontology. Series A, Biological sciences and medical sciences. 2001;56(3):56.

18. Chikuda $\mathrm{H}$, Yasunaga $\mathrm{H}$, Horiguchi $\mathrm{H}$, et al. Impact of age and comorbidity burden on mortality and major complications in older adults undergoing orthopaedic surgery: an analysis using the Japanese diagnosis procedure combination database. BMC musculoskeletal disorders. 2013;14:173.

19. Watters DA, Hollands MJ, Gruen RL, et al. Perioperative mortality rate 
(POMR): a global indicator of access to safe surgery and anaesthesia. World journal of surgery. 2015;39(4):856-864.

20. Thompson AM, Stonebridge PA. Building a framework for trust: critical event analysis of deaths in surgical care. BMJ (Clinical research ed.). 2005;330(7500):1139-1142.

21. Glance LG, Lustik SJ, Hannan EL, et al. The Surgical Mortality Probability Model: derivation and validation of a simple risk prediction rule for noncardiac surgery. Annals of surgery. 2012;255(4):696-702.

22. Hartholt KA, Stevens JA, Polinder S, van der Cammen TJ, Patka P. Increase in fall-related hospitalizations in the United States, 2001-2008. J Trauma. Jul;71(1):255-258.

23. Hartholt KA, van der Velde $\mathrm{N}$, Looman CW, et al. Trends in fallrelated hospital admissions in older persons in the Netherlands. Arch Intern Med. May 24 2010;170(10):905911.

24. Parkkari J, Kannus P, Palvanen M, et al. Majority of hip fractures occur as a result of a fall and impact on the greater trochanter of the femur: a prospective controlled hip fracture study with 206 consecutive patients. Calcified tissue international. 1999;65(3):183-187.

25. Graafmans WC, Ooms ME, Hofstee HM, Bezemer PD, Bouter LM, Lips P. Falls in the elderly: a prospective study of risk factors and risk profiles. American journal of epidemiology. Jun 1 1996;143(11):1129-1136.

26. Fukagawa NK, Wolfson L, Judge J, Whipple R, King M. Strength Is a Major Factor in Balance, Gait, and the Occurrence of Falls. The Journals of Gerontology Series A: Biological Sciences and Medical Sciences. 1995;50A(Special):64-67.

27. Moreland JD, Richardson JA, Goldsmith CH, Clase CM. Muscle weakness and falls in older adults: a systematic review and meta-analysis.
Journal of the American Geriatrics Society. 2004;52(7):1121-1129.

28. Cruz-Jentoft AJ, Baeyens JP, Bauer JM, et al. Sarcopenia: European consensus on definition and diagnosis: Report of the European Working Group on Sarcopenia in Older People. Age and ageing. Jul 2010;39(4):412-423.

29. Fielding RA, Vellas B, Evans WJ, et al. Sarcopenia: an undiagnosed condition in older adults. Current consensus definition: prevalence, etiology, and consequences. International working group on sarcopenia. Journal of the American Medical Directors Association. 2011;12(4):249-256.

30. Bahat G, Tufan A, Tufan F, et al. Cutoff points to identify sarcopenia according to European Working Group on Sarcopenia in Older People (EWGSOP) definition. Clinical nutrition (Edinburgh, Scotland). 2016.

31. Cruz-Jentoft AJ, Landi F, Schneider SMM, et al. Prevalence of and interventions for sarcopenia in ageing adults: a systematic review. Report of the International Sarcopenia Initiative (EWGSOP and IWGS). Age and ageing. 2014;43(6):748-759.

32. Gariballa S, Alessa A. Sarcopenia: prevalence and prognostic significance in hospitalized patients. Clinical nutrition (Edinburgh, Scotland). 2013;32(5):772-776.

33. Sousa AS, Guerra RS, Fonseca I, Pichel F, Amaral TF. Sarcopenia among hospitalized patients - A crosssectional study. Clinical nutrition (Edinburgh, Scotland). 2014.

34. Martinez BP, Batista AK, Gomes IB, Olivieri FM, Camelier FW, Camelier AA. Frequency of sarcopenia and associated factors among hospitalized elderly patients. BMC musculoskeletal disorders. 2015;16(1):108.

35. Hida $\mathrm{T}$, Ishiguro $\mathrm{N}$, Shimokata $\mathrm{H}$, et al. High prevalence of sarcopenia and reduced leg muscle mass in Japanese patients immediately after a hip fracture. Geriatrics $\mathcal{E}$ Gerontology International. 2013;13(2):413-420. 
36. González-Montalvo JI, Alarcón T, Gotor $\mathrm{P}$, et al. Prevalence of sarcopenia in acute hip fracture patients and its influence on shortterm clinical outcome. Geriatrics $\mathcal{E}$ gerontology international. 2015.

37. Di Monaco M, Castiglioni C, De Toma $E$, et al. Presarcopenia and sarcopenia in hip-fracture women: prevalence and association with ability to function in activities of daily living. Aging clinical and experimental research. 2015;27(4):465-472.

38. Singh FMA, Singh NA, Hansen RD, et al. Methodology and Baseline Characteristics for the Sarcopenia and Hip Fracture Study: A 5-Year Prospective Study. The Journals of Gerontology Series A: Biological Sciences and Medical Sciences. 2009;64A(5):568574.

39. Verdijk LB, Koopman R, Schaart G, Meijer K, Savelberg HH, van Loon LJ. Satellite cell content is specifically reduced in type II skeletal muscle fibers in the elderly. American journal of physiology. Endocrinology and metabolism. Jan 2007;292(1):E151-157.

40. Nilwik R, Snijders T, Leenders $M$, et al. The decline in skeletal muscle mass with aging is mainly attributed to a reduction in type II muscle fiber size. Experimental gerontology. 2013;48(5):492-498.

41. Verdijk LB, Snijders T, Beelen M, et al. Characteristics of muscle fiber type are predictive of skeletal muscle mass and strength in elderly men. Journal of the American Geriatrics Society. Nov 2010;58(11):2069-2075.

42. Gundersen K. Excitation-transcription coupling in skeletal muscle: the molecular pathways of exercise. Biol Rev Camb Philos Soc. Aug 2011;86(3):564-600.

43. Cheek DB. The control of cell mass and replication. The DNA unit--a personal 20-year study. Early human development. Dec 1985;12(3):211-239.

44. Kadi F, Charifi N, Denis C, Lexell J. Satellite cells and myonuclei in young and elderly women and men. Muscle Nerve. Jan 2004;29(1):120-127.

45. Manta P, Vassilopoulos D, Spengos M. Nucleo-cytoplasmic ratio in ageing skeletal muscle. Eur Arch Psychiatry Neurol Sci. 1987;236(4):235-236.

46. Renault V, Thornell LE, Eriksson PO, Butler-Browne G, Mouly V. Regenerative potential of human skeletal muscle during aging. Aging Cell. Dec 2002;1(2):132-139.

47. Verdijk LB, Snijders T, Drost $M$, Delhaas T, Kadi F, van Loon LJ. Satellite cells in human skeletal muscle; from birth to old age. Age (Dordrecht, Netherlands). 2014;36(2):545-547.

48. Karlsen A, Couppé C, Andersen JL, et al. Matters of fiber size and myonuclear domain; does size matter more than age? Muscle E nerve. 2015.

49. Farahmand BY, Michaëlsson K, Ahlbom A, Ljunghall S, Baron JA, Group S. Survival after hip fracture. Osteoporosis International. 2005;16(12):1583-1590.

50. Haentjens P, Magaziner J, ColónEmeric CS, et al. Meta-analysis: excess mortality after hip fracture among older women and men. Annals of internal medicine. 2010;152(6):380-390.

51. Mariconda M, Costa GG, Cerbasi S, et al. The determinants of mortality and morbidity during the year following fracture of the hip: a prospective study. The bone $\mathcal{E}$ joint journal. 2015;97B(3):383-390.

52. Bentler SE, Liu L, Obrizan M, et al. The aftermath of hip fracture: discharge placement, functional status change, and mortality. American journal of epidemiology. 2009;170(10):1290-1299.

53. Panula J, Pihlajamäki H, Mattila VM, et al. Mortality and cause of death in hip fracture patients aged 65 or older: a population-based study. BMC musculoskeletal disorders. 2011;12:105.

54. Abrahamsen B, van Staa T, Ariely R, Olson M, Cooper C. Excess mortality following hip fracture: a systematic 
epidemiological review. Osteoporosis international : a journal established as result of cooperation between the European Foundation for Osteoporosis and the National Osteoporosis Foundation of the USA. 2009;20(10):1633-1650.

55. Vochteloo AJ, Moerman S, Tuinebreijer WE, et al. More than half of hip fracture patients do not regain mobility in the first postoperative year. Geriatrics \& gerontology international. 2013;13(2):334-341.

56. Hartholt KA, van Beeck EF, Polinder $\mathrm{S}$, et al. Societal consequences of falls in the older population: injuries, healthcare costs, and long-term reduced quality of life. The Journal of trauma. Sep 2011;71(3):748-753.

57. Holt $G$, Smith R, Duncan $K$, Hutchison JD, Gregori A, Reid D. Outcome after sequential hip fracture in the elderly. The Journal of bone and joint surgery. American volume. Oct 3 2012;94(19):1801-1808.

58. Vetrano DL, Landi F, Volpato S, et al. Association of sarcopenia with shortand long-term mortality in older adults admitted to acute care wards: results from the CRIME study. The journals of gerontology. Series A, Biological sciences and medical sciences. 2014;69(9):1154-1161.

59. Kimyagarov S, Klid R, Fleissig Y, Kopel B, Arad M, Adunsky A. Skeletal muscle mass abnormalities are associated with survival rates of institutionalized elderly nursing home residents. The journal of nutrition, health $\mathcal{E}$ aging. May 2012;16(5):432-436.

60. Marzetti E, Calvani R, Tosato M, et al. Sarcopenia: an overview. Aging clinical and experimental research. 2017;29(1):1117.

61. Sousa AS, Guerra RS, Fonseca I, Pichel F, Amaral TF. Sarcopenia and length of hospital stay. European journal of clinical nutrition. 2015.

62. Landi F, Calvani R, Ortolani E, et al. The association between sarcopenia and functional outcomes among older patients with hip fracture undergoing in-hospital rehabilitation. Osteoporosis international : a journal established as result of cooperation between the European Foundation for Osteoporosis and the National Osteoporosis Foundation of the USA. 2017.

63. English KL, Paddon-Jones D. Protecting muscle mass and function in older adults during bed rest. Current opinion in clinical nutrition and metabolic care. 2010;13(1):34-39.

64. Wall BT, Dirks ML, Snijders T, Senden JM, Dolmans J, van Loon LJ. Substantial skeletal muscle loss occurs during only 5 days of disuse. Acta physiologica (Oxford, England). 2014;210(3):600-611.

65. D'Adamo C, Hawkes WG, Miller R, et al. Short-term changes in body composition after surgical repair of hip fracture. Age and Ageing. 2014;43(2):275-280.

66. Kortebein P, Ferrando A, Lombeida J, Wolfe R, Evans WJ. Effect of 10 days of bed rest on skeletal muscle in healthy older adults. JAMA : the journal of the American Medical Association. Apr 25 2007;297(16):17721774.

67. Dirks ML, Wall BT, Nilwik R, Weerts DHH, Verdijk LB, van Loon LJ. Skeletal muscle disuse atrophy is not attenuated by dietary protein supplementation in healthy older men. The Journal of nutrition. 2014;144(8):1196-1203.

68. Suetta C, Frandsen U, Jensen L, et al. Aging affects the transcriptional regulation of human skeletal muscle disuse atrophy. PloS one. 2012;7(12).

69. Suetta C. Plasticity and function of human skeletal muscle in relation to disuse and rehabilitation: Influence of ageing and surgery. Danish medical journal. 2017;64(8).

70. Hvid L, Aagaard P, Justesen L, et al. Effects of aging on muscle mechanical function and muscle fiber morphology during short-term immobilization and subsequent retraining. Journal of 
applied physiology. Dec 2010;109(6):1628-1634.

71. Sun T, Wang X, Liu Z, Chen X, Zhang J. Plasma concentrations of pro- and anti-inflammatory cytokines and outcome prediction in elderly hip fracture patients. Injury. 2011;42(7):707-713.

72. Bamman MM, Ferrando AA, Evans $\mathrm{RP}$, et al. Muscle inflammation susceptibility: a prognostic index of recovery potential after hip arthroplasty? American journal of physiology. Endocrinology and metabolism. 2015;308(8):9.

73. Di Monaco M, Castiglioni C, Di Monaco R, Tappero R. Association between low lean mass and low bone mineral density in 653 women with hip fracture: does the definition of low lean mass matter? Aging clinical and experimental research. 2017.

74. Mitchell SJ, Hilmer SN, Kirkpatrick $\mathrm{CM}$, et al. Estimation of lean body weight in older women with hip fracture. The journal of nutrition, health $\mathcal{E}$ aging. 2012;16(2):188-192.

75. Aubrey J, Esfandiari N, Baracos VE, et al. Measurement of skeletal muscle radiation attenuation and basis of its biological variation. Acta physiologica (Oxford, England). 2014;210(3):489-497.

76. Goodpaster BH, Kelley DE, Thaete FL, He J, Ross R. Skeletal muscle attenuation determined by computed tomography is associated with skeletal muscle lipid content. Journal of applied physiology (Bethesda, Md. : 1985). 2000;89(1):104-110.

77. Visser M, Harris TB, Fox KM, et al. Change in muscle mass and muscle strength after a hip fracture: relationship to mobility recovery. The journals of gerontology. Series $A$, Biological sciences and medical sciences. 2000;55(8):40.

78. Brown CJ, Redden DT, Flood KL, Allman RM. The underrecognized epidemic of low mobility during hospitalization of older adults. Journal of the American Geriatrics Society. 2009;57(9):1660-1665.

79. Pedersen MM, Bodilsen AC, Petersen $\mathrm{J}$, et al. Twenty-four-hour mobility during acute hospitalization in older medical patients. The journals of gerontology. Series A, Biological sciences and medical sciences. 2013;68(3):331-337.

80. Phillips SM, Tipton KD, Aarsland A, Wolf SE, Wolfe RR. Mixed muscle protein synthesis and breakdown after resistance exercise in humans. The American journal of physiology. 1997;273(1 Pt 1):107.

81. Holwerda AM, Kouw IW, Trommelen $\mathrm{J}$, et al. Physical Activity Performed in the Evening Increases the Overnight Muscle Protein Synthetic Response to Presleep Protein Ingestion in Older Men. The Journal of nutrition. 2016;146(7):1307-1314.

82. Pennings B, Koopman R, Beelen M, Senden JM, Saris WH, van Loon LJ. Exercising before protein intake allows for greater use of dietary protein-derived amino acids for de novo muscle protein synthesis in both young and elderly men. The American journal of clinical nutrition. 2011;93(2):322-331.

83. Paddon-Jones D, Sheffield-Moore M, Zhang XJ, et al. Amino acid ingestion improves muscle protein synthesis in the young and elderly. American journal of physiology. Endocrinology and metabolism. Mar 2004;286(3):E321-328.

84. Folbert E, Smit R, van der Velde D, Regtuijt M, Klaren H, Hegeman JHH. [Multidisciplinary integrated care pathway for elderly patients with hip fractures: implementation results from Centre for Geriatric Traumatology, Almelo, The Netherlands]. Nederlands tijdschrift voor geneeskunde. 2011;155(26).

85. Sullivan DH, Sun S, Walls RC. Proteinenergy undernutrition among elderly hospitalized patients: a prospective study. JAMA : the journal of the American Medical Association. Jun 2 1999;281(21):2013-2019. 
86. Allison SP, Rawlings J, Field J, Bean N, Stephen AD. Nutrition in the elderly hospital patient Nottingham studies. The journal of nutrition, health $\mathcal{E}$ aging. 2000;4(1):54-57.

87. Keys A. The residues of malnutrition and starvation. Science (New York, N.Y.). 1950;112(2909):371-373.

88. Katsanos CS, Kobayashi H, SheffieldMoore M, Aarsland A, Wolfe RR. Aging is associated with diminished accretion of muscle proteins after the ingestion of a small bolus of essential amino acids. The American journal of clinical nutrition. Nov 2005;82(5):10651073.

89. Cuthbertson D, Smith K, Babraj J, et al. Anabolic signaling deficits underlie amino acid resistance of wasting, aging muscle. FASEB journal : official publication of the Federation of American Societies for Experimental Biology. Mar 2005;19(3):422-424.

90. Janssen I, Heymsfield SB, Ross R. Low relative skeletal muscle mass (sarcopenia) in older persons is associated with functional impairment and physical disability. Journal of the American Geriatrics Society. May 2002;50(5):889-896.

91. Landi F, Liperoti R, Fusco D, et al. Sarcopenia and mortality among older nursing home residents. Journal of the American Medical Directors Association. Feb 2012;13(2):121-126.

92. Ferrando AA, Paddon-Jones D, Hays $\mathrm{NP}$, et al. EAA supplementation to increase nitrogen intake improves muscle function during bed rest in the elderly. Clinical nutrition. Feb 2010;29(1):18-23.

93. Volpi E, Ferrando AA, Yeckel CW, Tipton KD, Wolfe RR. Exogenous amino acids stimulate net muscle protein synthesis in the elderly. The Journal of clinical investigation. May 1 1998;101(9):2000-2007.

94. Pennings B, Groen B, de Lange A, et al. Amino acid absorption and subsequent muscle protein accretion following graded intakes of whey protein in elderly men. American journal of physiology. Endocrinology and metabolism. Apr 2012;302(8):E992-999.

95. Yang Y, Breen L, Burd NA, et al. Resistance exercise enhances myofibrillar protein synthesis with graded intakes of whey protein in older men. The British journal of nutrition. Nov 28 2012;108(10):17801788.

96. Pennings B, Boirie $\mathrm{Y}$, Senden JM, Gijsen AP, Kuipers H, van Loon LJ. Whey protein stimulates postprandial muscle protein accretion more effectively than do casein and casein hydrolysate in older men. The American journal of clinical nutrition. May 2011;93(5):997-1005.

97. Burd NA, Yang Y, Moore DR, Tang JE, Tarnopolsky MA, Phillips SM. Greater stimulation of myofibrillar protein synthesis with ingestion of whey protein isolate $\mathrm{v}$. micellar casein at rest and after resistance exercise in elderly men. The British journal of nutrition. Sep 28 2012;108(6):958-962.

98. Rieu I, Balage $\mathrm{M}$, Sornet $\mathrm{C}$, et al. Leucine supplementation improves muscle protein synthesis in elderly men independently of hyperaminoacidaemia. The Journal of physiology. Aug 15 2006;575(Pt 1):305315.

99. Volpi E, Kobayashi H, SheffieldMoore M, Mittendorfer B, Wolfe RR. Essential amino acids are primarily responsible for the amino acid stimulation of muscle protein anabolism in healthy elderly adults. The American journal of clinical nutrition. Aug 2003;78(2):250-258.

100. Wall BT, Hamer HM, de Lange A, et al. Leucine co-ingestion improves post-prandial muscle protein accretion in elderly men. Clinical nutrition. Jun 2013;32(3):412-419.

101. Gelfand RA, Barrett EJ. Effect of physiologic hyperinsulinemia on skeletal muscle protein synthesis and breakdown in man. J Clin Invest. Jul 1987;80(1):1-6. 
102. Denne SC, Liechty EA, Liu YM, Brechtel G, Baron AD. Proteolysis in skeletal muscle and whole body in response to euglycemic hyperinsulinemia in normal adults. The American journal of physiology. Dec 1991;261(6 Pt 1):E809-814.

103. Timmerman KL, Lee JL, Dreyer HC, et al. Insulin stimulates human skeletal muscle protein synthesis via an indirect mechanism involving endothelial-dependent vasodilation and mammalian target of rapamycin complex 1 signaling. The Journal of clinical endocrinology and metabolism. Aug 2010;95(8):3848-3857.

104. Hamer HM, Wall BT, Kiskini A, et al. Carbohydrate co-ingestion with protein does not further augment post-prandial muscle protein accretion in older men. Nutrition $\mathcal{E}$ metabolism. 2013;10(1):15.

105. Gorissen SH, Burd NA, Hamer HM, Gijsen AP, Groen BB, van Loon LJ. Carbohydrate coingestion delays dietary protein digestion and absorption but does not modulate postprandial muscle protein accretion. The Journal of clinical endocrinology and metabolism. Jun 2014;99(6):2250-2258.

106. Greenhaff PL, Karagounis LG, Peirce $\mathrm{N}$, et al. Disassociation between the effects of amino acids and insulin on signaling, ubiquitin ligases, and protein turnover in human muscle. American journal of physiology. Endocrinology and metabolism. Sep 2008;295(3):E595-604.

107. Borsheim E, Cree MG, Tipton KD, Elliott TA, Aarsland A, Wolfe RR. Effect of carbohydrate intake on net muscle protein synthesis during recovery from resistance exercise. Journal of applied physiology. Feb 2004;96(2):674-678.

108. Balagopal P, Rooyackers OE, Adey DB, Ades PA, Nair KS. Effects of aging on in vivo synthesis of skeletal muscle myosin heavy-chain and sarcoplasmic protein in humans. The American journal of physiology. Oct 1997;273(4 Pt 1):E790-800.

109. Rooyackers OE, Adey DB, Ades PA, Nair KS. Effect of age on in vivo rates of mitochondrial protein synthesis in human skeletal muscle. Proceedings of the National Academy of Sciences of the United States of America. Dec 24 1996;93(26):15364-15369.

110. Welle S, Thornton C, Jozefowicz R, Statt M. Myofibrillar protein synthesis in young and old men. The American journal of physiology. May 1993;264(5 Pt 1):E693-698.

111. Yarasheski KE, Zachwieja JJ, Bier DM. Acute effects of resistance exercise on muscle protein synthesis rate in young and elderly men and women. The American journal of physiology. Aug 1993;265(2 Pt 1):E210-214.

112. Katsanos CS, Kobayashi H, SheffieldMoore M, Aarsland A, Wolfe RR. A high proportion of leucine is required for optimal stimulation of the rate of muscle protein synthesis by essential amino acids in the elderly. American journal of physiology. Endocrinology and metabolism. Aug 2006;291(2):E381-387.

113. Volpi E, Sheffield-Moore M, Rasmussen BB, Wolfe RR. Basal muscle amino acid kinetics and protein synthesis in healthy young and older men. JAMA : the journal of the American Medical Association. Sep 12 2001;286(10):1206-1212.

114. Kumar V, Selby A, Rankin D, et al. Age-related differences in the doseresponse relationship of muscle protein synthesis to resistance exercise in young and old men. The Journal of physiology. 2009;587(Pt 1):211-217.

115. Volpi E, Mittendorfer B, Rasmussen $\mathrm{BB}$, Wolfe RR. The response of muscle protein anabolism to combined hyperaminoacidemia and glucoseinduced hyperinsulinemia is impaired in the elderly. The Journal of clinical endocrinology and metabolism. Dec 2000;85(12):4481-4490.

116. Biolo G, Ciocchi B, Lebenstedt $M$, Heer M, Guarnieri G. Sensitivity of 
whole body protein synthesis to amino acid administration during short-term bed rest. Journal of gravitational physiology : a journal of the International Society for Gravitational Physiology. 2002;9(1):8.

117. Drummond MJ, Dickinson JM, of ... FCS. Bed rest impairs skeletal muscle amino acid transporter expression, mTORC1 signaling, and protein synthesis in response to essential amino acids in older adults. American Journal of .... 2012.

118. Wall BT, Gorissen SH, Pennings B, et al. Aging Is Accompanied by a Blunted Muscle Protein Synthetic Response to Protein Ingestion. PloS one. 2015;10(11).

119. Carlsson P, Tidermark J, Ponzer S, Söderqvist A, Cederholm T. Food habits and appetite of elderly women at the time of a femoral neck fracture and after nutritional and anabolic support. Journal of human nutrition and dietetics : the official journal of the British Dietetic Association. 2005;18(2):117-120.

120. Bastow MD, Rawlings J, Allison SP. Benefits of supplementary tube feeding after fractured neck of femur: a randomised controlled trial. British medical journal. Nov 26 1983;287(6405):1589-1592.

121. Duncan DG, Beck SJ, Hood K, Johansen A. Using dietetic assistants to improve the outcome of hip fracture: a randomised controlled trial of nutritional support in an acute trauma ward. Age and ageing. 2006;35(2):148-153.

122. Miller MD, Bannerman E, Daniels LA, Crotty M. Lower limb fracture, cognitive impairment and risk of subsequent malnutrition: a prospective evaluation of dietary energy and protein intake on an orthopaedic ward. European journal of clinical nutrition. 2006;60(7):853-861.

123. Anbar R, Beloosesky Y, Cohen J, et al. Tight calorie control in geriatric patients following hip fracture decreases complications: a randomized, controlled study. Clinical nutrition (Edinburgh, Scotland). 2014;33(1):23-28.

124. Eneroth $\mathrm{M}$, Olsson U-BB, Thorngren K-GG. Nutritional supplementation decreases hip fracture-related complications. Clinical orthopaedics and related research. 2006;451:212-217.

125. Tkatch L, Rapin CH, Rizzoli R, et al. Benefits of oral protein supplementation in elderly patients with fracture of the proximal femur. Journal of the American College of Nutrition. 1992;11(5):519-525.

126. Espaulella J, Guyer H, Diaz-Escriu F, Mellado-Navas JA, Castells M, Pladevall M. Nutritional supplementation of elderly hip fracture patients. A randomized, double-blind, placebo-controlled trial. Age and ageing. 2000;29(5):425-431.

127. Delmi $\mathrm{M}$, Rapin $\mathrm{CH}$, Bengoa JM, Delmas PD, Vasey $\mathrm{H}$, Bonjour JP. Dietary supplementation in elderly patients with fractured neck of the femur. Lancet (London, England). 1990;335(8696):1013-1016.

128. Avenell A, Smith TO, Curtain JP, Mak JC, Myint PK. Nutritional supplementation for hip fracture aftercare in older people. The Cochrane database of systematic reviews. 2016;11.

129. Miller MD, Crotty M, Whitehead C, Bannerman E, Daniels LA. Nutritional supplementation and resistance training in nutritionally at risk older adults following lower limb fracture: a randomized controlled trial. Clinical rehabilitation. 2006;20(4):311-323.

130. Sullivan DH, Nelson CL, Bopp MM, Puskarich-May CL, Walls RC. Nightly enteral nutrition support of elderly hip fracture patients: a phase I trial. Journal of the American College of Nutrition. 1998;17(2):155-161.

131. Sullivan DH, Nelson CL, Klimberg VS, Bopp MM. Nightly enteral nutrition support of elderly hip fracture patients: a pilot study. Journal of the American College of Nutrition. 2004;23(6):683-691. 
132. Wyers CE, Reijven PL, Evers SM, et al. Cost-effectiveness of nutritional intervention in elderly subjects after hip fracture. A randomized controlled trial. Osteoporosis international : a journal established as result of cooperation between the European Foundation for Osteoporosis and the National Osteoporosis Foundation of the USA. 2013;24(1):151-162.

133. Schürch MA, Rizzoli R, Slosman D, Vadas L, Vergnaud P, Bonjour JP. Protein supplements increase serum insulin-like growth factor-I levels and attenuate proximal femur bone loss in patients with recent hip fracture. A randomized, double-blind, placebocontrolled trial. Annals of internal medicine. 1998;128(10):801-809.

134. Botella-Carretero JII, Iglesias B, Balsa JAA, Arrieta F, Zamarrón I, Vázquez C. Perioperative oral nutritional supplements in normally or mildly undernourished geriatric patients submitted to surgery for hip fracture: a randomized clinical trial. Clinical nutrition (Edinburgh, Scotland). 2010;29(5):574-579.

135. Hartgrink $\mathrm{HH}$, Wille J, König $\mathrm{P}$, Hermans J, Breslau PJ. Pressure sores and tube feeding in patients with a fracture of the hip: a randomized clinical trial. Clinical nutrition (Edinburgh, Scotland). 1998;17(6):287292.

136. Neumann M, Friedmann J, Roy MAA, Jensen GL. Provision of highprotein supplement for patients recovering from hip fracture. Nutrition (Burbank, Los Angeles County, Calif.). 2004;20(5):415-419.

137. Tidermark J, Ponzer S, Carlsson P, et al. Effects of protein-rich supplementation and nandrolone in lean elderly women with femoral neck fractures. Clinical nutrition. Aug 2004;23(4):587-596.

138. Myint MWW, Wu J, Wong E, et al. Clinical benefits of oral nutritional supplementation for elderly hip fracture patients: a single blind randomised controlled trial. Age and ageing. 2013;42(1):39-45.

139. Bruce D, Laurance I, McGuiness M, Ridley M, Goldswain P. Nutritional supplements after hip fracture: poor compliance limits effectiveness. Clinical nutrition (Edinburgh, Scotland). 2003;22(5):497-500. 




\title{
ADDENDUM
}

\author{
Summary
}

Samenvatting

Valorisation

Dankwoord

Curriculum Vitae 


\section{Summary}

Skeletal muscle mass is progressively lost with normal ageing. The loss of muscle mass and strength with aging has been termed sarcopenia. Sarcopenia is considered a syndrome increasing the risk of frailty and predicting physical disability, loss of independence, poor quality of life, and death. Skeletal muscle responds rapidly to changing conditions, and in situations such as injury, sickness, or immobilisation, the loss of muscle mass and function are accelerated. In the catabolic crisis model, successive episodes of exacerbated muscle loss are assembled, which is opposed by the traditional model of gradual linear loss of muscle mass with ageing. Hip fractures in the elderly population are the result of a simple fall in the majority of the cases. Skeletal muscle is fundamental for mobility and balance. Sarcopenia predisposes elderly to falls and fractures. Maintaining or increasing muscle mass and strength could, therefore, be a crucial factor in the prevention of hip fractures. After suffering a hip fracture, the combination of injury-related trauma, surgical intervention, preoperative fasting, and physical inactivity may result in further and accelerated muscle loss in the elderly patient. Intervention strategies to maintain skeletal muscle mass are warranted to attenuate muscle loss with ageing and during acute conditions. The present dissertation aimed to gain further insight into the presence and extent of skeletal muscle loss in older hip fracture patients before and during hospitalisation, and investigated different nutritional interventions aimed at counteracting muscle loss in (sarcopenic) elderly.

Surgical care is defined by a continuum of pre- peri-, and postoperative factors and events having potential impact on patient survival. In chapter 2 of this dissertation, we investigated whether the in-hospital outcomes of older surgical patients undergoing an orthopaedic intervention in urgent or emergent conditions are different from other patient groups. We observed a relationship between the urgency of surgery and in-hospital mortality in this group. In addition, non-elective surgery in orthopaedic patients was associated with higher critical care admission rates and a longer hospital stay. Moreover, an age of over 80 years and a higher ASA classification were identified as significant contributing factors to postoperative mortality.

Loss of skeletal muscle mass with aging is mainly the consequence of a decline in type II muscle fibre size. In chapter 3, we obtained muscle biopsies from older female hip fracture patients and compared skeletal muscle fibre characteristics with muscle biopsies form healthy young and older females. We showed that older female hip fracture patients suffer from both type I and type II muscle fibre atrophy. The 
type II muscle fibre atrophy was extensive, showing 30\% smaller muscle fibres in hip fracture patients when compared with age-matched controls. These differences in skeletal muscle (fibre) characteristics between the hip fracture patients and agematched controls likely predisposes the hip fracture patients to falls and fractures. Periods of inactivity and stress-inducing events can exacerbate the loss of muscle mass and change in muscle fibre characteristics. We hypothesised that a hip fracture would lead to more loss of skeletal muscle accompanied by concomitant changes on a muscle fibre level. In chapter 4 , we performed a prospective observational study and obtained pre- and post-operative CT-scans and muscle biopsies in older hip fracture patients. A substantial loss of whole thigh muscle $(5.4 \%)$ and quadriceps muscle $(4.5 \%)$ was observed during hospitalisation. The results from our previous study as described in chapter 3 were confirmed, showing pre-existing smaller type II muscle fibres when compared with type I muscle fibres in these older hip fracture patients. However, during hospitalisation, no further changes were observed in muscle fibre characteristics. We concluded that older patients recovering from an operatively treated hip fracture lose a substantial amount of skeletal muscle during hospitalisation.

Sarcopenia is of importance for hip fracture patients, because it puts them at risk for (recurrent) falls and fractures, but has also effects clinical outcomes. Nutrition plays a role in the development of sarcopenia and is also a potent intervention combatting the loss of skeletal muscle mass. Poor nutritional status, due to energy and protein malnutrition, is a well-known problem in older hip fracture patients. Modification of nutritional status using nutritional interventions could be beneficial in terms of improving outcomes. The effect of peri-operative nutritional interventions was evaluated and reviewed in chapter 5. Nutritional interventions during hospital stay can be applied in several ways such as the provision of protein dense food supplements, enteral feeds, or intravenous amino acid supplementation. Protein-enriched nutritional support seems to have a positive effect on nutritional status. The effectiveness of the intervention may be dependent on individual needs. Improvements in clinical outcomes such as less complications and shorter hospital stays were found in several of the intervention studies. However, outcomes in improvement of functional performance, functional independence, and mobility are conflicting. Adequately sized, randomised trials with robust methodology are required.

In chapter 6 and 7 of this dissertation, we performed tracer studies using stable isotope methodology to test the effect of protein administration on muscle protein synthesis rates in older individuals. In chapter 6, we determined the impact 
of the macronutrient composition of a nutritional supplement on the postprandial muscle protein synthetic response in healthy older men. Our participants were randomly assigned to ingest 21 gram of leucine-enriched whey protein with carbohydrate and fat, or an isonitrogenous supplement without carbohydrate and fat, or an isocaloric supplement without protein. We observed that ingestion of protein significantly increased muscle protein synthesis rates, whereas ingestion of carbohydrate and fat did not result in such an increase. No differences were observed between the group ingesting the protein supplement with other macronutrients and the group ingesting an isonitrogenous amount of protein only. Co-ingestion of carbohydrate and fat did not further modulate the postprandial muscle protein synthetic response to protein ingestion.

We performed a study to compare basal and postprandial muscle protein synthesis rates between sarcopenic and healthy older men in chapter 7 . We used the same nutritional supplement containing 21 gram of leucine-enriched whey protein, carbohydrate and fat. Basal muscle protein synthesis rates did not differ between the sarcopenic and healthy older men. Moreover, no differences were observed in the increase in muscle protein synthesis rates between groups when this amount of leucine-enriched whey protein was provided, which does not rule out that some level of anabolic resistance may be evident following the ingestion of smaller amounts of (non-leucine enriched) protein.

The final chapter elaborates on the primary findings described in this dissertation and identifies a number of topics that need to be addressed in the future. This dissertation shows that older hip fracture patients suffer from extensive skeletal muscle fibre atrophy, and that an exacerbated loss of muscle mass occurs postfracture during hospital admission in these patients. Targeted interventions to combat the loss of skeletal muscle mass during hospitalisation could contribute to improved outcomes. There is no substantial impairment in the anabolic sensitivity of skeletal muscle tissue in sarcopenic older patients given that an adequate nutritional stimulus is provided. Although numerous studies have studied nutritional interventions in hip fracture patients, the results on outcomes remain discrepant. Increasing the knowledge on the mechanisms responsible for the accelerated muscle loss in hip fracture patients and optimising nutritional interventions may contribute to the preservation of skeletal muscle mass and may consequently lead to more favourable clinical outcomes. 




\section{Samenvatting}

De afname van spiermassa met het klimmen van de leeftijd, in combinatie met een afname van spierkracht of spierfunctie, wordt sarcopenie genoemd. Sarcopenie wordt beschouwd als een syndroom dat het risico op kwetsbaarheid verhoogt en fysieke functionele achteruitgang, verlies van onafhankelijkheid, een slechte kwaliteit van leven en levensverwachting voorspelt. Spierweefsel is gevoelig voor veranderende omstandigheden waardoor in sommige situaties het verlies van spiermassa en spierfunctie wordt versneld, zoals na trauma, tijdens een periode van ziekte, of tijdens immobilisatie. In het 'catabolic crisis' model leiden opeenvolgende episodes van versnelde afname van spiermassa zonder adequaat herstel tot een sterkere afname van spiermassa over de tijd, en staat daarmee tegenover het traditionele sarcopenie model waarbij men uitgaat van een geleidelijk verlies van spiermassa met veroudering. Heupfracturen bij ouderen zijn vaak het gevolg van een laag-energetisch trauma, zoals een simpele val in huis of op straat. Skeletspieren zijn fundamenteel voor de mobiliteit en balans. Sarcopene ouderen, met verminderde spiermassa en spierkracht, hebben daarom een verhoogd risico op vallen met eventuele fracturen tot gevolg. Het behoud of bevorderen van spiermassa en spierkracht kan daarom een cruciale factor zijn bij het voorkomen van heupfracturen. Bij de oudere patiënt met een heupfractuur kan de combinatie van het trauma, de chirurgische interventie, het preoperatief nuchter blijven en de periode van verminderde fysieke inactiviteit resulteren in verdere en versnelde afname van spiermassa en spierkracht. Interventiestrategieën om spiermassa te behouden zijn nodig om spierverlies te verminderen, niet alleen bij normale veroudering maar juist ook tijdens periodes van versnelde achteruitgang. Het huidige proefschrift heeft tot doel gehad om verder inzicht te krijgen in het verlies van spiermassa bij oudere heupfractuurpatiënten vóór en tijdens ziekenhuisopname, en onderzocht verschillende voedingsinterventies gericht op het tegengaan van spierverlies bij (sarcopene) ouderen.

Chirurgische zorg wordt gedefinieerd door een continuüm van pre-, peri- en postoperatieve factoren en gebeurtenissen die een potentiële impact hebben op de overleving van de patiënt. In hoofdstuk 2 van dit proefschrift hebben we onderzocht of de uitkomsten van oudere patiënten die een niet-electieve trauma-chirurgische of orthopedisch-chirurgische interventie ondergaan verschillen van de uitkomsten van andere patiëntengroepen. We toonden een relatie tussen de urgentie van chirurgie en sterfte tijdens ziekenhuisopname aan onder traumachirurgische en orthopedische patiënten. Bovendien was niet-electieve chirurgie in deze groep geassocieerd met 
hogere opnamecijfers op de intensive care en met een langere ziekenhuisopname. Verder bleken een leeftijd hoger dan 80 jaar en een hogere ASA-classificatie geassocieerd te zijn met hogere postoperatieve mortaliteit.

Verlies van spiermassa is het gevolg van een afname in de grootte van spiervezels. Bij sarcopenie is er sprake van een uitgesproken atrofie van de type II spiervezels. In hoofdstuk 3 onderzochten we de kenmerken van spiervezels van oudere vrouwelijke heupfractuurpatiënten en vergeleken we deze met de spierbiopten van gezonde vrouwen van een zelfde leeftijd en van gezonde jonge vrouwen. In dit hoofdstuk toonden we aan dat oudere vrouwelijke heupfractuurpatiënten zowel type I als type II spiervezelatrofie hebben. De type II spiervezelatrofie was het meest uitgesproken. De heupfractuurpatiënten hadden $30 \%$ kleinere type II spiervezels in vergelijking met hun gezonde leeftijdsgenoten, wat een belangrijk kenmerk is van sarcopenie. Dit maakt dat deze patiënten een hoger risico hebben op vallen en dit heeft dus waarschijnlijk ook bijgedragen aan het oplopen van een heupfractuur. Perioden van inactiviteit en gebeurtenissen leidend tot een verhoogde stress respons kunnen de achteruitgang van spiermassa en de verandering van spiervezelkenmerken verergeren. Een heupfractuur zou daarom een verder verlies van spiermassa met veranderingen op spiervezelniveau tot gevolg kunnen hebben. In hoofdstuk 4 hebben we pre- en postoperatieve CT-scans gemaakt en spierbiopten afgenomen bij oudere patiënten met heupfracturen om dit verloop te kunnen bestuderen. Een aanzienlijk verlies van spiermassa van het gehele bovenbeen $(5,4 \%)$ en de quadriceps $(4,5 \%)$ werd geobserveerd tijdens de ziekenhuisopname. Ook in deze studie zagen we duidelijke spiervezelatrofie van de type II vezels bij de heupfractuurpatiënten, wat al aanwezig was op het moment van binnenkomst in het ziekenhuis. Tijdens ziekenhuisopname verloren de oudere heupfractuurpatiënten een aanzienlijke hoeveelheid spiermassa.

Sarcopenie verhoogt het risico op een heupfractuur, maar heeft waarschijnlijk ook effect op de uitkomsten na een heupfractuur. Voeding is een belangrijke factor voor het ontstaan van sarcopenie, en is ook een belangrijke interventie in de strijd tegen spiermassaverlies. Een verslechterde voedingsstatus bij heupfractuurpatiënten is een bekend probleem. Als de voedingsstatus van deze patiënten met behulp van voedingsinterventies verbeterd zou kunnen worden, kan dat ook een gunstig effect hebben op de uitkomsten van deze patiënten. We onderzochten daarom wat er in de literatuur al bekend is over de effecten van perioperatieve voedingsinterventies bij heupfractuurpatiënten in hoofdstuk 5. Voedingsinterventies kunnen op verschillende manieren worden toegepast, zoals het verstrekken van (eiwitrijke) voedingssupplementen, het stimuleren van de dagelijkse voedingsinname, of zelfs 
voedingsinterventies via sondes of intraveneuze toediening. Met name suppletie van eiwitten lijkt de voedingsstatus van heupfractuur patiënten aanzienlijk te kunnen verbeteren. Echter is het effect van een interventie niet geheel eenduidig tussen patiënten, en lijkt het zo te zijn dat interventies die toegespitst zijn op de individuele voedingsbehoeften het meeste effect sorteren. Verbeterde klinische uitkomsten zoals een afgenomen complicatiepercentage en kortere ziekenhuisopnames werden in verschillende van de interventiestudies beschreven, hoewel deze niet altijd van hoge kwaliteit zijn. Of voedingsinterventies ook een positief effect hebben op de spierfunctie en mobiliteit van de patiënt is nog onduidelijk. Er is sterker en eenduidiger bewijs nodig voor de effectiviteit van voedingsinterventiestrategieën op klinisch en fysiologisch relevante uitkomstmaten.

In hoofdstuk 6 en 7 van dit proefschrift hebben we experimenten uitgevoerd waarbij we met behulp van stabiele isotopenmethodologie het effect van een voedingsinterventie op de spiereiwitsynthese bij oudere personen hebben getest. In hoofdstuk 6 hebben we onderzocht of de samenstelling van een voedingssupplement, met een variatie in samenstelling van de macronutriënten eiwit, koolhydraten en vet, verschil maakt in de postprandiale spiereiwitsynthese van gezonde oudere mannen. We testten een supplement bestaande uit 21 gram leucine-verrijkt wei-eiwit, koolhydraten en vetten, en een supplement met dezelfde hoeveelheid eiwit maar zonder koolhydraten en vetten, en een isocalorisch supplement zonder eiwit. We zagen dat inname van beide supplementen waar eiwit in zat de spiereiwitsynthese aanzienlijk verhoogde, terwijl inname van alleen koolhydraten en vet niet in een meetbare toename resulteerde. Er was geen verschil in postprandiale spiereiwitsynthese tussen de twee afzonderlijke eiwitsupplementen. Co-ingestie van koolhydraten en vet in combinatie met 21 gram leucine-verrijkt weieiwit moduleert de spiereiwitsynthese dus niet in deze groep proefpersonen.

Aangezien sarcopene ouderen meer spiermassa hebben verloren dan hun leeftijdsgenoten zonder sarcopenie, zou het kunnen zijn dat er zij een verminderde anabole respons vertonen op voedingsinname of wellicht (ook) een verlaagde basale spiereiwitsynthese hebben in vergelijking met gezonde ouderen. Dit onderzochten we in hoofdstuk 7. We gebruikten hetzelfde voedingssupplement met 21 gram leucine-verrijkt wei-eiwit, koolhydraten en vet in deze tweede tracerstudie. We ontdekten dat de basale spiereiwitsynthese niet meetbaar verschilt tussen sarcopene en gezonde oudere mannen. Bovendien werd na inname van het voedingssupplement een vergelijkbare toename in de spiereiwitsynthese waargenomen in beide groepen. We toonden hiermee aan dat er geen structureel verschil is in basale spiereiwitsynthese tussen sarcopene en gezonde ouderen, en dat 
na inname van een adequaat voedingssupplement er ook geen postprandiaal verschil is.

Het laatste hoofdstuk gaat in op de primaire bevindingen zoals beschreven in dit proefschrift en identificeert een aantal onderwerpen die in de toekomst zouden moeten worden onderzocht. Dit proefschrift toont sarcopenie op vezelniveau aan bij oudere heupfractuurpatiënten, en laat zien dat ziekenhuisopname het verlies van spiermassa verergert. Voedingsinterventies tijdens ziekenhuisopname ter bestrijding van het spiermassaverlies kunnen mogelijk bijdragen aan betere klinische uitkomsten. Wanneer de juiste voedingsstimulus wordt gegeven, is er ook bij sarcopene ouderen een substantiële toename van de spiereiwitsynthese mogelijk. Hoewel talrijke studies de effecten van voedingsinterventies bij patiënten met een heupfractuur hebben bestudeerd, blijven de resultaten over de uitkomsten onduidelijk. Uitbreiding van de kennis over de onderliggende mechanismen die leiden tot het versnelde spiermassaverlies bij heupfractuurpatiënten en het optimaliseren van voedingsinterventies kan bijdragen aan het behoud van spiermassa en spierfunctie bij deze patiënten en kan bijgevolg tot gunstigere klinische uitkomsten leiden. 




\section{Valorisation}

\section{Relevance}

The aged population is rapidly growing, and the number of people aged 65 years and older is expected to nearly triple by 2050, then representing 16 percent of the world's population ${ }^{1}$. In high-income countries such as the Netherlands, predictions show that even 33\% of the population will be older than 60 years in 2050. These demographic shifts will have profound implications for our healthcare system. While infectious and acute disease are waning in Western societies, frailty and degenerative disease will emerge as more significant health problems. The increasing life expectancy thereby challenges society to maintain health and functional capacity in its older people. One of the age-related changes that strongly impacts on health and function is the gradual, progressive loss of skeletal muscle mass. Adults lose an average of $25 \%$ of their skeletal muscle mass between the age of 40 and 70 years, with an accelerated loss after the age of 70 years, although with individual variation. The co-occurrence of loss of muscle mass and decline in muscle function or strength is termed sarcopenia. Sarcopenia is a syndrome characterised by progressive and generalised loss of skeletal muscle mass and strength increasing the risk of frailty and predicting physical disability, loss of independence, poor quality of life, and death ${ }^{2}$. It is, therefore, considered an undesirable consequence of ageing with both personal and societal impact. From 2016, sarcopenia has been recognised as a disease entity and has been given an ICD-10-CM code (International Classification of Diseases, Clinical Modification). For these reasons it is of great importance to understand the various factors underlying sarcopenia and to develop effective interventions to prevent or delay the onset of sarcopenia.

The clinical relevance of sarcopenia is emphasised in elderly hip fracture patients. The decline in skeletal muscle mass and function predisposes to falls and fall-related fractures. The ability of skeletal muscle to generate an adequate amount of force is fundamental for balance and prevention of falling. Elderly suffering from sarcopenia, therefore, have a three times higher risk of falling, regardless of age and comorbidities ${ }^{3}$. The total number of hip fracture patients is expected to further increase in the upcoming decades as a consequence of the demographic changes. The cost of care for hip fracture patients are about three times greater than age and residency-matched controls without a fracture. The personal proverbial costs of a hip fracture are also high, since hip fracture patients have an increased risk of mortality. Up to $30 \%$ of hip fracture patients does not survive the first year following the injury. Importantly, due to a decline in mobility and function, more than half of the patients 
becomes unable of living independently. It is, therefore, not surprising that hip fracture patients experience lower quality of life than their age-matched controls.

This dissertation provides evidence that sarcopenia plays an aetiological role in suffering a hip fracture in the elderly. The loss of skeletal muscle mass with ageing can mainly be attributed to a reduced type II muscle fibre size, accounting for the majority of the loss of muscle mass ${ }^{4,5}$. Type II muscle fibres are essential for rapid muscle force production and are, therefore, essential in preventing falls. The work in this dissertation used percutaneous skeletal muscle biopsies of the $m$. vastus lateralis to assess muscle fibre characteristics of older hip fracture patients. We compared the muscle fibre characteristics of older hip fracture patients with age-matched controls without fall-related fractures in the medical history in one study, and compared muscle fibre characteristics between hospital admission and hospital discharge in another study. We demonstrate that older hip fracture patients suffer from sarcopenia at a muscle fibre level, showing extensive type II muscle fibre atrophy at time of hospital admission. Furthermore, we observed that older hip fracture patients even show signs of type I muscle fibre atrophy. We speculate that during hospital admission, older hip fracture patients suffer from on-going atrophy due to a combination of factors such as surgical intervention, pre-operative fasting, and physical inactivity. We observed substantial loss of skeletal muscle mass perioperatively during hospital admission, as measured with CT-scans to assess muscle cross-sectional areas of the upper legs. This emphasises the need for the development of effective interventional strategies to combat the loss of skeletal muscle mass in this compromised group of patients.

\section{Healthcare implementation and products}

Researchers nowadays have recognised the importance of sarcopenia as a prognostic indicator of post-operative outcome and discharge destination. Among hospitalised patients in general, sarcopenia seems to have the greatest prevalence at the orthopaedic trauma wards ${ }^{6}$. The European Working Group on Sarcopenia in Older People recommends using the presence of both low muscle mass and low muscle function for the diagnosis of sarcopenia ${ }^{2}$. Evaluation of sarcopenia in hip fracture patients can be challenging due to mobility problems and pain, both pre- and postoperative. However, the clinical features of sarcopenia are obvious in most of the hip fracture patients. It can be seen as the 'elephant in the (operating) room': it is easy to spot, but often ignored. Currently, in most Dutch hospitals, the treatment of hip fractures has evolved into fast-track surgical programs. This multidisciplinary approach includes preoperative optimisation of cardiac function, electrolyte 
disturbances, early surgery and early mobilisation, adequate analgesia, and thromboprofylaxis. The role of nutritional support can be integrated in these programs to target the on-going loss of skeletal muscle mass during hospitalisation. In pre-habilitation programs, which have been developed to prepare patients prior to hospitalisation and surgical treatment, the role of nutritional support is already more profound. Even though there is increasing awareness on the negative health consequences of hospitalisation in the older population, patients themselves are often unaware of the importance and relevance of nutrition and physical activity during their hospitalisation and subsequent recovery. Physicians, nutritionists, and physical therapists have a role to make patients aware that surgery and pharmaceuticals are not the only cornerstones of their treatment. In the ESPEN guidelines on clinical nutrition in surgery, integration of nutrition into the overall management of the patient, start of early nutritional therapy as soon as a nutritional risk becomes apparent, and early mobilisation to facilitate muscle and connective tissue protein synthesis and muscle function are recommended ${ }^{7}$. Targeted interventions to combat the loss of skeletal muscle mass and strength during hospitalisation and rehabilitation after a hip fracture may contribute to better outcomes and quality of life in the older hip fracture patients. These principles can lead to development of specific products and innovations in the (clinical) nutrition industry.

Stimulation of the protein synthetic response to food intake is one of the principles in the development of nutritional interventions. Older hip fracture patients may need other anabolic stimuli from a nutritional product than healthy (young) patients, because of the concept of anabolic resistance ${ }^{8,9}$. The current dissertation explores nutritional strategies to stimulate muscle protein synthesis rates in healthy and sarcopenic older individuals. We explored basal muscle protein synthesis rates in sarcopenic older adults, which has never been done before. We demonstrated that ingestion of a nutritional supplement containing 21 gram of leucine-enriched whey protein is effective in stimulating muscle protein synthesis, and that this is not modulated by the addition of carbohydrates and fat to the product. This is an important finding given that nutritional supplements provided in the hospital setting often contain all macronutrients. The findings on muscle protein synthesis in the sarcopenic older patient are also encouraging. We were able to effectively stimulate muscle protein synthesis rates in sarcopenic patients by ingesting this leucine enriched whey protein. This proves that targeting muscle loss in sarcopenic elderly is possible despite their anabolic resistance. The presented data could be used for further nutritional product development. However, studying the acute effects of a nutritional intervention in a laboratory setting in sarcopenic elderly can still be 
drastically different from the effect on muscle protein synthesis rates in sarcopenic hip fracture patients in a hospital setting. The optimal composition of a nutritional supplement for elderly hip fracture patients remains to be determined. Parts of this dissertation have been conducted within the framework of TIFN, a public-private partnership of universities and the nutritional industry, where research findings have been shared with industrial partners throughout the last years. This platform allows industries to implement scientific research into concept and product innovations and can help all partners solving more pieces of the puzzle. Combining knowledge will allow us to develop more effective intervention strategies to combat the devastating loss of muscle mass and/or strength in older hip fracture patients. 


\section{References}

1. Lutz W, Sanderson W, Scherbov S. The coming acceleration of global population ageing. Nature. 2008;451(7179):716-719.

2. Cruz-Jentoft AJ, Baeyens JP, Bauer JM, et al. Sarcopenia: European consensus on definition and diagnosis: Report of the European Working Group on Sarcopenia in Older People. Age and ageing. Jul 2010;39(4):412-423.

3. Landi F, Liperoti R, Russo A, et al. Sarcopenia as a risk factor for falls in elderly individuals: results from the ilSIRENTE study. Clinical nutrition. Oct 2012;31(5):652-658.

4. Nilwik R, Snijders T, Leenders M, et al. The decline in skeletal muscle mass with aging is mainly attributed to a reduction in type II muscle fiber size. Experimental gerontology. 2013;48(5):492-498.

5. Verdijk LB, Koopman R, Schaart G, Meijer K, Savelberg HH, van Loon LJ.
Satellite cell content is specifically reduced in type II skeletal muscle fibers in the elderly. American journal of physiology. Endocrinology and metabolism. Jan 2007;292(1):E151-157.

6. Sousa AS, Guerra RS, Fonseca I, Pichel F, Amaral TF. Sarcopenia among hospitalized patients - A crosssectional study. Clinical nutrition (Edinburgh, Scotland). 2014.

7. Weimann A, Braga M, Carli F, et al. ESPEN guideline: Clinical nutrition in surgery. Clinical nutrition (Edinburgh, Scotland). 2017;36(3):623-650.

8. Burd NA, Gorissen SH, van Loon LJ. Anabolic resistance of muscle protein synthesis with aging. Exerc Sport Sci Rev. Jul 2013;41(3):169-173.

9. Wall BT, Gorissen SH, Pennings B, et al. Aging Is Accompanied by a Blunted Muscle Protein Synthetic Response to Protein Ingestion. PloS one. 2015;10(11). 

Dankwoord 









\section{Curriculum Vitae}

Irene Fleur Kramer was born on 25 August 1987 in Utrecht, the Netherlands. She grew up with one younger brother in Amersfoort, where she graduated from the Johan van Oldenbarnevelt Gymnasium in 2005. Afterwards, she started her medicine study at Maastricht University with the ultimate goal of becoming a surgeon. During medical school, Irene Fleur completed clinical rotations in surgery in Lilongwe (Malawi), Utrecht, Roermond, and Maastricht. After graduating in November 2011, she started working as a PhD student at the Department of Human Biology and the Department of Surgery within NUTRIM School of Nutrition and Translational Research under the supervision of Professor Luc van Loon, Professor Martijn Poeze, and Dr. Lex Verdijk. During her PhD trajectory, Irene Fleur attended several national and international conferences and she was awarded with the 'Aanmoedigingsprijs' at the Pélerin Conference 2012 in Maastricht, and with the Dr. G.J. Heijmans Award at the Assistentensymposium Traumachirurgie 2013 in Soesterberg. Moreover, in 2014 she obtained the research grant from the Osteosynthesis and Trauma Care Foundation (OTC Europe) and continued her research on muscle loss in older hip fracture patients. During her PhD trajectory, Irene Fleur was a member of the board of the Pélerin Symposium 2013 of the MUMC+, and chair of the national SEOHS 2017 conference. In September 2015 she started as a surgical resident (ANIOS) at the Department of Surgery of the Jeroen Bosch Ziekenhuis in 's-Hertogenbosch. In 2016 she entered surgical training (AIOS) at the Gelderse Vallei Hospital in Ede (dr. A.M. Bosch and drs. J.E.M. Sybrandy) and worked there for almost three years. From May 2019 onwards, she will continue her surgical training at the Radboud University Medical Centre in Nijmegen (dr. B.H. Verhoeven and dr. O.R. Buyne). 


\section{List of publications}

2019

Holwerda AM, Paulussen KJM, Overkamp M, Goessens JPB, Kramer IF, Wodzig WKWH, Verdijk LB, van Loon LJC. Dose-Dependent Increases in Whole-Body Net Protein Balance and Dietary Protein-Derived Amino Acid Incorporation into Myofibrillar Protein During Recovery from Resistance Exercise in Older Men. Journal of Nutrition. 2019 Feb; 149(2): 221-230.

Kramer IF, Blokhuis TJ, Verdijk LB, van Loon LJC, Poeze M. Perioperative nutritional supplementation and skeletal muscle mass in older hip fracture patients. Nutrition Reviews. 2019 Apr; 77(4): 254-266.

Kouw IWK, Groen BBL, Smeets JSJ, Kramer IF, van Kranenburg JMX, Nilwik R, Geurts JAP, ten Broeke RHM, Poeze M, van Loon LJC, Verdijk LB. One week of hospital admission following elective hip surgery induces substantial muscle atrophy in older patients. JAMDA: Journal of American Medical Directors Asscoiation. 2019 Jan; 20(1): 35-42.

Kramer IF, Broen S, Nilwik R, van Kranenburg J, Hadfoune M, van Bijnen AA, Meex SJR, Groen BB, Kouw IWK, Winkens B, Verdijk LB, van Loon LJC, Poeze M. Skeletal muscle loss in elderly hip fracture patients during hospital admission. Submitted 2019 Feb.

2017

Kouw IWK, Holwerda AM, Trommelen J, Kramer IF, Bastiaanse J, Halson SL, Wodzig WKWH, Verdijk LB, van Loon LJC. Protein ingestion before sleep increases overnight muscle protein synthesis rates in healthy older men: a randomized controlled trial. Journal of Nutrition. 2017 Dec; 147(12): 2252-2261.

Kramer IF, Snijders T, Smeets J, Leenders M, van Kranenburg J, Verdijk LB, Poeze M, van Loon LJC. Extensive type II muscle fiber atrophy in elderly women undergoing acute hip surgery after a fall-related fracture. Journal of Gerontoly A: Biological Sciences and Medical Sciences. 2017 Oct;72 (10): 1369-1375.

Kramer IF, Verdijk LB, Hamer HM, Verlaan S, Luiking Y, Kouw IWK, Senden JM, van Kranenburg J, Poeze M, van Loon LJC. Both basal and post-prandial muscle protein synthesis rates, following the ingestion of a leucine-enriched whey protein supplement, are not impaired in sarcopenic older males. Clinical Nutrition. 2016 Sep. S0261-5614(16)31263-31268. 
Dirks ML, Wall BT, Kramer IF, Zorenc AH, Goessens JP, Gijsen AP, van Loon LJ. A single session of neuromuscular electrical stimulation does not augment postprandial muscle protein accretion. American Journal of Physiology Endocrinology and Metabolism. 2016 Jul 1;311(1):E278-285.

2015

Gorissen SH, Burd NA, Kramer IF, van Kranenburg J, Gijsen AP, Rooyackers $\mathrm{O}$, van Loon LJ. Co-ingesting milk fat with micellar casein does not affect postprandial protein handling in healthy older men. Clinical Nutrition. 2015 Dec 24. S0261-5614(15)00349-0.

Kramer IF, Verdijk LB, Hamer HM, Verlaan S, Luiking Y, Kouw IWK, Senden JM, van Kranenburg J, Gijsen AP, Poeze M, van Loon LJC. Impact of the macronutrient composition of a nutritional supplement on postprandial muscle protein synthesis rates in healthy older men: a randomized, double blind, controlled trial. Journal of Clinical Endocrinology and Metabolism. 2015 Nov;100(11):4124-4132.

2014

Kramer IF, Brouwers L, Brink PRG, Poeze M. Snowboarders' ankle, a review. British Medical Journal Case Reports. 2014 Oct.

Pearse RM, Moreno RP, Rhodes A, et al. For the European Surgical Outcomes Study (EuSOS) group for the Trials groups of the European Society of Intensive Care Medicine and the European Society of Anaesthesiology, Maastricht: Kramer IF, Poeze M. Mortality after surgery in Europe: a 7 day cohort study. The Lancet. 2012 Sep 22;380(9847):1059-1065

Knuiman P, Kramer IF. Contributions to the understanding of the anabolic properties of different dietary proteins. Journal of Physiology. 2012 Jun 15;590(12):2839-2840

Gho JMIH, Kramer IF Van Hulst RA, Kramer WLM. Decompressieziekte: Geringe klachten, ernstige gevolgen (Decompression illness: minor symptoms, major consequences). Nederlands Tijdschrift voor Geneeskunde. 2012;156(36):A4985 


\section{Presentations}

2016

17 th ECTES Congress, Vienna, 24-26 April. Muscle loss during hospital admission in hip fracture patients. Kramer IF, Broen S, Kouw IWK, van Kranenburg J, Verdijk LB, van Loon LJC, Poeze M.

2014

Annual NUTRIM day, 17 December, Maastricht. Basal and post-prandial muscle protein synthesis rates are not reduced in sarcopenic elderly. Kramer IF, Poeze M, Luiking YC, Verlaan S, Verdijk LB, van Loon LJC.

Pélerin Symposium, 8 October, Maastricht. Muscle protein synthesis rates in sarcopenic and healthy elderly. Kramer IF, Poeze M, Luiking YC, Verlaan S, Verdijk LB, van Loon LJC.

$36^{\text {th }}$ ESPEN Congress, 6-9 September, Geneva. Basal and post-prandial muscle protein synthesis rates are not reduced in sarcopenic elderly. Kramer IF, Poeze M, Luiking YC, Verlaan S, Verdijk LB, van Loon LJC.

2013

Traumadagen, 7-8 November, Amsterdam. Muscle atrophy in hip fracture patients. Kramer IF, Poeze M.

$14^{\text {th }}$ ECTES Congress, 4-7 May, Lyon. Muscle atrophy in elderly hip fracture patients. Kramer IF, van Loon LJC, Poeze M.

NVT Assistenten Symposium, 25 January, Soesterberg. Muscle atrophy in elderly hip fracture patients. Kramer IF, Poeze M.

Traumadagen, 1-2 November, Amsterdam. Muscle atrophy in elderly hip fracture patients. Kramer IF, Snijders T, Smeets J, Verdijk LB, Poeze M, van Loon LJC.

Pélerin Symposium, 11 October, Maastricht. Muscle characteristics of elderly women undergoing surgery for fall-related hip fractures.

$24^{\text {th }}$ ESPEN Congress, 8-11 September, Barcelona. Muscle atrophy in elderly hip fracture patients. Kramer IF, Snijders T, Smeets J, Verdijk LB, Poeze M, van Loon LJC. 
$17^{\text {th }}$ ECSS Congress, 4-7 July, Brugge. Extensive type II muscle fiber atrophy and reduced satellite cell content in elderly women undergoing surgery for fall-related hip fractures. Kramer IF, Snijders T, Smeets J, Verdijk LB, Poeze M, van Loon LJC.

\section{Awards and Grants}

2014

Personal research grant USD 50.000: Osteosynthesis \& Trauma Care Foundation Europe.

2013

G.J. Heijmans prijs. Nederlandse Vereniging voor Traumachirurgie assistenten symposium.

2012

Pélerin Aanmoediginsprijs. Pélerin Symposium. 